UNIVERSIDADE DE SÃO PAULO

ESCOLA DE ENFERMAGEM

TATIANA YONEKURA

\title{
NECESSIDADES DE SAÚDE: CONSTRUÇÃO DE INSTRUMENTO PARA O PLANEJAMENTO \\ REGIONAL EM SAÚDE
}

SÃO PAULO

2016 
TATIANA YONEKURA

\section{NECESSIDADES DE SAÚDE: CONSTRUÇÃO DE INSTRUMENTO PARA O PLANEJAMENTO \\ REGIONAL EM SAÚDE}

Tese apresentada ao Programa de PósGraduação em Enfermagem (PPGE) da Escola de Enfermagem da Universidade de São Paulo para a obtenção do título de Doutor em Ciências

Área de concentração: Cuidado em Saúde

Orientadora: Profa. Dra. Cassia Baldini Soares

\section{VERSÃO CORRIGIDA}

A versão original encontra-se disponível na Biblioteca da Escola de Enfermagem da Universidade de São Paulo e na Biblioteca Digital de Teses e Dissertações da Universidade de São Paulo

\section{SÃO PAULO}


AUTORIZO A REPRODUÇÃO TOTAL OU PARCIAL DESTE TRABALHO, POR QUALQUER MEIO CONVENCIONAL OU ELETRÔNICO, PARA FINS DE ESTUDO E PESQUISA, DESDE QUE CITADA A FONTE.

Assinatura:

Data:

Catalogação na Publicação (CIP) Biblioteca Wanda de Aguiar Horta

Escola de Enfermagem da Universidade de São Paulo

Yonekura, Tatiana

Necessidades de saúde: construção de instrumento para o planejamento regional em saúde / Tatiana Yonekura.

São Paulo, 2016. $207 \mathrm{p}$.

Tese (Doutorado) - Escola de Enfermagem da Universidade de São Paulo.

Orientadora: Prof. ㄹ Dr. ㄹ Cássia Baldini Soares

Área de Concentração: Cuidado em Saúde

1. Necessidades e demanda de serviços de saúde. 2 . Desigualdade em saúde. 3. Planejamento em saúde. 4. Enfermagem. 5. Métodos epidemiológicos. I. Título. 


\section{FOLHA DE APROVAÇÃO}

Nome: Tatiana Yonekura

Título: Necessidades de saúde: construção de instrumento para o planejamento regional em saúde

Tese apresentada ao Programa de Pós-Graduação em Enfermagem da Escola de Enfermagem da Universidade de São Paulo para obtenção do título de Doutor em Ciências.

Aprovado em:

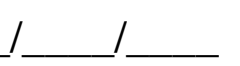

Banca Examinadora

Prof. Dr.

Instituição:

Julgamento:

Assinatura:

Prof. Dr. Instituição:

Julgamento:

Assinatura:

Prof. Dr. Instituição:

Julgamento:

Assinatura:

Prof. Dr. Instituição:

Julgamento: Assinatura:

Prof. Dr. Instituição:

Julgamento: Assinatura: 
$\mathcal{A}$ todos os Grasileiros que Gutam por transformações sociais, em torno dos direitos civis, políticos e sociais. 


\section{AGRADECIMENTOS}

Escrever os agradecimentos é um momento muito gratificante, pois percebo que não conseguiria chegar ao final dessa etapa sem o apoio e carinho de pessoas muito especiais... espero não ter esquecido ninguém.

À Cassia Baldini Soares, pela parceria de quase 10 anos (como o tempo passa rápido). Obrigada pelo carinho, respeito, apoio e compreensão que teve comigo em todos os momentos. Aprendi muito com você e espero ainda aprender mais.

À Celia Campos, pelo apoio neste e em outros projetos acadêmicos. Obrigada por compartilhar sua experiência e conhecimentos sobre necessidades de saúde.

À Elaine Thumé e Carla Trapé, pelas contribuições no exame de qualificação.

À Gislaine Godoi, Sonia Pereira, Jorge Silva e Edna Fragoso, pela parceria no trabalho e sobretudo pelos momentos de descontração.

À Olivia Gollub, amiga de longa data, que sempre está presente e disposta a ouvir e ajudar. Obrigada pelos incentivos do início ao fim deste trabalho.

À Marfiza Novaes, uma pessoa mais que especial, que fez de tudo para me ajudar. Sem você não conseguiria iniciar a coleta de dados no Espírito Santo. Obrigada pelo tempo dispensado, pelas caronas, pelas viagens e pelo apoio no processo de formação ação.

À Jeane Roza Quintans, por sempre estar à disposição, pelo apoio em todos os momentos e parceria em diversos projetos contra hegemônicos.

À Michelle Espadaro, Juliana Araujo, Mayla Kato, Claudia Matsuda, Thabata Cruz, Patrícia Albuquerque e Cintia Silva, pelo companheirismo e suporte principalmente nas fases mais difíceis dessa jornada.

À Michelly Ribeiro, pela revisão do instrumento.

Ao Jefferson Pereira, pelo trabalho artístico.

À Melissa Messias, parceira no estudo da metodologia qualitativa, que desde o início da jornada se preocupou com o andamento do projeto e sempre esteve a disposição para ajudar.

À Enilda Lara, pelo incentivo constante e pela oportunidade de participar do Núcleo de Pesquisa Qualitativa do HCor.

À Kassia Fernandes, pelo rápido trabalho de tradução do resumo. 
À Luiza Alvarenga e Eloá Ribeiro, trabalhadoras incansáveis do Espírito Santo, pelas contribuições neste trabalho.

I

À Solange Corradi, pelo apoio logístico na coleta de dados.

Aos meus queridos amigos, pelo apoio. À Rita Passos, Anita Gomes e Neidmar Coelho, pela convivência e acolhida no Espírito Santo.

Aos especialistas que participaram da validação e aos gestores que participaram das entrevistas, pelas contribuições, sem as quais este trabalho não se concretizaria.

Ao Hospital do Coração pela possibilidade de cursar o doutorado, em nome da Superintendente de Qualidade e Responsabilidade Social Bernardete Weber e do gestor do LIGRESS Armando De Negri Filho.

Aos trabalhadores do LIGRESS que contribuem para a melhoria do SUS.

E deixo por último os agradecimentos às pessoas mais importantes na minha vida.

Ao meu pai, uma pessoa querida e solidária, que fez diferença na vida de muitas pessoas, mas que não está mais entre nós. Obrigada pelo cuidado que sempre teve conosco, pela determinação, perseverança, sonhos e luta de uma vida melhor e mais justa para todos e todas.

À minha querida mãe que cuida de todos nós com muito carinho e paciência.

Ao Marcelo, Ricardo, Beatriz e Heloisa, pela convivência, solidariedade, presença e apoio em todos os momentos da minha vida.

À Sofia, Talita, Enzo e Leonardo, pela alegria contagiante que renova a vida e diminui os problemas.

A todos os meus tios, primos e agregados, pois tenho certeza que nunca deixarão de me apoiar. À Aline que mesmo de longe é uma torcedora muito presente.

A participação de vocês foi fundamental!

\section{Muito obrigada a todos.}


Yonekura T. Necessidades de saúde: construção de instrumento para o planejamento regional em saúde [tese]. São Paulo: Escola de Enfermagem. Universidade de São Paulo; 2016.

\section{RESUMO}

O objeto deste estudo é a identificação de necessidades de saúde por meio de um instrumento para gestores e técnicos das áreas de planejamento e gestão em saúde. O estudo considerou o arcabouço teórico-metodológico da Saúde Coletiva e particularmente da Epidemiologia Crítica que se fundamentam na categoria reprodução social para explicar os diferentes perfis de saúde e doença de um determinado território. Objetivo: construir um instrumento de captação de necessidades de saúde para subsidiar o planejamento regional em saúde. Método: Trata-se de um estudo metodológico que foi desenvolvido em quatro etapas: Etapa 1. Uma revisão integrativa para identificar os instrumentos de levantamento de necessidades de saúde existentes; Etapa 2. Entrevistas semiestruturadas e individuais com gestores da saúde para compreender as dificuldades no levantamento de necessidades. Os dados foram gravados, transcritos e analisados através da análise de conteúdo; Etapa 3. Construção de instrumento de levantamento de necessidades de saúde para subsidiar o planejamento regional em saúde; e Etapa 4. Validação de conteúdo por comitê de especialistas, por meio da técnica Delphi e índice de validade de conteúdo. Resultados: Em relação à revisão integrativa, foram identificados 17 instrumentos de levantamento de necessidades. As 123 variáveis utilizadas para identificar necessidades foram integradas em três categorias: necessidades de reprodução social, necessidades de presença do Estado e necessidades de participação política. Em relação às entrevistas, sete gestores de saúde da região metropolitana do Espírito Santo participaram do estudo. Quatro categorias compostas por 11 temas foram analisados: (1) Compreensão do conceito de necessidades de saúde, com um tema; (2) Necessidades de reprodução social, com dois temas; (3) Necessidades de presença do Estado, com sete temas; e (4) Necessidades de participação política, com um tema. A construção do instrumento envolveu a inclusão dos resultados da revisão e das entrevistas, resultando em material composto de introdução e cinco módulos (Módulo A - Identificação das classes sociais, Módulo B - Reconhecimento do território, Módulo C - Necessidades de reprodução social, Módulo D Necessidades de presença do Estado, e Módulo E - Necessidade de participação política). A validação de conteúdo foi realizada por meio da participação de oito especialistas. Tanto a introdução, quanto os módulos apresentaram de forma geral pontuação pelo índice de validade de conteúdo maior de 0,9 , o que representa clareza, pertinência e relevância adequados. Apenas um item foi classificado com baixa clareza $(0,75)$, e dessa forma precisou ser reformulado. Outras modificações foram realizadas, a partir da sugestão dos especialistas. Conclusão: o instrumento construído tem potencialidade para identificar necessidades de saúde, a partir da captação das desigualdades sociais dos diferentes territórios. Pondera-se no entanto que o instrumento é incapaz de sozinho sensibilizar gestores e técnicos das secretarias estaduais e municipais para a utilização e análise dos dados, e portanto sua utilização deve fazer parte de processos educativos que envolvam 
a compreensão dos referencias teórico-metodológicos que subsidiaram a construção do instrumento.

Palavras-chave: Necessidades e demanda de serviços de saúde, Desigualdade em saúde, Planejamento em saúde, Enfermagem, Métodos epidemiológicos 
Yonekura T. Health needs: development of an instrument for regional health planning [tese]. São Paulo: Escola de Enfermagem. Universidade de São Paulo; 2016.

\section{ABSTRACT}

This work takes as its object of study the health needs identification by an instrument for both managers and technicians of health planning and management areas. The study has considered the theoretical-methodological framework of Collective Health, and in particular Critical Epidemiology, which is based on the social reproduction category to explain different health-disease profiles in a given territory. Objective: to develop an instrument to assess health needs aiming at subsidizing regional planning in health. Method: This is a methodological study. This study was developed in four stages: Stage 1. An integrative literature review to identify existing instruments for health needs assessment; Stage 2. Semi-structured and individual interviews with health managers to understand difficulties in needs assessment. The data was recorded, transcribed, and analyzed by content analysis; Stage 3. Development of an instrument for health needs assessment to subsidize regional planning in health; and Stage 4. Content validation by a committee of experts, by means of the Delphi technique and content validity index. Results: In relation to the integrative review, 17 instruments for needs assessment were identified; the 123 variables used to identify needs were grouped into three categories: social reproduction needs, State presence needs, and political participation needs. In relation to the interviews, seven health managers of the metropolitan region of Espirito Santo State took part in this study. Four categories composed by 11 themes were analyzed: (1) Understanding of the health needs concept, with one theme; (2) Social reproduction needs, with two themes; (3) State presence needs, with seven themes; and (4) Political participation needs, with one theme. The instrument development included adding both literature review and the interviews' findings, resulting in a material divided in introduction and five modules (Module A - Identification of social classes, Module B - Territory recognition, Module $\mathrm{C}$ - Social reproduction needs, Module D - State presence needs, and Module E - Political participation needs). The content validation was performed by eight experts. In general the content validity index of the introduction as well as the modules was higher than 0.9 , what represents adequate clarity, pertinence, and relevance. Only one item was scored as low clarity (0.75), therefore needed to be reformulated. Other modifications were made according to the experts' suggestion. Conclusion: The instrument that has been developed has potential to identify health needs by analyzing social inequalities of the different territories. However, it should be considered that the instrument, by itself, is unable to raise awareness among managers and technicians of state and municipal secretaries in order to use and analyze data. Therefore, it should be used as part of educational processes that include the study of its theoretical-methodological framework.

Keywords: Services Needs and Demand, Health Inequalities, Health Planning, Nursing, Epidemiologic Methods 


\section{LISTA DE FIGURAS}

Figura 1 Mapa do Índice de Desenvolvimento Humano Municipal de 2010 por município brasileiro. São Paulo;

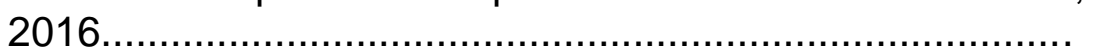

Figura 2 Distribuição dos cinco grupos socioeconômicos por regiões de saúde no Brasil. São Paulo;

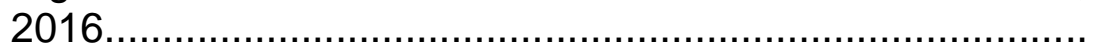

Figura 3 Diferenças conceituais entre problemas e necessidades de saúde. São Paulo; 2016.

Figura 4 Os quatro momentos do planejamento estratégico de Carlos Matus. São Paulo; 2016.

Figura 5 Módulos da Formação em Ação. São Paulo; 2015

Figura 6 Divisão do estado do Espirito Santo em regiões de saúde. São Paulo; 2016.

Figura 7 Distribuição dos grupos socioeconômicos por região de saúde. São Paulo; 2016.

Figura 8 Fluxograma da revisão integrativa sobre instrumentos de levantamento de necessidades de saúde. São Paulo; 2016. 


\section{LISTA DE QUADROS}

Quadro 1 Vantagens e desvantagens da avaliação de necessidades, na visão dos pesquisadores. São Paulo; 2016

Quadro 2 Visões a serem consideradas no levantamento de necessidades. São Paulo; 2016............................................ 34

Quadro 3 Diferenças entre revisão integrativa e revisão sistemática. São Paulo; 2016

Quadro 4 Instrumento para descrição dos dados dos estudos selecionados.

Quadro 5 Critérios da validação de conteúdo. São Paulo; 2016.

Quadro 6 Quadro para redação de sugestões de inclusão, modificação e exclusão. São Paulo; 2016

Quadro 7 Descrição das referências identificadas e selecionadas por base/fonte de dados. São Paulo; 2016.

Quadro 8 Descrição das referências incluídas por título e conceito de necessidades de saúde. São Paulo; 2016.

Quadro 9 Variáveis identificadas nos estudos incluídos e categorizadas. São Paulo; 2016.......................................... 73

Quadro 10 Categorias e temas. São Paulo; 2016.................................. 78

Quadro 11 Critérios para estratificação social do Observatório das Metrópoles. São Paulo; 2016............................................. 99

Quadro 12 Módulo A - Identificação das classes sociais e distribuição espacial no território. São Paulo; 2016.................................... 101

Quadro 13 Módulo B - Reconhecimento do território. São Paulo; 2016..... 101

Quadro 14 Módulo C - Necessidades de reprodução social. São Paulo; 2016.

Quadro 15 Módulo D - Necessidades de presença do Estado. São Paulo; 2016

Quadro 16 Módulo E - Necessidade de participação política. São Paulo; 2016.

Quadro 17 Experiência profissional dos especialistas. São Paulo; 2016... 108 
Quadro 18 Descrição da análise de cada módulo, segundo índice de validade de conteúdo (IVC). São Paulo, 2016..

Quadro 19 Descrição da análise de conteúdo de cada item, segundo número de critérios inadequados e adequados, e índice de validade de conteúdo. São Paulo, 2016

Quadro 20 Itens que sofreram alterações após validação de conteúdo.

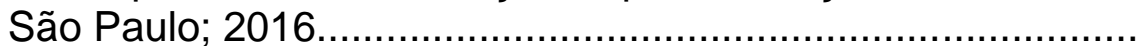

Quadro 21 Descrição das sugestões não incorporadas no instrumento e as respectivas justificativas. São Paulo; 2016.

Quadro 22 Propostas de temas e propostas para a agenda política. São Paulo; 2016 


\section{LISTA DE GRÁFICOS}

Gráfico 1 Período de publicação dos estudos incluídos. São Paulo;

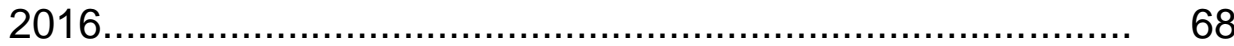

Gráfico 2 Distribuição da formação acadêmica dos participantes. São Paulo; 2016.................................................................. 76

Gráfico 3 Distribuição da década da formação dos participantes. São

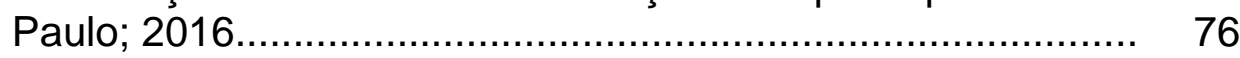

Gráfico 4 Número de participantes com pós-graduação. São Paulo;

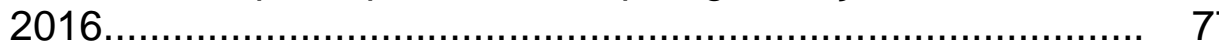

Gráfico 5 Cargos atuais dos participantes. São Paulo; 2016................ 77

Gráfico 6 Tempo de atuação na gestão pública. São Paulo; 2016.......... 77

Gráfico $7 \quad$ Experiência anterior na gestão pública. São Paulo; 2016....... 77

Gráfico 8 Distribuição da formação acadêmica dos participantes. São

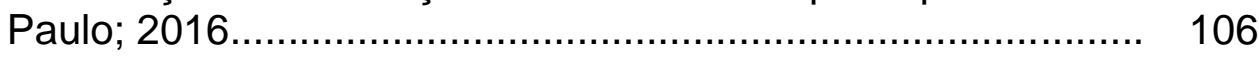

Gráfico 9 Distribuição da década da formação dos participantes São Paulo; 2016....................................................................... 106

Gráfico 10 Áreas de pós-graduação dos participantes. São Paulo; 2016.. 106

Gráfico 11 Cargo atual dos participantes. São Paulo; 2015.................. 107

Gráfico 12 Tempo na ocupação dos participantes. São Paulo; 2015........ 107 


\section{LISTA DE TABELAS}

Tabela 1 País de publicação dos estudos incluídos. São Paulo; 2016.... 67

Tabela 2 Descrição dos instrumentos incluídos na revisão por número de temas. São Paulo; 2016................................................... 71

Tabela 3 Temas utilizados para levanta necessidades. São Paulo;

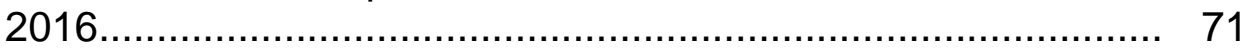

Tabela 4 Distribuição do sexo e idade dos participantes por número e porcentagem. São Paulo; 2016.............................................. 76

Tabela 5 Distribuição do sexo e idade dos participantes por número e porcentagem. São Paulo; 2016................................................ 105 


\section{LISTA DE SIGLAS}

CAPS Centro de Atenção Psicossocial

CNS Conselho Nacional de Saúde

Decit Departamento de Ciência e Tecnologia

DeCS Descritores em Ciências da Saúde

ES Espírito Santo

HCor Hospital do Coração

IBGE Instituto Brasileiro de Geografia e Estatística

IDH Índice de Desenvolvimento Humano

ILPI Instituições de longa permanência para idosos

IPEA Instituto de Pesquisa Econômica Aplicada

IVC Índice de validade de conteúdo

JBI Joanna Briggs Institute

LIGRESS Laboratório de Inovação em Planejamento, Gestão, Avaliação e Regulação de Políticas, Sistemas, Redes e Serviços de Saúde

MeSH Medical Subject Headings

MS Ministério da Saúde

NASF Núcleo de Apoio à Saúde da Família

OMS Organização Mundial da Saúde

PES Plano Estadual de Saúde

PMAQ Programa Nacional de Melhoria do Acesso e da Qualidade da Atenção Básica

PNAD Pesquisa Nacional por Amostra de Domicílios

PNUD Programa das Nações Unidas para o Desenvolvimento

PPA Plano Plurianual

PROADI Programa de Apoio ao Desenvolvimento Institucional do SUS

$\mathrm{RI}$

Revisão integrativa 
SAD Setor de assistência domiciliar

SAMU Serviço de Atendimento Móvel de Urgência

SciELO Scientific Electronic Library Online

SESA Secretaria Estadual de Saúde

SIM Sistema de Informação sobre Mortalidade

SINAN Sistema de Informação de Agravos de Notificação

SINASC Sistema de Informações Sobre Nascidos Vivos

SISREG Sistema Nacional de Regulação

SRS Superintendência Regional de Saúde

SUS Sistema Único de Saúde

TCLE Termo de Consentimento Livre e Esclarecido

UBS Unidade Básica de Saúde 


\section{SUMÁRIO}

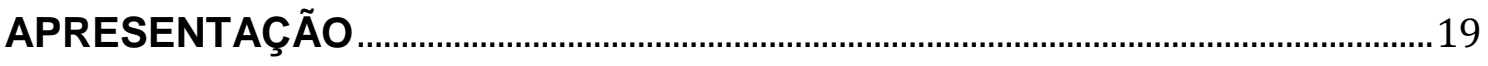

1. INTRODUÇÃO

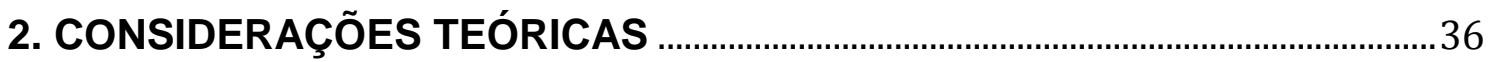

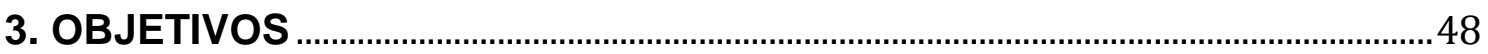

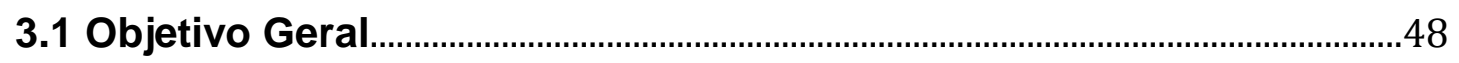

3.2 Objetivos Específicos ………………………………………………………….....

4. PROCEDIMENTOS METODOLÓGICOS ……………………………………….....50

4.1. TIPO DE PESQUISA ………………………………………………………....5

4.2. CAMINHO PERCORRIDO …………………………........................................50

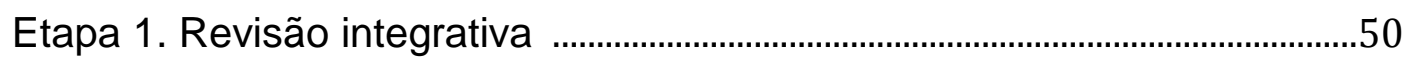

Etapa 2. Entrevistas com gestores de saúde........................................................56

Etapa 3. Construção de instrumento ......................................................................59

Etapa 4. Validação de conteúdo.............................................................................60

4.3. FORMA DE ANÁLISE DOS RESULTADOS …….........................................62

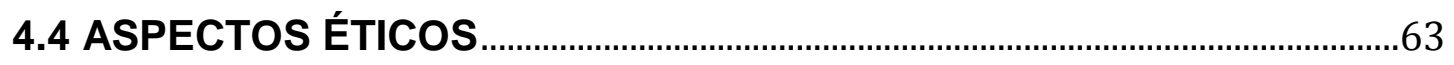

5. RESULTADOS

Etapa 1. Revisão Integrativa ......................................................................................65

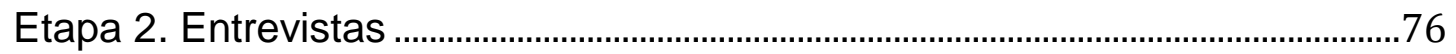

Etapa 3. Construção do instrumento .........................................................................98

Etapa 4. Validação de conteúdo ……………………………………………………..105

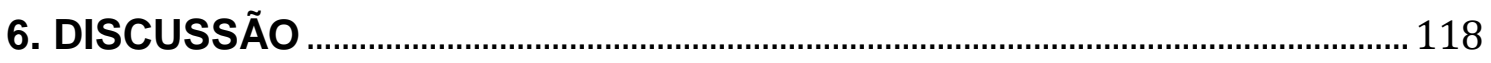

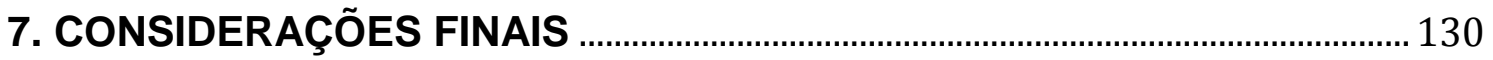

8. REFERÊNCIAS BIBLIOGRÁFICAS …………………...................................... 133

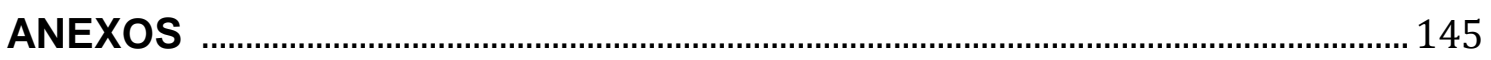

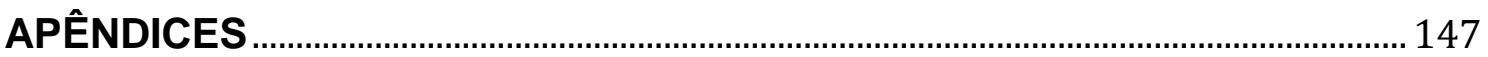




\section{APRESENTAÇÃO}

Durante a graduação, me empenhei no desenvolvimento de pesquisas na área de Saúde Coletiva. A oportunidade de realizar duas iniciações cientificas e de participar de outros projetos de integrantes do grupo de pesquisa foi muito desafiadora e enriquecedora, o que fortaleceu o meu interesse por estudos principalmente sobre desigualdade social, classe social e epidemiologia crítica.

Com o término da graduação, iniciei o mestrado na mesma linha de pesquisa, com foco na operacionalização do conceito de classe social na epidemiologia. Os estudos empíricos reforçaram a maior prevalência e incidência de problemas de saúde em classes com menor acesso à riqueza social.

Com o término do mestrado e aprovação em concurso público, atuei como enfermeira assistencial no setor de assistência domiciliar (SAD). Éramos responsáveis por aproximadamente 700 famílias da região metropolitana de São Paulo, cadastradas no SAD, e realizávamos visitas domiciliares para identificação de necessidades sociais, reconhecimento das condições de vida, realização de procedimentos, entre outros objetivos.

Nesse período, realizamos um estudo sobre as desigualdades sociais e os perfis epidemiológicos dos usuários. A pesquisa no serviço de saúde e com a participação dos trabalhadores foi uma experiência muito interessante, pois possibilitou articular a teoria científica com a assistência em saúde. Na prática, conseguimos identificar diferenças socioeconômicas e de saúde importantes entre os grupos sociais.

Atualmente, trabalho como pesquisadora no Laboratório de Inovação em Planejamento, Gestão, Avaliação e Regulação de Políticas, Sistemas, Redes e Serviços de Saúde do Hospital do Coração (LIGRESS/HCor). O HCor é considerado um dos seis hospitais filantrópicos de excelência e, em parceria com o Ministério da Saúde, desenvolve projetos no âmbito do Programa de Apoio ao Desenvolvimento Institucional do SUS - PROADI-SUS (Decit, 2011).

O PROADI-SUS visa o fortalecimento do SUS, através de estudos de avaliação e incorporação de tecnologia, capacitação de recursos humanos, pesquisas de interesse público em saúde e desenvolvimento de técnicas e operação de gestão em serviços de saúde (Decit, 2011). 
Assim, este projeto de doutorado congrega parte de uma investigação mais ampla intitulada "Apoio ao Desenvolvimento de Sistemas Regionais de Atenção Integrada à Saúde/Regiões de Saúde", desenvolvido pelo LIGRESS/HCor, cujo objetivo geral é potencializar um conjunto de capacidades estratégicas na gestão regional aplicada a gestores municipais e estaduais e promover o desenho de modelos integrados de serviços em redes. A orientação do planejamento proposto busca, por conseguinte, responder às necessidades sociais da população, traduzindo essas necessidades em um conjunto de modelos de provisão de serviços orientados pelos princípios da universalidade, integralidade e igualdade, explorando os requisitos para se obter acesso resolutivo, tanto em regiões metropolitanas, como em regiões de alta dispersão populacional. O projeto tem como campo de atuação os Estados do Amazonas e Espírito Santo. 


\section{INTRODUÇÃO}

O objeto deste estudo é a identificação de necessidades de saúde, por meio da elaboração de um instrumento para gestores e técnicos das áreas de planejamento e gestão em saúde.

As necessidades de saúde da população têm sido objeto de estudo, debate e políticas de saúde, por isso, diversos autores têm desenvolvido pesquisas para responder à questão, tanto da identificação, quanto da satisfação das necessidades.

Na prática, em geral, os modelos de serviços de saúde no SUS baseiam-se na concepção positivista do processo saúde-doença e não respondem às necessidades dos diferentes grupos sociais pertencentes às diversas regiões de saúde do Brasil, o que evidencia que as práticas de saúde devem ser revistas à luz da concepção da determinação social do processo saúde-doença (Brasil, 2006; Egry, Oliveira, 2008).

A identificação dos diferentes grupos sociais, distribuídos no território é uma das premissas da Saúde Coletiva que considera os contextos sociais, onde as pessoas vivem e trabalham, relacionados diretamente ao perfil saúde-doença e acesso aos serviços e ações de saúde (Soares, 2007).

O território, nessa perspectiva, é um espaço particular, dinâmico, histórico, social e desigual, ocupado diferentemente em função das distintas classes sociais em que se divide a sociedade (Santos, 2007). Assim, a consideração da desigualdade social no território é fundamental nesse contexto.

O Índice de Gini revelou diminuição na desigualdade de renda brasileira de forma acentuada e contínua a partir de 2001, relacionada diretamente à expansão trabalhista e políticas redistributivas. De acordo com a Pesquisa Nacional por Amostra de Domicílios (PNAD), entre 2001 e 2011, "a renda per capita brasileira dos $10 \%$ mais ricos aumentou $16,6 \%$ em termos acumulados, enquanto a renda dos mais pobres cresceu $91,2 \%$ no período". Entretanto, o país ainda apresenta uma das maiores desigualdades de renda no cenário internacional (IPEA, 2012; PNUD, 2013). 
Em relação ao desenvolvimento humano, mensurado através do Índice de Desenvolvimento Humano (IDH), o Brasil apresentou progressos consideráveis na última década nos indicadores renda per capita, expectativa de vida e acesso à educação. Em 2013, o país foi classificado na categoria desenvolvimento humano elevado, mantendo a $85^{a}$ posição no ranking, em um total de 177 países, embora com menor índice, se comparado a anos anteriores (PNUD, 2013).

O Brasil é marcado historicamente não só por desigualdades de renda, mas também por enormes desigualdades sociais e regionais, que impactam nas condições de trabalho, de vida e de saúde da população (Brito, 2008).

Observam-se ainda importantes disparidades sociais intra e intermunicipais no Brasil, relacionadas à renda per capita, expectativa de vida e acesso à educação. (Barros et al., 2007; PNUD, 2013). Com a classificação do IDH em cinco faixas de desenvolvimento humano (de muito baixa até muito alta), foi possível comparar os índices dos municípios brasileiros, o que permite identificar disparidades socioeconômicas e demográficas. Nota-se que ao mesmo tempo que nenhum município da região sul, sudeste e centro oeste foi classificado com o IDH muito baixo, nenhum município classificado com o IDH muito alto foi identificado no norte e nordeste, conforme Figura 1 (PNUD, 2013). 
Figura 1 - Mapa do Índice de Desenvolvimento Humano Municipal de 2010 por município brasileiro. São Paulo; 2016.

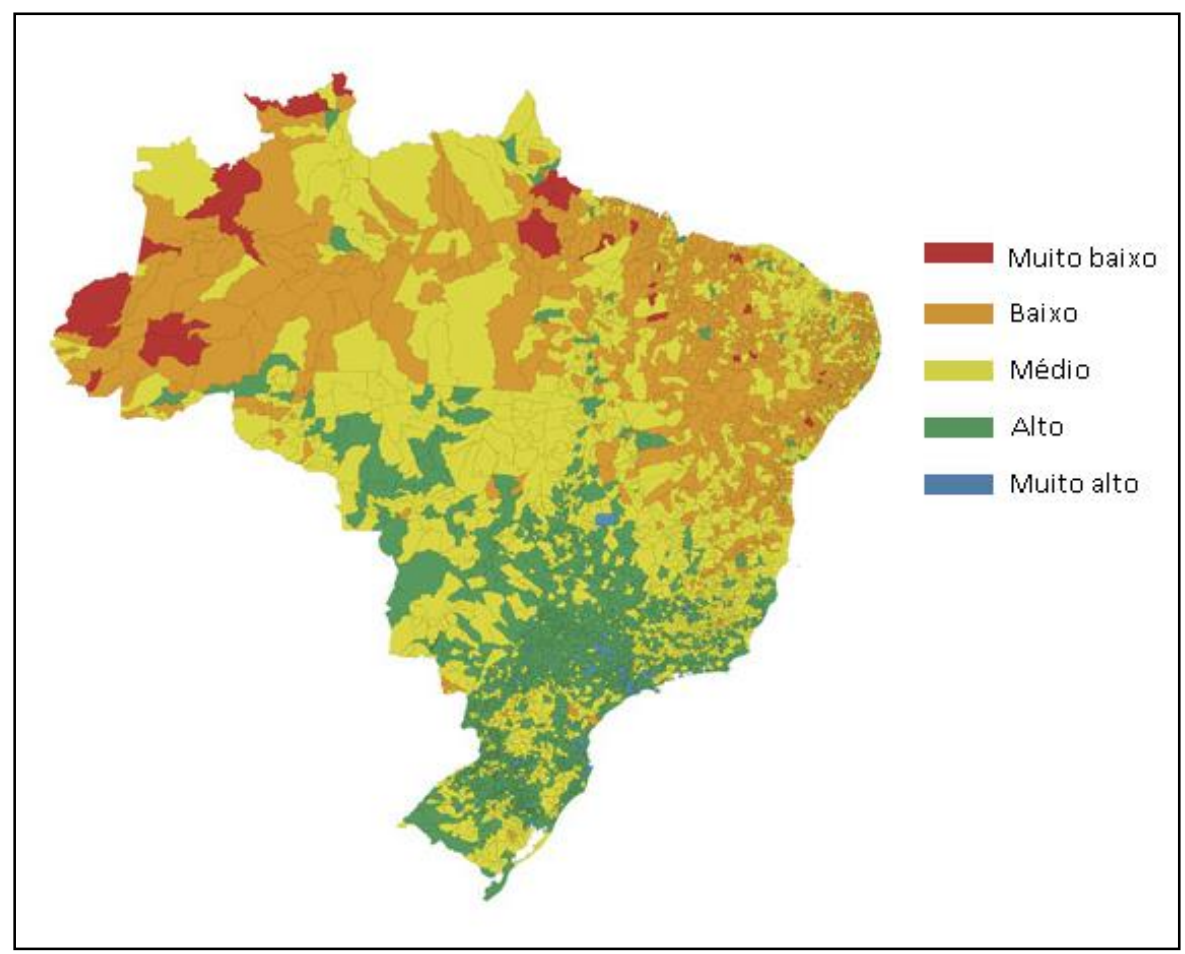

Fonte: Atlas Brasil - PNUD, 2013.

Disparidades socioeconômicas e de oferta e complexidade de serviços de saúde também são condições relevantes na realidade brasileira. Através da classificação em cinco grupos, desde o baixo desenvolvimento socioeconômico e baixa oferta de serviços até alto desenvolvimento socioeconômico e alta oferta de serviços, nota-se desigualdades importantes entre as regiões de saúde brasileiras. Ao se considerar a complexidade de serviços de saúde, as regiões de saúde das capitais brasileiras apresentam melhores resultados, comparadas às demais regiões (Figura 2). 
Figura 2 - Distribuição dos cinco grupos socioeconômicos por regiões de saúde no Brasil. São Paulo; 2016.

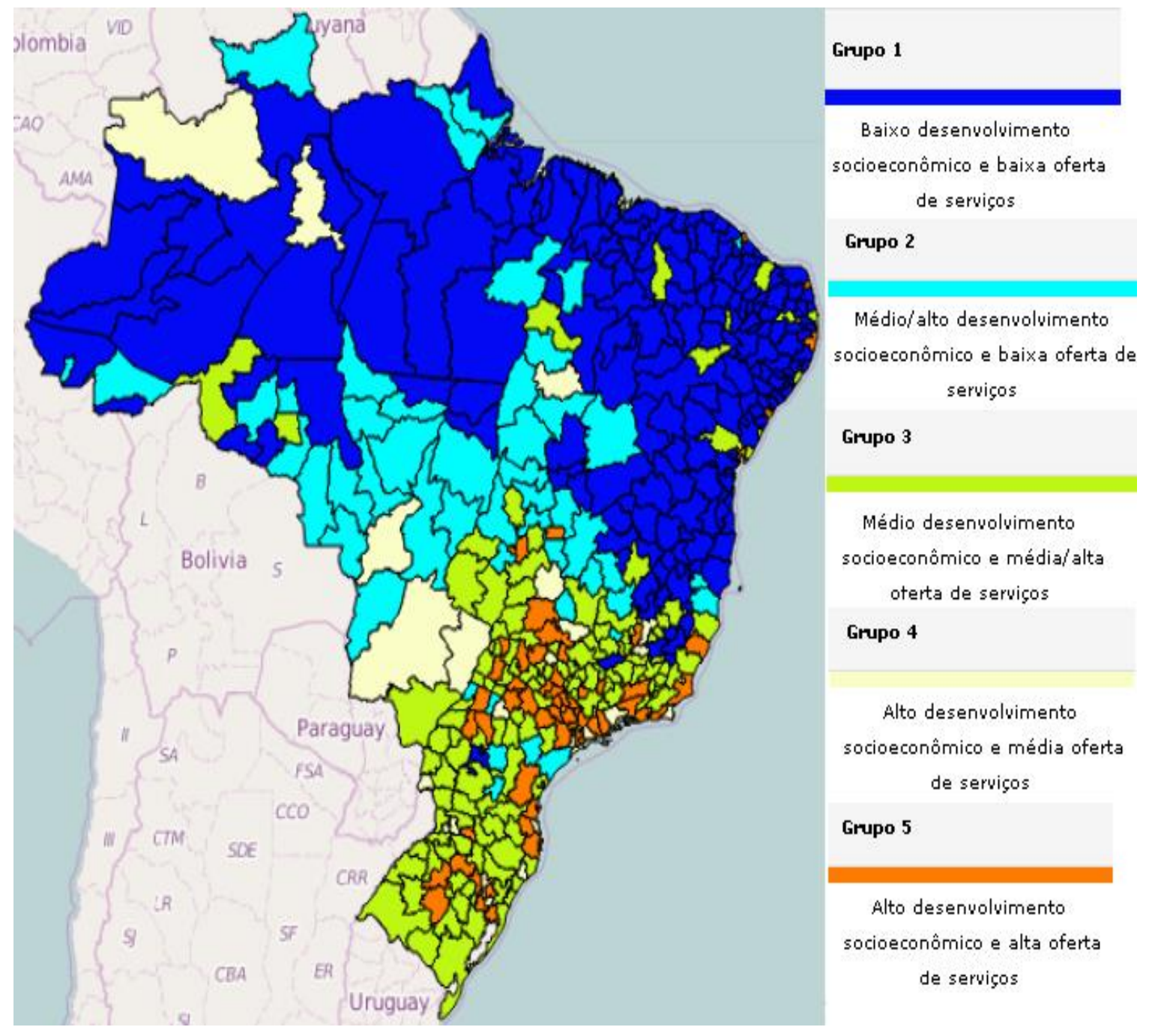

Fonte: Projeto Redes e Regiões (2014).

Trapé (2011) enfatiza a importância das identificações das micro desigualdades para revelar diferentes condições de moradia, de trabalho, de educação e de saúde em micro espaços, ou seja, desigualdades em um mesmo bairro e até mesmo em uma mesma rua. Entretanto, há limitações metodológicas na captação de micro desigualdades, já que dificilmente são captadas ou analisadas por meio de inquéritos populacionais tradicionais, ou não são expostas, como é o caso de índices gerais, como o IDH, que se valem de médias e por isso não expõem diferenças dentro da unidade que é tomada como referência (município, estado, pais) (Trapé, 2011). 
Baseada nessa limitação, Trapé (2011) utilizou instrumento, composto por variáveis de formas de trabalhar e de viver, para identificação de grupos sociais heterogêneos em micro espaços, e demonstrou a existência de alta heterogeneidade entre bairros, o que não aparecia em estudos que obtiveram médias, a partir de outras metodologias (Trapé, 2011). Contudo, algumas variáveis utilizadas neste estudo não estão disponibilizadas em bases de dados secundárias, o que dificulta a utilização do instrumento no planejamento.

Tomasi et al. (2003) revelaram que um aplicativo para a Atenção Primária que utiliza dados secundários e demanda ambulatorial tem potencialidade para identificar as características da população de referência de Unidades Básicas de Saúde, principais diagnósticos e encaminhamentos. Dessa forma, o aplicativo incide em problemas como falta de dados em cadastros da população de referência, falta de dados para elaboração de indicadores locais e desconhecimento da população de cobertura. A obtenção desses dados desagregados possibilita sistematizar informações para a avaliação da gestão e planejamento de ações de saúde (Tomasi et al., 2003).

As micro desigualdades são também evidenciadas por uma metodologia construída na perspectiva da Saúde Coletiva que, por meio de dados secundários, possibilita identificar e mapear grupos sociais por bairros ou distritos. Entretanto, as desigualdades internas aos grupos formados, como as desigualdades em uma mesma rua, não são possíveis de identificação, por dados secundários (Yonekura et al., 2010).

A desigualdade social brasileira também se manifesta no uso e acesso aos serviços de saúde. Louvison et al. (2008) evidenciaram que, no período de um ano, $83,3 \%$ dos idosos do município de São Paulo utilizaram serviços de saúde, sendo que as desigualdades no uso e acesso a esses serviços de saúde tendem a ser piores para os idosos com piores condições socioeconômicas. Os autores ressaltaram ainda que a capacidade de acesso e uso de serviços na população idosa está diretamente relacionada à renda, escolaridade, posse de seguro de saúde privado, indicando diferentes formas de adoecer e diferentes necessidades que impactam na qualidade de vida dessa população (Louvison et al., 2008). 
Diferentes problemas de saúde, de acordo com o bairro de moradia de idosos também são identificados. O problema de saúde mais frequente no grupo com melhor condição social foi a hipertensão arterial sistêmica, enquanto que o acidente vascular cerebral foi mais frequente no grupo com piores condições sociais (Yonekura, Silva, Souza, 2011).

A falta de acesso a serviços de saúde ocasiona uso recorrente de serviços de emergência e baixa utilização de cuidados preventivos pela população. Nesta situação, as condições de saúde da população, consequentemente, são piores, já que o foco da atenção à saúde é a doença e necessidades sociais relacionadas ao processo saúde-doença, mas que não se caracterizam como doenças já instaladas, e por isso não são consideradas nas ações em saúde (Pieh-Holder, Callahan, Young, 2012).

As deficiências de saneamento básico, relacionadas à comprometida prestação de serviços públicos, também têm impacto no consumo de consultas médicas, internações hospitalares, taxas de mortalidade e consequentemente nos gastos públicos (Teixeira et al., 2014). Em análise referente ao período de 2001 a 2009, é possível verificar a ocorrência de 758.750 internações hospitalares por ano e de 466.351 consultas referentes a doenças de notificação compulsória no Brasil, devido a deficiências de saneamento básico, com uma despesa total de 2,141 bilhões de reais, ou seja $2,84 \%$ do gasto total do SUS no período (Teixeira et al., 2014).

Os diagnósticos de causas de mortes mais frequentes, relacionados à falta de saneamento básico, foram diarreias e a doença de Chagas, que representaram mais de $83 \%$ do total de óbitos por causas definidas (em média nove mil mortes por ano) (Teixeira et al., 2014).

Problemas também são relatados em áreas com baixa provisão de Atenção Primária e população sem acesso a serviços de saúde, que apresentam altas taxas de mortalidade infantil, altas taxas de pobreza, e alta incidência de câncer, obesidade, diabetes e doenças cardiovasculares (Pieh-Holder, Callahan, Young, 2012). 
São marcantes as evidências de que o planejamento inadequado de serviços de saúde contribui para piores perfis de saúde-doença, na medida que não responde ao conjunto de necessidades de saúde.

\section{Planejamento baseado em necessidades de saúde}

Desde a Constituição Federal de 1988, a saúde é considerada um dever do Estado e um direito social do cidadão, bem como educação, alimentação, trabalho, moradia, transporte, lazer, segurança, previdência social, proteção à maternidade e à infância e a assistência aos desamparados (Brasil, 2015a), o que influencia diretamente o planejamento em saúde.

Segundo Rivera e Artmann (2012, p.12) o planejamento deve ser entendido como "um processo vinculado fortemente ao contexto histórico-social no qual se inserem os problemas e os atores que interagem no enfrentamento desses problemas".

Machado, Baptista e Lima (2010) ressaltam que a história do planejamento estatal é longa, tendo iniciado no Brasil no período entre 1889 e 1929, caracterizado pela centralização federal e por longos períodos de autoritarismo, principalmente, no primeiro governo Vargas (1930 e 1945) e no período militar (1964-1979). Nesses períodos, planos na área da saúde foram elaborados, entretanto, com a ausência de uma política de saúde unificada.

Reconhece-se que a crise do planejamento ocorreu entre 1980 e 1994, relacionada às reformas neoliberais, com ênfase na descentralização e nas privatizações que não visavam o planejamento nacional integrado e de longo prazo (Machado, Baptista, Lima, 2010). Mesmo com o reconhecimento constitucional do direito à saúde, a implantação do SUS ocorreu em contexto desfavorável à expansão de políticas sociais universalistas (Machado, Baptista, Lima, 2010).

A condução nacional da política de saúde foi unificada no Ministério da Saúde, cujo modelo de intervenção expressou uma fragilidade do planejamento integrado e a preponderância de estratégias de curto prazo. Apesar de os planos serem previstos nas leis da saúde como instrumentos de gestão das três esferas de governo, durante os anos noventa, o Ministério da Saúde não elaborou um plano nacional de saúde que explicitasse 0 
diagnóstico situacional, diretrizes, prioridades e recursos de forma abrangente (Machado, Baptista, Lima, 2010, p.2370).

No período de 1995-2002, o planejamento foi focado na consolidação da estabilidade financeira, na continuidade da abertura de mercados e de privatizações. Os instrumentos de planejamento tinham ênfase na gestão por resultados (Machado, Baptista, Lima, 2010).

No contexto de 2004 a 2007 as ênfases foram tanto na redução da desigualdade e maior inclusão social, quanto na aceleração do crescimento. Foi elaborado o Plano Nacional de Saúde, com a proposta de redução das desigualdades em saúde, ampliação do acesso com a qualificação e humanização, reforma do modelo de atenção e aprimoramento da gestão, redução de riscos e agravos, financiamento e controle social (Machado, Baptista, Lima, 2010).

O Pacto pela Saúde de 2006 foi caracterizado pela necessidade de mudanças na relação entre as esferas de governo na saúde, tendo ênfase nos instrumentos a serem adotados (Planos de Saúde e Programação Pactuada e Integrada) e no processo de pactuação intergovernamental. A adoção do critério de necessidades de saúde para o planejamento e a programação é um dos instrumentos operacionais destacados (Machado, Baptista, Lima, 2010).

A utilização de ferramentas operacionais no planejamento é útil para incidir nas causas dos problemas em uma realidade complexa, com um olhar estratégico e situacional (Brasil, 2015b).

$\mathrm{Na}$ literatura internacional, verifica-se a existência de diversas publicações desde a década de 70 sobre a identificação de necessidades. O termo "needs assessment' é o mais utilizado, conceituado e operacionalizado na literatura internacional (Kimmel, 1977; Kaufman, English, 1979).

A primeira etapa do planejamento é a de avaliar as necessidades, segundo (Kimmel, 1977), que também inclui as etapas de priorização de necessidades, avaliação, alocação de recursos e tomada de decisão. A avaliação também é utilizada para justificar a existência e proposta de crescimentos de programas ou serviços. 
Kaufman e English (1979) consideram a avaliação de necessidades, como um processo formal, que determina as lacunas entre o que é e o que precisa. $O$ conceito de necessidades gira em torno do que se precisa realizar para transformar os resultados atuais com os resultados desejados. A avaliação de necessidades é central para selecionar os problemas reais e identificar as informações pertinentes para a elaboração de intervenções apropriadas (Kaufman, English, 1979).

Stotz (1991) critica essa conceituação de natureza funcionalista, que destaca diferenças entre problemas e necessidades, conforme Figura 3. A perspectiva funcionalista expressa essa diferença, baseando-se na concepção de organismo biológico como sistema independente, cujas partes adoecem, de forma que doença seria o desvio dos padrões de normalidade. Para que o problema deixe de existir será necessário reparar o organismo e colocar o sistema plenamente em funcionamento, através da clínica (Viana, Soares, Campos, 2013).

Figura 3 - Diferenças conceituais entre problemas e necessidades de saúde na perspectiva funcionalista. São Paulo; 2016.

\begin{tabular}{|c|c|}
\hline Problemas & Necessidades de \\
$\begin{array}{c}\text { Estado de Saúde } \\
\text { observado } \\
\text { (ES.1) }\end{array}$ & $\begin{array}{c}\text { saúde } \\
\text { o que é necessário para } \\
\text { passar de ES.1 a ES.2 }\end{array}$ \\
$\begin{array}{c}\text { Corresponde a um estado } \\
\text { de saúde considerado } \\
\text { deficiente pelo indivíduo, } \\
\text { profissional ou } \\
\text { coletividade }\end{array}$ & $\begin{array}{c}\text { Expressa o desvio ou a } \\
\text { diferença entre o estado } \\
\text { ótimo e o estado atual ou } \\
\text { real. }\end{array}$ \\
\hline
\end{tabular}

Fonte: Stotz (1991).

Diversos estudos internacionais realizaram avaliação de necessidades de saúde com diferentes objetivos, finalidades, metodologias e populações. Fuller, Bentley e Shotton (2001) examinaram o impacto da avaliação de necessidade de saúde na Austrália e verificaram que em primeira instância a avaliação assegurou a participação da comunidade, compromisso com a mudança nos serviços de 
saúde e realocação de recursos regionais. Planos regionais foram elaborados para satisfação das necessidades e, nesse sentido, vantagens e desvantagens da avaliação no processo de planejamento foram identificadas, na visão dos pesquisadores, conforme Quadro 1.

Quadro 1 - Vantagens e desvantagens da avaliação de necessidades, na visão dos pesquisadores. São Paulo; 2016.

\begin{tabular}{|l|l|}
\hline \multicolumn{1}{|c|}{ Vantagens } & \multicolumn{1}{c|}{ Desvantagens } \\
\hline $\begin{array}{l}\text { Comprometimento e participação da } \\
\text { comunidade e dos trabalhadores }\end{array}$ & $\begin{array}{l}\text { Processo longo de avaliação e } \\
\text { planejamento }\end{array}$ \\
\hline Credibilidade & Trabalho e longo tempo para treinamento \\
\hline Uso rápido dos dados locais & $\begin{array}{l}\text { Planejamento local concluído fora do } \\
\text { âmbito do plano regional }\end{array}$ \\
\hline $\begin{array}{l}\text { Maior responsabilidade do gestor } \\
\text { regional com o planejamento }\end{array}$ & Papel mais difícil do gestor regional \\
\hline
\end{tabular}

Fonte: Fuller, Bentley e Shotton, (2001).

Li et al. (2009) e Ahari et al. (2012) acrescentam que a avaliação de necessidades também tem potência para racionalização de custos e mobilização comunitária para compreensão e discussão dos problemas e propostas de intervenção,

Em áreas remotas com baixa densidade populacional nos EUA, a falta de acesso a serviços de saúde, como da Atenção Primária, e atraso no tratamento e barreiras para o cuidado foram identificadas como problemas relevantes em uma avaliação de necessidades. Como estratégia de enfrentamento, a população buscava por conta própria assistência financeira e de transporte (Pieh-Holder, Callahan, Young, 2012).

Moura et al. (2010) revelaram diminuição das duas principais causas de internações em hospitais brasileiros por condições sensíveis à atenção primária, gastroenterites (-12\%) e asma (-31,8\%) no período e 1999 e 2006, ao mesmo tempo que observou-se aumento da cobertura da Estratégia Saúde da Família (ESF) (Malta et al., 2016). Entretanto, internações por pneumonias bacterianas 
aumentaram 142,5\%, o que evidencia a necessidade de identificar os determinantes das internações hospitalares (Moura et al., 2010).

Para a avaliação de necessidades, conferências, grupos focais, entrevistas e dados secundários podem ser utilizados como método e material de investigação. Segundo Kaufman e English (1979) e Feather et al (1994), não há consenso sobre as metodologias mais adequadas para avaliação de necessidades. Entretanto, esse processo requer planejamento e tomada de decisões, sendo fundamental a participação da comunidade, avaliação do tempo e recursos disponíveis.

Nakano e Comaru (2007) ressaltam a potencialidade do processo participativo na elaboração de planos diretores para o planejamento e gestão territorial.

\begin{abstract}
O processo participativo de elaboração do Plano Diretor, ao envolver diversos conhecimentos sobre a realidade local durante a elaboração das leituras técnicas, comunitárias e jurídicas, permite analisar uma grande gama de problemas relacionados com as formas de uso e ocupação do solo urbano e rural; com as demandas por serviços, equipamentos e infraestruturas urbanas; com a deterioração de ecossistemas e recursos naturais, entre outras problemáticas (Nakano, Comaru, 2007, p.18)
\end{abstract}

Uma dessas metodologias é a proposto pela província de Ontario no Canadá que considera nove etapas para o processo de levantamento de necessidade social, por meio de métodos quantitativos e qualitativos (Ontario, 2006). Trata-se de uma metodologia sistematizada pelo Ministério da Saúde, com a descrição de ferramentas para o planejamento e transformação do sistema de saúde em nível local e ampliado, a partir de necessidades de saúde. Não há uma definição clara e explícita do conceito de necessidades, mas há o relato do que deve estar incluído na metodologia: descrição da extensão de necessidades, serviços existentes, evidências e melhores práticas para os serviços, estabelecimento de prioridades, recomendações de novos programas ou alterações de programas já existentes.

Na avaliação de necessidades, deve-se considerar uma abordagem de: (1) populações, ao invés de necessidades individuais, (2) condições sociais e materiais de vida, em vez de cuidados de saúde, (3) saúde pública, em vez de 
cuidados clínicos, e (4) desigualdades na área da saúde, ao invés de médias gerais (Ontario, 2006).

Em relação aos métodos, Jordan et al. (1998) ressaltaram que métodos de participação pública devem ser incluídos para obtenção de dados de desigualdades na saúde e outros desconhecidos pelos trabalhadores. Os autores citaram:

- Consulta a cidadãos (representantes da opinião pública ou local): oportunidade dos cidadãos elaborarem perguntas e debater questões relevantes com os especialistas;

- Reuniões com usuários: facilitada por um moderador, as discussões com usuário, representantes da localidade, para identificar diversos pontos de vista sobre informações relevantes, fornecidas com antecedência;

- Grupos focais: grupos de discussão semiestruturados, liderados por um moderador. Discussões grupais são incentivadas para a obtenção de dados sobre questões específicas de interesse do pesquisador, possibilitando aos participantes a expressão, nos seus próprios termos, de experiências, pontos de vista, crenças, valores, atitudes, representações e necessidades sociais (Morgan, 1997).

- Inquéritos: podem ser enviados por correio ou distribuídos para uma grande amostra de respondentes, quando um tema já é conhecido detalhadamente.

- Pesquisas de opinião em painéis permanentes: grandes amostras da população que são pesquisados em intervalos constantes sobre assuntos que preocupam os governantes.

- Fóruns com especialistas também são utilizados para aprofundar as discussões sobre a temática (Feather et al, 1994).

O Planejamento dos serviços de saúde a partir das necessidades sociais da população requer o domínio de conceitos e instrumentos pra que haja uma correta captação da necessidade da população, sem reducionismos dos problemas sociais e de saúde.

Considerar as diferentes visões sobre as necessidades da população é recomendado por Matus, já que as interpretações são diferentes e relevantes para o planejamento estratégico (Matus, 1989). 
Neste caso, gestores do sistema de saúde, pesquisadores, trabalhadores de saúde e a população são fontes chaves para a discussão, levantamento, análise das necessidades sociais e efetivação de diretrizes e metas do planejamento (Silva, Batistella, Gomes, 2007) (Quadro 2). Lideranças comunitárias, representantes institucionais e moradores locais são também convidados para discussões sobre suas realidades locais (Nakano, Comaru, 2007).

Quadro 2 - Visões a serem consideradas no levantamento de necessidades. São Paulo; 2016.

\begin{tabular}{|l|l|}
\hline \multicolumn{1}{|c|}{$\begin{array}{c}\text { Visões a serem } \\
\text { consideradas }\end{array}$} & \begin{tabular}{l}
\multicolumn{1}{c|}{ Foco } \\
Gestores
\end{tabular} \\
$\begin{array}{l}\text { Relação custo-efetividade das ações, com } \\
\text { no financiamento, organização da atenção } \\
\text { integral, entre outros }\end{array}$ \\
\hline Pesquisadores & $\begin{array}{l}\text { Produção de conhecimentos e tecnologias } \\
\text { que possam resultar em melhorias } \\
\text { gerenciais, organizativas e operacionais } \\
\text { dos serviços de saúde }\end{array}$ \\
\hline Trabalhadores de saúde & $\begin{array}{l}\text { Limitações de infraestrutura, dificuldades } \\
\text { administrativas e condições e } \\
\text { precarização do trabalho }\end{array}$ \\
\hline População & $\begin{array}{l}\text { Atendimento integral de suas } \\
\text { necessidades, que são mais amplas, } \\
\text { relacionadas às condições de vida, ou } \\
\text { mais específicas, referentes ao acesso às } \\
\text { tecnologias, à humanização da atenção e } \\
\text { ao desenvolvimento de sua autonomia }\end{array}$ \\
\hline
\end{tabular}

Fonte: Silva, Batistella, Gomes, 2007

Em relação a formas de levantamento e monitoramento de necessidades, Nakamura et al. (2009) relatam que os instrumentos devem buscar identificar os 
determinantes do processo saúde-doença. Entretanto, instrumentos podem ser classificados de formas diversas, como descrevem Nakamura et al. (2009):

1) identificar os mais necessitados ou o público-alvo para as políticas de saúde pública, segundo critérios epidemiológicos;

2) garantir que os serviços de saúde possam responder da forma mais eficiente às necessidades de saúde da população ou

3) valorizar a abordagem proativa, centrada na participação da população e na possibilidade de sua autonomia na geração de recursos próprios de saúde.

Uma revisão sobre avaliação de necessidades buscou identificar e classificar os instrumentos de avaliação de necessidades de saúde existentes (Asadi-Lari, Gray, 2005). Foram identificados 31 instrumentos que foram classificados em quatro grupos de métodos de administração: entrevista, questionário auto administrado, avaliação rápida comunitária e avaliação rápida epidemiológica. Os indicadores e variáveis de cada instrumento não foram descritos.

Partindo dos fundamentos teórico-operacionais do campo de conhecimentos da Saúde Coletiva, esta investigação estabeleceu as seguintes perguntas de pesquisa: Existem instrumentos para planejar em saúde a partir de necessidades de saúde? Quais seriam os conteúdos e estratégias que comporiam e um instrumento de necessidades de saúde, a partir dos fundamentos da Saúde Coletiva? 


\section{CONSIDERAÇÕES TEÓRICAS}

A Saúde Coletiva, campo de saberes e práticas, que nasceu na América Latina, na década de 1970, e que se vale das Ciências Sociais em Saúde, propõe a compreensão do processo saúde-doença pautada em fundamentos marxistas, reconhecendo que os problemas trazidos pelo capitalismo contemporâneo são enfrentados de diferentes maneiras, de acordo com a realidade de reprodução social das diferentes classes sociais (Soares, 2007).

Paim e Almeida Filho (1998) consideram a Saúde Coletiva como campo interdisciplinar composto pelos conhecimentos da epidemiologia, do planejamento/administração de saúde e das ciências sociais em saúde. Breilh (1991) utilizou como categoria central a reprodução social sob as bases do marxismo, já que "permite analisar o processo produtivo em seu movimento, estudar a oposição dialética entre produção (...) e consumo individual" (Breilh, 1991, p.196).

A Teoria da Determinação Social do processo saúde doença é uma formulação desenvolvida nesse contexto. Esta teoria procura relacionar as formas de organização da sociedade com os determinantes sociais da saúde, captando as dimensões sociais e biológicas do processo (Granda, Breilh 1989).

Possas (1989) argumenta que a análise da estrutura social e da saúde na perspectiva da "determinação social da doença" precisa identificar as mediações envolvidas entre as classes sociais, padrões de morbidade e mortalidade e perfil epidemiológico da população, considerando as especificidades das formações sociais contemporâneas.

Entretanto, os estudos sob enfoque da determinação social do processo saúde-doença foram abandonados, em prol dos determinantes que possibilitam o Estado corresponsabilizar a comunidade e os indivíduos, sobressaindo intervenções na área de educação para a saúde (Stotz, 2016).

A chamada transição epidemiológica encaixa-se bem aos propósitos de justificar a substituição da forma de controle social exercida pelo Estado sobre as camadas mais pobres da classe trabalhadora, numa época dominada pelo predomínio das epidemias ou pestilências, pela internalização individual desse controle, dada a prevalência contemporânea das doenças crônico-degenerativas. Essa prevalência, quando atribuída a estilos de vida não saudáveis (muitos dos quais 
não evitáveis para a maioria da população), corresponde a uma espécie de culpabilização da vítima (Stotz, 2016, p.72).

A organização de serviços de saúde sob a perspectiva da Saúde Coletiva deve considerar os perfis epidemiológicos do coletivo, constituídos por perfis de reprodução social (produção e consumo) e perfis saúde-doença (morbidade/mortalidade). Perfis de reprodução social e de saúde-doença são caracterizados por condições de trabalho e de vida específicos de cada classe social (Granda, Breilh, 1989; Soares, 2007).

A utilização da categoria classe social para identificação das desigualdades sociais é fundamental para dar respostas adequadas às necessidades de saúde, compreendidas, a partir das considerações teóricas da Saúde Coletiva.

A Epidemiologia crítica também estuda sistematicamente os processos estruturais da sociedade e os perfis de reprodução social das diferentes classes sociais. As formas de vida e trabalho das classes sociais determinam diversas formas de adoecer e morrer, configurando perfis epidemiológicos de classes que estão em constante processo de modificação (Granda, Breilh, 1989). Soares et al. (2014, p.141) ressaltam que a Epidemiologia crítica na América Latina "começou a ser construída diante de marcantes contradições do cenário de desigualdades sociais. Alicerçada no Marxismo, compôs com ensinamentos humanistas da medicina social".

Granda e Breilh (1989) sintetizam a relevância da análise das formas de trabalho nos estudos epidemiológicos em quatro pontos: a) Condicionam as modalidades de desgaste e repouso: a repercussão na saúde do trabalhador, de sua família e seus próximos é implacável e é determinada pela inserção no aparelho produtivo; b) Determinam a intensidade e frequência de exposição aos benefícios e riscos do trabalho; c) Condicionam a quantidade e qualidade do consumo; e d) Determinam as formas de trabalho complementar, como infantil e materno.

Já as formas de consumo são definidos pelos acessos a bens e meios de subsistência socialmente produzidos de cada classe social. Granda e Breilh (1989) diferenciam o consumo simples, relacionado aos bens de manutenção, como alimentos, vestuário, habitação e recreação, do consumo ampliado, que inclui os bens de aperfeiçoamento, como educação, recreação estruturada, e artística. 
A Epidemiologia Crítica, ao trabalhar com a interdisciplinaridade entre ciências sociais e biológicas, expondo as contradições da sociedade capitalista, tem a potencialidade de superar a fragmentação e explicação da doença em múltiplos fatores (Soares et al., 2014).

Outra perspectiva da Epidemiologia é a chamada clássica ou tradicional que baseia-se na Teoria da Multicausalidade da doença. Tem como base o conceito de risco que identifica a probabilidade de um indivíduo desenvolver ou morrer de uma doença, considerando o coletivo em uma agregação estatística de indivíduos. A doença é o resultado de uma variedade de fatores individuais (Almeida-Filho, Rouquayrol, 1990, Breilh, 2015b).

Ayres (2014), ao descrever e analisar uma aula de Donnangelo, ressalta que a diferenciação entre as teorias das diferentes Epidemiologias não é o fato da análise do social ou falta dela. O social está presente em qualquer estudo epidemiológico no campo da objetividade. O que difere é o sentido político e a forma de caracterizá-lo.

Enquanto para os praticantes da Epidemiologia Clássica pode ser suficiente apenas reconhecer a inefável presença do social sob formulações matemática instrumentalmente pragmáticas, ou, na pior hipótese, buscar ativamente negá-la, por razões políticas ou ideológicas, conscientes ou não, para os epidemiologistas sociais dar visibilidade à tessitura social dos fenômenos que estudam é tarefa de modo algum negligenciável, se não for mesmo a principal. Dar essa visibilidade é o grande norte político da Epidemiologia Social (Ayres, 2014, p. 101).

Dessa forma, os pressupostos da Saúde Coletiva e particularmente os da Epidemiologia Crítica são utilizados em pesquisas que objetivam analisar e explicar criticamente um objeto de investigação, a partir de categorias centrais, como classe social e reprodução social.

É possível identificar na literatura estudos embasados na Epidemiologia Crítica e que evidenciam mudanças nas análises dos perfis saúde-doença. Um desse estudos é sobre o consumo frequente de bebidas alcoólicas por adolescentes. A partir da Epidemiologia Crítica, buscou-se identificar os potenciais de desgaste no trabalho (desemprego, registro, jornada, entre outros) e na vida (habitação precária, falta de espaços de lazer, entre outros), em contrapartida dos fatores de risco, que 
são amplamente trabalhados na perspectiva da Epidemiologia Tradicional (Fujimori et al., 2013).

Um outro exemplo é a intervenção sobre a dengue na perspectiva da Epidemiologia Crítica, realizada no Equador, que vai além dos fatores relacionados ao vetor, aos seres humanos e ao vírus, incidindo sobre modos de determinação: 1) Do processo de transmissão; 2) dos padrões de exposição e vulnerabilidade; 3) Das políticas públicas e a gestão; 4) Da capacidade coletiva e familiar de enfrentamento; 5) Da construção histórico social de ecossistemas com ênfase nos processos (Breilh, 2013). Nessa perspectiva, o estudo epidemiológico concluiu que o grau de exposição à dengue varia de acordo com a classe social dos indivíduos. A análise pautou-se principalmente nas seguintes evidências:

- A degradação rápida das melhores terras e a expansão de grandes monopólios empresariais, já que empresas privadas assumiram quase metade da fronteira agrícola. A ampla aplicação de fumigação aérea e impregnação de produtos químicos nas raízes foram utilizadas para acelerar os lucros e baratear os custos das empresas.

- O aquecimento do solo que contribui para acelerar e encurtar os ciclos reprodutivos do mosquito, além de encurtar os tempos de replicação do vírus em seus organismos. Os agrotóxicos matam os predadores do mosquito e rompem o equilíbrio ecossistêmico. Já o desmatamento e a devastação da floresta destroem os refúgios dos predadores do mosquito;

- Os trabalhadores da agroindústria se alojam nos bairros mais degradados da cidade, com precariedade de habitação, saneamento e fornecimento de água potável, gerando a multiplicação de criadouros dos mosquitos na proximidade dos domicílios.

- No estudo foram comparados bairros de distintas classes sociais e comprovou-se que há uma diferença significativa nos índices de morbidade e nos indicadores entomológicos.

Um desafio da Epidemiologia Crítica no século XXI é o debate e incorporação de categorias chaves, Estado, dominação de classe e hegemonia, para compreensão e intervenção em uma sociedade capitalista, num período de 
acumulação acelerada e interesses estratégicos de grupos poderosos (Breilh, 2015b).

Nota-se que a Epidemiologia Crítica é capaz de explicar as causas do processo saúde-doença e subsidiar o levantamento de necessidades de saúde das diferentes classes sociais de um território.

Considerando que a temática das necessidades vem sendo amplamente estudada em diversas perspectivas teóricas, buscou-se contextualizar o objeto necessidades de saúde, a partir do pressuposto da Saúde Coletiva e particularmente da Epidemiologia Crítica.

O conceito marxista de necessidade refere-se à necessidade socialmente produzida, historicamente determinada e que se materializa de forma desigual, considerando as classes sociais dos indivíduos (Heller, 1978). Nesse sentido, necessidades sociais não são necessidades individuais, já que são representativas de todos os indivíduos de uma formação social (Heller, 1978).

Para Marx e Engels (1977), as necessidades são humanas, históricas e dinâmicas e estão em constante modificação na relação entre os homens.

\begin{abstract}
Os homens devem estar em condições de poder viver a fim de fazer história. Mas, para viver, é necessário antes de mais beber, comer, ter um teto onde se abrigar, vestir-se, etc., O primeiro fato histórico é pois a produção dos meios que permitem satisfazer as necessidades, a produção da própria vida material (...) O segundo ponto a considerar é que uma vez satisfeita a primeira necessidade, a ação de satisfazê-la e o instrumento utilizado para tal conduzem a novas necessidades e essa produção de novas necessidades constitui o primeiro fato histórico (Marx, Engels, 1977, p.39).
\end{abstract}

Heller (1986, p.170) definiu necessidade como um "desejo consciente, aspiração, intenção dirigida a todo o momento para certo objeto", seja uma mercadoria ou um modo de vida. Para a autora, as necessidades são distinguidas como naturais, necessárias e alienadas. As primeiras referem-se à conservação e perpetuação da vida, incluindo necessidades de alimentação, abrigo, de contato social, sexual e de cooperação. Já as necessidades necessárias envolvem a liberdade, a autorrealização, a autonomia, a autodeterminação, a atividade moral e a reflexão. São necessidades individuais, sócio historicamente produzidas. As necessidades alienadas são próprias do capitalismo e estão relacionadas a dinheiro, poder e posse de objetos. 
Vale ressaltar que as necessidades sociais na sociedade capitalista não são necessidades de toda a sociedade, já que estão no contexto da sociedade produtora de mercadorias, dividida por classes sociais com interesses contraditórios (Puccini, 2002).

O conceito de necessidades radicais refere-se às necessidades que nascem na sociedade capitalista, como resultado do desenvolvimento da sociedade civil e que orientam os sujeitos para uma forma de vida que se opõe às relações de subordinação e domínio. São relacionadas às necessidades da classe operária e capazes de promover a revolução e mudanças sociais (Heller, 1978). Apesar da impossibilidade de satisfação dessas necessidades em uma sociedade capitalista, Puccini (2002, p.59) ressalta que não devem ser entendidas como sonhos ou utopias, já que "motivam a práxis que transcende a sociedade que as determina".

A teoria ressalta que não há um "interesse geral", considerando as forças ideológicas contrárias das elites privilegiadas e dominantes e da classe trabalhadora (Puccini, 2002). Nesse sentido, tornar consciente a dialética das necessidades radicais é uma mudança pertinente para a crítica de práticas hegemônicas na saúde.

Em relação à natureza do homem, considera-se que enquanto um ser natural, apresenta necessidades, assim como os outros seres naturais. As necessidades aparecem como "aquilo que precisa "necessariamente" ser satisfeito para que esse ser continue sendo um ser" (Gonçalves, 1992, p. 19). Entretanto, ao pensar nas necessidades e no processo de trabalho desencadeado com intencionalidade para satisfazê-las, o homem se diferencia e se caracteriza como um ser humano sócio histórico.

O processo de trabalho é uma categoria central que está relacionada à satisfação de uma necessidade, já que o produto gerado por este processo satisfaz potencialmente uma necessidade (Campos, Bataiero, 2007; Gonçalves, 1992). O lugar ocupado pelo trabalhador dentro da divisão do trabalho determina a estrutura da necessidade ou ao menos delimita seu limite (Heller, 1978). Heller (1978) considera que todo trabalho humano tem como finalidade a satisfação de necessidades propriamente humanas. 
No que se refere aos serviços de saúde, a reorganização do processo de trabalho e a instrumentalização do trabalhador para a compreensão das necessidades são recomendadas para que a política do direito à saúde se concretize (Campos, Mishima, 2005; Moraes, Bertolozzi, Hino, 2011).

Campos e Mishima (2005) relatam que os processos de trabalho de trabalhadores de uma Unidade Básica de Saúde não abrangiam o reconhecimento das necessidades de saúde da população, nem o conhecimento sistemático dos grupos sociais do território. Há também um conflito entre o que os usuários apresentam como demandas e o que os trabalhadores reconhecem como necessidades na Atenção Básica (Moraes, Bertolozzi, Hino, 2011). Ressalta-se a necessidade de instrumentos específicos da Saúde Coletiva para os trabalhadores trabalharem com a identificação de necessidades (Moraes, Bertolozzi, Hino, 2011).

A partir da perspectiva da Saúde Coletiva e dos resultados de um estudo empírico, Campos e Mishima (2005) propuseram três categorias para a análise das necessidades de saúde:

(1) Necessidade de presença do Estado (responsabilidade pela garantia de serviços públicos e acesso a direitos universais): atribuição do Estado para provisão de serviços para o atendimento dos problemas e necessidades de saúde;

É atribuição do Estado a satisfação da necessidade de saúde e um direito do cidadão (Leopardi, 1992; Campos, Mishima, 2005).

(2) Necessidades de reprodução social: relacionada à sobrevivência da população, considerando as classes sociais que habitam os territórios e que apresentam diversidade nas condições de vida e trabalho, com potenciais de fortalecimento e desgaste que resultam em diferentes perfis de saúde-doença. Ao Estado também foi atribuído à satisfação de necessidades de reprodução social, como saneamento básico, inserção formal no trabalho (Campos, Mishima, 2005).

Muitas causas de doenças se relacionam com a insalubridade, precariedade e exclusão, em relação aos acessos a políticas públicas existentes nos locais de moradia e nos espaços geossociais (Nakano, Koga, 2013, p.163).

(3) Necessidade de participação política: relacionada a grupos organizados da sociedade civil que lutam pela garantia dos direitos dos interessados: notou-se 
que a participação política da sociedade civil é mais evidente, onde há menor satisfação das necessidades de saúde (Campos, Mishima, 2005).

Em relação ao planejamento em saúde, Stotz (1991) defende que o conceito de necessidades de saúde pode subsidiar a elaboração de planos para melhoria das condições de saúde da população.

A descrição das formas de viver da população local, distrital, regional ou nacional é um dos passos da análise das necessidades que subsidia a identificação das necessidades populacionais, áreas de necessidades não satisfeitas; a utilização de recursos racionalmente; o elenco de prioridades; e a influência na política pública e no planejamento e prioridades de pesquisa (Wright, Williams, Wilkinson, 1998).

O planejamento em saúde pode ser entendido como um instrumento de intervenção social com visão de futuro, objetivos determinados, existência de um sujeito, no caso o Estado, indicação de caminho e alternativas e ações necessárias para atingir o objetivo (Castiel, Rivera, 1985). Matus, em entrevista para Huertas (1996), relata que o planejamento é capaz de prever algumas possibilidades, reconhecendo a impossibilidade de conhecer o futuro.

Além disso, o planejamento parte de uma visão de mundo, o que determina o caminho a ser seguido e os problemas a serem enfrentados (Chorny, Kuschnir, Taveira, 2008). A identificação e contextualização dos problemas devem estar claramente descritos, por meio de métodos, com a explicitação das causas e razões para a situação encontrada (Chorny, Kuschnir, Taveira, 2008).

\begin{abstract}
A neutralidade metodológica, que sugere ao usuário que ele tem liberdade para optar dentre diversos métodos para usos similares, esconde o fato de que alguns desses métodos são obsoletos e poucos rigorosos; outros não são alternativos, mas complementares ou aplicáveis em outros campos e níveis da realidade social. Contudo, por causa da crise intelectual que sofrem os poucos órgãos tradicionais de planejamento que sobrevivem, eles não sabem o que propor como alternativa às suas velhas ferramentas e limitam-se a mostrar aos usuários um catálogo dos métodos disponíveis (Matus, em entrevista para Huertas, 1996, p. 18).
\end{abstract}

A portaria GM/MS № 3.085 regulamenta o Sistema de Planejamento do SUS (Brasil, 2006). Um dos objetivos específicos é "formular metodologias e modelos básicos dos instrumentos de planejamento, monitoramento e avaliação que 
traduzam as diretrizes do SUS, com capacidade de adaptação às particularidades de cada esfera administrativa".

O planejamento em saúde, de acordo com o Decreto 7.508/11, constitui-se em obrigação para os entes federados, que através do Mapa da Saúde, deve identificar necessidades de saúde para o planejamento integrado. O mesmo decreto enfatiza que, em âmbito estadual, o planejamento da saúde deve ser realizado de maneira regionalizada (Brasil, 2011).

O planejamento regional caracteriza-se pela "institucionalização de regiões e/ou elaboração de projetos vinculados às regiões geográficas específicas" (Albuquerque, Viana, 2015, p.29). Internacionalmente é conduzido de forma estratégica desde a primeira metade do século XX. Na década de 70, o planejamento regional perdeu força, por questões inerentes ao projeto neoliberal de interesses privados e de mercado. Já no Brasil, é uma estratégia recente da política de saúde que ganhou força nos anos 2000 , tendo em vista a garantia dos princípios do SUS (Albuquerque, Viana, 2015).

Duarte et al. (2015) ressaltam que há dois momentos para o processo de regionalização, relacionados à criação de regiões de saúde e à organização de serviços. As regiões de saúde "são espaços geográficos contínuos, delimitados a partir de identidades culturais, econômicas e sociais e de redes de comunicação e infraestrutura de transportes compartilhados". Em relação aos serviços, a finalidade é "integrar a organização, o planejamento e a execução de ações e serviços de saúde" (Brasil, 2011), tendo em vista os princípios do SUS de universalização, integralidade e equidade com maior qualidade e ao menor custo financeiro (Duarte et al., 2015).

A organização das regiões segue lógicas distintas, relacionadas ao movimento intramuros com foco na epidemiologia, no planejamento de serviços ou no fluxo interno dos usuários, e no movimento extramuros com foco no reconhecimento a área de abrangência e o entorno, não focado nos limites geográficos, o que possibilita propostas diversas de regionalização (Duarte et al., 2015).

Albuquerque e Viana (2015) reconhecem que há desigualdades sociais e espaciais marcantes nas regiões, além de demandas e interesses contraditórios de 
sujeitos e instituições públicos e privadas. Nessa perspectiva, "o planejamento regional serve para enfatizar o caráter público e universal do direito à saúde, reforçando o papel do Estado" (Albuquerque, Viana, 2015, p.32).

O reconhecimento de necessidades de saúde é um processo intrínseco à regionalização e ao planejamento em saúde. Stotz (2016) ressalta que a formulação, acompanhamento e avaliação das políticas de saúde deve ser precedida de identificação do perfil de necessidades de saúde.

A relevância do levantamento de necessidades no planejamento é debatida e defendida há várias décadas, entretanto é possível verificar que planejar tendo como eixo as necessidade de saúde ainda não é um processo consolidado e utilizado na gestão e planejamento em saúde.

No planejamento estratégico situacional (PES), diferentemente do planejamento normativo, no qual o sujeito do planejamento é único (Estado), vários sujeitos interagem, condicionados por uma realidade social. Há diversas explicações e visões de mundo para os problemas, já que existem sujeitos com variados níveis de governabilidade que interagem entre si (Rivera, Artmann, 2012).

O PES supõe um momento explicativo, normativo, estratégico e táticooperacional (Matus, 1989), conforme Figura 3.

O levantamento de necessidades está relacionado com o momento explicativo, quando ocorre a descrição e explicação dos contextos e problemas a serem analisados no planejamento. Descritores ou indicadores quantitativos e qualitativos são utilizados nesse momento para subsidiar a identificação das causas de problemas, relacionados a um ou mais setores, tendo fundamentação intersetorial. No momento normativo, o plano de intervenção é estruturado para descrever as ações para atingir as causas e modificar os descritores, com resultados esperados de cada ação. No momento estratégico, a análise de viabilidade é realizada, bem como a construção de estratégias para tornar o plano viável. A posição dos sujeitos são estabelecidas frente ao plano e o grau de interesse nas ações. Já no momento tático-operacional, o plano é colocado em prática e monitorado para identificação de outros problemas ou redefinir as estratégias (Matus, 1989). 
Conforme Rieg e Araujo Filho (2002) ilustraram na Figura 4, os quatro momentos do PES são cíclicos, mas podem não seguir um único caminho ou uma mesma ordem, a depender de cada realidade a ser enfrentada.

Figura 4 - Os quatro momentos do planejamento estratégico de Carlos Matus. São Paulo; 2016.

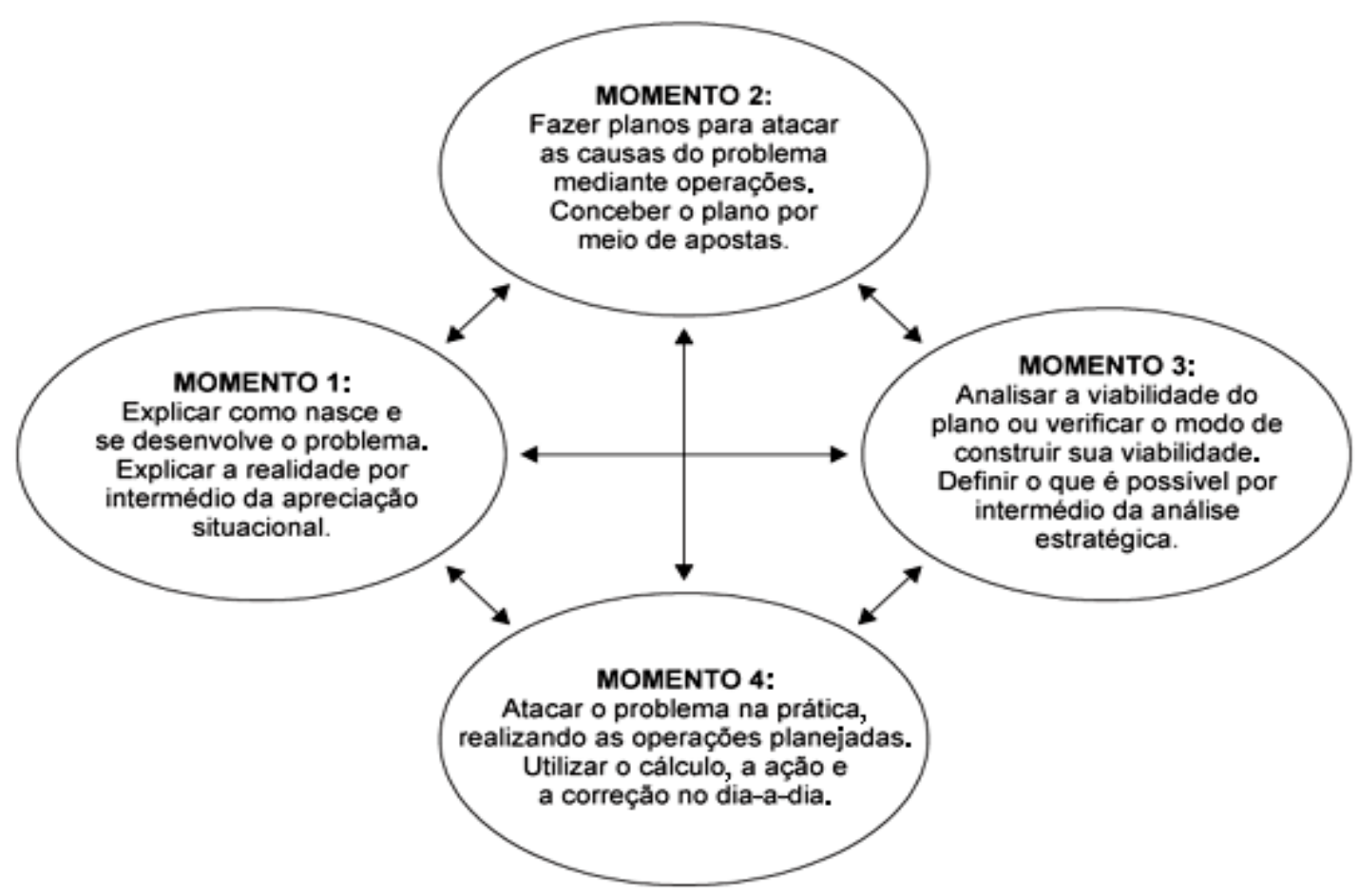

Fonte: Rieg, Araujo Filho (2002). 


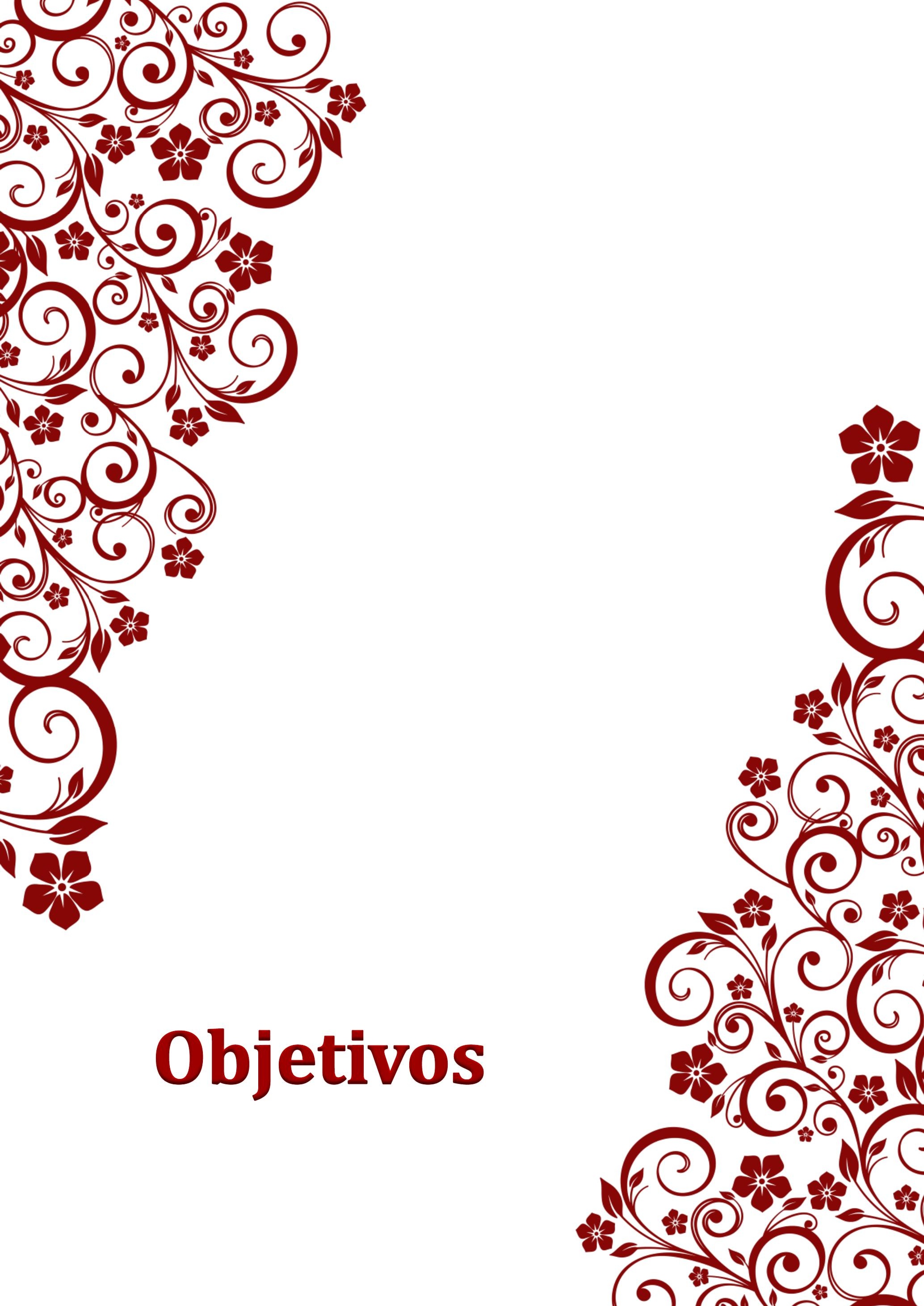




\section{OBJETIVOS}

\subsection{Objetivo Geral}

- Construir um instrumento de levantamento de necessidades de saúde para subsidiar o planejamento regional em saúde.

\subsection{Objetivos Específicos}

- Identificar e analisar instrumentos de levantamento de necessidades de saúde, utilizados no planejamento em saúde.

- Compreender as dificuldades do planejamento e gestão baseado nas necessidades de saúde.

- Identificar e sistematizar um conjunto de variáveis, a partir da categoria necessidade de saúde.

- Validar um instrumento de levantamento de necessidades de saúde. 


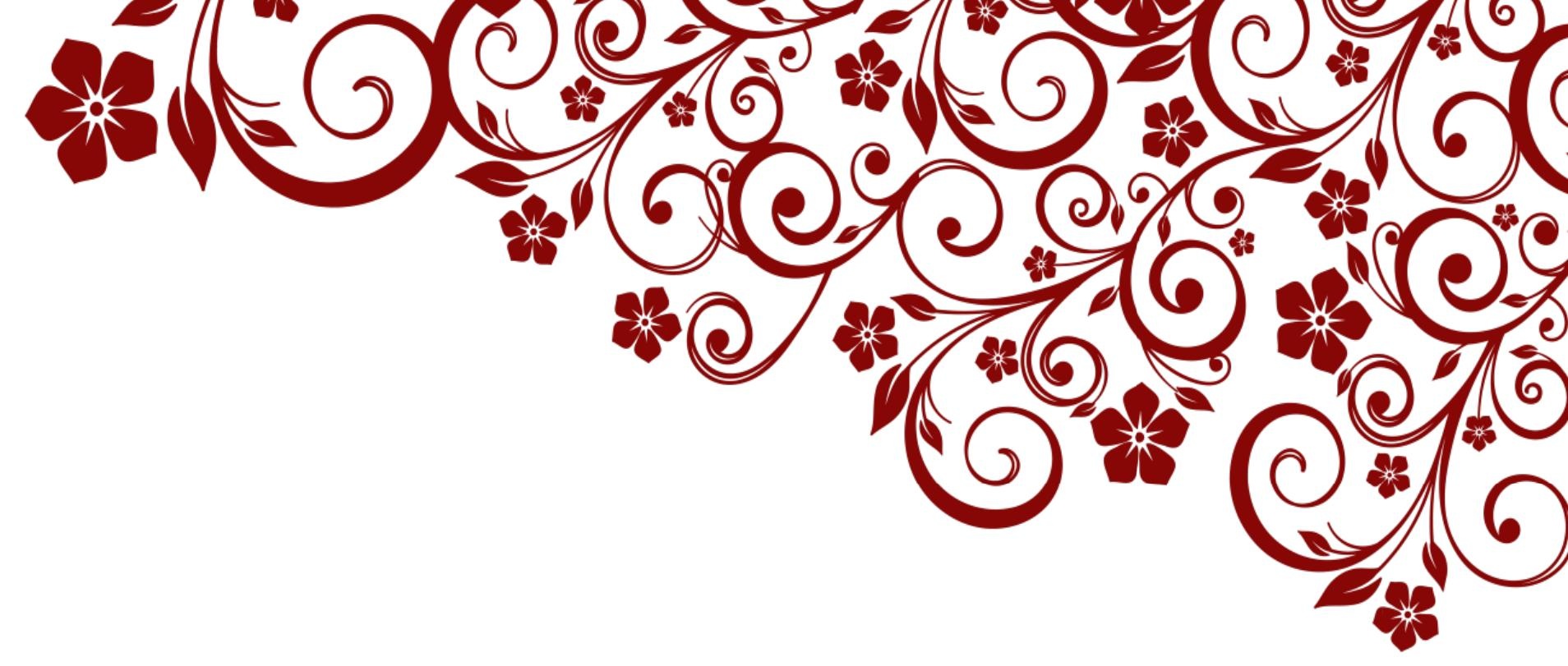

\section{Procedimentos metodológicos}

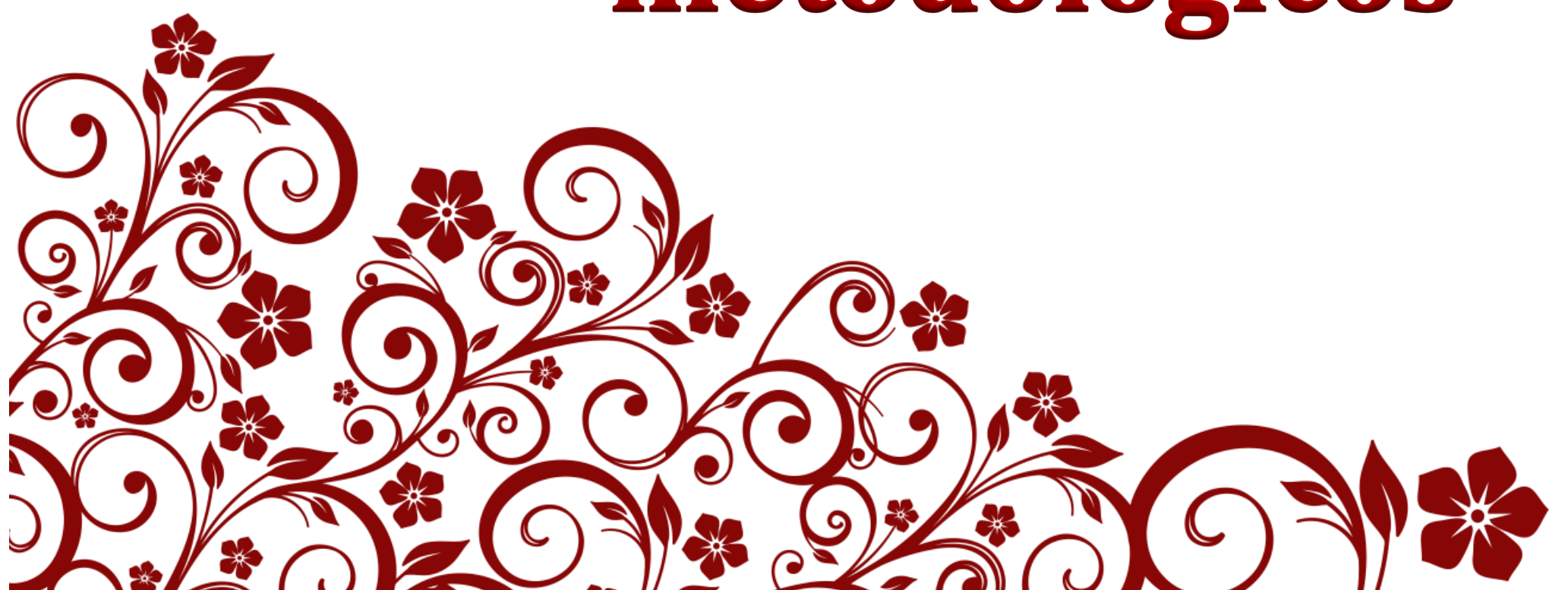




\section{PROCEDIMENTOS METODOLÓGICOS}

\subsection{TIPO DE PESQUISA}

Trata-se de um estudo metodológico, que utilizou abordagens teórica e qualitativa em quatro etapas: 1) Revisão integrativa (RI) sobre instrumentos de levantamento de necessidades sociais; 2) Entrevistas com gestores de saúde, que participaram de um processo de formação, para analisar as dificuldades práticas no levantamento de necessidades; 3) Construção de instrumento de captação de necessidades sociais para subsidiar o planejamento regional em saúde; e 4) Validação de conteúdo por comitê de especialistas.

\subsection{CAMINHO PERCORRIDO}

\section{Etapa 1. Revisão integrativa (RI) sobre instrumentos de levantamento de necessidades sociais}

O objetivo da Rl foi identificar e analisar instrumentos de levantamento de necessidades sociais, utilizados no planejamento em saúde.

Segundo Whittemore e Knafl (2005), a Rl é um método de revisão que permite, não só a compreensão de problemas relevantes, mas também a definição de novos conceitos, revisão de teorias e metodologias, já que permite a inclusão simultânea de estudos empíricos e teóricos.

Assim como a revisão sistemática (RS), os procedimentos metodológicos da $\mathrm{RI}$ devem ser rigorosos, com a descrição detalhada das etapas realizadas pelos pesquisadores para garantir a legitimidade das evidências estabelecidas (Cooper, 1982; Beyea e Nicoll, 1998; Soares et al., 2014).

Entretanto, diversas etapas diferenciam a RI da RS, conforme Quadro 3. 
Quadro 3 - Diferenças entre revisão integrativa e revisão sistemática. São Paulo; 2016.

\begin{tabular}{|l|l|}
\hline \multicolumn{1}{|c|}{ Revisão integrativa } & \multicolumn{1}{c|}{ Revisão sistemática } \\
\hline $\begin{array}{l}\text { Possibilita perguntas específicas ou } \\
\text { amplas }\end{array}$ & Deve ter uma pergunta bem definida \\
\hline $\begin{array}{l}\text { Possibilita a inclusão de estudos } \\
\text { quantitativos, qualitativos e teóricos na } \\
\text { mesma revisão, com o objetivo de } \\
\text { compreender um fenômeno de forma } \\
\text { ampla }\end{array}$ & $\begin{array}{l}\text { Possibilita a inclusão de estudos com } \\
\text { abordagens quantitativas ou }\end{array}$ \\
\hline $\begin{array}{l}\text { Permite definir conceitos, rever teorias } \\
\text { e analisar questões metodológicas }\end{array}$ & $\begin{array}{l}\text { Permite identificar e analisar a melhor } \\
\text { avaliação metodológica crítica dos } \\
\text { estudos primários }\end{array}$ \\
\hline $\begin{array}{l}\text { Tipo de revisão incipiente na } \\
\text { enfermagem brasileira }\end{array}$ & $\begin{array}{l}\text { Tipo de revisão muito utilizado e } \\
\text { estabelecido na saúde pública }\end{array}$ \\
\hline
\end{tabular}

Fonte: Booth (2001); Whittemore, Knafl (2005); Mendes, Silveira, Galvão (2008); JBI (2014); Hoga et al. (2014); Soares et al (2014).

Dessa forma, justifica-se a escolha da RI, já que a análise do objeto do estudo desta $\mathrm{Rl}$ envolve questões metodológicas dos instrumentos disponíveis na literatura, ao invés da melhor evidência de resultados quantitativos ou qualitativos dos estudos, foco das RS.

Esta $\mathrm{RI}$ foi realizada conforme a seguinte proposição metodológica de Soares et al. (2014): 1. Formar um grupo para desenvolver a RI , 2. Elaborar a introdução da revisão, 3. Formular a pergunta e o objetivo da revisão, 4. Descrever a metodologia da revisão, 5. Analisar e interpretar os dados empíricos, 6. Apresentar resultados, 7. Interpretar e discutir resultados, e 8. Divulgar resultados.

Em relação à etapa 1 e 2, esta $R I$ teve dois participantes e a introdução foi incorporada na introdução desta tese. As demais etapas metodológicas estão apresentadas abaixo. 


\section{Pergunta da revisão:}

Quais os métodos de levantamento de necessidades de saúde para o planejamento em saúde?

\section{Objetivo:}

Identificar os métodos de levantamento de necessidades de saúde para o planejamento em saúde.

\section{PICo}

O PICO ou PICo é um acrônimo utilizado para subsidiar a pergunta da revisão sistemática e elaborar a estratégia de busca (JBI, 2014). Em revisões integrativas, a utilização não é usual, mas considera-se a aplicabilidade importante e útil nesse tipo de revisão, tanto para a elaboração da pergunta, quanto na elaboração da estratégia de busca (Hoga et al., 2014).

Em revisões sistemáticas quantitativas, o PICO tem como significado: $\mathbf{P}=$ paciente, população ou problema; I = intervenção; C = comparação e; $\mathbf{O}=$ resultado ou desfecho, relativo à palavra outcome. Já nas revisões qualitativas, o PICo é definido por: P de paciente ou população; I de fenômeno de interesse; e Co de contexto). Pelas características desta RI de levantar instrumentos de necessidades, optou-se por utilizar o PICo de revisões sistemáticas qualitativas, conforme descrição abaixo:

P (Problema) - identificação das necessidades de saúde

I (Intervenção) - instrumento para levantamento de necessidades de saúde

Co (Contexto) - planejamento em saúde

\section{Critérios de inclusão}

\section{Tipos de participantes}

Não se aplica.

\section{Tipos de intervenção/fenômeno de interesse}

O fenômeno de interesse são os instrumentos para levantamento de necessidades de saúde utilizados no planejamento em saúde. 


\section{Tipos de estudo}

Foram incluídos estudos teóricos, metodológicos, de opinião e da literatura cinza, escritos nos idiomas inglês, espanhol ou português e sem limitação de data de publicação (a busca foi realizada em janeiro de 2015, sendo consideradas as referências publicadas até 2014).

\section{Critérios de exclusão}

Instrumentos para levantamento de necessidades individuais, específicas de pessoas com alguma doença, serviço ou faixa etária, ou que não descreveram as variáveis para identificação de necessidades de saúde.

\section{Estratégia de busca}

\section{Bases de dados}

A busca foi realizada nos seguintes recursos informacionais:

1) PubMed

3) LILACS

4) JBI COnNECT

5) SciELO - Scientific Electronic Library Online

A literatura cinza também foi consultada, por meio dos seguintes recursos informacionais:

6) EVIPnet (OMS)

7) Google Acadêmico

\section{Descritores e estratégia de busca}

Foi considerado como definidores da estratégia de busca para cada base os descritores do vocabulário internacional usado na área da saúde, MeSH - Medical Subject Headings [Vocabulário de Assuntos Médicos] construído pela National Libray of Medicine [Biblioteca Nacional de Medicina] para literatura indexada no PubMed, combinados através de operadores Booleanos. Para literatura indexada na 
base de dados latino-americana LILACS, utilizou-se o DeCS (Descritores em Ciências da Saúde), que constitui uma versão traduzida e adaptada do MeSH.

Os descritores utilizados estão abaixo descritos

Planning Techniques

Community Health Planning

Regional Health Planning

Social Planning

Health Facility Planning

Need

Determinação de Necessidades de Cuidados de Saúde

Necessidades e Demandas de Serviços de Saúde

Políticas, Planejamento e Administração em Saúde

Apoio ao Planejamento em Saúde

Planejamento em Saúde Comunitária

Planejamento em Saúde

As estratégias de busca foram descritas por base de dados no Apêndice 1.

\section{Forma de descrição de dados}

Foi desenvolvido um instrumento para descrição dos dados (Quadro 4), com os seguintes componentes: número, título, ano, autores, afiliação dos autores, país do estudo, objetivo do estudo, tipo de estudo, metodologia utilizada, variáveis utilizadas, entre outras variáveis.

Quadro 4 - Instrumento para descrição dos dados dos estudos selecionados. São Paulo; 2016.

\begin{tabular}{|l|l|l|l|l|l|l|l|l|l|l|}
\hline $\mathrm{N}$ & Título & Ano & $\begin{array}{c}\text { Autor } \\
\text { (es) }\end{array}$ & País & $\begin{array}{c}\text { Objetivo } \\
\text { do } \\
\text { estudo }\end{array}$ & Método & Técnica & $\begin{array}{c}\text { Variáveis } \\
\text { utilizadas }\end{array}$ & Conclusão & $\begin{array}{c}\text { Inclusão/ } \\
\text { Exclusão }\end{array}$ \\
\hline 1 & & & & & & & & & & \\
\hline 2 & & & & & & & & & & \\
\hline 3 & & & & & & & & & & \\
\hline 4 & & & & & & & & & & \\
\hline 5 & & & & & & & & & & \\
\hline 6 & & & & & & & & & & \\
\hline 7 & & & & & & & & & & \\
\hline 8 & & & & & & & & & & \\
\hline
\end{tabular}


A partir deste instrumento foi construído um quadro analítico com a descrição de todos os instrumentos identificados.

\section{Forma de análise dos dados}

Primeiramente, os estudos foram classificados por ano, procedência dos autores, tema/objeto específico analisado, natureza, tipo de estudo, resultados obtidos, país de publicação e outras classificações que responderam aos objetivos específicos. Em seguida, os conteúdos foram analisados de acordo com os instrumentos identificados.

\section{Conflito de interesse}

Não há.

Foi identificada uma revisão de literatura sobre instrumentos de avaliação de necessidades de saúde (Asadi-Lari, Gray, 2005). Esta revisão não foi incluída, pois não identificou nenhum estudo com a descrição de variáveis de instrumentos específicos para o planejamento em saúde. Contudo, os resultados embasaram a introdução e discussão do tema. 


\section{Etapa 2. Entrevistas com gestores de saúde}

Foram realizadas entrevistas semiestruturadas com gestores com o objetivo de compreender as dificuldades do planejamento e gestão baseado nas necessidades sociais.

As entrevistas são formas de interação social, que captam formalmente a fala do sujeito sobre determinado tema, constituindo representações e reflexões sobre a realidade que o sujeito vivencia, a partir da interação entre o entrevistador e o entrevistado (Thiollent, 1982, Minayo, 2013). Nas entrevistas semiestruturadas, utiliza-se um roteiro previamente elaborado pelo pesquisador com questionamentos em sequencia para compreender fenômenos sociais (Trivinos, 1987).

Esta etapa foi realizada no Espírito Santo (ES), já que o estado de atuação do projeto mais amplo, que alberga este subprojeto ("Apoio ao Desenvolvimento de Sistemas Regionais de Atenção Integrada à Saúde/Regiões de Saúde") foi pactuado com o Ministério da Saúde em 2014.

Em 2014, foi realizada uma formação para gestores e técnicos da Secretaria Estadual de Saúde (SESA) e das quatro Superintendências Regionais de Saúde (SRS), com o objetivo de desenvolver capacidades estratégicas na gestão regional. Já em 2015, foram realizadas quatro formações em cada região de saúde (norte, central, metropolitana e sul) para os gestores e técnicos das secretarias municipais.

A formação é composta por cinco módulos (Figura 5) com atividades presenciais e de dispersão que integram o conteúdo de cada módulo, de forma sequencial. 
Figura 5. Módulos da Formação em Ação . São Paulo; 2016.
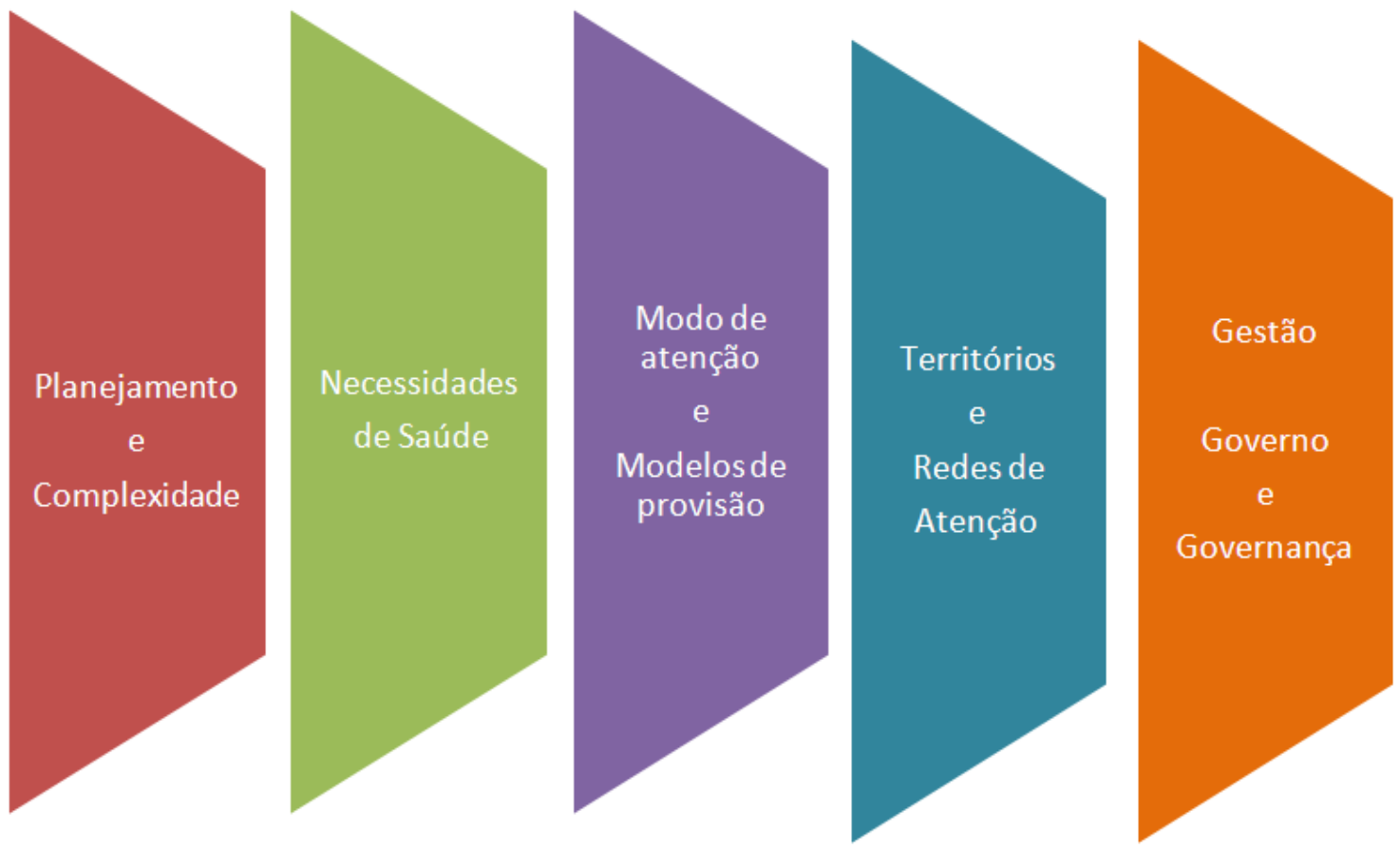

A partir dos contatos estabelecidos pela Formação de 2014 e 2015, gestores municipais e estaduais foram convidados para realização de entrevista semiestruturada, orientadas por um roteiro semiestruturado (Apêndice 2) e um questionário de caracterização do participante (Apêndice 3). As entrevistas foram gravadas e transcritas, sendo realizadas nas instituições dos gestores.

O ES tem uma população estimada de 3.929.911 para 2015, distribuída em 46.096,925 km2, sendo o menor e o menos populoso estado da região sudeste ${ }^{1}$. Dos 78 municípios, 52,56\% apresentam menos de 20 mil habitantes, 33,33\% têm entre 20 e 50 mil habitantes e $11,54 \%$ têm uma população maior que 100 mil habitantes (PDR, 2011).

Partindo do pressuposto que a integração da organização, o planejamento e a execução de ações e serviços de saúde deve ocorrer a partir das Regiões de Saúde, foram consideradas as quatro regiões de saúde do ES, conforme Figura 6 (PDR, 2011).

\footnotetext{
${ }^{1}$ Ver em: http://www.ibge.gov.br/estadosat/perfil.php?lang=\&sigla=es
} 
Figura 6 - Divisão do estado do Espirito Santo em regiões de saúde. São Paulo; 2016.

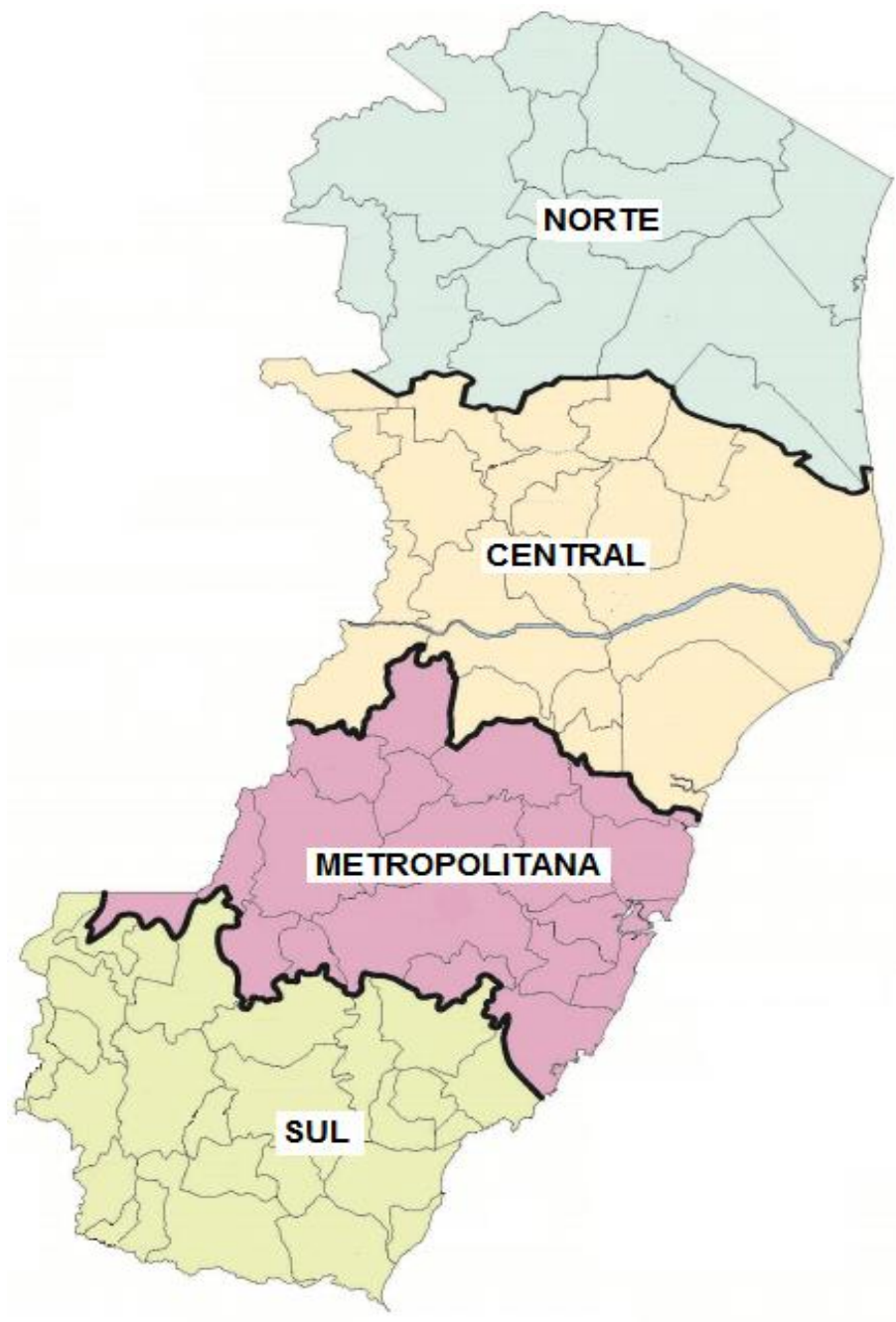

Fonte: PES, 2012.

Em relação ao desenvolvimento socioeconômico e oferta de serviços, a Figura 7 mostra que a região norte apresenta médio/alto desenvolvimento socioeconômico e baixa oferta de serviços, ao contrário da região metropolitana que apresenta alto desenvolvimento socioeconômico e alta oferta de serviços. 
Figura 7 - Distribuição dos grupos socioeconômicos por região de saúde. São Paulo; 2016.

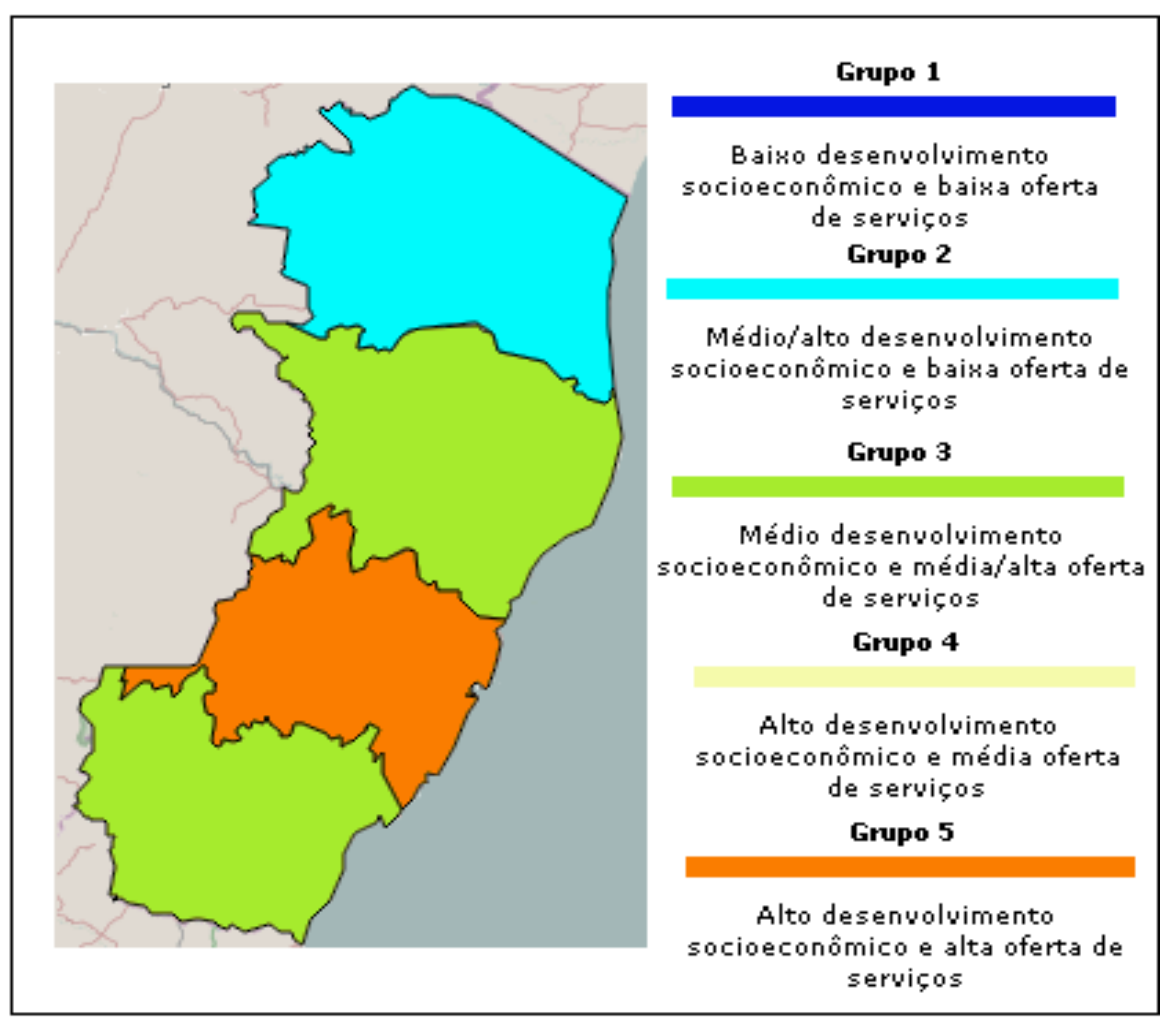

Fonte: Região e Redes².

Etapa 3. Construção de instrumento de captação de necessidades sociais para subsidiar o planejamento regional em saúde

Coluci, Alexandre e Milani (2015) citam diversos recursos utilizados para construção de instrumentos: revisão de literatura, experiência pessoal do elaborador do instrumento, opinião de especialistas, conhecimentos de peritos, escalas já existentes, relatos da população-alvo, observação clínica, resultados de pesquisas. Entrevistas e grupos focais também são utilizados nesse processo (Coluci, Alexandre, Milani, 2015)

A construção foi desenvolvida em quatro sub etapas:

A) Definição dos módulos componentes do instrumento, a partir do referencial teórico da Saúde Coletiva: a taxonomia elaborada por Campos e Mishima (2005) foi

\footnotetext{
${ }^{2}$ Disponível em: http://www.resbr.net.br/indicadores/view/ Acessos em: 05/07/2014.
} 
utilizada para estruturar os módulos; B) Incorporação dos resultados da Rl; C) Revisão a partir da análise das entrevistas com gestores; D) Ordenação dos módulos; e) Composição das etapas de cada módulo a partir da identificação de variáveis e indicadores: foram buscados estudos teóricos, metodológicos ou empíricos, que trabalharam com a identificação de necessidades ou de reprodução social e evidenciaram variáveis e indicadores relevantes para a análise das necessidades, para subsidiar as etapas de cada módulo.

As ilustrações foram selecionadas de acordo com o tema de cada módulo do instrumento, por meio de um banco de imagens, no qual o HCor mantem uma assinatura para uso.

\section{Etapa 4. Validação de conteúdo por especialistas}

Após a etapa de construção, o instrumento foi submetido a um comitê de especialistas nas áreas de Planejamento e gestão de serviços de saúde, Epidemiologia, Saúde Coletiva e Necessidades Sociais para a validação de conteúdo. Os critérios para seleção dos especialistas foram: ter conhecimento teórico e experiência profissional nas áreas citadas anteriormente e trabalhar com pesquisas científicas ou com o tema na prática profissional.

A validação de conteúdo é fundamental para verificar se os itens do instrumento elaborado representam o conceito e a construção teórica a ser julgada (Contandriopoulos et al., 1999).

Alexandre e Coluci (2011) realizaram uma revisão integrativa sobre os abordagens recomendados na validação de conteúdo que consistem em: desenvolvimento do instrumento, adaptação cultural, avaliação por um comitê de juízes e medidas quantitativas para avaliar o conteúdo.

Utilizou-se a técnica Delphi na validação de conteúdo que consiste no julgamento dos itens do instrumento por um grupo composto por juízes, engajados na área do estudo, permitindo a obtenção de opiniões qualificadas (Piola, Vianna, Vivas-Consuelo, 2002; Castro, Rezende, 2009).

Castro e Rezende (2009), por meio de revisão bibliográfica, evidenciaram potencialidades sobre a técnica Delphi, relacionadas à utilização da técnica em diversas áreas do conhecimento como enfermagem, educação e gerenciamento em 
instituições de ensino ou de saúde; acesso de especialistas distantes geograficamente com experiências diversificadas; e menor custo pela dispensa de transporte, tempo, correio, acomodação, alimentação e remuneração dos especialistas. As limitações também foram identificadas: desistência de especialistas e demora no retorno dos questionários para o pesquisador. De uma forma geral, os estudos que utilizaram a técnica obtiveram resultados positivos, alcançando os objetivos propostos.

É possível identificar também a utilização da técnica em temas, como tendências da saúde no Brasil (Piola, Vianna, Vivas-Consuelo, 2002), no processo de planejamento estratégico (Martins, Souza, Melo, 2006) e avaliação de necessidades (Hsu, Sandford, 2007).

Neste estudo, foram selecionados 14 especialistas que receberam uma carta convite, o instrumento desenvolvido especificamente para a validação com orientação de avaliação de cada item, no que se refere à clareza, relevância e pertinência, por meio de escala Likert de cinco pontos, sendo 1 = nada, 2 = muito pouco, 3 = mais ou menos, 4 = provavelmente, e 5 = totalmente (Quadros 5 e 6), e uma breve caracterização dos especialistas (Apêndice 4).

Quadro 5 - Critérios da validação de conteúdo. São Paulo; 2016.

\begin{tabular}{|c|c|c|c|c|c|c|c|c|c|c|c|c|c|c|}
\hline \multicolumn{4}{|c|}{ Clareza } & \multicolumn{4}{c|}{ Relevância } & \multicolumn{4}{c|}{ Pertinência } \\
\hline $\begin{array}{c}\text { A linguagem do item está } \\
\text { clara para a dimensão em } \\
\text { que ele está inserido? }\end{array}$ & \multicolumn{4}{c|}{$\begin{array}{c}\text { O item apresentado é } \\
\text { relevante para o tema? }\end{array}$} & $\begin{array}{c}\text { A linguagem e o conteúdo } \\
\text { do item estão precisos para } \\
\text { a dimensão em que ele } \\
\text { está inserido? }\end{array}$ \\
\hline $\mathbf{1}$ & $\mathbf{2}$ & $\mathbf{3}$ & $\mathbf{4}$ & $\mathbf{5}$ & $\mathbf{1}$ & $\mathbf{2}$ & $\mathbf{3}$ & $\mathbf{4}$ & $\mathbf{5}$ & $\mathbf{1}$ & $\mathbf{2}$ & $\mathbf{3}$ & $\mathbf{4}$ & $\mathbf{5}$ \\
\hline
\end{tabular}

Havia no instrumento também um espaço para redação de sugestões, inclusões, modificações e exclusões de itens, conforme Quadro 6 abaixo:

Quadro 6 - Quadro para redação de sugestões de inclusão, modificação e exclusão. São Paulo; 2016.

\begin{tabular}{|l|l|l|}
\hline & Não & Se sim, informar qual: \\
\hline Incluiria & & \\
\hline Modificaria & & \\
\hline Excluiria & & \\
\hline
\end{tabular}


Likert é um tipo de escala de mensuração de cinco pontos, construída por Rensis Likert em 1932, sendo utilizada em diversas áreas, como psicologia, educação e marketing (Dalmoro, Vieira, 2013). Apesar de existir diversas escalas com pontos que variam de dois a 11 e não haver consenso sobre a melhor opção, Preston e Colman (2000) relatam que escalas de dois a quatro pontos têm poder menor de discriminação de respostas, comparadas a escalas de cinco pontos ou mais. Em relação à preferência, as escalas de cinco a dez são mais fáceis de preenchimento, enquanto as de dois a quatro são relativamente mais rápidas, mas desfavorável na possibilidade de manifestar adequadamente as percepções (Preston, Colman, 2000).

Após a validação de conteúdo, a versão final do instrumento foi submetida a revisão de português por especialista da área.

\subsection{FORMA DE ANÁLISE DOS RESULTADOS}

Os dados da revisão integrativa foram analisados, por meio da descrição das características dos estudos e análise crítica dos instrumentos disponíveis, considerando a aplicabilidade na prática. As categorias de necessidades de Campos e Mishima (2005) foram utilizadas para a análise das variáveis e indicadores dos instrumentos.

Em relação aos dados qualitativos coletados através da entrevistas, a análise foi realizada de acordo com orientação de Bardin (1977) para análise temática que define procedimentos sistemáticos e objetivos para descrever o conteúdo e identificar os núcleos de sentido.

As considerações de Triviños (1992) também foram tomadas como referência. $O$ autor toma como base metodológica de interpretação a corrente dialética e, dessa forma, enfatiza o potencial qualitativo da análise de conteúdo dos textos e não apenas seu potencial quantitativo. O autor reitera a importância da clareza teórica do pesquisador, sem o que não considera possível reconhecer o conteúdo das mensagens analisadas.

Foram realizadas várias leituras de cada entrevista e observações escritas nas margens para a identificação dos temas centrais, possibilitando o agrupados 
dos temas em categorias mais amplas, a partir dos fundamentos teóricos da pesquisa.

$\mathrm{Na}$ análise quantitativa, a sistematização dos dados foi realizada no programa Excel, para cálculo do índice de validade de conteúdo (IVC) de cada item, através da seguinte fórmula: IVC = Número de respostas 4 e $5 /$ Número total de respostas. O IVC mede a concordância sobre alguns aspectos do instrumento e dos itens. Optou-se por considerar as opções 4 e 5 (provavelmente e totalmente claro, relevante e pertinente), já que são as opções que não designam alterações nos itens. Os itens e o instrumento foram considerados válidos, se obtivessem uma concordância mínima de 0,80 (Davis, 1992; Polit, Beck, Hungler, 1995; Alexandre, Coluci, 2011).

Os itens que não obtiveram 0,80 de concordância ou com sugestões de alterações foram avaliados e, se pertinentes, adaptados no instrumento. Todas as sugestões e alterações foram descritas no resultado, bem como a justificativa de não inclusão de sugestões.

Em função da especificidade das alterações que foram recomendadas pelos especialistas, considerou-se desnecessária nova avaliação do instrumento revisado.

\subsection{ASPECTOS ÉTICOS}

O estudo foi aprovado pelo Comitê de Ética em Pesquisa da Escola de Enfermagem da Universidade de São Paulo (número CAAE 47336715.1.0000.5392) (Anexo 1) e conduzido em conformidade com todas as exigências éticas que envolvem as pesquisas com seres humanos, de acordo com a Resolução № 466/12 do Conselho Nacional de Saúde (CNS/MS). Todos os gestores, que foram convidados para a entrevista e aceitaram participar, assinaram um Termo de Consentimento Livre e Esclarecido (TCLE) (Apêndice 5). 


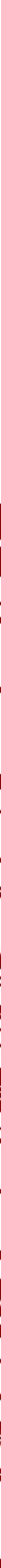




\section{RESULTADOS}

Os resultados foram apresentados de acordo com as etapas.

\subsection{Etapa 1. Revisão Integrativa}

A Figura 8 descreve o fluxograma desta revisão. Foram identificadas 2.991 referências e selecionadas 105 através dos títulos e resumos. Após a exclusão de referências duplicadas ou indisponíveis, 81 referências foram avaliadas na íntegra, a partir dos critérios de elegibilidade. Destas, 64 foram excluídas, por incongruência com os critérios de inclusão, e 17 foram incluídas (Quadro 7). 
Figura 8 - Fluxograma da revisão integrativa sobre instrumentos de levantamento de necessidades de saúde. São Paulo; 2016.

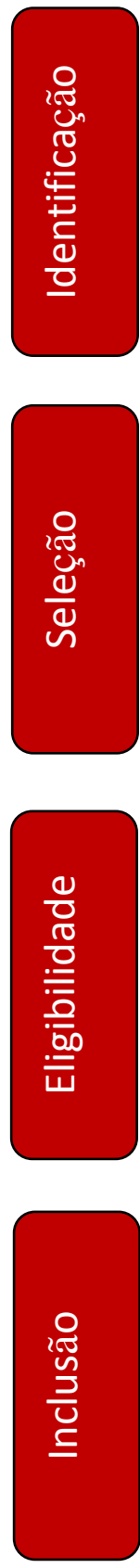

Total de referências recuperadas pela estratégia de busca $(n=2.964)$
Referências identificadas por outras fontes

$$
(n=27)
$$

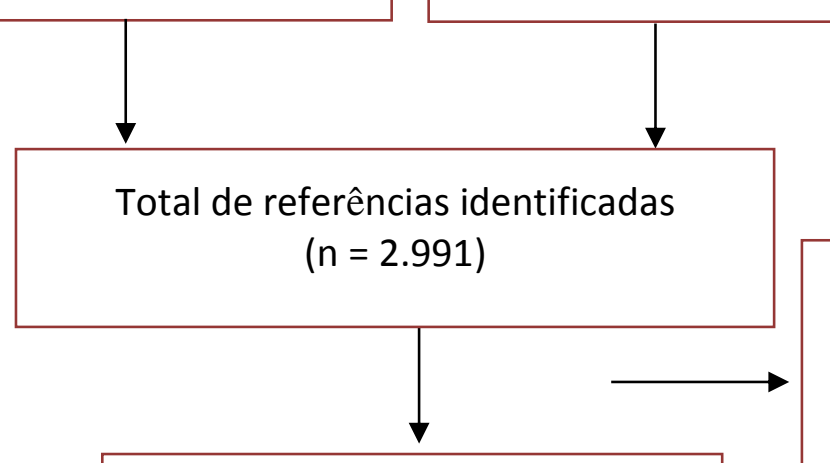

Referências excluídas pelo título e resumo $(n=2.886)$

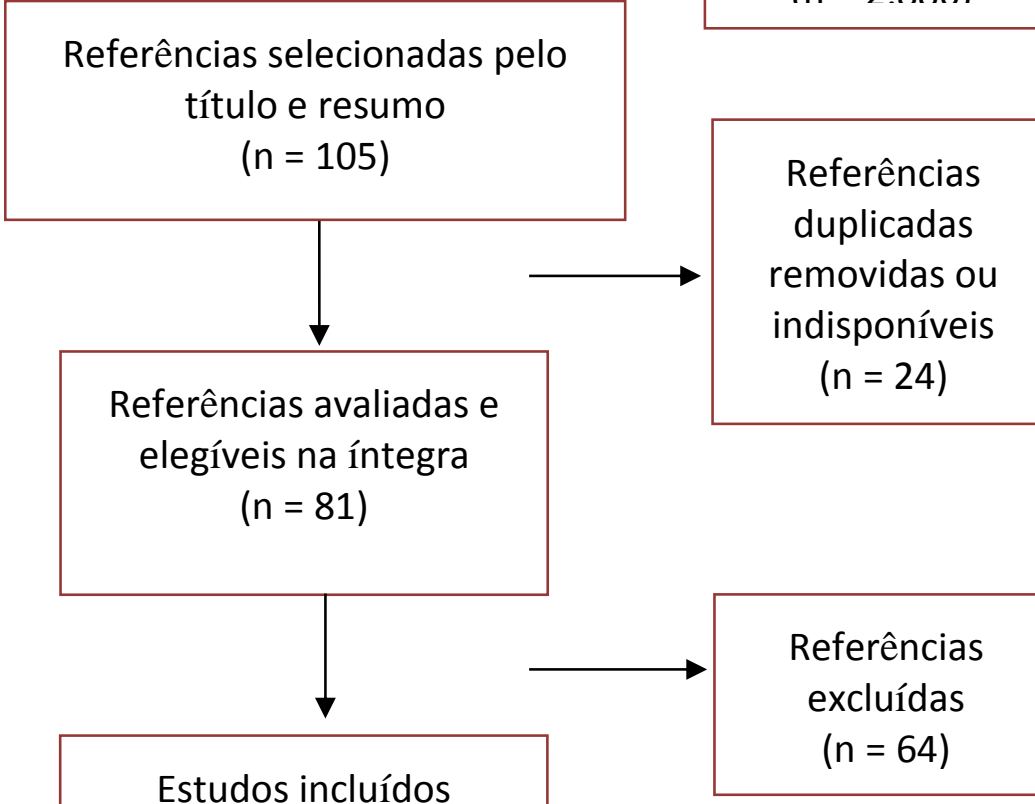

$$
(n=17)
$$

Fonte: Moher et al. (2009) 
Quadro 7 - Descrição das referências identificadas e selecionadas por base/fonte de dados. São Paulo; 2016.

\begin{tabular}{|l|c|c|c|}
\hline \multicolumn{1}{|c|}{$\begin{array}{c}\text { Bases/Fontes de } \\
\text { dados }\end{array}$} & Identificadas & Selecionadas & Incluídas \\
\cline { 2 - 4 } & 1.408 & 57 & 9 \\
\hline PubMed & 51 & 2 & 1 \\
\hline EILACS & 25 & 0 & 0 \\
\hline JBI & 57 & 0 & 0 \\
\hline SciELO & 226 & 9 & 1 \\
\hline Google Acadêmico & 1.197 & 32 & 5 \\
\hline $\begin{array}{l}\text { Outras fontes (busca } \\
\text { manual e referência } \\
\text { de referência) }\end{array}$ & 27 & 105 & 17 \\
\hline Total & $\mathbf{2 . 9 9 1}$ & 5 & \\
\hline
\end{tabular}

\section{Características dos estudos}

Foram incluídos 17 estudos da literatura de 10 países, conforme Tabela 1. Observa-se que a maior parte dos estudos foi publicada nos Estados Unidos da América (EUA). O período de publicações de maior número foi entre 2000 e 2009 (Gráfico 1).

Tabela 1 - País de publicação dos estudos incluídos. São Paulo; 2016.

\begin{tabular}{lcc}
\hline \multicolumn{1}{c}{ País } & N & $\%$ \\
\hline EUA & 8 & 47,1 \\
Brasil & 1 & 5,9 \\
Canadá & 1 & 5,9 \\
China & 1 & 5,9 \\
Colômbia & 1 & 5,9 \\
Dinamarca & 1 & 5,9 \\
\hline
\end{tabular}




\begin{tabular}{lcc}
\hline Escócia & 1 & 5,9 \\
Espanha & 1 & 5,9 \\
Inglaterra & $\mathbf{1}$ & 5,9 \\
Venezuela & $\mathbf{1}$ & 5,9 \\
Total & $\mathbf{1 7}$ & $\mathbf{1 0 0}$ \\
\hline
\end{tabular}

Gráfico 1 - Período de publicação dos estudos incluídos. São Paulo; 2016.

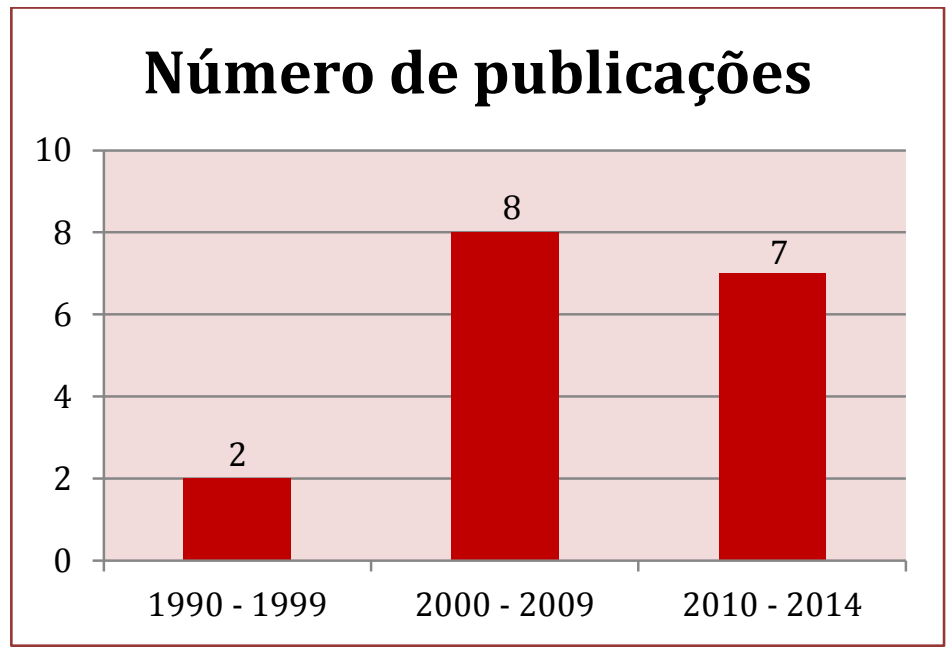

\section{Síntese dos achados}

Nota-se que 9 estudos não descreveram o conceito de necessidades que embasou a construção ou utilização do instrumento. Dois estudos apresentaram conceitos na perspectiva de intervenção em doenças e problemas de saúde (Lee et al., 2009; Li et al., 2009). A Teoria dos Determinantes Sociais foi utilizada em cinco estudos (Barnett, 2011; São Paulo, 2010; Granados, Aguilera, Martín, 2007; WHO, 2001; Wright, Williams, Wilkinson, 1998). Já um estudo ampliou a apreensão das necessidades, ao incluir os conceitos de direitos humanos, equidade e justiça (Negri, Achuri, 2008) (Quadro 8). 
Quadro 8 - Descrição das referências incluídas por ano e conceito de necessidades de saúde. São Paulo; 2016.

\begin{tabular}{|c|c|c|}
\hline Referência & Ano & Conceito de necessidades de saúde \\
\hline Vyas et al. & 2013 & Não apresentou \\
\hline $\begin{array}{l}\text { Gervasio, } \\
\text { McAloon }\end{array}$ & 2013 & Não apresentou \\
\hline Barnett & 2011 & $\begin{array}{l}\text { Perfil de saúde-doença e qualidade de vida dos moradores } \\
\text { da comunidade }\end{array}$ \\
\hline Dubowitz et al. & 2011 & Não apresentou \\
\hline $\begin{array}{l}\text { Heredia- } \\
\text { Martínez, } \\
\text { Artmann, Porto }\end{array}$ & 2010 & Não apresentou \\
\hline São Paulo & 2010 & $\begin{array}{l}\text { São expressas nas condições demográficas, } \\
\text { epidemiológicas e sociais da população residente nos } \\
\text { diversos distritos, refletindo a demanda potencial aos } \\
\text { serviços e permitindo a ordenação das regiões da cidade, } \\
\text { segundo graus de necessidade de investimentos e } \\
\text { organização de ofertas na área da saúde. }\end{array}$ \\
\hline QIIP & 2010 & Não apresentou \\
\hline Lee et al. & 2009 & Presença de doenças \\
\hline Li et al. & 2009 & Problemas de saúde e fatores de risco \\
\hline Thein et al. & 2009 & Não apresentou \\
\hline Kazda et al. & 2009 & Não apresentou \\
\hline $\begin{array}{l}\text { Negri Filho, } \\
\text { Achury }\end{array}$ & 2008 & $\begin{array}{l}\text { Parte da perspectiva da garantia de direitos como um meio } \\
\text { para alcançar a justiça e a equidade. As necessidades } \\
\text { diferem, de acordo com o território, onde habitam as } \\
\text { pessoas de diferentes classes sociais, gêneros, etnias e } \\
\text { gerações. }\end{array}$ \\
\hline
\end{tabular}




\begin{tabular}{|c|c|c|}
\hline $\begin{array}{l}\text { Granados, } \\
\text { Aguilera, Martín }\end{array}$ & 2007 & $\begin{array}{l}\text { Variáveis individuais relevantes, como idade, educação e } \\
\text { outros. A utilização de serviços nos territórios foi uma } \\
\text { variável proxy para necessidades. A equidade foi levada em } \\
\text { consideração: igual uso de serviços de saúde para todos os } \\
\text { indivíduos que apresentam as mesmas características } \\
\text { independentemente do local onde vivem. }\end{array}$ \\
\hline Novins et al. & 2004 & Não apresentou \\
\hline WHO & 2001 & $\begin{array}{l}\text { Necessidades são necessidades sentidas e expressas pela } \\
\text { população local, bem como aqueles definidos por } \\
\text { profissionais. Estado de saúde da população local; } \\
\text { identificação dos principais fatores de risco e causas de } \\
\text { problemas de saúde; identificação das ações necessárias. }\end{array}$ \\
\hline $\begin{array}{l}\text { Wright, } \\
\text { Williams, } \\
\text { Wilkinson }\end{array}$ & 1998 & $\begin{array}{l}\text { Necessidades de saúde incorporam os determinantes } \\
\text { sociais e ambientais de saúde, tais como privação, } \\
\text { habitação, alimentação, educação, emprego. Esta definição } \\
\text { mais ampla nos permite olhar para além dos limites do } \\
\text { modelo médico baseado em serviços de saúde. As } \\
\text { necessidades de saúde de uma população estão em } \\
\text { constantes mudanças, sendo que muitas não serão } \\
\text { passíveis de intervenção médica. As necessidades de saúde } \\
\text { são aquelas que podem se beneficiar de cuidados de saúde } \\
\text { ou de mudanças sociais e ambientais mais amplas } \\
\text { transformações ambientais }\end{array}$ \\
\hline $\begin{array}{l}\text { Murray, } \\
\text { Graham }\end{array}$ & 1995 & Não apresentou \\
\hline
\end{tabular}

O Apêndice 6 mostra a descrição das referências incluídas, por local do estudo, ano, autor (es), método e tipo de instrumento e variáveis utilizadas. Quanto ao tipo de instrumento, nove (53\%) envolviam coleta de dados quanti-qualitativos, com a aplicação de questionário com dados secundários em bases de dados nacionais, bases disponíveis ou em bases científicas, complementada com entrevistas com informantes-chave, população e/ou trabalhadores, grupo focal ou observações da realidade. A utilização de sistemas de informação geográfica também foi citada para o mapeamento geográfico dos dados. Sete $(41 \%)$ instrumentos eram somente quantitativos com a apresentação de itens abertos e/ou fechados. Destes, dois estudos elaboraram um índice de necessidades de saúde, por meio da análise estatística de variáveis socioeconômicas e demográficas Os sistemas de informação geográfica também foram utilizados em alguns 
instrumentos. Já o único instrumento qualitativo (6\%) valeu-se do grupo focal para apreensão de dados sobre necessidades de saúde (Apêndice 6).

No que se refere à categorização dos indicadores ou variáveis utilizadas, dez $(55,5 \%)$ instrumentos continham temas de análise para descrição dos dados a serem coletados. A Tabela 2 mostra que as variáveis foram classificadas em dois a oito temas.

Tabela 2 - Descrição dos instrumentos incluídos na revisão por número de temas. São Paulo; 2016.

\begin{tabular}{l|c|c}
\hline \multicolumn{1}{c|}{ Temas } & N & \% \\
\hline Duas & 1 & 10 \\
Três & 2 & 20 \\
Quatro & 3 & 30 \\
Cinco & 3 & 30 \\
Oito & 1 & 10 \\
\hline Total & $\mathbf{1 0}$ & $\mathbf{1 0 0}$ \\
\hline
\end{tabular}

A Tabela 3 mostra as 14 temas dos instrumentos identificadas, evidenciando que as mais utilizadas foram: (1) Características do território e perfil socioeconômico e demográfico da comunidade, (2) Mortalidade e causas de morte, (3) Utilização de serviços, (4) Problemas de saúde/Doenças/Perfil de saúde-doença, e (5) Questões econômicas e políticas sociais.

Tabela 3 - Temas utilizados para levanta necessidades. São Paulo; 2016.

\begin{tabular}{l|l}
\hline Temas & N \\
\hline Características do território e perfil socioeconômico e & 4 \\
demográfico da comunidade & \\
Mortalidade e causas de morte & 4 \\
Utilização de serviços & 4 \\
Problemas de saúde/Doenças/Perfil de saúde-doença & 4 \\
Questões econômicas e políticas sociais & 3 \\
Desigualdade social/Pobreza & 2 \\
Ciclo vital & 2 \\
Fatores de risco/Fatores que alteram o comportamento & 2 \\
Educação & 2 \\
Cultura & 2 \\
Formas de viver & 1 \\
\hline
\end{tabular}




\begin{tabular}{l|l}
\hline Abastecimento de água & 1 \\
\hline Renda & 1 \\
Desemprego e falta de seguro de saúde & 1 \\
\hline
\end{tabular}

Para proceder à análise das variáveis utilizadas nos estudos, utilizou-se a taxonomia de Campos e Mishima (2005), conforme explicitado no capítulo das considerações teóricas, com o objetivo de integrar os resultados dos estudos incluídos.

A literatura evidencia o maior número de variáveis na categoria reprodução social $(\mathrm{N}=69)$. Foram elaboradas cinco subcategorias, denominadas de: (1) Reconhecimento do território, (2) Caracterização da população socioeconômica e demográfica, (3) Condições de vida, (4) Condições de trabalho, e (5) Perfil saúdedoença. Na categoria presença do estado, foram identificadas sete subcategorias com 49 variáveis: (1) Saúde, (2) Educação, (3) Social, (4) Segurança, (5) Lazer e cultura, (6) Transporte público, e (7) Políticas. Já na categoria Participação política, as duas subcategorias foram (1) Organização comunitária e (2) Participação da população (cinco variáveis no total) (Quadro 9). 
Quadro 9 - Variáveis identificadas nos estudos incluídos e categorizadas. São Paulo; 2016.

\section{Categoria}

Variáveis

Reprodução Reconhecimento do território: área geográfica, limites, meio social ambiente, poluição, desigualdades de saúde, resíduos perigosos, organização e estrutura da comunidade.

Caracterização da população socioeconômica e demográfica: idade, gênero, religião, estado civil, raça, naturalidade, renda familiar, utilização da língua inglesa em casa, migração, analfabetos maiores de 15 anos, atividade física (frequência), tabagismo, gestantes Adolescentes ( $<20$ anos), qualidade de vida, ciclo vital (proporção de crianças, adolescentes, adultos e idosos), língua nativa, crise financeira, problemas para comprar alimentos, insegurança alimentar, comportamentos agressivos do parceiro, uso de álcool e tabaco, uso de cinto de segurança nos automóveis, fonte de recursos econômicos, seguro médico, estado subjetivo da saúde, dados sobre as tendências da população, crescimento da população.

Condições de vida: domicílios sem abastecimento de água, esgotamento sanitário, propriedade da residência, imóveis para alugar, tamanho da residência.

Condições de trabalho: posição ocupacional, satisfação com o trabalho, renda, renda familiar, desemprego, dias por ano de ausência no trabalho.

Perfil saúde-doença: prevalência e/ou incidência de doenças, doença agudas no último ano, Mortalidade por idade, gênero e causa da morte, morbidade, doenças ocupacionais, deficiência, consumo de medicamentos. Indicadores específicos: Coeficiente de Mortalidade Infantil, Coeficiente de Mortalidade por Infecção Respiratória Aguda (< 5 anos), Taxa de Fertilidade Total, Razão de Mortalidade Materna, Coeficiente de Incidência de Sífilis Congênita, Proporção de Pré-Natal Inadequado (menos de 7 consultas), Prevalência de Hipertensão Arterial (20 a 59 anos), Prevalência de Diabetes (20 a 59 anos), Taxa de Mortalidade por Doenças Crônicas relacionadas à Hipertensão, e Diabetes (30 e 59 anos), Taxa de Mortalidade por Acidentes (20 e 59 anos), Mortalidade Precoce em Idosos (\% de óbitos de 60 a 69 anos em relação, ao total de óbitos em 60 anos e mais), Taxa de Mortalidade de Idosos por Pneumonia 


\begin{tabular}{|c|c|}
\hline & $\begin{array}{l}\text { (60 anos e mais), Taxa de Mortalidade de Idosos por Acidente (60 } \\
\text { anos e mais). }\end{array}$ \\
\hline $\begin{array}{l}\text { Presença do } \\
\text { Estado }\end{array}$ & $\begin{array}{l}\text { Saúde: distribuição dos serviços de saúde, utilização, proximidade e } \\
\text { cobertura de serviços e programas de saúde, vacinação, utilização } \\
\text { de serviços de urgência e ambulatoriais, análises diagnósticas, } \\
\text { sexualidade e reprodução, uso de serviços nos últimos seis meses, } \\
\text { acesso aos serviços de saúde: internações hospitalares, } \\
\text { hospitalizações evitáveis, intervenções cirúrgicas, tempo de } \\
\text { permanência hospitalar, diagnóstico na alta hospitalar, } \\
\text { procedimentos hospitalares, readmissões hospitalares em um ano, } \\
\text { dados obstétricos, lista de espera, programas dentro dos serviços, } \\
\text { proximidade de fontes de alimentos saudáveis, realização de exame } \\
\text { físico no último ano, contato com profissional de saúde, cuidados } \\
\text { primários, secundários e terciários. } \\
\text { Educação: quantitativo e acesso aos serviços educativos. } \\
\text { Assistência Social: quantitativo e acesso aos serviços sociais, } \\
\text { suporte social. } \\
\text { Segurança: caracterização da criminalidade (detenções e atividades } \\
\text { criminosas). } \\
\text { Lazer e cultura: quantitativo e acesso aos serviços de cultura, lazer } \\
\text { e desporto, como parques, instalações recreativas e espaços } \\
\text { abertos. } \\
\text { Transporte público: acesso ao transporte público. } \\
\text { Políticas: políticas nacionais, regionais e locais de saúde, sociais, de } \\
\text { nutrição e segurança alimentar, existência, cobertura, acessibilidade, } \\
\text { aceitação e identificação de áreas com necessidade de mudanças. }\end{array}$ \\
\hline $\begin{array}{l}\text { Participação } \\
\text { política }\end{array}$ & $\begin{array}{l}\text { Organização comunitária: Estrutura e capacidade da comunidade } \\
\text { para enfrentar as desigualdades. } \\
\text { Participação da população: para ação sobre os problemas, grau de } \\
\text { representação nas áreas de definição e desenho de políticas } \\
\text { públicas. }\end{array}$ \\
\hline
\end{tabular}


Os estudos incluídos nesta RI evidenciaram que há diversos instrumentos elaborados e utilizados no planejamento, com predomínio de quatro ou cinco categorias $(60 \%)$. Nota-se que poucas variáveis de condições de vida e trabalho foram utilizadas, ao contrário das variáveis de perfil saúde-doença e das de características socioeconômicas. Esse resultado está em consonância com a Epidemiologia clássica, que objetiva estudar as doenças, por meio da análise de características socioeconômicas e demográficas. Dessa forma, não evidencia o processo de determinação social do processo saúde-doença e não aponta as classes ou frações de classe mais atingidas. Ressalta-se que nenhum instrumento revelou formas de identificação de classes sociais.

A categoria presença do Estado foi embasada principalmente por variáveis de utilização e acesso a serviços de saúde e a categoria participação política foi composta por poucas variáveis. 


\subsection{Etapa 2. Entrevistas}

\subsubsection{Caracterização dos participantes da pesquisa}

Foram realizadas sete entrevistas individuais com gestores da região de saúde metropolitana, que duraram em média 45 minutos, no segundo semestre de 2015. Os participantes tinham em média 51 anos e eram em sua maioria do sexo feminino (Tabela 4).

Tabela 4 - Distribuição do sexo e idade dos participantes por número e porcentagem. São Paulo; 2016.

\begin{tabular}{l|c|c}
\hline Sexo & N & $\%$ \\
\hline Feminino & 5 & 71,4 \\
\hline Masculino & 2 & 28,6 \\
\hline Total & $\mathbf{7}$ & $\mathbf{1 0 0}$ \\
\hline
\end{tabular}

\begin{tabular}{l|c|c|}
\hline Idade & $\mathbf{N}$ & $\%$ \\
\hline $\mathbf{4 0}-\mathbf{4 9}$ anos & 2 & 28,6 \\
\hline $\mathbf{5 0}-\mathbf{5 9}$ anos & 4 & 57,1 \\
\hline $\mathbf{6 0}-\mathbf{6 9}$ anos & 1 & 14,3 \\
\hline Total & $\mathbf{7}$ & $\mathbf{1 0 0}$ \\
\hline
\end{tabular}

No que se refere à formação acadêmica, observa-se que $57 \%$ eram formados na área da saúde $43 \%$ na área de humanas (Gráfico 2) e a maioria formou-se na década de 90 (57\%) (Gráfico 3).

Gráfico 2 - Distribuição da formação Acadêmica dos participantes. São Paulo; 2016.

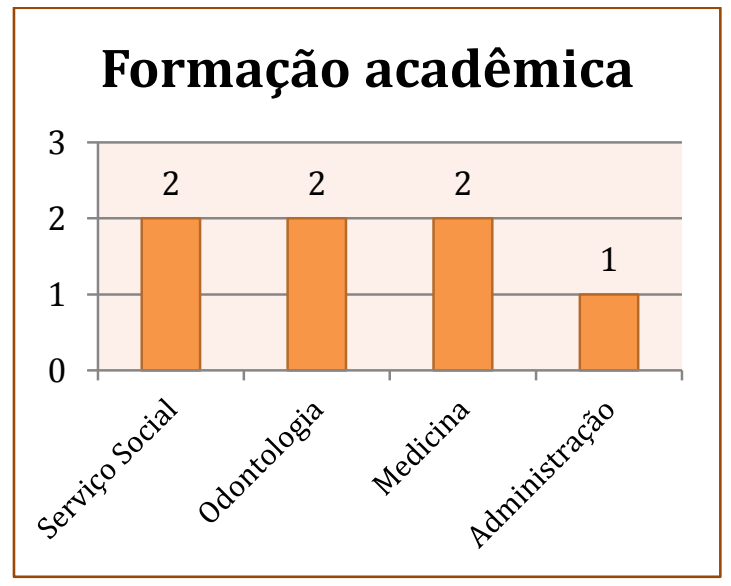

Gráfico 3 - Distribuição da década da formação dos participantes . São Paulo; 2016.

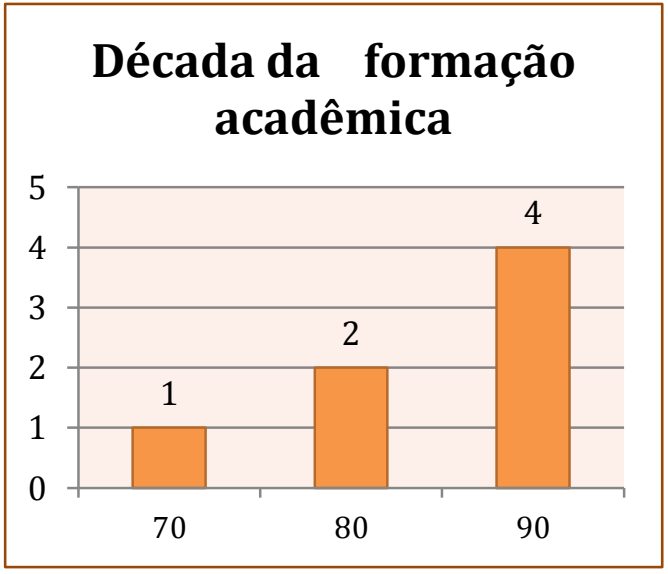


Todos os gestores tinham uma ou mais especializações em Saúde Coletiva, Saúde Pública, Saúde da Família, Administração Pública, Gestão da Saúde, Auditoria, Regulação, Controle e Avaliação e dois tinham mestrado acadêmico (Gráfico 4). Dos sete gestores, 71,4\% eram secretários municipais, conforme Gráfico 5.

Gráfico 4 - Número de participantes Com pós-graduação. São Paulo; 2016.
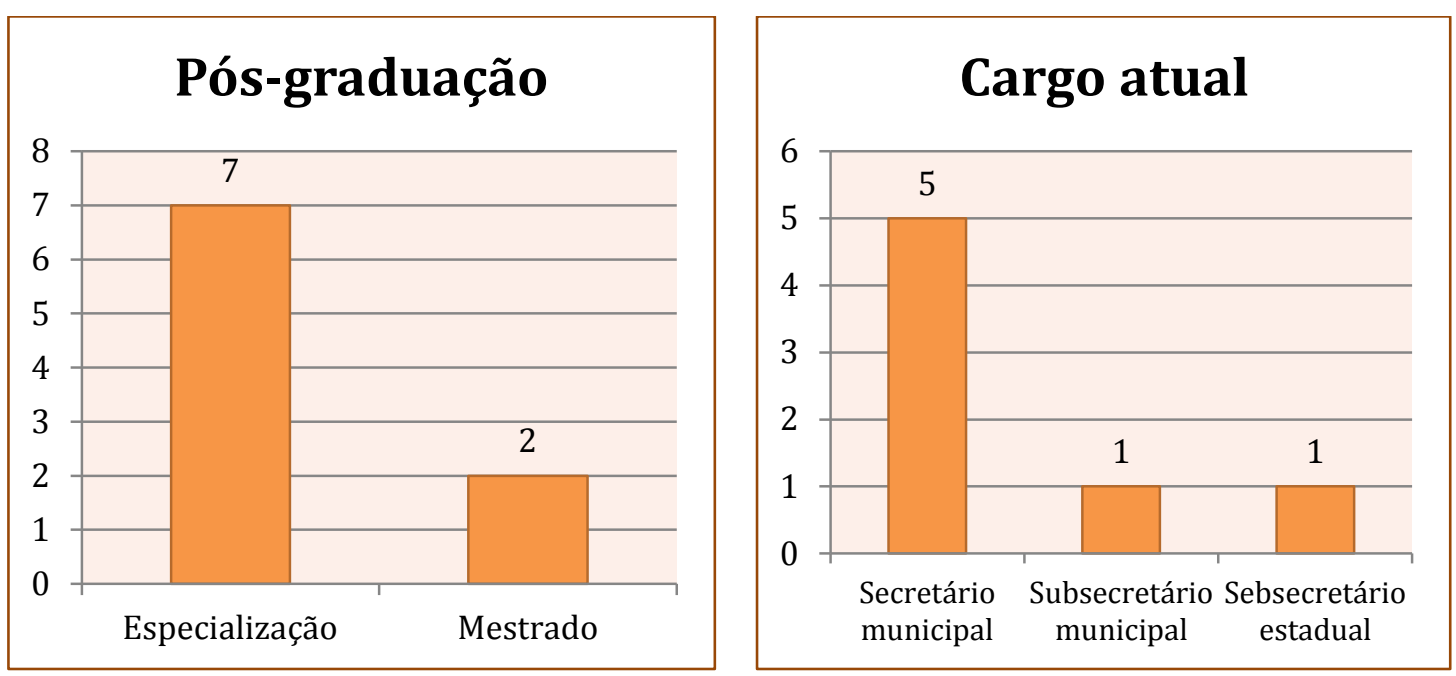

Em relação à gestão pública, a média foi de 15 anos de atuação em secretarias municipais de saúde (100\%), secretarias estaduais de saúde $(57 \%)$, e coordenação de serviços (57\%) (Quadros 6 e 7).

Gráfico 6 - Tempo de atuação na Gráfico 7 - Experiência anterior na Gestão pública. São Paulo; 2016. Gestão pública. São Paulo; 2016.

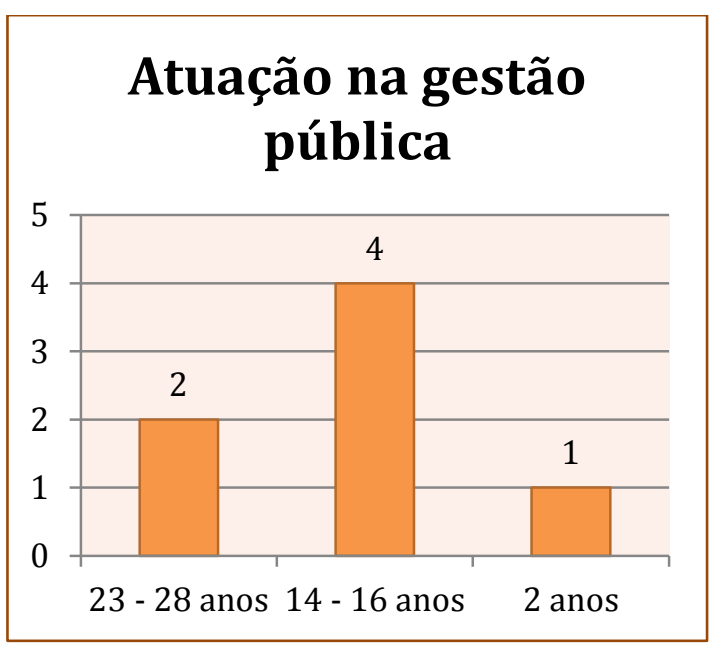

\section{Experiência anterior}

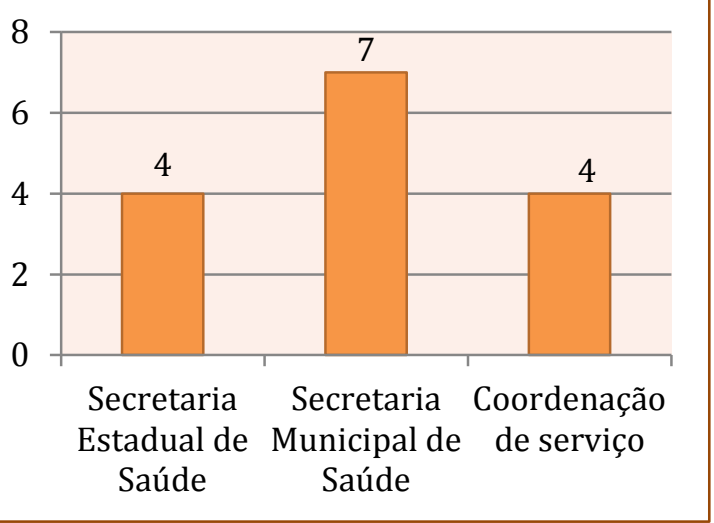




\subsubsection{O que dizem os participantes de pesquisa?}

O Quadro 10 descreve as categorias e os temas extraídos das entrevistas.

Quadro 10 - Categorias e temas. São Paulo; 2016.

\begin{tabular}{|c|c|}
\hline Categorias & Temas \\
\hline $\begin{array}{l}\text { 1. Compreensão de } \\
\text { necessidades de saúde }\end{array}$ & $\begin{array}{l}\text { - Complexidade e polissemia do conceito } \\
\text { do ponto de vista teórico-metodológico e } \\
\text { operacional }\end{array}$ \\
\hline $\begin{array}{l}\text { 2. Necessidades de } \\
\text { reprodução social }\end{array}$ & $\begin{array}{l}\text { - Desconhecimento do território e de } \\
\text { informações locais } \\
\text { - Reconhecimento da heterogeneidade do } \\
\text { território }\end{array}$ \\
\hline $\begin{array}{l}\text { 3. Necessidades de presença } \\
\text { do Estado }\end{array}$ & $\begin{array}{l}\text { - Interesses políticos e particulares em } \\
\text { detrimento dos interesses públicos } \\
\text { - Fragmentação e fragilidades das } \\
\text { instituições do Estado } \\
\text { - Projeto neoliberal: entre a crítica e o } \\
\text { discurso da promoção da saúde } \\
\text { - Pressão pelo acionamento do direito à } \\
\text { saúde } \\
\text { - Recurso financeiro para efetivar o direito } \\
\text { à saúde } \\
\text { - SUS refém da política } \\
\text { - Crítica à incompreensão do modelo de } \\
\text { atenção e desorganização dos serviços } \\
\text { Papel da universidade no SUS }\end{array}$ \\
\hline $\begin{array}{l}\text { 4. Necessidades de } \\
\text { participação política }\end{array}$ & $\begin{array}{l}\text { - Interesses particulares em detrimento } \\
\text { dos direitos sociais }\end{array}$ \\
\hline
\end{tabular}

Descreve-se abaixo a análise dos resultados, de acordo com as categorias e temas, seguidos dos discursos correspondentes. 


\section{Compreensão de necessidades de saúde e das metodologias de apreensão}

\section{- Complexidade e polissemia do conceito do ponto de vista teórico- metodológico e operacional}

Os participantes mostram não ter familiaridade a matriz teórico-metodológica e operacional que envolve 0 conceito de necessidades de saúde como necessidades sociais já que em geral parecem se apoiar na Teoria dos Determinantes Sociais [E2, E3]. Reconhecem, no entanto, a forte hegemonia do planejamento pela demanda, oferta e centrado na doença [E1, E2, E3, E6, E7].

A minha maior crítica é o desconhecimento que a gente tem sobre necessidades (...) $O$ estudo de necessidades é difícil metodologicamente. A gente não tem uma metodologia para isso. Nós, gestores, não fomos treinados para isso [E1].

Conhecer a necessidade é praticamente impossível, dado que é tradição do nosso país que a gente conhece necessidade pela oferta e demanda. A gente não consegue nem estudar aquilo que é obvio que é a oferta. Conhecer a necessidade pela oferta, a gente nem disso dá conta, porque a gente não planeja, a gente vive apagando incêndio, um incêndio atrás de outro, porque infelizmente não dá para parar tudo e dizer ninguém mais adoeça. Esse apagar de incêndio é desgastante, por isso que a gente não consegue parar. Tem que correr atrás de uma nova estratégia de gestão, de planejamento, respondendo as necessidades, o que vai fazer você conhecer um pouco mais as necessidades e atacar as causas e não já nas consequências [E1].

Necessidades sociais de moradia, de educação, lazer, esporte, do trabalho. Essas necessidades vão dizer sobre o adoecimento da população. Ter uma casa, um trabalho, acesso à escola, boa formação. Se as pessoas têm suas necessidades sociais atendidas, vão ter maior qualidade de vida, acesso às informações $e$ consequentemente menos problemas de saúde [E2].

A gente sempre trabalhou muito na demanda. A demanda do que eu tenho, o que eu tenho aqui e posso comprar. A gente tem essa grande oferta, que não é necessária, que não é prioridade. Também dos desejos das pessoas, qualquer um, trabalhador, gestor, eu quero, mas não é a necessidade real ou a gente acha que é e não é 
tão real assim. A gente fica muito na demanda e no desejo. Desejo politico, de cada pessoa, no que ela acredita [E2].

Eu considero necessidade social é quando você olhar o indivíduo não só com aquela necessidade imediata do tratamento ali. Quando eu converso com o prefeito, eu digo que a gente tem que olhar $o$ saneamento da casa do indivíduo, às vezes eu vou com a minha equipe na casa de um idoso. Chegando lá, como eu vou poder garantir a medicação, o atendimento médico, fisioterapia? Quando eu chego lá, o indivíduo está em uma sujeira, não tem ninguém para tomar conta. O contexto do indivíduo não só somente com aquele atendimento ali. É preciso ter um olhar em um contexto de cidadão. O que ele precisa mais? Eu vejo essa necessidade social muito mais ampla, do que somente aquele imediatismo. Só que a necessidade imediata e a demanda ainda estão internalizadas na cultura da população e do planejamento de um modo geral [E3].

A gente da saúde acaba sendo engolido pelo planejamento pela demanda e muito centrado na doença. Só que planejar pela necessidade torna os processos mais efetivos [E6].

É sair da oferta do mercado e da procura da pessoa, a necessidade é qual o perfil epidemiológico, o que deixa aquela população na vulnerabilidade, o que ali dentro expõe as pessoas, claro que pode ter a exposição, pode ter a oferta, pode ter tudo isso e a população não demandar aquela necessidade. O gestor só consegue identificar necessidades pelos sistemas de informação que te trazem isso, não tem outra forma. Naquele território, é preciso avaliar os sistemas de informação, daquele serviço ali [E7]. 


\section{Necessidades de reprodução social}

\section{- Desconhecimento do território e de informações locais}

Os discursos ressaltam a necessidade de conhecer as desigualdades sociais e as características dinâmicas de cada território, para identificar com mais profundidade as condições de vida, relacionadas à moradia, lazer, e atividade física, ainda que vistas de maneira fragmentada [E1, E2, E6]. Houve falas no sentido de que a busca de informações deveria ser realizada também em outros setores, fora o da saúde e em sistemas de informação [E1, E3, E7]. A ausência de dados para monitoramento e avaliação e a importância da espacialização das necessidades e do monitoramento foram enfatizados pelos participantes [E1, E3].

A intersetorialidade falha e a gente só conhece uma parte da realidade, a gente teria que estar muito junto com os outros setores para conhecer a realidade como um todo [E1].

Você não está começando uma realidade do zero, você está começando uma realidade em andamento, que já está andando. Já tem alguma coisa constituída. A gente não monitora, a gente coleta dados, mas a gente não avalia os dados. A gente não tem frequência de monitoramento e nem utiliza isso para repensar o planejamento, rever o planejamento [E1].

Falta um olhar mais apurado da política pública, um olhar da região, conhecer a região, conhecer aquela peculiaridade da região para trabalhar a região, trabalhar as diferenças sociais. Hoje já foi feito um levantamento sobre o esgotamento sanitário, coleta de lixo, moradia, das condições de moradia. Hoje todos tem moradia? E as moradias de papelão? Tem um projeto que vem melhorando as moradias. As pessoas que vivem nas ruas, algumas famílias já foram atendidas, outras ainda estão em processo. Muitos não têm documentos, não querem. A questão do lazer, do esporte, atividade física, a gente vem trabalhando nessa qualidade para o cidadão [E2].

Eu sinto uma fragilidade nossa que é o monitoramento. É frágil, muito difícil fazer. É consumido muito tempo para a realização, do dia a dia e as pessoas têm dificuldade. Aqui a gente tem um instrumento que é o PMAQ [Programa Nacional de Melhoria do Acesso e da Qualidade da Atenção Básica]. A gente tem pego aqueles parâmetros, aqueles questionários para usar como balizador, para gente fazer monitoramento, avaliação e tal. Mas é muito tudo novo. 
Se você executou, você tem que ver o impacto daquilo, qual é o gargalo que existe, como a gente vai corrigir e melhorar [E3].

Eu, como administrador, não sei fazer gestão sem uma informação na mão. Aí, aqui não tinha nada registrado. O que tinha de registro era assim. Eu falava, bom, você tem que comprar esse equipamento, esse insumo, esse material, por quê? Qual o quantitativo que a gente tem de gasto? Vamos comprar cestas básicas para estimular a população que trabalha com tuberculose e hanseníase? Mas quantos pacientes você tem cadastrado? Ninguém tinha a informação de nada, era tudo assim [E3].

Você planeja de acordo com o seu território, espacializa onde tem mais necessidades. É importante, você direciona as suas ações e racionaliza os recursos. Tem mais potência [E6].

O gestor só consegue identificar necessidades pelos sistemas de informação que te trazem isso, não tem outra forma. Naquele território, é preciso avaliar os sistemas de informação, daquele serviço ali [E7].

\section{- Reconhecimento da heterogeneidade do território}

A complexidade da região de saúde metropolitana, composta por municípios de pequeno e grande porte e heterogeneidades territoriais históricas e sociais, repercute no planejamento, o que traz à tona a potencialidade da regionalização da provisão de serviços de saúde, em contraposição à municipalização [E2, E3, E6, E7]. Populações específicas, como as privadas de liberdade e as ciganas, apresentam necessidades particulares que também devem entrar no debate do processo regional [E4, E6].

A gente tem que pensar nas regiões de saúde, a gente tem que pensar como evoluir para um olhar regional. Nós ainda somos muito municipalistas [E2].

Embora a gente tenha na região metropolitana lbatiba que é pequenininho e temos Vitória que é gigante ou Serra, a gente tem que pensar regional. Como vamos ter efetividade de assistência, uma continuidade da atenção básica até o terceiro nível de assistência, se a gente não pensar regional? Eu vejo que é uma impactada para que a gente aceite a regionalização, mas que não pense primeiro em mim como uma ilha. Sair do muro. Olhar para fora [E3]. 
A gente tem que sair do lugar do município, um lugar constituído ao longo da construção do SUS e se constituir como região. E a nossa região metropolitana é uma região atípica em todos os aspectos, com várias realidades, com comunidades distintas e a gente tem que compor essa região, contemplando todas essas diferenças. Diferenças em todos os sentidos, inclusive nas necessidades sociais. Os municípios lá de cima têm histórias diferentes que tem uma produção social diferente da nossa. Como constituir uma região, considerando a singularidade de cada município? Esse é o desafio. A discussão da regionalização é para contribuir aqui nessa construção. Eu aposto muito na regionalização, na construção das redes assistenciais. As redes foram discutidas isoladamente uma da outra, para mim não funciona. Só existe rede em âmbito regional e com cada município com sua atenção básica resolutiva e qualificada. A gente tem que investir nisso e insistir nessa construção [E6].

A região metropolitana tem uma complexidade muito maior, pois não pode só pensar nos municípios da sua região. Temos um pouco mais da metade da população do estado em cinco municípios que se concentram aqui. Então, não adianta eu trabalhar bem aqui, fazer isso, fazer aquilo, se o município vizinho não faz. O mosquito não vê essa barreira. A urgência é a mesma coisa. O SAMU [Serviço de Atendimento Móvel de Urgência] vai levar lá ou cá e a gente tem que estar preparado para o todo [E7].

A questão dos presídios, como não é uma realidade da maioria dos municípios, a gente fica muito sozinho no debate. Quando você chega em uma reunião e fala de presídio, eles não têm interesse em ouvir, porque não é problema deles. Só que eu tenho uma realidade diferente que eu tenho que atender. Nas reuniões eles falam o seguinte: população é sua, o problema é $\operatorname{seu}[\mathrm{E} 4]$.

Nós temos população privada de liberdade que é sempre um gargalo, pois é terra de ninguém. A gente tenta fazer essa interlocução com a Secretaria de Estado e com a Secretaria de Justiça para ver como a gente trabalha questões dessa população. Nós temos populações em condições especiais, população cigana, de identificar essa população. É preciso 
também estratificar a população, verificar quais necessidades especificas tem essas populações [E6]. 


\section{Necessidades de presença do Estado}

\section{- Interesses políticos e particulares em detrimento de interesses públicos}

Os participantes denunciam a predominância de interesses políticos e particulares, contrários aos interesses públicos, interferindo diretamente nos processos de trabalho dos gestores, o que inviabiliza o levantamento de necessidades e intervenções públicas [E1, E3, E4, E6].

A gente vive em uma sociedade que é cada vez mais autocentrada, cada individuo é uma ilha e cada ilha tem suas necessidades e suas necessidades são prioridades diante de qualquer outra. A gente vive em um mundo individualista, então cada um olhando para si [E1].

Você tem que ser extremamente diplomático, extremamente resistente à frustação, otimista e persistente, porque você não consegue grandes resultados. Você vai ver pequenos resultados, pequenos avanços, às vezes grandes retrocessos, às vezes grandes dificuldades e principalmente descontinuidades políticas que é o que mata. Você às vezes tem um grande avanço durante quatro anos e em seis meses tudo acaba [E1].

Ano que vem os grandes recursos serão todos voltados para ganhar a próxima eleição. Isso é uma declaração feita a público que ninguém estranha, porque parece que normatizou, no Brasil é normal. Um gestor que faz uma declaração dessa não está preocupado com o SUS, com as necessidades e ainda que estivesse, se ele é um gestor de saúde, um secretário de saúde, que está inserido dentro de uma prefeitura, vai dançar [E1].

A gente tem interferências políticas fortíssimas, nós temos interesses inúmeros, de classes, de sindicatos, de todos os atores que sempre estão envolvidos em sistemas universais de saúde, com a diferença que geralmente as referências que nós temos são de países com sociedades mais evoluídas no sentido de tempo de amadurecimento social [E1].

Quando eu falo, prefeito, prioriza o esgotamento sanitário, porque você vai me ajudar daqui três ou quatro anos a reduzir o número de atendimentos. Quando eu vou pedir ao prefeito 
para colocar dinheiro na saúde e ele tem outra solicitação de secretário para obra... a obra ganha de mim, pois tem visibilidade política. Eu tenho um gestor que às vezes prioriza outra área que não seja a minha [E3].

Ninguém converge para um mesmo interesse. Cada um puxa, não faz uma força central, cada um puxa para seu interesse. É muito complicado [E3].

Porque se nós não tivéssemos o poder político interferindo, nós conseguiríamos fazer o SUS muito melhor. E é muito difícil a gente trabalhar com isso, porque a gente é técnico e quer fazer o nosso trabalho direitinho. A interferência política é péssima e ela acontece. O prefeito também está em um contexto que ele obedece a câmara de vereadores, influência do estado e isso é muito forte aqui [E4].

É um momento difícil, o tempo político do município é diferente do estado e da união. Estamos finalizando uma gestão e o estado está começando, a união está começando. Isso tem uma repercussão prática. Praticamente o município tem um ano que fica pleno. Porque no primeiro ano de gestão do município ainda está se apropriando, o segundo ano do município o estado e a união estão no processo eleitoral, o terceiro ano que o município tem, essas gestões estão iniciando, é o que a gente percebe esse ano. É agora que o governo do estado está passando a marcha mais veloz, porque até chegar, trocar a equipe, ver o que propõe leva um ano. Então a gente está no final do ano e agora, só que no próximo ano o município entra em movimento eleitoral que é extremamente complicado [E6].

\section{- Fragmentação e fragilidades das instituições do Estado}

Os gestores citam a fragmentação e as fragilidades das instituições do Estado e descrevem algumas críticas, entre elas: falta de intersetorialidade entre a saúde e os demais setores [E1, E2, E3, E6], atuação nas causas dos problemas está fora do setor saúde [E6] e papel do Estado não está claro no planejamento regional [E3]. 
A falta de intersetorialidade de você trabalhar com outros setores e os outros setores enxergarem o setor saúde como mais um setor, e não como um setor depositário final de tudo, porque a sensação que eu tenho é essa, não é problema meu, está todo mundo morrendo de acidente de trânsito, não é um problema da polícia rodoviária federal, é um problema da saúde, se encerra na saúde [E1].

Trabalhar de forma intersetorial não é fácil, a gente fala muito da intersetorialidade, mas a gente tem nossas dificuldades de envolver outros setores, de comunicação [E2].

As ações intersetoriais são pontuais e encontramos uma resistência muito grande. Eu falo assim com a secretária de educação. Eu preciso da sua parceira, porque o seu público é o meu público. Se o seu público for bem trabalhado em sala de aula e com família e tudo, a gente vai diminuir o número de gente na porta das unidades. A gente vai ter mais pessoas sendo assistidas. Eu percebo também que a população está muito carente. Carente de ser ouvida, de afetividade, de toque, de conversa, de atenção [E3].

A gente acabou na construção dos anos, de absorver todas as coisas com a gente. A gente não chega diz não, isso não é bem assim, isso não é gerado no setor saúde. Tem gente que fala assim, tem um problema na estrada que as pessoas ficam cobrando, que tem que ter SAMU, que tem que ter acesso à urgência, mas ninguém modifica a estrada, ninguém fala disso. Tem que intervir no raio da estrada, não é ter mais SAMU, entendeu. Essas coisas a gente não consegue. Muita dificuldade, essa interlocução com a sociedade não está no colo da saúde. A intervenção nas condições de vulnerabilidade e fragilidade das pessoas está fora do setor saúde. Todas as políticas sociais têm que estar integradas para dar conta disso. Quando eu falei da população em situação de rua, o que que é isso? Não é tirar a população da rua, é dar condições para que elas possam viver com liberdade, que tenham condições de vida, acesso ao trabalho, acesso à escolaridade, questões que a gente tem que investir. O SUS tem que trabalhar a intersetorialidade. A gente não faz isso, a gente não avança nisso. A gente vê outros setores falando nisso, mas a intersetorialidade a gente sempre falou, mas não consegue efetivar em sua plenitude [E6]. 
A região é importante, na lei 8080 já falava da regionalização, mas a gente fortaleceu no início os municípios. Movimentos municipalistas, porque o cidadão mora no município, é no município que as coisas acontecem, mas os municípios não dão conta, sozinhos não dão conta, ainda mais no país temos municípios muito pequenos com 10.000 habitantes, 4.000 habitantes. Não dá conta, não tem como dar conta. Um mamógrafo para 4.000. Então, é muito diferente. $A$ gente olha muito para o nosso pedaço, esse dinheiro é meu e vou gastar com o meu. Não é como na casa da gente, primeiro o meu município e depois o outro. Como a gente consegue ampliar esse olhar, do eu e do nós. Tanto os prefeitos, os secretários, quanto a população, tem que ter uma identidade. $O$ estado que pode ser um grande condutor desse processo. Ele tem que saber conduzir isso, se não também você cria algumas divergências entre sul e norte, metropolitana, central. Você precisa fazer um trabalho de autonomia para essas regiões, de uma forma harmônica que não é fácil, porque você vai mudar uma logica de funcionamento, de pensar [E2].

Eu percebo que a SESA (Secretaria Estadual de Saúde) como central precisa nos ajudar. A orquestradora precisa estar conosco. Porque assim, essa fragilidade da necessidade de um apoio, é nossa. A gente precisa desse apoio de nível central para dar uma força, não para nos carregar, mas para dizer não vou aceitar mais esse tipo de planejamento. Porque se o nível central não disser, opa, você não está fazendo. Depois de ter feito, você continua no retrocesso? Vamos reformular aqui. Senão o pessoal resiste $e$ esvazia. E continua reclamando a vida inteira, porque não mudou a forma de planejar. Não é para cuidar da gente, para carregar a gente, mas é para ser o orquestrador. E dizer assim, você não está planejando. O planejamento baseado em necessidades é assim. Aqui não é assim, reformula para cá. $A$ região metropolitana por ela ter essa característica tão diferente que eu te falei de necessidades, aqui é pequeno, aqui é gigante, a Serra está em um nível de central de regulação deles, eles têm uma regulação deles interna. Eles pensam assim, eu estou em outra situação, tenho que ter um olhar diferenciado. Na verdade eu tenho que ter um olhar regional, não sou sozinho, sou regional [E3].

Precisa entrar com um convencimento político do planejamento regional e foi aí que nós paramos. Os gestores municipais e aí o principal gestor de um município é o prefeito, o secretário é o executor, o ordenador, mas o gestor político é o prefeito, e é ele que tem que comprar essa ideia. É ele que tem que aceitar a rede. $O$ gestor depois vai organizar junto com o estado essa rede, ele precisa estar pactuando junto com o estado. $O$ estado precisa estar junto 
para melhorar as estruturas, colocar recursos, município também colocando recurso [E7].

\section{- Projeto neoliberal: entre a crítica e o discurso da promoção da saúde}

O projeto liberal é criticado pelos gestores que citam a fragmentação da saúde [E3], retrocessos intencionados [E6], influência do mercado e projetos de privatizações [E7]. Nota-se que alguns gestores enfocam as ações de saúde na responsabilização do indivíduo pela sua saúde, com propostas de medidas de intervenção provisórias, que não atacam as raízes dos problemas [E1, E2, E3, E4, E6].

Há dias que você pensa em desistir, porque eu falo assim, o financiamento está muito ruim, muito fragmentado, tudo está muito fragmentado [E3].

A mídia usa com muita força e com muita eficiência o usuário. Ela faz a coisa para o usuário dizer que o SUS é ruim e ele diz. Ele está a todo o momento na mídia, dizendo que o SUS não presta, com muita força, com intencionalidade [E6].

O SUS, embora já seja um moço, nós ainda não cumprimos as promessas constitucionais. Estamos longe de cumprir o SUS legal, do jeito que está no termo constitucional, SUS para todos, integral com equidade, universal, a gente está longe disso. Cada vez a gente percebe a movimentação de alguns movimentos de puxar para trás, mas cada vez mais as pessoas estão usando o SUS [E6].

O SUS nunca esteve tão fragilizado. Nós estamos em um momento bastante complicado, mas o SUS está consolidado. Todo mundo que fala do momento que estamos passando, fala dessa mesma forma. Que isso vai passar, essa crise que é econômica e política, afeta 0 sistema, lógico, mas vai passar. A gente tem que tomar um pouco de cuidado, pois tem todo um não interesse da parte da economia, capital estrangeiro que esse sistema nosso não dê certo, para ter brechas no mercado. Então, a gente tem que tomar muito cuidado nesse período para não tomar certas atitudes e ter algumas ações que podem prejudicar o Sistema Único, qualquer coisa que leve a privatização. Seria um retrocesso [E7].

Você tem que acreditar, porque às vezes você leva uns percalços que você tem vontade de desistir, porque o que te consome o tempo todo é aquilo que vem todo dia, o incêndio que a gente apaga. É 
aquilo que atropela todo o planejamento, que desmonta tudo. Então isso é que desmotiva. Você tem que conhecer bem o sistema, acreditar nele. Isso está desse jeito, porque está errado, tem uma forma de fazer certo, aí você se alimenta para poder continuar [E7].

Não vou planejar, não vou comprar consulta, não vou comprar exame, de acordo com a fila que tenho na regulação. Só que isso está posto. $O$ que a gente precisa fazer é comprar serviços para ofertar de acordo com a necessidade. Tem que virar isso, mas essa virada que é difícil, pois o mercado não está pronto para essa virada. Ele oferta aquilo que vai ter mais recursos e nem sempre o que é necessidade está ligado a ganhos e aí vem o papel do estado, estado que e falo de poder, não o estado Espírito Santo, São Paulo. Estado da saúde de regular esse mercado [E7].

A mamografia, você tem mamografia a cada quadrado, todo lugar que você vai tem um mamógrafo e a gente não tem necessidade de tanto mamógrafo. Você vê uma campanha política que as mulheres exponham a mama à radiação como se fizesse mamografia de seis e seis meses fosse uma coisa saudável em todo mundo. A gente sabe que não é e se for pelo mercado vai fazer. O mercado é a propaganda, é a mídia, isso leva e a população vai, ela não tem a informação e nós temos que fazer esse papel [E7].

Esse projeto de uma vida mais saudável, ele acaba sendo, isso é um projeto que joga para o individuo repensar a própria saúde [E1].

A gente percebe que o próprio cidadão precisa se responsabilizar pela sua saúde (...) os médicos do Programa Mais Médicos nos ajudam muito a dizer para a pessoa, a sua saúde está na sua mão. Nada adianta você vir aqui buscar o remédio, se você não mudar o hábito de vida [E3].

Época de seca deu mosquito demais, pernilongo, só que o povo vem tudo em cima da gente, porque eles querem que a gente resolva 0 problema. E eles não entendem que a saúde também é corresponsabilização deles que eles têm que cuidar da casa deles, para não acumular lixo, para não acumular alimento podre e eles não entendem isso. Eles acham que a saúde que tem que resolver [E4].

\section{- Pressão pelo acionamento do direito à saúde}

A judicialização é relatada como a mais forte pressão sofrida, para a garantia do direito à saúde. O judiciário é criticado por enfocar as ações nos direitos individuais, em detrimento dos direitos sociais, que é entendido pelos gestores como uma interferência, 
mesmo com legalidade, desconsiderando os processos de trabalho já instaurados pela gestão pública [E1, E5].

Nós conhecemos a necessidade baseada na oferta e nós conhecemos a justiça batendo na nossa porta todos os dias, ameaçando nos prender. O gestor fica perdido nisso, fica nessa guerra, sendo que o único responsável legal, que vai para a cadeia que está com CPF é o dele. Então ele fica mais perdido nesse apagar de incêndios de focos de incêndio, ao invés de planejar [E1].

Eu só temo a questão do judiciário. Ele interfere muito e diretamente nessa questão de causalidade e tem uma visão de defesa de direito que é constitucional e não estou dizendo que é ilegítimo, mas por isso que a minha principal crítica ao SUS é essa, porque ele garantiu o direito, mas não garantiu as condições, então como isso vai ficar. Isso vai ser uma batalha social, uma batalha jurídica e de gestão que eu não sei de mortos e feridos quem vai sobreviver. Eu vou garantir o direito sim, o judiciário e o Ministério Público vão garantir o direito do cidadão, pois é função deles, é legitimo, mesmo que eles tenham uma interpretação esquisita com relação ao que é garantido como direito e a maneira que ele jogue pelo ralo que é o interesse de um, um e um, não é o interesse de todos socialmente [E1].

Cada dia, todo dia a gente recebe uma liminar, uma determinação judicial, isso é frequente. De todo o tipo, solicitando internação, exame, consulta, medicamento, fralda. Nunca fui em nenhuma reunião que envolvesse judiciário e gestor que chegasse a uma conclusão. Simplesmente fica claro que eles têm o poder e que eles mandam e a gente tem que cumprir e é isso aí. Eu acho que o judiciário não poderia interferir nisso aí. Deveria controlar as filas, as filas de internação, as filas de consultas, as filas de exames e cobrar que a fila seja respeitada. Esse seria o papel dele. E cobrar que se aumente a oferta de exames, de internação do estado ou do responsável, no caso, dependendo do exame o estado, dependendo da consulta o município, internação, o responsável, que se cobre que tem uma fila e que a fila seja respeitada e que se aumente a oferta de serviços que estão pedindo [E5].

\section{- Recurso financeiro insuficiente para efetivar o direito à saúde}

Recursos financeiros insuficientes são as críticas mais fortes dos gestores, já que há comprometimento dos processos de trabalho da gestão e planejamento de ações e serviços de saúde [E1, E2, E3, E5, E6, E7]. Ressaltam-se também a má 
gestão de recursos [E1], o fechamento de serviços de saúde [E7], demora para o atendimento das demandas dos usuários [E3] e a justificativa para não trabalhar sobre as necessidades [E6].

O planejamento é regido em parte pela necessidade que é demonstrada pela oferta ou falta de oferta e em grande parte pelo sistema de recurso financeiro que é a lógica do financiamento. A gente prioriza baseado no Pacto pela Saúde, prioriza aquelas ações que são priorizadas pelo Ministério [E1].

O financeiro que não é suficiente, muitas vezes eles querem colocar a culpa só no gestor que não se tem gestão no país. Você tem maus gestores? Sim, você tem mau de tudo. Você tem mau médico, mau enfermeiro, mau assistente social, mau empresário. Você tem de tudo. Você tem o bom político e o mau também. Mas a gente sabe que o subfinanciamento é real, você pensar que os municípios investem em torno de 20 a $25 \%$ com saúde e então é um gasto significativo dos municípios [E2].

O custeio que é um problema muito sério que o SUS tem, nós recebíamos $R \$ 30.000$ e gastávamos $R \$ 750.000 /$ mês só em um serviço [E3].

O subfinanciamento arrebenta o processo de trabalho. As legislações exigem a garantia de trabalho, garantia de assistência e eu não tenho de onde tirar. Aí, eu fico com a fila de espera da demanda de especialidades muito grande [E3].

A cada dia o município tem que assumir mais responsabilidade de saúde. Então, o município de uns anos para cá está trabalhando para manter o que tem, não tem como planejar [E5].

Planejar com pouco recurso é muito complexo. A gente tem alguns planejamentos, a gente quer constituir as equipes, quer completar os quadros das unidades básicas, oferecer os atendimentos de ginecologia e obstetrícia, mas muitas vezes a gente está limitado pela lei de responsabilidade fiscal. A gente não pode contratar, pela limitação de recurso que a gente não tem. $A$ gente não consegue disponibilizar todas as medicações que precisa. A gente não consegue manter uma estrutura adequada das unidades, por conta dos recursos financeiros [E5].

Nós estamos com uma grande dificuldade com a lei de responsabilidade fiscal. A queda de arrecadação do município foi violenta. Quanto mais tem queda, mais cedo você atinge a lei de 
responsabilidade fiscal. A gente não consegue reduzir, porque as pessoas precisam dos seus trabalhos e ao mesmo tempo a gente convive com o dilema de não conseguir colocar gente para dentro e não conseguir preencher [E6].

A educação cuida da população de uma determinada faixa etária, nós cuidamos dessa mesma população em toda sua vida, do nascer ao morrer e nós temos $15 \%$ do orçamento para fazer isso. A educação tem 20\%. Não que a educação não tenha que ter. Nós teríamos que ter a obrigatoriedade da aplicação de $25 \%$ e a gente tem que ter uma aplicação federal muito maior, do que a gente tem. A gente vem brigando por isso, porque veio com a descentralização do sistema, veio a obrigação de fazer e executar, mas o recurso nunca veio. Essa lógica de financiamento por tabela é totalmente ultrapassada [E7].

A gente está fechando serviço, por questão financeira. O que já estava difícil, está se tornando um pouco mais difícil. Um desafio [E7].

O planeja SUS é muito frágil, muito frágil. O planejamento do SUS fica muito refém do recurso. A gente pensa e fala em necessidade, mas aí acaba caindo na armadilha do recurso. A gente encaixa no que tem no recurso. A gente não planeja nem para as necessidades que tem que organizar e estruturar serviços e ações, a gente fica preso na oferta de recursos e no que vem, as ofertas são muito direcionadas até no repasse do governo federal [E6].

\section{- Crítica à incompreensão do modelo de atenção e desorganização dos serviços}

A incompreensão do modelo de atenção básica que ordena e integra pontos do sistema de saúde, por parte da população e da mídia foi relatada, como necessidade de intervenção para discussões críticas com foco em questões prioritárias e pertinentes principalmente na atenção básica [E2, E3].

Nota-se que no contexto dos gestores a alta cobertura da atenção básica não reflete na efetividade das intervenções sobre os problemas do território [E3, E6]. A provisão de serviços, em nível regional, ainda é incipiente, o que ocasiona ao mesmo tempo diversidades de um mesmo serviço em uma região [E5] e falta de outros, comprometendo o atendimento [E3]. 
A população ainda pede o ginecologista, o pediatra, o cardiologista. Vemos que não conseguimos passar para a população o incorporar desse novo modelo de atenção à saúde, da estratégia, do médico generalista. A gente tem alta cobertura de estratégia, mas todos querem que nas unidades tenham ginecologista de apoio, pediatria de apoio e clínico de apoio. Então assim, não conseguimos mudar essa lógica, no atendimento, a maioria da população tem essa dificuldade. A imprensa também. O meio de comunicação tem dificuldade de entender qual o modelo de atenção. Quando a gente vai dar uma entrevista para a televisão, rádio, jornal. Eles perguntam quantos pediatras, ginecologistas, a gente explica o modelo de atenção e eles insistem, quantos pediatras. Nós não conseguimos, essa questão de entender o que é esse modelo, é uma questão que a gente tem que trabalhar, pensar na população e com os meios de comunicação, que podem ser grandes parceiros ou como hoje que não são parceiros. A gente tem um olhar muito distorcido do que é o SUS que é preocupante e que pode melhorar. Essas questões são importantes, da formação, do financiamento, divulgação do que é o SUS, do modelo de gestão. Esse modelo hoje, nós temos o acesso, mas não temos a qualidade e a resolutividade na atenção básica [E2].

A Estratégia Saúde da Família tem que ser repensada no país, porque cobertura não garante efetividade. E a população ainda tem uma dificuldade para entender o que é a Estratégia, a população ainda tem a cultura de achar que ela chega ali e o médico está ali para ela ser atendida [E3].

A UPA (Unidade de Pronto Atendimento) está sendo o hospital. 0 que os médicos estão pedindo hoje é tomografia, ressonância para tratar o paciente dentro da UPA. Porque eu vejo assim, que é como eu falei da necessidade de repensar, porque eu não sei se a gente está recebendo um efeito cascata de um serviço mal feito e agora está todo mundo desesperado. Eu não costumo falar que a culpa é de. É nossa. Eu falo assim, a partir do momento que eu ampliei a assistência da atenção básica, automaticamente, médicos também encaminhando para especialidades. O profissional de saúde nosso tem dificuldade de dar referência e contra referência [E3].

Aqui no estado não existe uma regionalização. Você tem vários hospitais, vários serviços, onde você tem cada um ofertando praticamente a mesma coisa. Você tem uma descentralização que você gera um custo muito grande, muito alto com uma produtividade muito baixa. Você tem neurocirurgia em vários hospitais da grande Vitória que geram um custo enorme que você poderia ter em um único hospital [E5]. 
É uma preocupação grande, pois uma atenção básica fragilizada fragiliza todo o sistema. Enquanto a gente está falando de regionalização, de construção de redes, construir redes com uma atenção básica fragilizada é impossível, pois é ela que ordena a entrada no sistema. Se eu não dou conta de resolver no meu âmbito de resolutividade, eu vou encaminhar para o nível seguinte e isso é complicado, quando a gente fala em construção de rede. A dificuldade é muito grande no acesso à média complexidade, ambulatorial e hospitalar [E6].

\section{- Papel da universidade no SUS}

Questiona-se o papel da universidade, diante das demandas sociais do setor saúde, mais especificamente sobre formação e qualificação de trabalhadores em Saúde Pública, pesquisas e projetos de extensão universitária. Houve críticas sobre a falta de divulgação dos resultados das pesquisas acadêmicas nos serviços que serviram de campo de estudo e sobre qual o impacto das pesquisas nos serviços de saúde [E2, E6].

O profissional não foi formado para o SUS. A identidade do serviço público, a identidade com a população, de estar trabalhando na política pública. Isso precisa ser trabalhado nas faculdades, universidades. Como isso, a gente não ser corrompido pelo próprio sistema capitalista [E2].

A academia se ausentou, esteve muito presente na construção do SUS. Desde a oitava conferência a academia estava presente, estava protagonista, mas ela se afastou, ela se ausentou. Ela fica enclausurada nos seus muros. Ela no máximo fica na capital, no interior tem muita dificuldade. Vamos provocar a universidade para vir para cá, se juntar com nós. Ela se ausentou muito do debate, da presença na gestão, uma lacuna que a gente tem que colocar em debate e preencher essa lacuna. A academia é importante, sair para pensar, na extensão, na pesquisa. Não é fazer a pesquisa e ir embora. Tem que ser feita, dar devolutiva, ver como contribui para qualificar o SUS local. Mas acho que tem que dar uma sacudida na academia. Há também carência de profissionais formados em saúde pública [E6].

Há essa dificuldade, o processo de planejamento do SUS precisa de qualificação, precisa de técnicos qualificados para a gente poder caminhar mais, profissionalizar o planejamento [E6]. 


\section{Necessidades de participação política}

\section{Interesses particulares em detrimento dos direitos sociais}

Os gestores ressaltam por um lado a relevância dos instrumentos e espaços de participação política, mas por outro a predominância de interesses pessoais em detrimento dos direitos sociais, com manipulações da voz da sociedade civil e descomprometimento com o planejamento em saúde para melhoria das condições de vida e trabalho da população [E1, E5, E7]. A organização e participação política da sociedade são ressaltadas como fundamentais, perante a ausência de atuação do Estado em questões sociais [E7].

Essa sociedade tem que começar a demandar suas necessidades, para isso precisa estar organizada em torno do social e não em torno do individual. Isso eu não vejo acontecer a curto prazo no nosso país. É um amadurecimento social, mas é também um amadurecimento individual que demora, amadurecimento antropológico e isso a gente não vai ver tão cedo. Um país que você tem 7.500 crianças em trabalho infantil, que legado ele vai deixar para essas crianças? Que legado que ele vai deixar para essa sociedade? Que preocupação ele tem com essas crianças? Um país onde o número de vítimas de violência é deste tamanho, que sociedade é essa? Você pega aquilo que é registrado, violência contra mulher, violência contra criança, abuso sexual infantil... Se a gente não cuida desse nosso legado, das nossas crianças, como é que vou querer um país melhor daqui para frente? Do ponto de visto do amadurecimento social, a gente tem muito a trabalhar, é um amadurecimento da sociedade que tem que ser multi setorial e tem que ser incentivado [E1].

A representatividade nos conselhos é muito questionada. Quem é representante? Quem representa o conselho nacional de saúde, quem representa o conselho estadual de saúde? Quem representa os municipais? De que maneira essas pessoas se inserem, elas colaboram de verdade? Isso para mim não é nenhum ganho, é uma grande perda, porque se você for fazer um apanhado geral do país e ver qual é essa representatividade, quem são esses representantes e o que de fato eles representam e até o mesmo o que eles entendem sobre a representação social e sobre o SUS, você fica um pouco decepcionado [E1].

Ainda precisa melhorar o planejamento em nível local. Nós temos conselhos locais em todas as nossas unidades, nos serviços e o 
usuário ainda é, a participação ainda não é efetiva. A gente tem que pensar um pouco e melhorar um pouco a formação dos conselhos locais, dos conselheiros e envolvê-los na questão do planejamento [E2].

Os conselhos locais usam a função deles para fazer politica. A grande maioria dos conselheiros tem interesses políticos. Hoje estão para apoiar a administração ou para ir contra a administração. Não tem o fator nenhum que faça crescer isso. Nunca vi nenhuma atitude positiva. Não representam a população. Não tem essa maturidade, até porque a maioria são pessoas que não entendem nada de saúde. São pessoas que não têm capacidade de modificar, influenciar alguma coisa. A voz da população acaba não aparecendo. Interesse pessoal, defendem os interesses pessoais dos bairros deles, não enxergam o município como um todo, enxergam a porta da casa dele, a rua que ele mora, a unidade do bairro dele. Eles vem para cá com esse intuito, não para crescer. Não é democrático. Um espaço que era para ser democrático, mas não é [E5].

A participação social é muito fraca. Os instrumentos para participação são fantásticos. Os espaços criados, os conselhos locais, conselho municipal, conferências, se tudo isso funcionasse, com pessoas preparadas para estar ali representando o poder público, os profissionais e usuários, teria um resultado fantástico, mas a maioria das pessoas que estão ali representa a si mesmo, os seus interesses próprios, não há interesse de uma categoria, de uma comunidade [E7]. 


\subsection{Etapa 3. Construção do instrumento}

A elaboração do instrumento de leitura de necessidades desenvolveu-se em 4 etapas:

A) Definição dos módulos componentes do instrumento, a partir do referencial teórico da Saúde Coletiva:

A partir da taxonomia de Campos e Mishima (2005), foram definidos três módulos: necessidades de reprodução social, necessidades de presença do Estado e necessidade de participação política. Considerando que a identificação das classes sociais é um pressuposto teórico da Saúde Coletiva e da Epidemiologia Crítica e que há metodologias específicas sobre o tema disponíveis na literatura, optou-se por acrescentar um módulo para essa finalidade, denominado “Identificação das classes sociais e distribuição espacial no território.

Esta módulo foi embasado na metodologia proposta do Observatório das Metrópoles por Ribeiro e Ribeiro (2011), já que utiliza um sistema de categorias sócio-ocupacionais para a identificação de classes sociais, por meio de dados secundários de bases nacionais. Além disso, houve uma aplicação prática da metodologia na região metropolitana do Rio de Janeiro com resultados relevantes e pertinentes para o levantamento de necessidades.

A estratificação social levou em consideração quatro critérios (Ribeiro, Ribeiro, 2011), conforme Quadro 11. A partir desses critérios, os autores elaboraram uma metodologia para a identificação de classes sociais que foi descrita no instrumento. 
Quadro 11 - Critérios para estratificação social do Observatório das Metrópoles. São Paulo; 2016.

\begin{tabular}{|c|c|}
\hline Critérios & Justificativa \\
\hline $\begin{array}{l}\text { 1. Relação capital X } \\
\text { trabalho }\end{array}$ & $\begin{array}{l}\text { - ser proprietário ou não da atividade econômica é a } \\
\text { principal característica que define a posição dos indivíduos } \\
\text { no processo de produção. } \\
\text { - separação dos indivíduos que são empregadores ou } \\
\text { conta-própria dos indivíduos que são empregados. } \\
\text { - distinção entre empregadores, que possuem empregados } \\
\text { e autônomos. } \\
\text { - distinção entre grandes empregadores dos pequenos. } \\
\text { - distinção entre os chamados conta-própria, ou trabalhador } \\
\text { autônomo, quanto à profissionalização. }\end{array}$ \\
\hline $\begin{array}{l}\text { 2. Trabalho manual } \mathrm{X} \\
\text { trabalho não-manual }\end{array}$ & $\begin{array}{l}\text { - normalmente a ocupação não manual exige algum nível } \\
\text { de escolaridade (médio ou superior). Ocupações não } \\
\text { manuais cuja exigência é apenas o nível médio, } \\
\text { normalmente caracterizam-se por serem atividades } \\
\text { técnicas. } \\
\text { - no trabalho manual, há exigência de certo nível de } \\
\text { qualificação (o que não é o mesmo que escolaridade). } \\
\text { - há que separar os trabalhadores agrícolas dos } \\
\text { trabalhadores industriais }\end{array}$ \\
\hline $\begin{array}{l}\text { 3. Trabalho de } \\
\text { comando } X \text { trabalho } \\
\text { subordinado }\end{array}$ & $\begin{array}{l}\text { - diferenças importantes da atividade de comando sejam de } \\
\text { direção, gerência e supervisão, com as ocupações } \\
\text { subordinadas, que são comandadas por outrem. } \\
\text { - nas ocupações de comando há diferenças se a atividade é } \\
\text { exercida em grandes empresas ou em pequenas em } \\
\text { empresas }\end{array}$ \\
\hline $\begin{array}{l}\text { 4. Trabalho público } X \\
\text { trabalho privado }\end{array}$ & $\begin{array}{l}\text { - demarcador de posições sociais diferenciadas na } \\
\text { sociedade brasileira. }\end{array}$ \\
\hline
\end{tabular}

Fonte: Ribeiro, Ribeiro (2011). 


\section{B) Incorporação dos resultados da RI:}

Os resultados da RI embasaram a elaboração de um módulo, denominado "Reconhecimento do território" para a descrição das características específicas do território. $\mathrm{Na} \mathrm{Rl}$, este módulo estava vinculado à categoria necessidades de reprodução social, entretanto, optou-se pela elaboração de um novo módulo, devido a diferenças nos objetivos de cada módulo e na forma de descrição dos dados.

\section{C) Revisão a partir da análise das entrevistas com gestores:}

As entrevistas subsidiaram a construção de uma introdução com uma breve justificativa para o levantamento de necessidades, de acordo com os pressupostos deste estudo, o levantamento da oferta de serviços, no módulo "Necessidades de presença do Estado e a organização dos módulos, para que ao mesmo tempo o instrumento seja manuseado de forma compreensível, dinâmica e por meio de dados disponíveis em bancos de dados nacionais, estaduais ou municipais.

\section{D) Ordenação dos módulos:}

Definidos os cinco módulos, além da introdução, procedeu-se a etapa de ordenação dos módulos. Para o módulo $A$, foi definido que a identificação das classes sociais é o ponto de partida para o levantamento de necessidades, já que as mesmas determinam socialmente o processo saúde-doença. A partir das classes sociais, faz-se necessário reconhecer as características do território (módulo B), onde habitam as diferentes classes sociais. O módulo seguinte $(\mathrm{C})$ foi selecionado por conter questões de necessidade de reprodução social, a partir das classes sociais e do território. Da mesma forma, as necessidades de presença do Estado (Módulo D) e necessidades de participação política (Módulo E) visam identificar os potenciais serviços para responder às necessidades de reprodução social e os grupos organizados da sociedade civil que lutam pela garantia dos direitos dos interessados, respectivamente. 


\section{E) Composição das etapas de cada módulo a partir da identificação de} variáveis e indicadores.

Com exceção do módulo $A$ que já tem uma metodologia definida, foram identificadas referências bibliográficas sobre cada módulo que evidenciam a importância e embasam a inclusão de cada item do instrumento, conforme Quadros $12,13,14,15$ e 16.

Quadro 12 - Módulo A - Identificação das classes sociais e distribuição espacial no território. São Paulo; 2016.

\begin{tabular}{|l|l|}
\hline \multicolumn{1}{|c|}{ Etapas } & \multicolumn{1}{c|}{ Referências } \\
\hline $\begin{array}{l}\text { Etapa 1. Identificação das ocupações, } \\
\text { por meio de banco dados secundários }\end{array}$ & $\begin{array}{l}\text { Laurell (1982); Krieger, Williams, } \\
\text { Moss (1997); Galobardes et al. } \\
\text { (2006); Trapé (2011); Ribeiro, Ribeiro } \\
(2011) \text {; Yonekura (2011); Marmot, Bell } \\
(2016) ; \text { Stotz (2016) }\end{array}$ \\
\hline $\begin{array}{l}\text { Etapa 2. Agrupamento das } \\
\text { ocupações em categorias sócio- } \\
\text { ocupacionais e em agregados sócio- } \\
\text { ocupacionais }\end{array}$ & Ribeiro, Ribeiro (2011) \\
\hline $\begin{array}{l}\text { Etapa 3. Análises estatísticas para } \\
\text { identificação das classes sociais, por } \\
\text { meio de um programa estatístico }\end{array}$ & Ribeiro, Ribeiro (2011) \\
\hline Etapa 4. Geoprocessamento & WHO (2001); Ribeiro, Ribeiro (2011) \\
\hline
\end{tabular}

Quadro 13 - Módulo B - Reconhecimento do território. São Paulo; 2016.

\begin{tabular}{|l|l|}
\hline \multicolumn{1}{|c|}{ Etapas } & \multicolumn{1}{|c|}{ Referências } \\
\hline $\begin{array}{l}\text { Etapa 1. Caracterização histórica do } \\
\text { território }\end{array}$ & WHO (2001) \\
\hline $\begin{array}{l}\text { Etapa 2. Caracterização da atividade } \\
\text { econômica }\end{array}$ & Nakamura et al. (2009) \\
\hline Etapa 3. Caracterização ambiental & WHO (2001) \\
\hline $\begin{array}{l}\text { Etapa 4. Caracterização de } \\
\text { assentamentos precários }\end{array}$ & $\begin{array}{l}\text { Santos (2007); Ministério das Cidades } \\
\text { (2010); Nakano, Koga (2013) }\end{array}$ \\
\hline
\end{tabular}


Quadro 14 - Módulo C - Necessidades de reprodução social. São Paulo; 2016.

\begin{tabular}{|c|c|}
\hline Etapas & Referências \\
\hline $\begin{array}{l}\text { Etapa 1. Caracterização das } \\
\text { condições de trabalho }\end{array}$ & $\begin{array}{l}\text { Nakamura et al. (2009), Marmot, Bell } \\
\text { (2016) }\end{array}$ \\
\hline Formalidade & Trapé (2011) \\
\hline Benefícios advindos do trabalho & Trapé (2011) \\
\hline Jornada semanal de trabalho & Nakamura et al. (2009), Trapé (2011) \\
\hline Seguro desemprego & Trapé (2011) \\
\hline Etapas & Referências \\
\hline $\begin{array}{l}\text { Etapa 2. Caracterização das } \\
\text { condições de vida }\end{array}$ & $\begin{array}{l}\text { Galobardes et al. (2006); Nakamura et } \\
\text { al. (2009); Trapé (2011); Marmot, Bell } \\
\text { (2016) }\end{array}$ \\
\hline Propriedade do domicílio & Nakamura et al. (2009); Trapé (2011) \\
\hline Tipo de domicílio & $\begin{array}{l}\text { WHO (2001); Yonekura et al. (2010), } \\
\text { Trapé (2011) }\end{array}$ \\
\hline Material predominante do domicílio & Nakamura et al. (2009); Trapé (2011) \\
\hline Cômodos como dormitório & Nakamura et al. (2009); Trapé (2011) \\
\hline $\begin{array}{l}\text { Acesso a microcomputador com } \\
\text { acesso à internet }\end{array}$ & Trapé (2011) \\
\hline Número de automóveis & Yonekura et al. (2010); Trapé (2011) \\
\hline Número de motocicletas & Trapé (2011) \\
\hline Forma do abastecimento de água & $\begin{array}{l}\text { Galobardes et al. (2006); Nakamura et } \\
\text { al. (2009); Trapé (2011) }\end{array}$ \\
\hline $\begin{array}{l}\text { Forma de abastecimento de } \\
\text { iluminação elétrica }\end{array}$ & Nakamura et al. (2009); Trapé (2011) \\
\hline Esgotamento sanitário & $\begin{array}{l}\text { WHO (2001); Galobardes et al. } \\
\text { (2006); Nakamura et al. (2009); } \\
\text { Yonekura et al. (2010); Trapé (2011) }\end{array}$ \\
\hline Destino do lixo & Nakamura et al. (2009); Trapé (2011) \\
\hline Acesso à internet & Trapé (2011) \\
\hline Densidade morador/dormitório & $\begin{array}{l}\text { Krieger, Williams, Moss (1997); Trapé } \\
\text { (2011) }\end{array}$ \\
\hline Etapas & Referências \\
\hline $\begin{array}{l}\text { Etapa 3. Caracterização do perfil } \\
\text { sociodemográfico: }\end{array}$ & Trapé (2011) \\
\hline Sexo & Trapé (2011); Marmot, Bell (2016) \\
\hline Cor ou raça & $\begin{array}{l}\text { Krieger, Williams, Moss (1997); Trapé } \\
\text { (2011); Marmot, Bell (2016) }\end{array}$ \\
\hline Gênero & $\begin{array}{l}\text { Krieger, Williams, Moss (1997); WHO } \\
(2001)\end{array}$ \\
\hline Religião & WHO (2001); Trapé (2011) \\
\hline Nacionalidade & Trapé (2011) \\
\hline Tempo de moradia & Trapé (2011) \\
\hline Escolaridade & Galobardes et al. (2006); Yonekura et \\
\hline
\end{tabular}




\begin{tabular}{|l|l|}
\hline & $\begin{array}{l}\text { al. (2010); Fujimori et al. (2013); } \\
\text { Marmot, Bell (2016) }\end{array}$ \\
\hline Estado civil & Yonekura et al. (2010); Trapé (2011) \\
\hline Yaxa de fecundidade & Trapé (2011) \\
\hline Movimentos migratórios & \multicolumn{1}{|c|}{ Referências } \\
\hline $\begin{array}{l}\text { Etapa 4. Caracterização do perfil de } \\
\text { saúde }\end{array}$ & $\begin{array}{l}\text { Nakamura et al. (2009); Fujimori et al. } \\
\text { (2013) }\end{array}$ \\
\hline Doenças prevalentes/incidentes & $\begin{array}{l}\text { Laurell (1982); Krieger, Williams, } \\
\text { Moss (1997); WHO (2001); Nakamura } \\
\text { et al. (2009) }\end{array}$ \\
\hline Doenças relacionadas ao trabalho & WHO (2001) \\
\hline Acidentes de trânsito & Nakamura et al. (2009) \\
\hline Mortalidade infantil & $\begin{array}{l}\text { Krieger, Williams, Moss (1997); } \\
\text { Fujimori et al. (2013) }\end{array}$ \\
\hline Mortalidade/Causas de morte & $\begin{array}{l}\text { Laurell (1982); Krieger, Williams, } \\
\text { Moss (1997); WHO (2001) }\end{array}$ \\
\hline Natalidade & WHO (2001); Galobardes et al. (2006) \\
\hline Pessoas com deficiência & WHO (2001) \\
\hline
\end{tabular}

Quadro 15 - Módulo D - Necessidades de presença do Estado. São Paulo; 2016.

\begin{tabular}{|l|l|}
\hline \multicolumn{1}{|c|}{ Etapas } & \multicolumn{1}{c|}{ Referências } \\
\hline $\begin{array}{l}\text { Etapas 1 a 4. Identificação de } \\
\text { serviços sob responsabilidade do } \\
\begin{array}{l}\text { Estado, população sob cobertura do } \\
\text { serviço, quantidade de atendimentos } \\
\text { e bairros, municípios ou regiões } \\
\text { atendidas }\end{array}\end{array}$ & $\begin{array}{l}\text { WHO (2001); IPEA (2009); Nakamura } \\
\text { et al. (2009) }\end{array}$ \\
\hline Assistência social & IPEA (2009) \\
\hline Educação & IPEA (2009) \\
\hline Infraestrutura - Transporte & $\begin{array}{l}\text { WHO (2001); IPEA (2009); Nakamura } \\
\text { et al. (2009) }\end{array}$ \\
\hline Segurança pública & IPEA (2009) \\
\hline Lazer e Cultura & $\begin{array}{l}\text { WHO (2001); IPEA (2009); Nakamura } \\
\text { et al. (2009) }\end{array}$ \\
\hline Saúde & IPEA (2009); Nakamura et al. (2009) \\
\hline
\end{tabular}


Quadro 16 - Módulo E - Necessidade de participação política. São Paulo; 2016.

\begin{tabular}{|l|l|}
\hline \multicolumn{1}{|c|}{ Etapas } & \multicolumn{1}{|c|}{ Referências } \\
\hline $\begin{array}{l}\text { Etapa 1. Identificação de grupos } \\
\text { organizados da sociedade civil que } \\
\text { lutam pela garantia dos direitos dos } \\
\text { interessados. }\end{array}$ & Trapé (2011); Bravo, Menezes (2013) \\
\hline $\begin{array}{l}\text { Etapa 2. Identificação da área central } \\
\text { da reinvindicação (saúde, } \\
\text { saneamento, entre outros) }\end{array}$ & Bravo, Menezes (2013) \\
\hline $\begin{array}{l}\text { Etapa 3. Identificação dos problemas } \\
\text { reivindicados }\end{array}$ & Bravo, Menezes (2013) \\
\hline $\begin{array}{l}\text { Etapa 4. Identificação das propostas } \\
\text { de superação e ações já realizadas }\end{array}$ & Bravo, Menezes (2013) \\
\hline
\end{tabular}

Dessa forma, a primeira versão do instrumento consistiu em material com 40 páginas, dividido em introdução e cinco módulos com quatro etapas cada:

Módulo A - Identificação das classes sociais: utilização de uma metodologia para identificação das classes sociais e sua distribuição no território, mensurando as concentrações e dispersões no território entre os grupos sociais.

* Módulo B - Reconhecimento do território: descrição de características do território.

* Módulo C - Necessidades de reprodução social: descrição das condições de trabalho e vida e dos perfis epidemiológicos das classes sociais.

* Módulo D - Necessidades de presença do Estado: descrição da presença do estado, por meio da oferta de serviços.

Módulo E - Necessidade de participação política: descrição dos grupos organizados da sociedade civil que lutam pela garantia dos direitos dos interessados.

No que se refere às ilustrações, foram selecionadas 10 figuras, relacionadas à: desigualdade social, áreas urbana e rural, território, condições de vida e de trabalho, instituições educativas, participação política e ciclo social vital. 


\subsection{Etapa 4. Validação de conteúdo do instrumento de necessidades de saúde}

\subsubsection{Caracterização dos participantes da pesquisa}

Dos 14 especialistas convidados, oito tinham disponibilidade e aceitaram a participação. A idade dos especialistas variou de 32 e 66 anos, com média de 52 anos, sendo majoritariamente do sexo feminino (87,5\%) (Tabela 5).

Tabela 5 - Distribuição do sexo e idade dos participantes por número e porcentagem. São Paulo; 2016.

\begin{tabular}{l|c|c}
\hline Sexo & $\mathrm{N}$ & $\%$ \\
\hline Feminino & 7 & 87,5 \\
\hline Masculino & 1 & 12,5 \\
\hline Total & 8 & 100 \\
\hline
\end{tabular}

\begin{tabular}{l|c|c}
\hline Idade & $\mathrm{N}$ & $\%$ \\
\hline $32-39$ anos & 2 & 25 \\
\hline $40-49$ anos & 1 & 12,5 \\
\hline $50-59$ anos & 1 & 12,5 \\
\hline $60-66$ anos & 4 & 50 \\
\hline Total & 8 & 100 \\
\hline
\end{tabular}

Em relação à formação acadêmica, observa-se que seis eram formados na área da saúde duas na área de humanas (Gráfico 8) Um especialista tinha duas formações na área de humanas. Cinco formaram-se na década de 80 (55\%). (Gráfico 9). 
Gráfico 8- Distribuição da formação Acadêmica dos participantes. São Paulo; 2016.

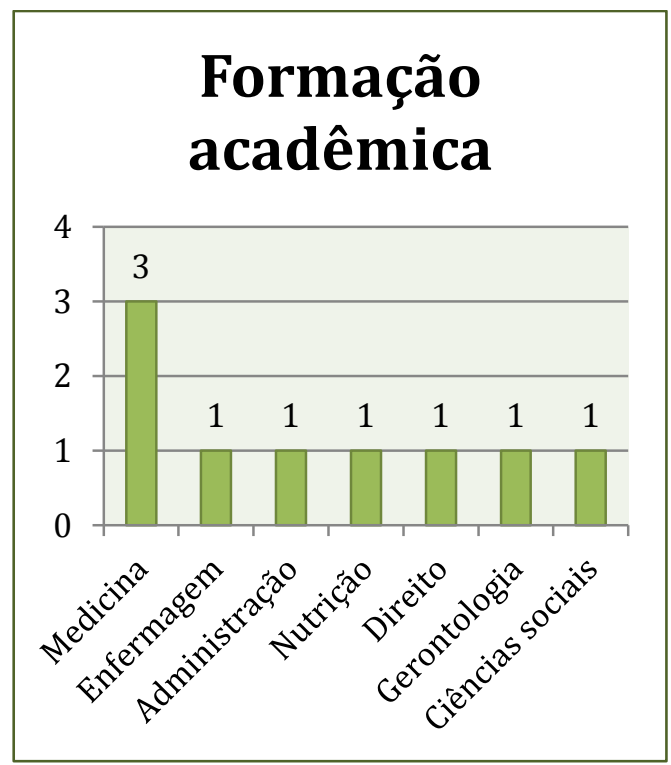

Gráfico 9 - Distribuição da década da formação dos participantes . São Paulo; 2016.

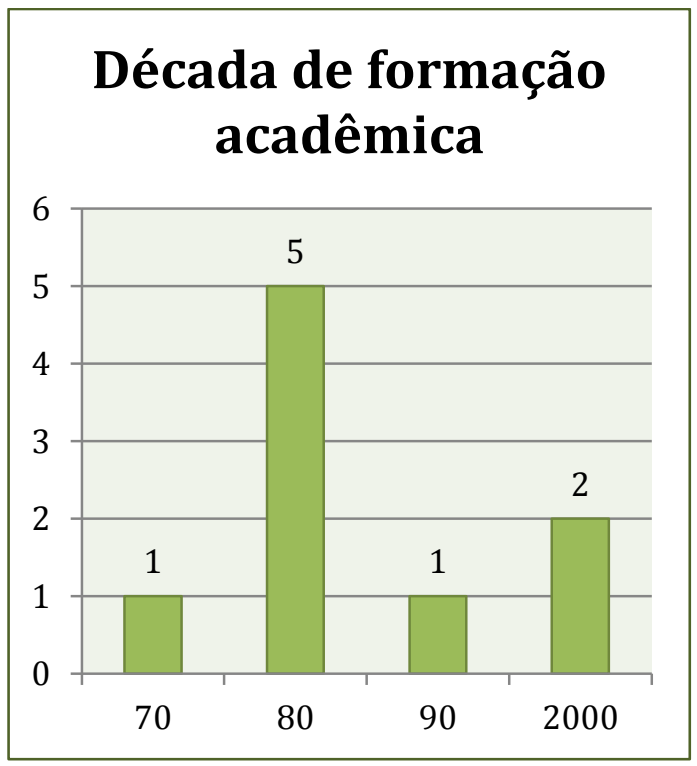

No que se refere à pós-graduação, cinco (62,5\%) possuíam especialização, cinco $(62,5 \%)$ mestrado e dois $(25 \%)$ doutorado. O Gráfico 10 mostra que as áreas de pós-graduação dos especialistas são predominantemente na área da saúde (91,6\%) (Gráfico 10).

Gráfico 10 - Áreas de pós-graduação dos participantes. São Paulo; 2016.

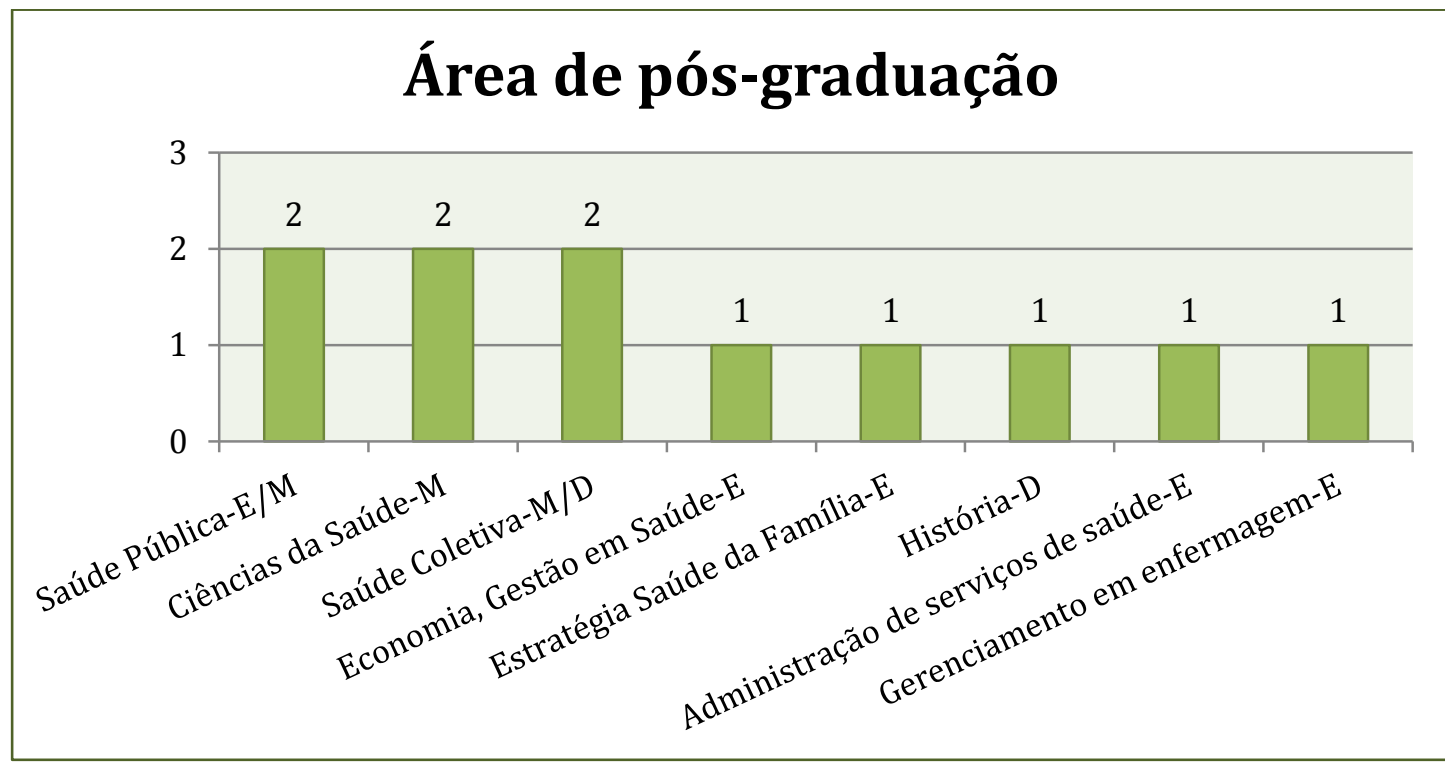

*E=Especialização, M=Mestrado, e D=Doutorado 
Os dados sobre trabalho revelam que seis $(75 \%)$ especialistas trabalhavam em instituições públicas e dois (25\%) em instituições filantrópicas, sendo o maior número de pesquisadores e de 5 a 10 anos no cargo (37,5\%) (Gráficos 11 e 12). Nota-se que três especialistas que trabalhavam na gestão e planejamento (dois coordenadores de área da secretária estadual de saúde e um administrador) avaliaram o instrumento.

Gráfico 11 - Cargo atual dos participantes. São Paulo; 2016

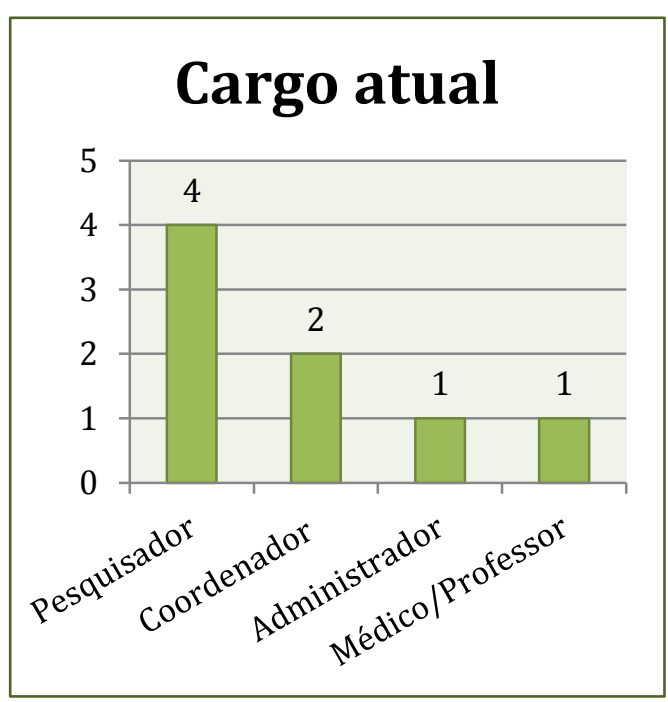

Gráfico 12 - Tempo na ocupação dos participantes. São Paulo; 2016.

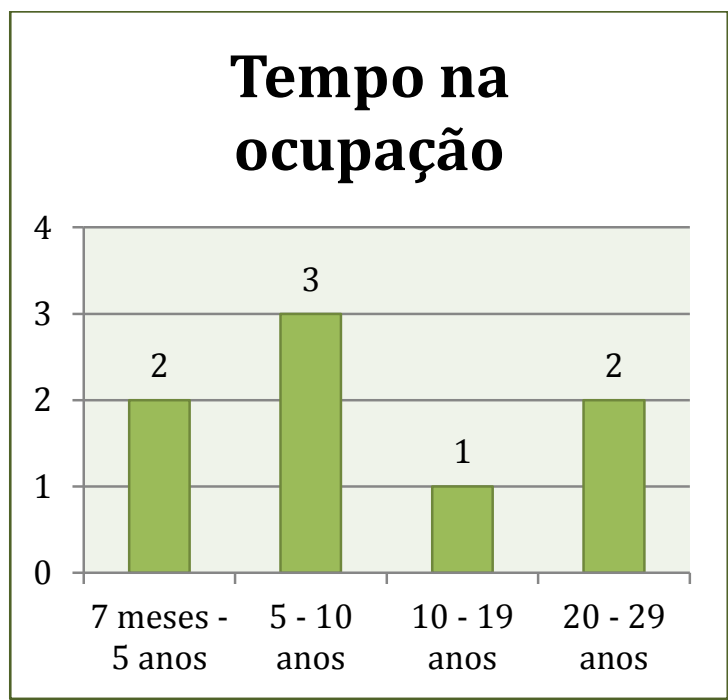

Em relação à experiência profissional, nota-se que todos já realizaram ou participaram de pesquisas científicas, seis coordenaram serviços de saúde e cinco trabalharam na área de planejamento e gestão de serviços ou ações de saúde (Quadro 17). Seis especialistas também tinham experiência no tema de necessidades, no que se refere à pesquisa e levantamento no território, e quatro tinham experiência em docência. 
Quadro 17 - Experiência profissional dos especialistas. São Paulo; 2016.

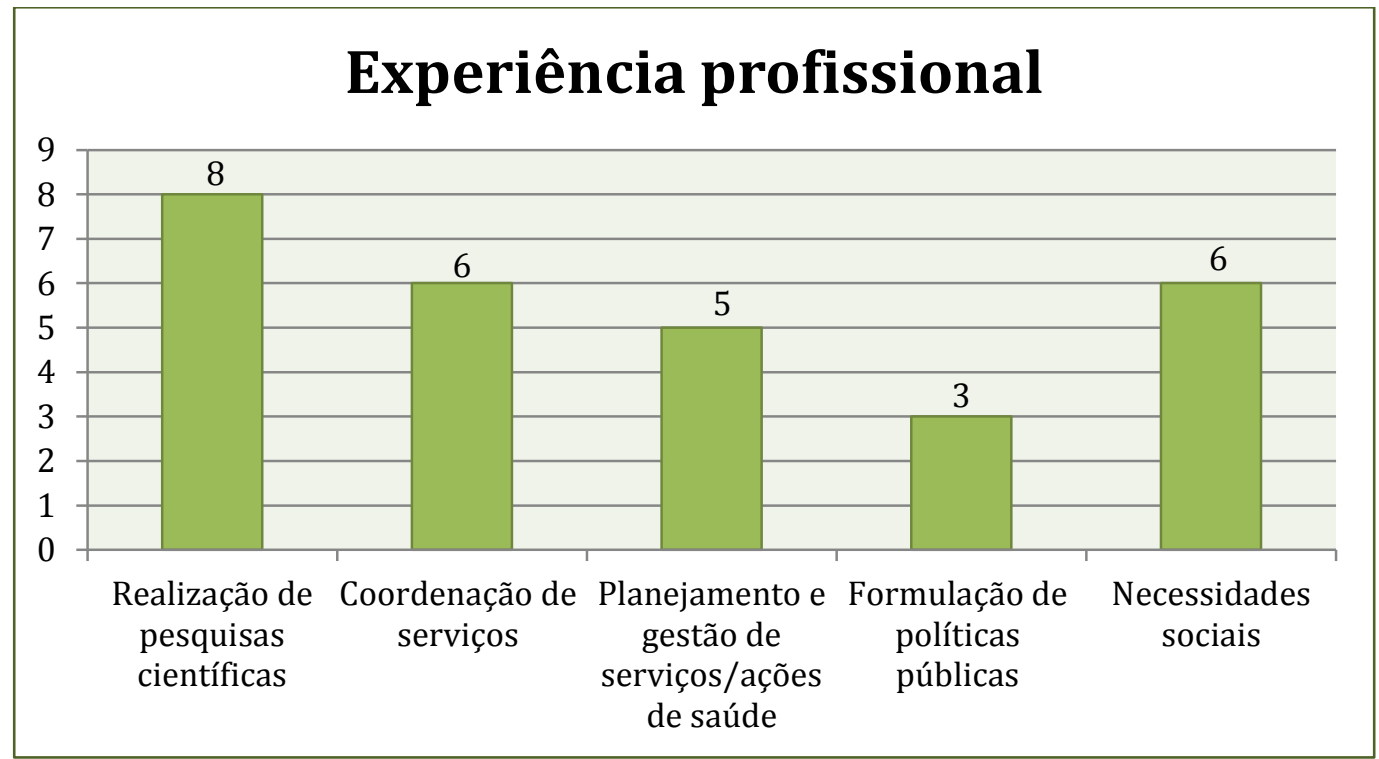

\subsection{2 - Análise de conteúdo}

O Quadro 18 mostra o número de itens avaliados e a nota, referente à clareza, relevância e pertinência por módulo. De forma geral, não houve necessidade de mudança na estrutura do instrumento, em relação à distribuição e ordem dos módulos. Os seis módulos apresentaram IVC maior que 0,9 em todos os itens.

Quadro 18 - Descrição da análise de cada módulo, segundo índice de validade de conteúdo (IVC). São Paulo, 2016.

\begin{tabular}{|l|c|c|c|c|c|}
\hline & $\begin{array}{c}\text { No de itens } \\
\text { avaliados }\end{array}$ & \multicolumn{3}{|c|}{ IVC } \\
\hline Introdução & 1 & 1 & 1 & 1 \\
\hline Módulo A & 4 & 0,96 & 1 & 0,93 \\
\hline Módulo B & 4 & 0,9 & 0,93 & 1 \\
\hline Módulo C & 4 & 0,96 & 0,9 & 1 \\
\hline Módulo D & 6 & 0,97 & 0,95 & 1 \\
\hline Módulo E & 4 & 0,9 & 1 & 0,96 \\
\hline
\end{tabular}

${ }^{*} \mathrm{C}=$ clareza, $\mathrm{R}=$ relevância, $\mathrm{P}=$ pertinência 
Entretanto, na análise específica de cada item, apenas um, referente à etapa 3 do módulo $B$, teve pontuação de 0,75 , na análise de clareza, o que levou a reelaboração da escrita. Os demais itens apresentaram pontuação igual ou maior de 0,87, sendo considerados adequados. O Quadro 19 descreve a pontuação e o resultado do IVC da introdução e das etapas do instrumento.

Quadro 19 - Descrição da análise de cada item, segundo pontuação e índice de validade de conteúdo (IVC). São Paulo, 2016.

\begin{tabular}{|c|c|c|c|c|c|c|}
\hline & Análise & 1 ou 2 & 3 & 4 & 5 & IVC \\
\hline \multirow{3}{*}{ Introdução } & Clareza & 0 & 0 & 4 & 4 & 1 \\
\hline & Relevância & 0 & 0 & 0 & 8 & 1 \\
\hline & Pertinência & 0 & 0 & 2 & 6 & 1 \\
\hline \multicolumn{7}{|c|}{ Módulo A } \\
\hline \multirow{3}{*}{ Etapa 1} & Clareza & 0 & 0 & 1 & 7 & 1 \\
\hline & Relevância & 0 & 0 & 0 & 8 & 1 \\
\hline & Pertinência & 0 & 0 & 0 & 8 & 1 \\
\hline \multirow{3}{*}{ Etapa 2} & Clareza & 0 & 0 & 0 & 8 & 1 \\
\hline & Relevância & 0 & 0 & 0 & 8 & 1 \\
\hline & Pertinência & 0 & 0 & 0 & 8 & 1 \\
\hline \multirow{3}{*}{ Etapa 3} & Clareza & 0 & 1 & 1 & 6 & 0,87 \\
\hline & Relevância & 0 & 0 & 0 & 8 & 1 \\
\hline & Pertinência & 0 & 1 & 0 & 7 & 0,87 \\
\hline \multirow{3}{*}{ Etapa 4} & Clareza & 0 & 0 & 3 & 5 & 1 \\
\hline & Relevância & 0 & 0 & 0 & 8 & 1 \\
\hline & Pertinência & 0 & 1 & 0 & 7 & 0,87 \\
\hline \multicolumn{7}{|c|}{ Módulo B } \\
\hline \multirow{3}{*}{ Etapa 1} & Clareza & 0 & 0 & 0 & 8 & 1 \\
\hline & Relevância & 0 & 0 & 0 & 8 & 1 \\
\hline & Pertinência & 0 & 0 & 0 & 8 & 1 \\
\hline \multirow{3}{*}{ Etapa 2} & Clareza & 0 & 1 & 0 & 7 & 0,87 \\
\hline & Relevância & 0 & 1 & 0 & 7 & 0,87 \\
\hline & Pertinência & 0 & 0 & 0 & 8 & 1 \\
\hline \multirow{3}{*}{ Etapa 3} & Clareza & 0 & 2 & 0 & 6 & 0,75 \\
\hline & Relevância & 0 & 0 & 0 & 8 & 1 \\
\hline & Pertinência & 0 & 0 & 0 & 8 & 1 \\
\hline \multirow{3}{*}{ Etapa 4} & Clareza & 0 & 0 & 1 & 7 & 1 \\
\hline & Relevância & 0 & 1 & 0 & 7 & 0,87 \\
\hline & Pertinência & 0 & 0 & 0 & 8 & 1 \\
\hline \multicolumn{7}{|c|}{ Módulo C } \\
\hline \multirow{2}{*}{ Etapa 1} & Clareza & 0 & 0 & 1 & 7 & 1 \\
\hline & Relevância & 0 & 0 & 1 & 7 & 1 \\
\hline
\end{tabular}


Resultados

\begin{tabular}{|c|c|c|c|c|c|c|}
\hline & Pertinência & 0 & 0 & 1 & 7 & 1 \\
\hline \multirow{3}{*}{ Etapa 2} & Clareza & 0 & 1 & 2 & 5 & 0,87 \\
\hline & Relevância & 0 & 1 & 1 & 6 & 0,87 \\
\hline & Pertinência & 0 & 0 & 1 & 7 & 1 \\
\hline \multirow{3}{*}{ Etapa 3} & Clareza & 0 & 0 & 1 & 7 & 1 \\
\hline & Relevância & 0 & 1 & 0 & 7 & 0,87 \\
\hline & Pertinência & 0 & 0 & 0 & 8 & 1 \\
\hline \multirow{3}{*}{ Etapa 4} & Clareza & 0 & 0 & 0 & 8 & 1 \\
\hline & Relevância & 0 & 1 & 0 & 7 & 0,87 \\
\hline & Pertinência & 0 & 0 & 0 & 8 & 1 \\
\hline \multicolumn{7}{|c|}{ Módulo D } \\
\hline \multirow{3}{*}{$\begin{array}{l}\text { Assistência } \\
\text { social }\end{array}$} & Clareza & 0 & 1 & 0 & 7 & 0,87 \\
\hline & Relevância & 0 & 1 & 0 & 7 & 0,87 \\
\hline & Pertinência & 0 & 0 & 0 & 8 & 1 \\
\hline \multirow{3}{*}{ Educação } & Clareza & 0 & 0 & 0 & 8 & 1 \\
\hline & Relevância & 0 & 0 & 0 & 8 & 1 \\
\hline & Pertinência & 0 & 0 & 0 & 8 & 1 \\
\hline \multirow{3}{*}{$\begin{array}{l}\text { Infraestrutura } \\
\text { - Transporte }\end{array}$} & Clareza & 0 & 0 & 0 & 8 & 1 \\
\hline & Relevância & 1 & 0 & 0 & 7 & 0,87 \\
\hline & Pertinência & 0 & 0 & 0 & 8 & 1 \\
\hline \multirow{3}{*}{$\begin{array}{l}\text { Segurança } \\
\text { pública }\end{array}$} & Clareza & 0 & 0 & 0 & 8 & 1 \\
\hline & Relevância & 0 & 0 & 0 & 8 & 1 \\
\hline & Pertinência & 0 & 0 & 0 & 8 & 1 \\
\hline \multirow{3}{*}{$\begin{array}{l}\text { Lazer e } \\
\text { Cultura }\end{array}$} & Clareza & 0 & 0 & 0 & 8 & 1 \\
\hline & Relevância & 0 & 0 & 0 & 8 & 1 \\
\hline & Pertinência & 0 & 0 & 0 & 8 & 1 \\
\hline \multirow{3}{*}{ Saúde } & Clareza & 0 & 0 & 0 & 8 & 1 \\
\hline & Relevância & 0 & 0 & 0 & 8 & 1 \\
\hline & Pertinência & 0 & 0 & 0 & 8 & 1 \\
\hline \multicolumn{7}{|c|}{ Módulo E } \\
\hline \multirow{3}{*}{ Etapa 1} & Clareza & 0 & 0 & 0 & 8 & 1 \\
\hline & Relevância & 0 & 0 & 0 & 8 & 1 \\
\hline & Pertinência & 0 & 0 & 0 & 8 & 1 \\
\hline \multirow{3}{*}{ Etapa 2} & Clareza & 0 & 1 & 0 & 7 & 0,87 \\
\hline & Relevância & 0 & 0 & 0 & 8 & 1 \\
\hline & Pertinência & 0 & 0 & 0 & 8 & 1 \\
\hline \multirow{3}{*}{ Etapa 3} & Clareza & 0 & 1 & 1 & 6 & 0,87 \\
\hline & Relevância & 0 & 0 & 1 & 7 & 1 \\
\hline & Pertinência & 0 & 1 & 0 & 7 & 0,87 \\
\hline \multirow{3}{*}{ Etapa 4} & Clareza & 0 & 1 & 3 & 4 & 0,87 \\
\hline & Relevância & 0 & 0 & 0 & 8 & 1 \\
\hline & Pertinência & 0 & 0 & 0 & 8 & 1 \\
\hline
\end{tabular}


O Apêndice 7 descreve os comentários realizados nos campos de inclusão, modificação ou exclusão do instrumento de validação por módulo e etapa do instrumento. No Quadro 20, há a descrição de todas as alterações, baseadas nos comentários:

Quadro 20 - Itens que sofreram alterações após validação de conteúdo. São Paulo; 2016.

Parte

Introdução

\section{Versão construída}

Pág. 4 - (...) que coloca a doença e atenção às doenças

Pág. 5 - (1) Por exemplo, Exclusão de citação. diferentemente de planejar a partir da necessidade, planejar a partir da demanda parte dos atendimentos realizados, de acordo com a oferta de serviços. Nessa perspectiva, as reais necessidades sociais não são expressas no planejamento. Castiel e Rivera (1985) ressaltam que o planejamento baseado na oferta de serviços analisa problemas de sub ou superutilização, com foco na adequação da oferta à demanda, ignorando dados demográficos epidemiológicos.

(2) Planejar para toda a população ou para a população "SUS dependente"?

Pág. 6 - Carlos Matus ressalta o potencial

Pág. 7 - Planejar pela necessidade

Pág. 8 - Suas identidades sociais se constituem política e institucionalmente

\section{Versão validada}

(...) que coloca a atenção às doenças

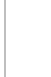




\begin{tabular}{|c|c|c|}
\hline & $\begin{array}{l}\text { Pág. } 8 \text { - (...) uma forma de } \\
\text { vida que se opõe às relações } \\
\text { de subordinação e domínio }\end{array}$ & $\begin{array}{l}\text { (...) uma forma de vida que se opõe } \\
\text { às relações de subordinação e } \\
\text { domínio da classe social dominante. }\end{array}$ \\
\hline \multirow[t]{3}{*}{ Módulo A } & $\begin{array}{l}\text { Materiais necessários: } \\
\text { Programa computacional de } \\
\text { processamento de dados } \\
\text { espaciais }\end{array}$ & $\begin{array}{l}\text { Programa computacional de } \\
\text { processamento de dados espaciais } \\
\text { (há vários softwares livres para } \\
\text { Geoprocessamento e programas para } \\
\text { realizar mapas, como Excel e SPSS). }\end{array}$ \\
\hline & $\begin{array}{l}\text { Materiais necessários: } \\
\text { Inclusão de item }\end{array}$ & $\begin{array}{l}\text { - (ou outro trabalhador capacitado } \\
\text { para análises estatísticas) } \\
\text { - Nos casos de indisponibilidade de } \\
\text { auxilio de estatístico, buscar os dados } \\
\text { sobre ocupações no IBGE [Instituto } \\
\text { Brasileiro de Geografia e Estatística]. } \\
\text { e realizar a distribuição das diferentes } \\
\text { ocupações pelo território, de forma a } \\
\text { caracterizá-lo pela dispersão ou } \\
\text { concentração geográfica de de do do } \\
\text { ocupacoes. }\end{array}$ \\
\hline & $\begin{array}{l}\text { Etapa 3: } \\
\text { - Superior } \\
\text { - Médio } \\
\text { - Popular-operário } \\
\text { - Popular }\end{array}$ & $\begin{array}{l}\text { - Superior (maior percentual de } \\
\text { pessoas nas categorias de dirigentes, } \\
\text { profissionais de nível superior e } \\
\text { pequenos empregadores, que são as } \\
\text { categorias mais elevadas da } \\
\text { hierarquia social). } \\
\text { - Médio (maior proporção de pessoas } \\
\text { na categoria ocupações médias). } \\
\text { - Popular-operário (maior proporção } \\
\text { na categoria dos trabalhadores do } \\
\text { terciário especializado). } \\
\text { - Popular (maior proporção na } \\
\text { categoria dos trabalhadores do } \\
\text { secundário). }\end{array}$ \\
\hline \multirow[t]{3}{*}{ Módulo B } & $\begin{array}{l}\text { Materiais necessários: } \\
\text { Inclusão de item }\end{array}$ & $\begin{array}{l}\text { Metodologias qualitativas ou ativas, } \\
\text { como busca de informantes-chave, } \\
\text { entrevistas com moradores, } \\
\text { observações participantes, visitas aos } \\
\text { territórios, entre outras. }\end{array}$ \\
\hline & $\begin{array}{l}\text { Etapa 2: } \\
\text { Inclusão de item }\end{array}$ & $\begin{array}{l}\text { - Diferenciar área urbana e rural. } \\
\text { - Caracterizar atividades de economia } \\
\text { informal e ilícita (atividades de venda } \\
\text { de produtos sem taxação de } \\
\text { impostos, narcotráfico, prostituição). } \\
\text { - Caracterizar áreas públicas de } \\
\text { consumo de drogas. }\end{array}$ \\
\hline & Etapa 3: & Identificar e localizar geograficamente \\
\hline
\end{tabular}




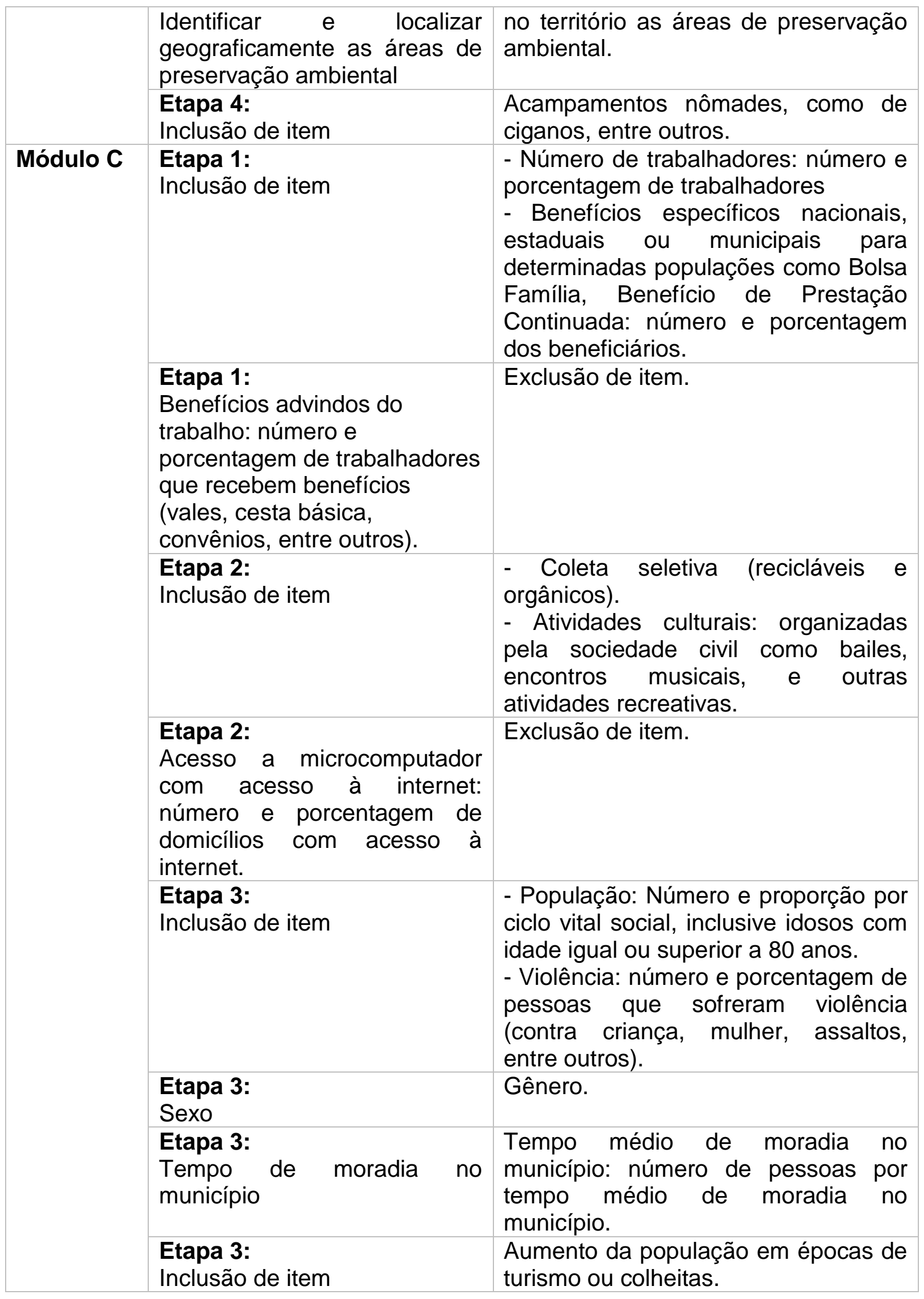




\begin{tabular}{|c|c|c|}
\hline & $\begin{array}{l}\text { Etapa 4: } \\
\text { Caracterização do perfil de } \\
\text { saúde }\end{array}$ & $\begin{array}{l}\text { Caracterização do perfil de saúde- } \\
\text { doença. }\end{array}$ \\
\hline & $\begin{array}{l}\text { Etapa 4: } \\
\text { Inclusão de item }\end{array}$ & $\begin{array}{l}\text { Acidentes por causas externas: taxa } \\
\text { dos acidentes por causas externas. }\end{array}$ \\
\hline \multirow[t]{12}{*}{ Módulo D } & $\begin{array}{l}\text { Assistência social: Inclusão } \\
\text { de item }\end{array}$ & $\begin{array}{l}\text { Centro dia para idosos, instituições de } \\
\text { longa permanência (ILPI) e outros. }\end{array}$ \\
\hline & $\begin{array}{l}\text { Assistência social: } \\
\text { População sob } \\
\text { responsabilidade }\end{array}$ & Área de abrangência territorial. \\
\hline & $\begin{array}{l}\text { Educação: } \\
\text { Inclusão de item }\end{array}$ & Creches privadas, outros. \\
\hline & $\begin{array}{l}\text { Educação: } \\
\text { Escolas de ensino } \\
\text { profissionalizante }\end{array}$ & $\begin{array}{l}\text { Escolas de ensino profissionalizante } \\
\text { públicas, Escolas de ensino } \\
\text { profissionalizante privadas, Escola de } \\
\text { educação para adultos públicas, } \\
\text { Escola de educação para adultos } \\
\text { privadas. }\end{array}$ \\
\hline & $\begin{array}{l}\text { Educação: } \\
\text { Creches }\end{array}$ & Creches públicas. \\
\hline & $\begin{array}{l}\text { Infraestrutura - transportes: } \\
\text { Inclusão de item }\end{array}$ & $\begin{array}{l}\text { Ciclovias, metrô, trem e/ou } \\
\text { embarcações fluviais, ruas sem } \\
\text { asfalto, transporte para pessoas com } \\
\text { deficiência, Outros. }\end{array}$ \\
\hline & $\begin{array}{l}\text { Segurança pública: } \\
\text { Inclusão de item }\end{array}$ & Institutos Médicos Legais, outros. \\
\hline & $\begin{array}{l}\text { Segurança pública: } \\
\text { Fundação casa }\end{array}$ & $\begin{array}{l}\text { Fundações Casa feminino } \\
\text { Fundações casa masculino. }\end{array}$ \\
\hline & $\begin{array}{l}\text { Lazer e cultura: } \\
\text { Inclusão de item }\end{array}$ & Outros. \\
\hline & $\begin{array}{l}\text { Saúde: } \\
\text { Inclusão de item }\end{array}$ & $\begin{array}{l}\text { Ambulância privada, Farmácia } \\
\text { popular, UBS com Estratégias Saúde } \\
\text { da Família. }\end{array}$ \\
\hline & $\begin{array}{l}\text { Saúde: } \\
\text { CAPS } \\
\text { NASF } \\
\text { SAMU }\end{array}$ & $\begin{array}{l}\text { Centro de Atenção Psicossocial } \\
\text { (CAPS) } \\
\text { Núcleo de Apoio à Saúde da Família } \\
\text { (NASF) } \\
\text { Serviço de Atendimento Móvel de } \\
\text { Urgência (SAMU) }\end{array}$ \\
\hline & $\begin{array}{l}\text { Saúde: } \\
\text { Estratégia Saúde da Família }\end{array}$ & Exclusão de item. \\
\hline Módulo E & $\begin{array}{l}\text { Materiais necessários: } \\
\text { Inclusão de item }\end{array}$ & $\begin{array}{l}\text { Metodologias qualitativas ou ativas, } \\
\text { como busca de informantes-chave, } \\
\text { entrevistas com moradores, } \\
\text { observações participantes, visitas aos } \\
\text { territórios, entre outras. }\end{array}$ \\
\hline
\end{tabular}




\begin{tabular}{|c|c|c|}
\hline & $\begin{array}{l}\text { Etapa 1: } \\
\text { Direito dos interessados }\end{array}$ & Direitos civis. \\
\hline & $\begin{array}{l}\text { Etapa 3: } \\
\text { Identificar os problemas para } \\
\text { os quais se reivindicam } \\
\text { soluções reivindicados } \\
\text { Etapa 4: } \\
\text { Inclusão de item }\end{array}$ & $\begin{array}{l}\text { Identificar os problemas para os quais } \\
\text { os grupos organizados reivindicam } \\
\text { soluções. } \\
\text { O Guia para o mapeamento e } \\
\text { caracterização de assentamentos } \\
\text { precários (2010) define que } \\
\text { assentamento precário é ocupado por } \\
\text { moradores de baixa renda, tais como } \\
\text { cortiços, loteamentos irregulares de } \\
\text { periferia, favelas e assemelhados, } \\
\text { bem como os conjuntos habitacionais } \\
\text { que se acham degradados. }\end{array}$ \\
\hline & $\begin{array}{l}\text { Etapa 4: } \\
\text { Identificar as propostas de } \\
\text { superação, relacionadas aos } \\
\text { problemas para os quais se } \\
\text { reivindicam soluções } \\
\text { reivindicados, e as ações já } \\
\text { realizadas }\end{array}$ & $\begin{array}{l}\text { Identificar as propostas de superação, } \\
\text { relacionadas aos problemas para os } \\
\text { quais se reivindicam soluções, assim } \\
\text { como as ações realizadas. }\end{array}$ \\
\hline & $\begin{array}{l}\text { Etapa 4: } \\
\text { Inclusão de item }\end{array}$ & Ações realizadas no Quadro 2. \\
\hline Apêndice & Inclusão de item & $\begin{array}{l}\text { Inclusão dos módulos correspondente } \\
\text { de cada sistema de informação. }\end{array}$ \\
\hline
\end{tabular}

As sugestões não incorporadas no instrumento estão descritas no quadro abaixo com as respectivas justificativas. 
Quadro 21 - Descrição das sugestões não incorporadas no instrumento e as respectivas justificativas. São Paulo; 2016.

\begin{tabular}{|c|c|c|}
\hline Parte & Sugestões & Justificativa \\
\hline \multirow[t]{2}{*}{ Módulo A } & $\begin{array}{l}\text { Etapa 1: } \\
\text { MT, MAPA e INSS }\end{array}$ & $\begin{array}{l}\text { Nessa etapa, todos os dados } \\
\text { necessários são disponibilizados } \\
\text { e categorizados pelo IBGE. }\end{array}$ \\
\hline & $\begin{array}{l}\text { Etapa 2: } \\
\text { População ativa e não ativa e } \\
\text { outras; Tive dúvida sobre a } \\
\text { questão da aposentada; Abrir } \\
\text { campo para "outros", de modo } \\
\text { a admitir categorias sócio- } \\
\text { ocupacionais emergentes, a } \\
\text { exemplo de assistentes } \\
\text { religiosos, "cuidadores", } \\
\text { "facilitadores" na } \\
\text { escolarização, etc. }\end{array}$ & $\begin{array}{l}\text { A metodologia categoriza as } \\
\text { ocupações que já estão } \\
\text { padronizadas, a partir dos } \\
\text { códigos do IBGE, que inclui as } \\
\text { ocupações emergentes. }\end{array}$ \\
\hline Módulo B & $\begin{array}{l}\text { Etapa 1: } \\
\text { EPI }\end{array}$ & $\begin{array}{l}\text { Item muito específico para o } \\
\text { módulo. }\end{array}$ \\
\hline Módulo C & $\begin{array}{l}\text { Etapa 2: O IBGE não } \\
\text { apresenta uma categorização } \\
\text { desses dados? }\end{array}$ & $\begin{array}{l}\text { Não há categorização dos dados } \\
\text { sobre condição de vida pelo } \\
\text { IBGE. }\end{array}$ \\
\hline \multirow[t]{2}{*}{ Módulo D } & $\begin{array}{l}\text { Assistência social: } \\
\text { Administração } \quad \text { regional ou } \\
\text { distrital }\end{array}$ & $\begin{array}{l}\text { As administrações de serviços } \\
\text { não foram inclú́das no } \\
\text { instrumento porque sofrem muita } \\
\text { variação nos municípios. }\end{array}$ \\
\hline & $\begin{array}{l}\text { Saúde: } \\
\text { Incluiria a vulnerabilidade } \\
\text { programática }\end{array}$ & $\begin{array}{l}\text { De maneira geral, não há } \\
\text { serviços disponíveis baseados } \\
\text { na deteçãa de vulnerabilidade. }\end{array}$ \\
\hline \multirow[t]{2}{*}{ Módulo E } & $\begin{array}{l}\text { Etapa 4: } \\
\text { Direito dos GLBT }\end{array}$ & $\begin{array}{l}\text { A consideração dos direitos no } \\
\text { instrumento não está } \\
\text { operacionalizada por áreas } \\
\text { específicas. Os direitos dos } \\
\text { GLBT entrariam na descrição do } \\
\text { módulo. }\end{array}$ \\
\hline & $\begin{array}{l}\text { Etapa 4: } \\
\text { O Quadro deve estar abaixo e } \\
\text { cada item a medida que se } \\
\text { identifica o objetivo. }\end{array}$ & $\begin{array}{l}\text { A inclusão do quadro em cada } \\
\text { etapa é visualmente difícil. }\end{array}$ \\
\hline
\end{tabular}

A versão final do instrumento encontra-se no Apêndice 8. 


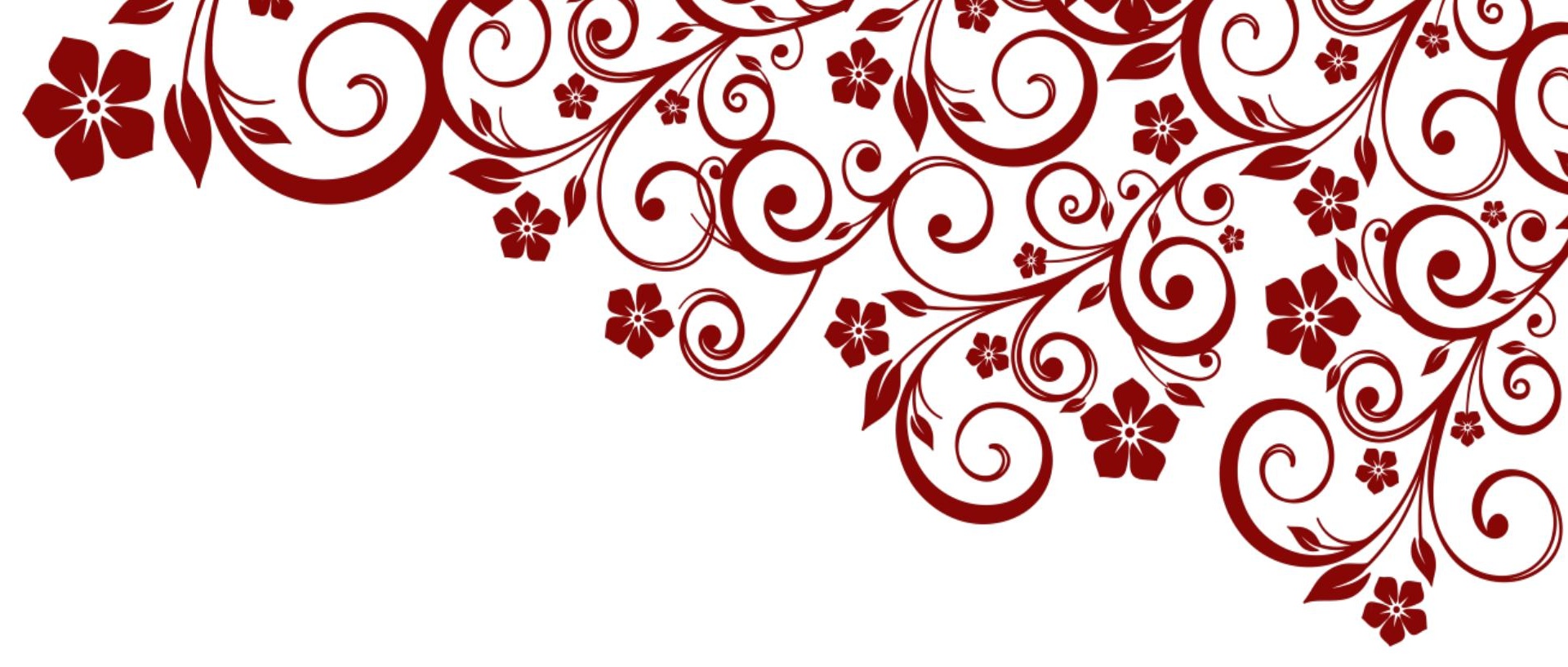

Discussão

$(9$ 


\section{DISCUSSÃO}

Em síntese, o estudo de RI identificou, por meio de 17 estudos, as variáveis utilizadas em instrumentos de levantamento de necessidades, classificadas em três categorias: necessidades de reprodução social, necessidade de presença do Estado e necessidade de participação política.

A epidemiologia é um instrumento fundamental para identificar e intervir sobre as condições de produção de saúde-doença no território (Drummond, 2009). Para isso, requer dados quantitativos ou qualitativos e informações, considerando os determinantes sociais, e as formas disponíveis de captação, relacionadas a sistemas de informação em saúde (Fujimori et al., 2013).

Para reconhecimento do território, Thumé, Soares e Dilélio (2013) destacam os sistemas de informação do Departamento de Informática do SUS, IBGE, plano municipal de saúde, relatório de gestão e imagens de satélite de livre e fácil acesso. As imagens de satélite permitem identificar espacialmente diversas características do território, como distribuição dos domicílios, áreas verdes, acidentes geográficos e áreas de risco, e distribuição de serviços (Thumé, Soares, Dilélio, 2013).

A coleta de dados padronizada e sistematizada, indicando onde e como esses dados foram obtidos, é fundamental para a geração de informação epidemiológica consistente (Fujimori et al., 2013; Thumé, Soares, Dilélio, 2013).

Foram identificados métodos quantitativos, qualitativos ou quanti-qualitativos para o levantamento de necessidades. Minayo (2013) ressalta que os métodos mais utilizados na Saúde Coletiva são os quantitativos, pela epidemiologia, que visam principalmente identificar dados, indicadores, tendências observáveis ou produzir modelos teóricos, e os qualitativos, mais presentes nas ciências sociais com foco no estudo da história, das percepções, crenças, relações e representações. Ambos os métodos podem ser utilizados na pesquisa social com resultados relevantes e complementares entre si (Minayo, 2013).

Em relação aos conceitos teóricos, nove em um total de 17 estudos não apresentaram nenhuma definição sobre necessidades e pressupostos teóricos. A complexidade e polissemia não só do conceito teórico, mas também do ponto de vista metodológico e operacional também foram identificadas, a partir das entrevistas com gestores. 
Campos e Bataiero (2007) identificaram grande número de publicações científicas utilizando a temática das necessidades, centradas principalmente no âmbito hospitalar. Entretanto, são escassos estudos com enfoque na Atenção Primária principalmente na perspectiva da Saúde Coletiva. Identificou-se também que 66 de um total de 73 publicações $(90,4 \%)$ não abordavam o conceito de necessidades (Campos, Bataiero, 2007).

Puccini (2002) ressalta as diferentes interpretações do conceito de necessidades e o caráter não neutro na sociedade capitalista. Nesse contexto, não há um "interesse geral" ou necessidades de toda a sociedade, já que há interesses de classe sociais e necessidades pessoais de homens particulares nesse contexto (Puccini, 2002).

Os resultados de pesquisas devem estar vinculados a teorias para embasar as interpretações e recomendações que subsidiam as tomadas de decisão de formuladores de políticas (O'Connell, 2009; Soares, Yonekura, 2011). A explicitação da teoria utilizada nos estudos é fundamental para justificar a intervenção, entretanto ainda são encontrados estudos que não descrevem claramente as teorias que embasam o fenômeno estudado (Davies, Walker, Grimshaw, 2010). Soares e Yonekura (2011) ressaltam que as revisões sistemáticas também carecem de explicitação de teorias. Nesse sentido, a falta de clareza sobre o modelo de construção da evidência científica pode gerar questionamentos sobre quem as produziu e com qual interesse (Breilh, 2015b).

Quem constrói a evidência? E a partir de qual modelo? Porque, se as evidências são feitas por aqueles que detêm interesses econômicos, ou seja, se são evidências ligadas aos interesses, logo, essas evidências estarão naturalmente enviesadas, e serão adequadas a esses interesses e não à realidade. Portanto, devemos refletir sobre quem produziu as evidências e onde são publicadas (Breilh, 2015b, p.535).

As categorias mais utilizadas nos instrumentos foram características do território e perfil socioeconômico e demográfico da comunidade, mortalidade e causas de morte, utilização de serviços e problemas de saúde/doenças/perfil de saúde-doença.

Batistella (2007) destaca que o estudo de problemas de saúde no território deve considerar a compreensão das complexas relações entre o homem e o seu 
espaço/território de vida e trabalho e suas características históricas, econômicas, culturais, epidemiológicas e sociais. A identificação de como a população adoece, utiliza serviços e morre é relevante para o estudo de necessidades, mas não permite identificar e intervir nas causas, sem correlação com outros dados.

Bases secundárias são utilizadas para obtenção desses dados. Contudo, observam-se limitações em sua utilização, relacionadas a subnotificação de doenças e causas de morte, notificação com dados faltantes e mal elaboradas, desatualização dos dados (Moura et al., 2010; Malta et al., 2016).

A utilização de modelos operacionais de classe social é relevante para possibilitar que os estudos epidemiológicos expliquem as diferenças nos perfis de saúde-doença de uma sociedade. Considera-se que a necessidade de reprodução social é a necessidade das classes sociais (Campos, Mishima, 2005). Negri Filho (2014) explora a necessidade de representar as classes sociais e aproximá-las do território, de forma espacial que possibilite a análise das heterogeneidades.

Nesse sentido, construiu-se um módulo com o objetivo de identificação das classes sociais no território, na tentativa de trabalhar com as diferenças sociais no levantamento de necessidades. A metodologia de Ribeiro e Ribeiro (2011) tomou como base a propriedade ou não dos meios de produção, o que para Stotz (2016) é relevante para o estudo de necessidades.

O "estado de saúde", as possibilidades e dificuldades de exercer
rotineiramente as atividades vitais, bem como a satisfação de
carências físicas, emocionais e espirituais, variam de acordo com a
posição social de grupos de indivíduos face aos meios de produção e
de vida, ou seja, se eles têm ou não a propriedade desses meios.
Pois a propriedade (ou não propriedade) dos meios de produção e de
vida separa a sociedade em dois grandes grupos ou classes sociais,
recurso de poder que permite à classe proprietária sujeitar a dos não
proprietários, de modo a se apropriar da riqueza produzida por estes
últimos. A desigualdade social no processo de adoecer e de morrer
constitui a expressão desta divisão social (Stotz, 2016, p. 69).

O enfoque sobre a individualização do processo saúde-doença com medidas de mudança de comportamento, culpabilizando o indivíduo ainda está presente nos processos de trabalhos dos gestores. Stotz (2007) atualiza a discussão sobre os chamados comportamentos individuais de risco como causa dos problemas de saúde e a implicação para as práticas em saúde. As ações dos serviços de saúde 
como a de adesão ao tratamento e de orientação para prevenção de comportamento "de risco" não levam em consideração as condições sociais que permanecem ocultas nos serviços de saúde. A solução normativa "você tem isso, deve fazer aquilo" ainda domina as ações para a resolução de problemas (Stotz, 2007).

O problema é que as relações entre os problemas percebidos no nível individual e os de sua relação mais ampla e determinação ou condicionamento social não são facilmente percebidas e compreendidas pelos indivíduos [...] Daí a importância de se entender as dificuldades que as pessoas têm de andar sua própria vida, vinculando, por meio da escuta e do diálogo, as experiências com as formas de enfrentar o adoecimento a hipertensão arterial, o diabetes, os transtornos mentais leves em regra decorrentes da desorganização da vida em razão de desemprego, insuficiência de renda, violência social, perda de ou rupturas na relação com pessoas queridas (Stotz, 2007, p.49-50).

A perspectiva de mudança de comportamento continua dominante no capitalismo atual com a ênfase na individualidade, esforços para levar uma vida saudável e responsabilidades individuais pelos problemas de caráter social (Stotz, David, 2013; Soares, 2015)

Ferreira e Latorre (2012) ressaltam que o enfoque individual ou de determinação reflete na seleção de indicadores em saúde em estudos epidemiológicos. Dessa forma, indicadores unicamente do indivíduo são utilizados para o enfoque da saúde como responsabilidade pessoal. Já os indicadores compostos e contextuais, relacionados às história de vida e das condições estruturais do ambiente, acesso às políticas públicas, são defendidos por aqueles que reconhecem a exploração e a injustiça social.

Desconhecimento do território e necessidades de informações locais são ressaltados pelos gestores. O território é outra questão compreendida de diversas formas. Na Epidemiologia tradicional, as três categorias básicas correspondem a lugar, pessoa e tempo (Breilh, 2015a). A crítica de Breilh (2015a, p.536) é que nessa perspectiva considera-se "individual, em vez de coletivo; lugar como lugar físico e não como uma geografia crítica do processo; e tempo como uma foto congelada e não como uma história das coisas".

Contudo, o reconhecimento da historicidade, heterogeneidades e desigualdade no território é defendida por autores como Santos (2007), Breilh 
(2015a) e Nakano e Koga (2013). É importante analisar as características de ocupação do espaço urbano nesta perspectiva, além de qualificá-la. A expansão de novos bairros ou loteamentos urbanos não ocorre de forma homogênea. As classes médias e altas concentram-se em geral em áreas com melhores condições urbanísticas de serviços, equipamentos e infraestrutura que muitas vezes estão presentes antes da ocupação do espaço (Nakano, Koga, 2013). O inverso ocorre nas classes baixas que antes da presença das condições urbanísticas ocupam áreas em localizações periféricas, a partir de assentamentos precários. Omissões históricas da presença do Estado sobre as políticas urbanas, habitacionais e fundiárias no processo de urbanização são ressaltadas por Nakano e Koga (2013)

Outra categoria presente nos resultados foi a presença do Estado. Considera-se fundamental a presença do Estado para o desenvolvimento social e econômico, em um país com enormes desigualdades regionais, como o Brasil. Kuschnir e Chorny (2010, p. 2308) defendem que os sistemas nacionais de saúde "não podem abdicar de sua responsabilidade de garantia do direito", ampliando o acesso aos serviços e diminuindo as desigualdades;

a realidade nos mostra uma grande lacuna entre a efetivação desse importante direito e as ações do Estado, que, em muitas situações, não está cumprindo com suas atribuições, nem com 0 desenvolvimento de ações sem planejamento adequado (Oliveira et. al, 2015, p.533).

Entretanto, o financiamento do SUS é contestado pelos gestores como um dos maiores problemas para a efetivação dos direitos sociais. Marques e Mendes (2005) ressaltam que a partir da adoção da descentralização do SUS, mais especificamente, a municipalização das ações e serviços de saúde, nos anos 1990, os municípios tiveram um comprometimento maior no financiamento da saúde e maior dependência de recursos federais. Dessa forma, os municípios, reféns de recursos financeiros do governo federal, focavam suas ações em políticas ministeriais já estabelecidas.

Ainda sobre o financiamento do SUS, Marques e Mendes (2005, p.174) relatam que "ao mesmo tempo em que se implanta o SUS, com base no princípio da construção da universalidade, agrava-se a crise fiscal e financeira do Estado, limitando o aporte de recursos para a saúde e para a seguridade. As políticas 
neoliberais atingiram com mais força os princípios de universalidade e igualdade do SUS, já que focalizou as ações em saúde e no conceito de equidade com alocação de recursos para os excluídos (Campos, Viana, Soares, 2005). Campos, Viana e Soares (2005) ainda ressaltam outros impactos do neoliberalismo:

Os sucessivos governos neoliberais no Brasil ampliaram as bases da nova configuração estatal. Além de apoiar as mudanças necessárias para a chamada "reestruturação produtiva", com a corrosão dos direitos trabalhistas e outras ações (incluindo a criação dos "contratos temporários", o aumento do tempo para aposentadoria etc.), cortes nos gastos estatais, privatização, sujeição do público ao privado (tanto no nível da prioridade da ação estatal quanto em propostas de "parceria", que apontam para maior privatização e mercantilização do estatal), políticas financeiras de ajuste, políticas de assistência social paliativas em substituição às políticas estruturais etc. (Campos, Viana, Soares, p.86)

A análise do espaço público e privado mostrou que tanto os serviços públicos de atenção básica, quanto os de maior complexidade estão sujeitos a privatizações, entendidas como "a perda de poder das instituições públicas de intermediação entre a sociedade e o poder executivo". (Calipo, Soares, 2008, p.135).

não apenas os governantes e parlamentares praticam a corrupção sobre os fundos públicos, mas não há a percepção social de uma esfera pública das opiniões, da sociabilidade coletiva, da rua como espaço comum, assim como não há a percepção dos direitos à privacidade e à intimidade. Do ponto de vista dos direitos sociais, há um encolhimento público; do ponto de vista dos interesses econômicos, um alargamento do privado, tornando a sociedade presa fácil do neoliberalismo e por ele fascinada (Chauí, 1995, p.75)

Ainda no neoliberalismo, Borges et al. (2012) ressaltam que não há neutralidade na grande mídia. É intrínseca a relação entre seguros privados de saúde e o "hiperdimencionamento" de crises financeiras e de assistência, que objetiva levar para a população a mensagem de insegurança e falta de cobertura assistencial.

Em relação ao processo de organização dos serviços, o ES ainda enfrenta problemas de fragmentação e fragilidades, como falta de serviços básicos de saúde e grande quantidade de serviço de uma mesma especialidade em uma mesma região. O levantamento de serviços e indicadores desagregados resulta em 
importantes resultados para os gestores públicos no planejamento, formulação e avaliação de política públicas brasileiras (IPEA, 2009).

O processo de regionalização, na ótica de organização dos serviços, tem a potencialidade de otimizar os recursos, já que pressupõe que determinados procedimentos raros e caros não são necessários em todo e qualquer município e região (Duarte et al., 2015).

Os contextos regionais e peculiares de cada região, como áreas metropolitanas, rurais e indígenas, implicam em planejamento e gestão distintos de serviços a ações em saúde. Nakano e Comaru (2007) relatam que a região amazônica apresentava altas taxas de crescimento e ainda déficits significativos, em relação à habitação, infraestrutura e saneamento ambiental. A região vivencia-se um processo de urbanização descontrolado, com condições de vida e trabalho inadequados, impactando nas áreas de proteção ambiental. Para o planejamento, foram caracterizados os processos de urbanização, levantadas as organizações e instituições governamentais e não governamentais, levantamento de problemas e inclusão das populações indígenas, considerando valores culturais, usos, costumes e tradições. "O princípio do respeito aos direitos culturais dessas populações tradicionais deve nortear todas as formulações" (Nakano, Comaru, 2007, p.17).

Sobre o direito à saúde, o acesso à justiça é uma das formas para a efetivação desse direito (Marques, 2008). Os gestores percebem a judicialização como forte tensão e pressão pela centralização nos direitos individuais. Entretanto, Marques (2008) ressalta o processo como avanço na efetivação do direito à saúde.

Se, por um lado, a crescente demanda judicial acerca do acesso a medicamentos, produtos para a saúde, cirurgias, leitos de UTI, dentre outras prestações positivas de saúde pelo Estado, representa um avanço em relação ao exercício efetivo da cidadania por parte da população brasileira, por outro, significa um ponto de tensão perante os elaboradores e executores da política no Brasil, que passam a atender um número cada vez maior de ordens judiciais, garantindo as mais diversas prestações do Estado (Marques, 2008, p.65).

O número de artigos científicos sobre o tema da judicialização tem aumentado nos últimos anos, sendo publicados nas principais revistas de Saúde Pública brasileiras principalmente na área de acesso a medicamentos (Oliveira et al., 2015). 
Há também diversos interesses e percepções na judicialização. Sobre o acesso a medicamentos, Oliveira et al. (2015) verificaram que a maioria dos receituários era proveniente do setor privado, com envolvimento de escritórios de advocacia. Medeiros, Diniz e Schwartz (2013) relataram haver evidências que os custos dos advogados são financiados pelo setor privado, como empresas distribuidoras ou indústrias farmacêuticas. Três pontos são ressaltados para a análise da judicialização (Medeiros, Diniz e Schwartz, 2013, p.1088):

1) na composição de interesses de laboratórios e empresas distribuidoras de medicamentos de alto custo cuja eficácia clínica ainda está sob avaliação. Ainda há falta de evidências científicas de eficácia dos medicamentos não padronizados, bem como se há resistência terapêutica aos medicamentos terapêuticos (Marques, 2008).

2) nas dificuldades do Estado em administrar a política de assistência farmacêutica, quanto aos critérios de incorporação tecnológica, transparência e publicidade dos atos.

3) nas dificuldades do Estado em administrar uma política farmacêutica quando instrumentos típicos de administração - planejamento, compras em escala, controle de estoques, chamadas de preços - não podem ser usados em decorrência de determinações judiciais.

Oliveira et al. (2015) relacionam também a judicialização a cidadãos com maior conhecimento de seus direitos.

O papel da universidade no SUS foi questionado pelos gestores que sentem a ausência da universidade em questões problemáticas e atuais do SUS, como formação e qualificação. Pesquisas pontuais que não atuam nas causas dos problemas também são criticadas.

Guzzo e Euzébios Filho (2005) ressaltam que o sistema educacional também é fortemente afetado pelo neoliberalismo, o que consequentemente impacta na formação de trabalhadores da saúde não centrada nas necessidades das populações (Thumé, Soares, Dilélio, 2013).

O papel que o sistema educacional exerce para a manutenção da desigualdade social pode ser analisado com mais clareza, a partir do impacto do neoliberalismo na acentuação da tensão existente entre Educação pública e privada. O neoliberalismo caracteriza-se, dentre outras coisas, pela acentuação da concentração de renda de um pequeno grupo social e pelo fortalecimento dos investimentos 
privados em detrimento do público (...) tanto a lógica de mercantilização do ensino, que contribui para o fortalecimento do sistema privado, quanto a desvalorização do ensino público, são elementos que se unem para aprofundar a desigualdade social e instalar uma crise no sistema educacional brasileiro (Guzzo, Euzébios Filho, 2005, p.45)

Na sociedade capitalista de classes sociais, a educação emancipatória tem um importante papel na luta da classe trabalhadora, no sentido da consciência crítica, abrindo espaços para discutir os impactos do neoliberalismo (Guzzo, Euzébios Filho, 2005).

Stotz e David (2013, p.89) questionam "se é possível uma educação universal em uma sociedade divida em classes, marcada pelo fenômeno da dominação", onde as intervenções em saúde são pautadas no combate à doença e exploração da força de trabalho, tendo em vista a obtenção de lucro pela classe dominante.

A formação de trabalhadores nesse contexto é um desafio que a Educação Popular enfrenta ao reconhecer a dominação de classe, não pré-estabelecendo palavras de ordem e verdades. Sendo um movimento social, a Educação Popular, embasada nos conceitos de Paulo Freire, é composta por grupos de pesquisadores, trabalhadores e técnicos da saúde, ativistas, técnicos com diferentes visões de mundo (Stotz, David, 2013).

Em relação à participação política, Bravo e Menezes (2013) ressaltam que o SUS é fruto de lutas sociais e patrimônio do povo brasileiro e recomendam a luta em defesa da saúde. A destruição do SUS, a partir da conceituação de saúde como mercadoria, ocorre em diversos estados brasileiros, relacionada à privatização e lucros de organizações sociais e fundações privadas (Bravo e Menezes, 2013).

Temas e propostas, com foco na relação Estado-sociedade e na organização dos conselhos, para a agenda política de saúde são propostas por Bravo e Menezes (2013). Estas devem ser debatidas e assumidas pelas instituições de defesa à saúde pública estatal e versam sobre (Quadro 22): 
Quadro 22 - Propostas de temas e propostas para a agenda política. São Paulo; 2016.

\section{Relação Estado-sociedade Organização dos conselhos}

$\checkmark$ Luta pela democratização do Estado $\quad \checkmark$ Luta pela efetivação do controle

$\checkmark$ Divulgação e democratização das informações sobre as políticas de seguridade social e de saúde em particular

$\checkmark$ Articulação deum Fórum unificado de Seguridade Social, com a participação dos conselhos de saúde e da assistência social

\section{$\checkmark \quad$ Luta pela revogação da extinção do} Conselho Nacional de Seguridade Social

$\checkmark$ Criação de meios eficazes para articular a sociedade civil, envolvendo diversas entidades

\section{$\checkmark$ Defesa incondicional do SUS} público, estatal, gratuito, universal, de qualidade e sob a administração direta do Estado

\section{Articulação entre os diferentes}

$\checkmark$ Retorno constante e permanente dos conselheiros às suas bases

$\checkmark$ Estabelecimento de canais de interlocução dos conselhos com a sociedade

\section{$\checkmark$ Constituição de assessoria aos conselhos}

$\checkmark$ Realização de cursos de capacitação política para conselheiros da sociedade civil

$\checkmark \quad$ Luta pela gestão e pelos serviços públicos de qualidade

$\checkmark$ Defesa de investimentos de recursos públicos no setor público

$\checkmark \quad$ Luta contra todas as formas de privatização da rede pública de serviços: OSs, OSCIPs, Fundações Estatais de Direito Privado e Empresa Brasileira de Serviços Hospitalares, etc.

$\checkmark \quad$ Luta contra a inconstitucionalidade da lei que cria as organizações sociais

$\checkmark \quad$ Defesa de concursos públicos e da carreira pública no serviço público

Fonte: Bravo, Menezes (2013). 
A participação contra a restrição de direitos pelo Estado neoliberal que privilegia os interesses do capital é fundamental para a ampliação da esfera pública (Campos, Mishima, 2005). Silva (2012) ressalta que a participação social possibilita modificação da realidade concreta pela mobilização do coletivo e a garantia de reconhecimento das necessidades de saúde pelo Estado.

Os resultados sobre construção e validação do instrumento revelaram que o método utilizado foi adequado e permitiu sistematizar o conceito de necessidades, a partir do referencial da Saúde Coletiva, em um instrumento.

Estudos metodológicos de construção de índices, instrumentos e manuais são comuns e necessários na área da saúde. Para que sejam úteis, os instrumentos de medida devem ser desenvolvidos e validados de maneira adequada (Coluci, Alexandre, Milani, 2015).

Pode-se evidenciar na literatura, construções e validações de: índice sobre vulnerabilidade socioambiental (Guimarães et al., 2014), escala de valores sociomorais (Tavares et al., 2016), instrumento sobre avaliação de egressos da graduação em enfermagem (Vieira, Ohara, Domenico, 2016) e manual educativo sobre o trabalho de parto e parto (Teles et al., 2014).

Alexandre e Coluci (2011) ressaltam que é crescente o número de instrumentos construídos na área da saúde, o que requer rigor, tanto na fase de construção, quanto na escolha e utilização. 


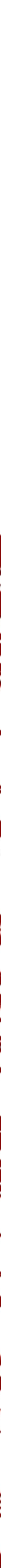




\section{CONSIDERAÇÕES FINAIS}

Neste trabalhou, buscou-se construir um instrumento de levantamento de necessidades, a partir da perspectiva teórica da Saúde Coletiva e particularmente da Epidemiologia Crítica. Os procedimentos metodológicos foram efetivos para a consecução dos objetivos, já que:

* Por meio da RI, se identificou instrumentos e métodos de levantamento de necessidades no planejamento em saúde: evidenciou-se 17 instrumentos de levantamento de necessidades sociais, sendo a maioria de origem norte-americana. De forma geral, o conceito de necessidades não estava claramente explicitado, sendo que a Saúde Coletiva não foi citada em nenhum estudo. Métodos qualitativos, quantitativos e quanti-qualitativos foram utilizados, de forma a identificar as necessidades sociais de diversos aspectos.

De acordo com os resultados da RI, é possível estabelecer implicações para a prática e para a pesquisa: Implicações para a prática: A utilização de instrumentos é adequada para o levantamento de necessidades e é recomendada, tanto pela literatura internacional, quanto pela nacional, sendo fundamental para o planejamento em saúde. Foram identificados diversos métodos, sendo que a definição do processo depende do tempo e recursos disponíveis. Implicações para a pesquisa: Novos estudos são necessários para que variáveis importantes, principalmente relacionadas à reprodução social das classes sociais, sejam capturadas pelos instrumentos e analisadas a luz da Saúde Coletiva e particularmente da Epidemiologia Crítica. As necessidades de participação política também devem ser mais aprofundadas em novos instrumentos.

* As entrevistas permitiram compreender a dificuldade no levantamento de necessidades. O conceito de necessidades de saúde é desconhecido e e a expressão está quase sempre relacionada de maneira muito geral ao conceito de determinantes sociais, sem distinção clara da determinação da classe social no processo saúde-doença. As metodologias de operacionalização de necessidades também não são conhecidas ou utilizadas pelos gestores.

* A construção dos módulos do instrumento, a partir dos resultados anteriores foi concluída, bem como a identificação das etapas de cada módulo e a 
ordenação do conteúdo. O método utilizado foi considerado adequado, por permitir alcançar os resultados esperados.

* A validação ocorreu por meio da validação de conteúdo, sendo avaliada por oito especialistas. As análises dos dados revelaram apenas uma etapa com problema de clareza e sugestões de alteração no conteúdo, por meio dos campos abertos. Foi elaborada a versão final, contemplando as evidências da literatura, das entrevistas com gestores e da validação por especialistas.

\section{Para fazer a síntese:}

O instrumento construído e validado tem potencialidade para mostrar as necessidades e desigualdades sociais de classe que determinam o processo saúdedoença, na perspectiva da Saúde Coletiva e em particular da a Epidemiologia Crítica, já que busca parte da identificação das classes sociais no território. Entretanto, somente o instrumento não é capaz de sensibilizar os gestores e técnicos das secretarias estaduais ou municipais para a utilização e análise dos dados. 
(10)

\section{Referências}

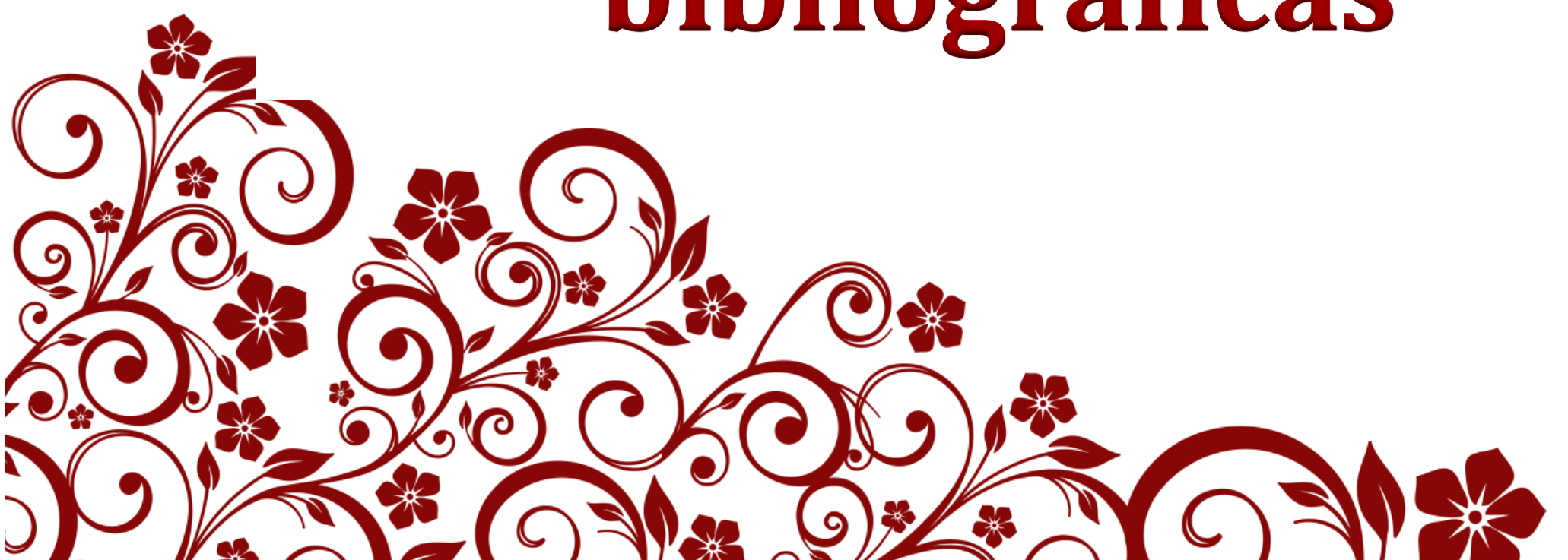

\section{bibliográficas}




\section{REFERÊNCIAS BIBLIOGRÁFICAS}

Ahari SS, Habibzadeh S, Yousefi M, Amani F, Abdi R. Community based needs assessment in an urban area: a participatory action research project. BMC Public Health. 2012;12(161):1-8.

Albuquerque MV, Viana $A$. Perspectivas de região e redes na política de saúde brasileira. Saúde Debate. 2015;39(n.esp):28-38.

Alexandre NMC, Coluci MZO. Validade de conteúdo nos processos de construção e adaptação de instrumentos de medidas. Cien Saude Colet. 2011;16(7):3061-3068.

Almeida Filho N, Rouquayrol MZ. Introdução à Epidemiologia Moderna. Rio de Janeiro: Abrasco; 1990.

Asadi-Lari M, Gray D. Health needs assessment tools: progress and potential. Int J Technol Assess Health Care. 2005;21(3):288-97.

Ayres JRCM. O social na Epidemiologia: reflexões metacríticas. In: Carvalheiro J, Heimann LS, Derbi M. O social na epidemiologia: um legado de Cecília Donnangelo. São Paulo: Instituto da Saúde; 2014. p. 99-118.

Bardin, L. Analise de conteúdo . 4a. ed. português. Lisboa: Edições 70; 2008.

Barnett K. Best Practices for Community Health Needs Assessment and Implementation Strategy Development: A Review of Scientific Methods, Current Practices, and Future Potential. Oakland: The Public Health Institute, Atlanta: The Centers for Disease Control and Prevention; 2011.

Batistella C. Abordagens contemporâneas do conceito de saúde. In: Fonseca AF, Corbo AMDA (org). O território e o processo saúde-doença. Rio de Janeiro: EPSJV/Fiocruz; 2007.

Beyea S, Nicoll LH. Writing an integrative review. AORN J. 1998;67(4):877-80.

Booth A. A Cochrane or cock-eyed? How should we conduct systematic reviews of qualitative research? Qualitative Evidence-based Practive Conferences. Conventry University; 2001.

Borges FT, Moimaz SAS, Siqueira CA, Garbin CAS. Anatomia da privatização neoliberal do Sistema Único de Saúde: O Papel das Organizações Sociais de Saúde. São Paulo: Cultura Acadêmica; 2012.

Brasil. Portaria n 3.085 , de $1^{\circ}$ de dezembro de 2006. Regulamenta o Sistema de Planejamento do SUS, 2006. 
Brasil. Ministério das Cidades. Guia para mapeamento e caracterização de assentamentos precários. Brasília: Ministério das Cidades; 2010.

Brasil. Decreto oㅜ 7.508, de 28 de junho de 2011. Regulamenta a Lei no 8.080, de 19 de setembro de 1990, para dispor sobre a organização do Sistema Único de Saúde SUS, o planejamento da saúde, a assistência à saúde e a articulação interfederativa, e dá outras providências, 2011.

Brasil. Constituição,1998. Emenda constitucional n. 90, de 15 de setembro de 2015. Dá nova redação ao art. 6o da Constituição Federal, para introduzir o transporte como direito social, 2015a.

Brasil. Ministério da Saúde. Manual de planejamento no SUS / Ministério da Saúde, Fundação Oswaldo Cruz. Brasília: Ministério da Saúde, 2015b.

Bravo MIS, Menezes JSB. Participação popular em saúde. In: Soares CB, Campos CMS (Org.). Fundamentos de saúde coletiva e o cuidado de enfermagem. Barueri: Manole; 2013. p.49-74.

Breilh J. Epidemiologia. Economia, política e saúde. São Paulo: Hucitec; 1991.

Breilh J. La determinación social de la salud como herramienta de ruptura hacia la nueva salud pública (salud colectiva). VIII Seminário Internacional de Salud Pública, Saberes en Epidemiologia en EI Siglo XXI. Universidad Nacional de Colômbia; 2013.

Breilh J. Epidemiología del siglo XXI y ciberespacio: repensar la teoría del poder y la determinación social de la salud. Rev. bras. epidemiol. 2015a;18(4):972-982.

Breilh J. Entrevista: Jaime Breilh. Trab. educ. saúde. 2015b;13(2):533-540.

Brito F. Transição demográfica e desigualdades sociais no Brasil. Rev. bras. Estud. Popul. 2008; 25(1):5-26.

Calipo SM, Soares CB. Público e privado na reforma do Sistema de Saúde no Brasil. Soc. Debate. 2008;14(1):119-38.

Campos CMS, Bataiero MO. Necessidades de saúde: uma análise da produção científica brasileira de 1990 a 2004. Interface (Botucatu). 2007;11(23):605-618.

Campos CMS, Mishima SM. Necessidades de saúde pela voz da sociedade civil e do Estado. Cad. Saúde Pública. 2005;21(4):1260-1268.

Campos CMS, Viana N, Soares CB. Mudanças no capitalismo contemporâneo e seu impacto sobre as políticas estatais: o SUS em debate. Saúde soc. 2015;24(Suppl 1): 82-91. 
Castiel LD, Rivera FJU. Planejamento em saúde e epidemiologia no Brasil: casamento ou divórcio? Cad. de Saúde Pública. 1985;1(4):447-456.

Castro AV, Rezende M. A técnica Delphi e seu uso na pesquisa de enfermagem: revisão bibliográfica. REME. 2009;13(3):429-434.

Chauí M. Cultura política e política cultural. Estud. av.1995;9(23):71-84.

Chorny AH, Kuschnir R, Taveira MT. Planejamento e programação em saúde. Texto para fixação de conteúdos e seminário. Rio de Janeiro: FIOCRUZ; 2008.

Coluci MZO, Alexandre NMC, Milani D. Construção de instrumentos de medida na área da saúde. Ciênc. saúde coletiva. 2015;20(3):925-936.

Contandriopoulos AP, Champagne F, Potvin L, Denis JL, Boyle P. Saber preparar uma pesquisa. $3^{\underline{a}}$ ed. São Paulo: Hucitec, Abrasco; 1999.

Cooper HM. Scientific guidelines for conducting integrative research reviews. Rev Educ Res. 1982;52(2):291-302.

Dalmoro M, Vieira KM. Dilemas na construção de escalas tipo likert: o número de itens e a disposição influenciam nos resultados? Revista Gestão Organizacional. 2013;6(Esp):161-174.

Davies P, Walker AE, Grimshaw JM. A systematic review of the use of theory in the design of guideline dissemination and implementation strategies and interpretation of the results of rigorous evaluations. Implement Sci. 2010;5:14.

Davis LL. Instrument review: getting the most from a panel of experts. Appl Nurs Res. 1992;5(4):194-197.

Decit. Departamento de Ciência e Tecnologia, Secretaria de Ciência, Tecnologia e Insumos Estratégicos, Ministério da Saúde. Programa de Desenvolvimento Institucional do Sistema Único de Saúde. Rev Saúde Pública. 2011;45(4):808-11.

Drummond M. Epidemiologia em serviços de saúde: conceitos, instrumentos e modos de fazer. In: Campos GWS et al. (org.). Tratado de saúde coletiva. São Paulo: Hucitec-Fiocruz; 2009.

Duarte LS, Pessoto UC, Guimarães RB, Heimann LS, Carvalheiro JR, Cortizo CT, et al. Regionalização da saúde no Brasil: uma perspectiva de análise. Ciênc. saúde coletiva. 2015. 24(2):472-485.

Dubowitz T, Williams M, Steiner ED, Weden MM, Miyashiro L, Jacobson D, Lurie N. Using Geographic Information Systems to Match Local Health Needs With Public Health Services and Programs. Am J Public Health. 2011;101(9):1664-5. 
Egry EY, Oliveira MAC. Marcos Teóricos e conceituais de necessidades. In: Egry EY (org). As necessidades em saúde na perspectiva da Atenção Básica: guia para pesquisadores. São Paulo: Dedone Editora, 2008.

Feather J, McGowan V, Moore M. Planning health needs assessment: the basic choices. Saskatoon: Prairie Region Health Promotion Research Centre; 1994.

Ferreira MAF, Latorre MRDO. Desigualdade social e os estudos epidemiológicos: uma reflexão. Ciênc. saúde coletiva. 2012; 17(9): 2523-2531.

Fujimori E, Borges ALV, Sato APS, Trapé CA, Yonekura T. Epidemiologia e Saúde Coletiva. In: Soares CB, Campos CMS (Org.). Fundamentos de saúde coletiva e o cuidado de enfermagem. Barueri: Manole; 2013. p.173-216.

Fuller J, Bentley B, Shotton D. Use of community health needs assessment for regional planning in country South Australia. Aust. J. Rural Health. 2001;9:12-17

Galobardes B, Shaw M, Lawlor DA, Lynch JW, Davey Smith G. Indicators of socioeconomic position (part 1). J Epidemiol Community Health. 2006 Jan;60(1):712.

Gervasio K, McAloon, C. Community Health Needs Assessment Report Trenton, New Jersey. New Jersey: New Jersey Health Initiatives, Robert Wood Johnson Foundation; 2013.

Gonçalves RBM. Práticas de Saúde: processos de trabalho e necessidades. São Paulo: Centro de Formação dos Trabalhadores em Saúde da Secretaria Municipal da Saúde, 1992. (Cadernos Cefor, 1 - Série textos)

Granados RM, Aguilera JDJ, Martín JJM. Estimation of an index of regional health needs in Spain using count regression models with filter. Health Policy. 2007 Apr;81(1):4-16.

Granda E, Breilh J. Saúde na sociedade - guía pedagógico sobre um novo enfoque do método epidemiológico. São Paulo: Cortez; 1989.

Guimarães RM, Mazoto ML, Martins RN, Carmo CN, Asmus Cl. Construção e validação de um índice de vulnerabilidade socioambiental para a vigilância e gestão de desastres naturais no Estado do Rio de Janeiro, Brasil. Ciênc. saúde coletiva. 2014;19(10):4157-4165.

Guzzo RSL, Euzébios Filho A. Desigualdade social e sistema educacional brasileiro: a urgência da educação emancipadora. Escritos educ. 2005;4(2):39-48.

Heller A. Teoría de las necesidades en Marx. Barcelona: Peninsola, 1978. 
Heredia-Martínez HL, Artmann E, Porto SM. Enfoque comunicativo del Planeamiento Estratégico Situacional en el nivel local: salud y equidad en Venezuela. Cad. Saúde Pública. 2010; 26(6):1194-1206.

Hoga LAK, Soares CB, Gonçalves, BG, Yonekura T, Secoli SR. Enfermagem Baseada em Evidiências. In: Bresciani HR, Martini JG, Mai LD (Org.). Programa de Atualização em Enfermagem Saúde do Adulto. Porto Alegre: Artmed Panamericana; 2014. p. 9-34.

Hsu CC, Sandford BA. The Delphi technique: making sense of consensus. Practical Assessment, research \& evaluation. 2007;12(10):1-8.

Huertas F. O método PES: entrevista com Matus. São Paulo: FUNDAP, 1996.

IPEA. Instituto de Pesquisa Econômica Aplicada. Presença do estado no Brasil: federação, suas unidades e municipalidade. Brasília: Ipea; 2009.

JBI. Joanna Briggs Institute. Joanna Briggs Institute Reviewers' Manual. Adelaide: The Joanna Briggs Institute; 2014.

Jordan J, Dowswell T, Harrison S, Lilford RJ, Mort M. Whose priorities? Listening to users and the public. BMJ. 1998 May 30;316(7145):1668-70.

Kaufman RA. English FW. Needs assessment. Concept and Application. New Jersey: Educational Techonology Publications; 1979.

Kazda MJ, Beel ER, Villegas D, Martinez JG, Patel N, Migala W. Methodological Complexities and the Use of GIS in Conducting a Community Needs Assessment of a Large U.S. Municipality. J Community Health. 2009 Jun;34(3):210-5.

Krieger N, Williams DR, Moss NE. Measuring social class in US public health research: concepts, methodologies and guidelines. Annu. Rev. Public Health. 1997;18:341-378. 1982;2: 7-25.

Kuschnir R, Chorny AH. Redes de atenção à saúde: contextualizando o debate. Ciênc. saúde coletiva. 2010;15(5):2307-2316.

Laurell AC. A saúde-doença como processo social. In: Nunes ED (organizador). Medicina Social: aspectos históricos e teóricos. São Paulo: Global; 1982.

Lee S, Ma GX, Juon HS, Martinez G, Hsu CE, Bawa J. Assessing the needs and guiding the future: findings from the health needs assessment in 13 Asian American communities of Maryland in the United States. J Immigr Minor Health. 2009;13(2):395-401.

Leopardi MT. Necessidades de saúde e cidadania. Texto Contexto Enferm. 1992; 1(1):54-73. 
Li Y, Cao J, Lin H, Li D, Wang Y, He J. Community health needs assessment with precede-proceed model: a mixed methods study. BMC Health Serv Res. 2009 Oct 9;9:1-14.

Louvison MCP, Lebrão ML, Duarte YAO, Santos JLF, Malik AM, Almeida ES. Desigualdades no uso e acesso aos serviços de saúde entre idosos do município de São Paulo. Rev Saúde Pública 2008;42(4):733-40.

Machado CV, Baptista TWF, Lima LD. O planejamento nacional da política de saúde no Brasil: estratégias e instrumentos nos anos 2000. Cien Saude Colet. 2010;15(5):2367-2382.

Malta DC, Santos MAS, Stopa SR, Vieira JEB, Melo EA, Reis AAC. A Cobertura da Estratégia de Saúde da Família (ESF) no Brasil, segundo a Pesquisa Nacional de Saúde, 2013. Ciênc. saúde coletiva. 2016; 21(2): 327-338.

Marmot M, Bell R. Social inequalities in health: a proper concern of epidemiology. Ann Epidemiol. 2016;26:238-240.

Marques RM, Mendes A. Os dilemas do financiamento do SUS no interior da seguridade social. Economia Sociedade. 2005;14(1):159-175.

Marques SB. Judicialização do direito à saúde. Revista de Direito Sanitário. 2008;9(2):65-72.

Martins DA, Souza DMO, Melo KCNS. Utilização do Método Delphi no processo de planejamento estratégico: duas perspectivas e a garantia de eficiência e heterogeneidade. XXVI ENEGEP - Fortaleza, CE, Brasil, 9 a 11 de Outubro de 2006. p.1-9.

Marx K, Engels F. A Ideologia Alemã. Barcelona: Grijalbo; 1977.

Matus C. Fundamentos da planificação situacional. In: Rivera, F. Javier Uribe (org.). Planejamento e programação em saúde: um enfoque estratégico. São Paulo: Cortez, p.105-176, 1989.

Medeiros M, Diniz D, Schwartz IVD. A tese da judicialização da saúde pelas elites: os medicamentos para mucopolissacaridose. Ciênc. saúde coletiva. 2013;18(4):1079-1088.

Mendes KDS, Silveira RCCP, Galvão CM. Revisão integrativa: método de pesquisa para a incorporação de evidências na saúde e na enfermagem. Texto Contexto Enferm. 2008;17(4):758-64.

Minayo MCS. O desafio do conhecimento. São Paulo: HUCITEC; 2013. 
PES. Plano Estadual de Saude 2012/2015. Vitoria: Secretaria Estadual de Saúde, 2012.

Moher D, Liberati A, Tetzlaff J, Altman DG, The PRISMA Group. Preferred Reporting Items for Systematic Reviews and Meta-Analyses: The PRISMA Statement. PLoS Med. 2009;6(6):e1000097.

Moraes PA, Bertolozzi MR, Hino P. Percepções sobre necessidades de saúde na Atenção Básica segundo usuários de um serviço de saúde. Rev Esc Enferm USP. 2011;45(1):19-25.

Morgan DL. Focus group as qualitative research. 2 ed. Newbury Park (CA): Sage Publication; 1997.

Moura BLA, Cunha RC, Aquino R, Medina MG, Mota ELA, Macinko J et al. Principais causas de internação por condições sensíveis à atenção primária no Brasil: uma análise por faixa etária e região. Rev. Bras. Saude Mater. Infant. 2010;10(Suppl 1): s83-s91.

Murray SA, Graham LJC. Practice based health needs assessment: use of four methods in a small neighbourhood. BMJ. 1995;310:1443-8.

Nakamura E, Egry EY, Campos CMS, Nichiata LYI, Chiesa AM, Takahashi RF. O potencial de um instrumento para o reconhecimento de vulnerabilidades sociais e necessidades de saúde: saberes e práticas em saúde coletiva. Rev Latino-am Enfermagem. 2009;17(2): 253-258.

Nakano AK, Comaru FA. São Gabriel da Cachoeira: o planejamento e a gestão territorial num município indígena da Amazônia. XII Encontro da Associação Nacional de Pós-Graduação e Pesquisa em Planejamento Urbano e Regional. 21 a 25 de maio de 2007. Belém; 2007.

Nakano AK, Koga D. Os territórios da urbanidade e a promoção da saúde. In: Soares CB, Campos CMS (Org.). Fundamentos de saúde coletiva e o cuidado de enfermagem. Barueri: Manole; 2013. p.143-172.

Negri Filho AD. Seleção de indicadores de saúde relevantes para caracterizar e monitorar sua determinação social. Fórum Classes sociais, território e saúde: questões metodológicas e políticas. 6 a 8 de junho de 2013. Petrópolis; 2013.

Negri Filho AD, Achury NJM. Instrumento basico para la lectura integral de necesidades sociales en los territorios y definición de las agendas territoriales. Bogotá: Secretaría Distrital Integración Social; 2008.

Novins D, LeMaster P, Thurman PJ, Plested B. Describing community needs: examples from the circles of care initiative. Am Indian Alsk Native Ment Health Res. 2004;11(2):42-58. 
O'Connell KA. Theories used in nursing research on smoking cessation. Annu Rev Nurs Res. 2009;27(1):33-62.

Oliveira MRMO, Delduque MC, Sousa MF, Mendonça AVM. Judicialização da saúde: para onde caminham as produções científicas? Saúde Debate. 2015;39(105):514524.

Ontario. Assessing Need. The Health Planner's Toolkit. Health System Intelligence Project. Ontario: Ministry of Health and Long-Term Care; 2006.

Paim JS, Almeida Filho N. Saúde coletiva: uma "nova saúde pública" ou campo aberto a novos paradigmas?. Rev. Saúde Pública. 1998;32(4):299-316.

PDR. Plano Diretor de Regionalização. Vitória: Secretaria Estadual da Saúde; 2011.

PES. Plano Estadual de Saúde 2012-2015. Vitória: Secretaria Estadual da Saúde; 2012.

Pieh-Holder KL, Callahan C, Young P. Qualitative needs assessment: healthcare experiences of underserved populations in Montgomery County, Virginia, USA. Rural Remote Health. 2012;12:2045.

Piola S, Vianna S, Vivas-Consuelo D. Estudo Delphi: atores sociais e tendências do sistema de saúde brasileiro. Cad. Saúde Pública. 2002;18(Sup):182-190.

PNUD. Programa das Nações Unidas para o Desenvolvimento. Relatório do Desenvolvimento Humano 2013. A Ascensão do Sul: Progresso Humano num Mundo Diversificado. New York: PNUD, 2013.

Polit D, Beck C, Hungler B. Fundamentos de Pesquisa em enfermagem. Porto Alegre: Artes Médicas; 1995.

Possas C. Epidemiologia e sociedade. Heterogeneidade estrutural e saúde no Brasil. São Paulo: Hucitec, 1989.

Preston CC, Colman AM. Optimal number of response categories in rating scales: reliability, validity, discriminating power, and respondent preferences. Acta Psychol (Amst). 2000;104:1-15.

Puccini PT. Limites e possibilidades de uma proposta de humanização dos serviços públicos e satisfação dos usuários na luta pelo direito a saúde [dissertação]. Campinas: Faculdade de Ciências Médicas, Universidade Estadual de Campinas; 2002. 
QIIP. Quality Improvement \& Innovation Partnership. Assessing the needs and guiding the future: findings from. Needs assessment resource guide. Ontario: QIIP; 2010.

Ribeiro LCQ, Ribeiro MG. Análise social do espaço urbano-metropolitano: Fundamentos teórico-metodológicos e descrição dos procedimentos técnicos. Rio de Janeiro: Institutos Nacionais de Ciência e Tecnologia, Observatório das Metrópoles; 2011.

Rieg DL, Araujo Filho T. Planejamento estratégico situacional e mapeamento cognitivo em uma situação concreta: o caso da pró-reitora de extensão da UFSCAR. Gestão \& Produção. 2002;9(2):163-179.

Rivera FJU, Artmann E. Planejamento e gestão em saúde: conceitos, história e propostas. Rio de Janeiro: FIOCRUZ; 2012.

Santos M. O espaço do cidadão. São Paulo: Editora da Universidade de São Paulo; 2007.

São Paulo (SP). Secretaria Municipal da Saúde. Coordenação de Epidemiologia e Informação - CEInfo. Índice de Necessidades em Saúde da Cidade de São Paulo. São Paulo: CEInfo; 2010.

Silva BRB. Práticas de enfermeiras da USF Jardim Boa Vista: em pauta a participação social [dissertação]. São Paulo: Escola de Enfermagem, Universidade de São Paulo; 2012.

Silva JPV, Batistella C, Gomes ML. Problemas, Necessidades e Situação de Saúde: uma revisão de abordagens para a reflexão e ação da equipe de saúde da família In: Fonseca AF, Corbo AMD (org). Problemas, território e o processo saúdedoença. Rio de Janeiro: EPSJV/Fiocruz, 2007. p.159-176.

Soares CB. Consumo contemporâneo de drogas e juventude: a construção do objeto da perspectiva da saúde coletiva [tese livre-docência]. São Paulo: Escola de Enfermagem da Universidade de São Paulo; 2007.

Soares $\mathrm{CB}$. Os desafios da epidemiologia crítica e as respostas do capitalismo às suas dificuldades de reprodução: o caso da esfera cibernética. Rev. bras. epidemiol. 2015;18(4):990-994.

Soares CB, Hoga LAK, Peduzzi M, Sangaleti C, Yonekura T, Silva DRAD. Revisão integrativa: conceitos e métodos utilizados na enfermagem. Rev Esc Enferm USP. 2014; 48(2):335-45. p. 119-147.

Soares CB, Trape CA, Yonekura T, Campos CMS. Marxismo, trabalho e classes sociais: epidemiologia crítica como instrumento da saúde coletiva. In: Carvalheiro J, 
Heimann LS, Derbi M. O social na epidemiologia: um legado de Cecília Donnangelo. São Paulo: Instituto da Saúde; 2014. p. 99-118.

Soares CB, Yonekura T. Revisão sistemática de teorias: uma ferramenta para avaliação e análise de trabalhos selecionados. Rev Esc Enferm USP. 2011;45(6):1507-14.

Stotz EM. Necessidades de saúde: mediações de um conceito (contribuições das Ciências Sociais para a fundamentação teórico-metodológica de conceitos operacionais da área de planejamento em saúde) [tese]. Rio de Janeiro: Escola Nacional de Saúde Pública; 1991.

Stotz EN. Enfoque sobre educação popular e saúde. Cad de educação popular e saúde. Serie B. Textos básicos de saúde. Brasília; 2007.

Stotz EN. Necessidades de saúde: conceito, valor, política. Uma revisão autocrítica. Intervozes. 2016;1(1):66-75.

Stotz EN, David HMSL. Educação popular e saúde. In: Soares CB, Campos CMS (Org.). Fundamentos de saúde coletiva e o cuidado de enfermagem. Barueri: Manole; 2013. p.75-106.

Tavares MR, Menin MSS, Bataglia PUR, Vinha TPi, Tognetta, LRP, Martins RA, Moro A. Construção e validação de uma escala de valores sociomorais. Cadernos de Pesquisa. 2016;46(159):186-210

Teixeira JC, Oliveira GS, Viali AM, Muniz SS. Estudo do impacto das deficiências de saneamento básico sobre a saúde pública no Brasil no período de 2001 a 2009 . Eng Sanit Ambient. 2014;19(1);87-96.

Teles LMET, Oliveira AS, Campos FC, Lima TM, Costa CC, Gomes LFS, et al. Construção e validação de manual educativo para acompanhantes durante 0 trabalho de parto e parto. Rev Esc Enferm USP. 2014;48(6):977-84.

Thein K, Zaw KT, Teng RE, Liang C, Julliard K. Health needs in Brooklyn's Chinatown: a pilot assessment using rapid participatory appraisal. J Health Care Poor Underserved. 2009;20:378-394.

Thiollent MJM. Crítica Metodológica, Investigação Social e Enquete Operária. São Paulo: Polis; 1982.

Thumé E, Soares MA, Dilélio AS. Projetos e ações inovadoras na atenção primária à saúde. In: Soares CB, Campos CMS (Org.). Fundamentos de saúde coletiva e o cuidado de enfermagem. Barueri: Manole; 2013. p. 349-368.

Tomasi E, Facchini LA, Osorio A, Fassa AG. Aplicativo para sistematizar informações no planejamento de ações de saúde pública. Rev. Saúde Pública. 2003;37(6): 800-806. 
Trapé CA. A operacionalização do conceito de classes sociais em epidemiologia crítica: uma proposta a partir da categoria reprodução social [tese]. São Paulo: Escola de Enfermagem, Universidade de São Paulo; 2011.

Triviños ANS. Introdução à pesquisa em ciências sociais: a pesquisa qualitativa em educação. São Paulo: Atlas; 1987.

Viana N, Soares CB, Campos CMS. Reprodução social e o processo saúde-doença. In: Soares CB, Campos CMS (org). Fundamentos de saúde coletiva e o cuidado de enfermagem. Barueri: Manole; 2013. p.107-142.

Vieira MA, Ohara CVS, Domenico EBL. Construção e validação de instrumento para a avaliação de egressos da graduação em enfermagem. Rev. Latino-Am. Enfermagem. 2016; 24:e2710.

Vyas AN, Chaudhary N, Ramiah K, Landry M. Addressing a growing community's health needs: project SAHNA (South Asian Health Needs Assessment). J Immigr Minor Health. 2013;15(3):577-83.

Whittemore R, Knafl K. The integrative review: updated methodology. J Adv Nurs. 2005;52(5):546-53.

Wright J, Williams R, Wilkinson JR. Development and importance of health needs assessment. BMJ. 1998;316:1310-1313.

Yonekura T. A operacionalização do conceito de classe social na epidemiologia: uma revisão sistemática [tese]. São Paulo: Escola de Enfermagem, Universidade de São Paulo; 2011.

Yonekura T, Soares CB, Minuci EG, Campos CMS, Trape CA. Mapa das juventudes de Santo André, SP: instrumento de leitura das desigualdades sociais. Rev. Saúde Pública. 2010;44(1):45-52.

Yonekura T, Silva CA, Souza GAG. Perfil epidemiológico de idosos atendidos em um serviço de assistência domiciliar do município de São Paulo. In: VIII Congresso Brasileiro de Epidemiologia, 2011, São Paulo. Resumos do Congresso Brasileiro de Epidemiologia, 2011.

Whittemore R, Knafl K. The integrative review: updated methodology. J Adv Nurs. 2005;52(5):546-53.

WHO. World Health Organization. Community health needs assessment. Copenhagen: WHO; 2001.

Wright J, Williams R, Wilkinson JR. Development and importance of health needs assessment. BMJ. 1998 Apr 25;316(7140):1310-3. 
(1)

\section{Anexos e}

\section{Apêndices}

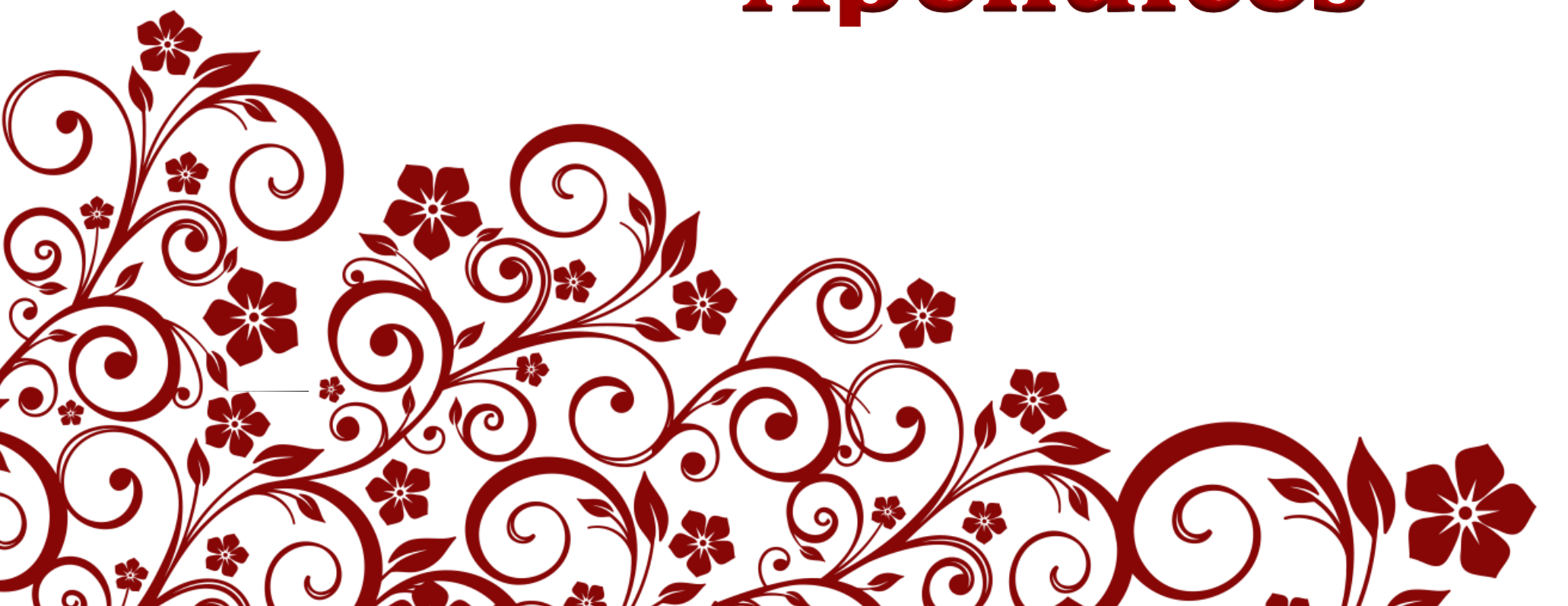




\section{ANEXO 1 \\ Parecer do Comitê de Ética da Escola de Enfermagem da Universidade de São Paulo}

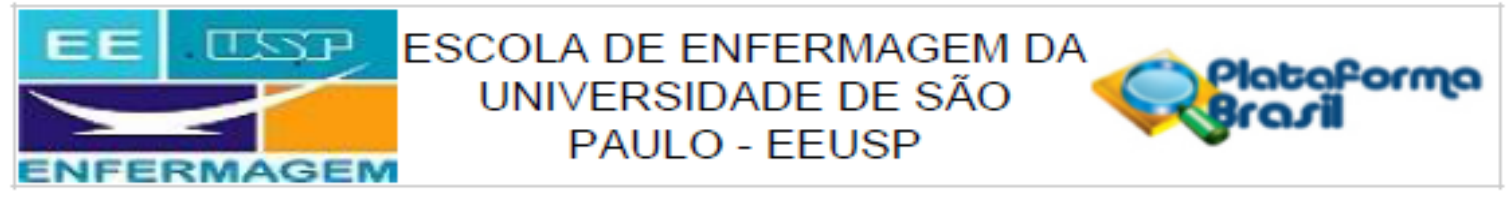

\section{PARECER CONSUBSTANCIADO DO CEP}

\section{DADOS DO PROJETO DE PESQUISA}

Título da Pesquisa: Necessidades de saúde: estratégias e instrumentos para o planejamento regional em saúde

Pesquisador: Tatiana Yonekura

Área Temática:

Versão: 1

CAAE: 47336715.1 .0000 .5392

Instituição Proponente: Escola de Enfermagem da Universidade de São Paulo - EEUSP

Patrocinador Principal: Financiamento Próprio

\section{DADOS DO PARECER}

Número do Parecer: 1.180.534

Data da Relatoria: 11/08/2015

Apresentação do Projeto:

O projeto propõe identificar necessidades de saúde, de modo a favorecer a elaboração de estratégias e instrumentos para o planejamento regional em saúde, em três etapas operacionais: 1) Revisão integrativa sobre instrumentos de levantamento de necessidades sociais; 2) Desenvolvimento de instrumento de captação de necessidades sociais, a partir da revisão integrativa, de entrevista com gestores da área da saúde; 3) Conferência com especialistas.

Objetivo da Pesquisa:

Construir um instrumento de captação de necessidades de saúde para subsidiar o planejamento estratégico regional

Avaliação dos Riscos e Benefícios:

As duas primeiras etapas não dependem de participantes. A terceira, que utiliza participantes, será feita por meio de entrevistas e conferência.

Comentários e Considerações sobre a Pesquisa:

O projeto contempla a perspectiva da Saúde Coletiva e de acordo com a taxonomia: necessidades de reprodução social, necessidades de presença do Estado e necessidades de participação social. Apresentase em conformidade com todas as exigências éticas que envolvem as pesquisas com seres humanos,

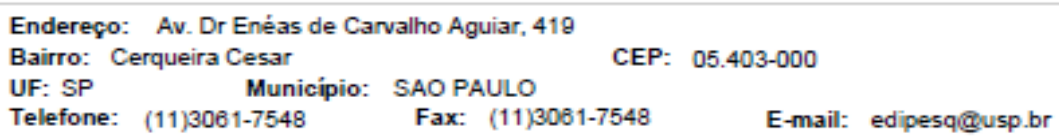




\section{$\left.\begin{array}{c}\text { EE CSSP ESCOLA DE ENFERMAGEM DA } \\ \text { UNIVERSIDADE DE SÃO } \\ \text { PAULO - EEUSP }\end{array}\right\} \begin{gathered}\text { Plotoforma } \\ \text { Brofil }\end{gathered}$}

Contnuaçăo do Parecer: 1.180.534

Considerações sobre os Termos de apresentação obrigatória:

Apresenta o TCLE QUE garante o voluntarismo e o direito do sujeito desistir da entrevista a qualquer momento. $O$ sigilo das informações também está garantido.

Recomendações:

Não há

Conclusões ou Pendências e Lista de Inadequações:

Avaliação favorável ao projeto proposto nos seus aspectos éticos.

Situação do Parecer:

Aprovado

Necessita Apreciação da CONEP:

Não

Consideraçôes Finais a critério do CEP:

Este CEP informa a necessidade de registro dos resultados parciais e finais na Plataforma Brasil.

Esta aprovação não substitui a autorização da instituição coparticipante, antes do início da coleta de dados.

SAO PAULO, 11 de Agosto de 2015

Assinado por:
Marcelo José dos Santos
(Coordenador)

(Coordenador)

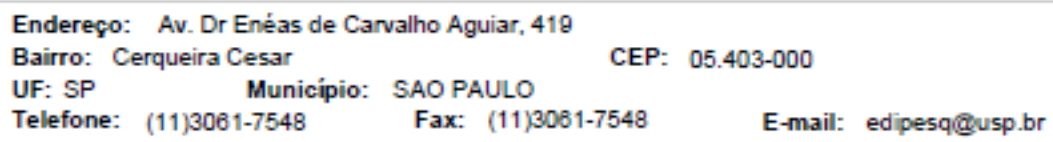




\section{APÊNDICE 1 - Procedimentos metodológicos da revisão integrativa}

As estratégias de busca específicas para cada base de dados foram descritas abaixo:

\begin{tabular}{|c|c|}
\hline Bases de dados & Estratégia \\
\hline PubMed & 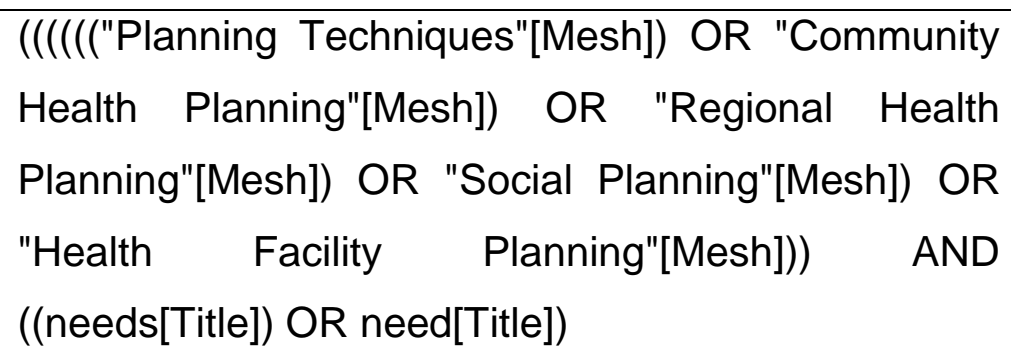 \\
\hline LILACS & $\begin{array}{l}\text { "Determinação de Necessidades de Cuidados de } \\
\text { Saúde" OR "Necessidades e Demandas de Serviços } \\
\text { de Saúde" [Descritor de assunto] and "Políticas, } \\
\text { Planejamento e Administração em Saúde" OR } \\
\text { "Planejamento em Saúde" OR "Planejamento em } \\
\text { Saúde Comunitária" OR "Apoio ao Planejamento em } \\
\text { Saúde" [Descritor de assunto] }\end{array}$ \\
\hline EVIPNet & ti:(Need OR needs) AND Planning \\
\hline JBI COnNECT & $\begin{array}{l}\text { Need(Title, Abstract or Keywords) OR Needs(Title, } \\
\text { Abstract or Keywords) }\end{array}$ \\
\hline SciELO & $\begin{array}{l}\text { necessidades [Palavras do título] or necessidade } \\
\text { [Palavras do título] and saúde [Todos os índices] }\end{array}$ \\
\hline Google A & Healt \\
\hline
\end{tabular}




\section{APÊNDICE 2 - Roteiro de entrevista individual}

1) Conte-me sobre sua trajetória profissional

2) Como é feito o planejamento em saúde? E em âmbito regional?

2) Qual a sua crítica sobre a atual forma de planejamento em saúde?

3) O que você entende por necessidades de saúde?

4) Qual a relevância para identificar necessidades para o planejamento?

5) Há dificuldades na captação de necessidades? Por que? 
APÊNDICE 3 - Questionário de caracterização do participante

Iniciais:

Ano de nascimento:

Sexo: ( ) Feminino ( ) Masculino

Município de nascimento:

Município de moradia:

( ) Graduação:

Ano de formação:

( ) Especialização:

( ) Mestrado:

( ) Doutorado:

( ) Pós-Doutorado:

( ) Outra:

Instituição em que trabalha atualmente:

Cargo:

Tempo nesta ocupação:

Áreas de atuação:

( ) Secretaria Estadual de Saúde

Área (s):

Cargo:

Período:

( ) Secretaria Municipal de Saúde

Área (s):

Cargo:

Período:

( ) Serviço de saúde

Área (s):

Cargo:

( )

Período:

( ) Outro:

Área (s):

Cargo:

Período: 


\section{APÊNDICE 4 - Caracterização dos especialistas}

1. Ano de nascimento:

2. Sexo: ( )Masculino ( )Feminino

3. Instituição em que trabalha:

4. Tipo de instituição:

( )Pública

( )Privada

( )Outra Qual:

5. Cargo ocupado:

6. Tempo nesta ocupação:

8. Graduação:

9. Ano da graduação:

10. Pós-Graduação:

( ) Especialização
( ) Mestrado
( ) Doutorado
( ) Pós-Doutorado
( ) Outra. Qual?

Área:

Área:

Área:

Área:

Área:

11. Experiência em:

( ) Formulação de políticas públicas

( ) Planejamento e gestão de serviços/ações de saúde

) Coordenação de serviços

) Necessidades sociais

( ) Realização de pesquisas científicas 


\section{APÊNDICE 5 - Termo de Consentimento Livre e Esclarecido}

\section{Registro dos esclarecimentos da pesquisadora aos participantes da pesquisa.}

Eu, Tatiana Yonekura, doutoranda da Universidade de São Paulo, orientada pela Prof. ${ }^{a}$ Dr. ${ }^{-}$Cassia Baldini Soares, venho convidá-lo (a) a participar da pesquisa intitulada "Necessidades de saúde: estratégias e instrumentos para o planejamento regional em saúde", a qual tem por objetivo construir um instrumento de captação de necessidades de saúde para subsidiar o planejamento estratégico regional.

Para tanto, você está sendo convidado a participar de uma entrevista gravada, que será conduzida pela pesquisadora no local e momento de sua escolha.

O estudo não acarretará em despesas financeiras, danos ou riscos diretos a você como participante. Destaca-se que o sigilo das informações e o anonimato serão garantidos.

A sua participação no estudo é voluntária, podendo deixá-lo a qualquer momento, se assim o desejar. Caso aceite participar, solicito a sua assinatura no item II deste documento e Ihe será entregue uma via do Termo de Consentimento.

A pesquisadora estará à disposição para esclarecer dúvidas no preenchimento deste termo e desde já agradece pela sua atenção e coloca-se à disposição para quaisquer esclarecimentos sobre a pesquisa.

Rubrica do participante da pesquisa

Rubrica do pesquisador 
O endereço do Comitê de Ética em Pesquisa (CEP) da Escola de Enfermagem é: Av. Dr. Enéas de Carvalho Aguiar, 419, telefone (11) 3061-7548, e-mail edipesq@usp.br. O contato com a pesquisadora pode ser realizado pelo telefone (11) 972515750 ou pelo e-mail tatiana.yonekura@usp.br

São Paulo, de de 2015.

\section{Tatiana Yonekura - pesquisadora}

\section{Registro e assinatura do participante da pesquisa}

$\mathrm{Eu}$, compreendo os objetivos desta pesquisa e concordo em participar de forma livre da mesma, entendendo que as informações serão utilizadas apenas para realização do estudo, que não sofrerei qualquer tipo de sanção ou prejuízo, caso desista de participar deste estudo.

Declaro, ainda, que ao ser convidado a participar desta pesquisa, todos os esclarecimentos foram prestados pela pesquisadora.

São Paulo, de de 2015.

Assinatura do participante 


\section{APÊNDICE 6 - Descrição das referências incluídas, por local do estudo, método e tipo de instrumento e variáveis}

\section{utilizadas}

\begin{tabular}{|c|c|c|c|}
\hline Referência & $\begin{array}{l}\text { Local do } \\
\text { estudo }\end{array}$ & Método e tipo de instrumento & Variáveis utilizadas \\
\hline $\begin{array}{c}\text { Vyas et al., } \\
2013\end{array}$ & EUA & $\begin{array}{l}\text { Questionário com } 41 \text { variáveis } \\
\text { Instrumento quantitativo }\end{array}$ & $\begin{array}{l}\text { Sociodemográficas (gênero, estado civil, paridade, naturalidade e renda familiar), } \\
\text { utilização da língua inglesa em casa, realização de exame físico no último ano, forma de } \\
\text { busca primária de informações de saúde, percepção da saúde, atividade física } \\
\text { (frequência) e tabagismo. }\end{array}$ \\
\hline $\begin{array}{l}\text { Gervasio, } \\
\text { McAloon, } \\
\quad 2013\end{array}$ & EUA & $\begin{array}{l}\text { Questionário dividido em cinco } \\
\text { categorias, de acordo com barreiras. A } \\
\text { partir da análise estatística das } \\
\text { barreiras, cada código de } \\
\text { endereçamento postal é classificado em } \\
\text { uma escala entre } 1 \text { (baixa necessidade) } \\
\text { e } 5 \text { (alta necessidade) para análise } \\
\text { geográfica. } \\
\text { Instrumento quantitativo }\end{array}$ & $\begin{array}{l}\text { 1. Barreiras relacionadas à renda: porcentagem de agregados familiares com mais de } 65 \\
\text { anos, menos de } 18 \text { anos, mulheres solteiras com filhos menores de } 18 \text { anos abaixo da } \\
\text { linha de pobreza. } 2 \text {. Barreira cultural: porcentagem de minorias populacionais, população } \\
\text { com mais de cinco anos que fala um idioma diferente do inglês como língua principal. } 3 . \\
\text { Barreira educacional: porcentagem da população com mais de } 25 \text { anos sem um diploma } \\
\text { do ensino médio. } 4 \text {. Barreira de seguro: porcentagem da população com } 16 \text { ou mais } \\
\text { anos, sem emprego, população sem seguro de saúde. } 5 \text {. Barreira de habitação: } \\
\text { porcentagem de familiares que alugam sua casa. }\end{array}$ \\
\hline $\begin{array}{l}\text { Barnett, } \\
2011\end{array}$ & EUA & $\begin{array}{l}\text { 1) um painel nacional de especialistas, } \\
\text { 2) entrevistas com informantes-chave } \\
\text { com os principais líderes de todo o } \\
\text { país, 3) desenvolvimento do relatório } \\
\text { desse processo, 4) o desenvolvimento } \\
\text { de um compêndio de ferramentas e } \\
\text { recursos para apoiar o processo de } \\
\text { melhoria da saúde da comunidade. } \\
\text { Sistemas de informação geográfica } \\
\text { Instrumento quanti-qualitativo }\end{array}$ & $\begin{array}{l}\text { Prevalência e/ou incidência de doenças, utilização de serviços, renda familiar, } \\
\text { desemprego, propriedade da residência, imóveis para alugar, detenções e atividades } \\
\text { criminosas, proximidade de fontes de alimentos saudáveis, proximidade de serviços } \\
\text { básicos e sociais, parques, instalações recreativas, espaços abertos, acesso ao } \\
\text { transporte público. }\end{array}$ \\
\hline
\end{tabular}




\begin{tabular}{|c|c|c|c|}
\hline $\begin{array}{l}\text { Dubowitz et } \\
\text { al., } 2011\end{array}$ & EUA & $\begin{array}{l}\text { Sistemas de informação geográfica } \\
\text { Instrumento quantitativo }\end{array}$ & $\begin{array}{l}\text { Acesso aos dados geográficos disponíveis (mapear dados sociodemográficos e fatores } \\
\text { de saúde, bem como, a localização e o alcance dos programas e serviços dos } \\
\text { departamentos de saúde local). Ex.: expectativa de vida, distribuição de fatores de risco } \\
\text { (pobreza, resíduos perigosos) e distribuição dos serviços de saúde (hospitais, clínicas e } \\
\text { prestadores de serviços); Recursos e capacidade técnica (recursos para o mapeamento, } \\
\text { recursos para análise, incluindo recursos humanos, financeiros e tecnológicos - } \\
\text { software); Estrutura Organizacional Responsiva (capacidade de utilizar as informações } \\
\text { geradas por meio de análises do GIS ou mapeamento para melhorar a prestação de } \\
\text { serviços e os esforços do programa). }\end{array}$ \\
\hline
\end{tabular}




\begin{tabular}{|c|l|l|l|}
\hline & & $\begin{array}{l}\text { Tuberculose Pulmonar Bacilífera, Coeficiente de Incidência de Leptospirose, Coeficiente } \\
\text { de Incidência de Meningite. }\end{array}$ \\
\hline QIIP, 2010 & Canadá & $\begin{array}{l}\text { Dados secundários, observações e } \\
\text { entrevistas. Nove categorias de } \\
\text { indicadores } \\
\text { Instrumento quanti-qualitativo }\end{array}$ & $\begin{array}{l}\text { 1. Utilização de serviços de saúde: internações hospitalares, hospitalizações evitáveis, } \\
\text { utilização de serviços de urgência e ambulatoriais, tempo de permanência hospitalar e } \\
\text { lista de espera. 2. Mortalidade: mortes por específicas causas. 3. Fatores de risco: } \\
\text { comportamentos de saúde, como fumar, beber, dieta e atividade física. 4. Questões } \\
\text { econômicas e políticas. 5. Privação: baixa renda, pobreza, insegurança alimentar. 6. } \\
\text { Demográfico: crescimento da população, estrutura da população e distribuição da } \\
\text { população. 7. Percepção dos envolvidos. 8. Indicadores comunitários: capital social e o } \\
\text { impacto na saúde. }\end{array}$ \\
\hline $\begin{array}{c}\text { Lee et al., } \\
2009\end{array}$ & EUA & $\begin{array}{l}\text { Grupo focal } \\
\text { Instrumento qualitativo }\end{array}$ & $\begin{array}{l}\text { Percepção sobre doenças físicas e mentais na comunidade em toda a população e nos } \\
\text { grupos vulneráveis, como crianças, adolescentes, idosos e mulheres. }\end{array}$ \\
\hline China & $\begin{array}{l}\text { 5 fases: 1 e 2) Questionário e grupo } \\
\text { focal; 3) Questionário e grupo focal; 4) } \\
\text { Questionário e grupo focal; 5) } \\
\text { Entrevista } \\
\text { Instrumento quanti-qualitativo }\end{array}$ & $\begin{array}{l}\text { 1 e 2) problemas de saúde, 3) fatores de risco comportamentais e ambientais, 4) fatores } \\
\text { que afetam o comportamento e 5) recursos em termos de política e organizações. }\end{array}$ \\
\hline $\begin{array}{c}\text { Thein et al., } \\
2009\end{array}$ & EUA & $\begin{array}{l}\text { Avaliação participativa rápida, por meio } \\
\text { de entrevistas com membros da } \\
\text { população e trabalhadores e dados } \\
\text { secundários } \\
\text { Instrumento quanti-qualitativo }\end{array}$ & $\begin{array}{l}\text { Nível 4: Saúde e Política Social. } \\
\text { Nível 3: Serviços relacionados à saúde: Serviços Educativos, Serviços de Saúde e } \\
\text { Serviços Sociais. } \\
\text { Nível 2: Dimensões ecológicas e sociais que influenciam a saúde: Ambiente físico, } \\
\text { socioeconômico, doença e incapacidades. } \\
\text { Nível 1: Comunidade e saúde: Perfil da Comunidade, organização comunitária e } \\
\text { Estrutura e capacidade da comunidade para corrigir as desigualdades }\end{array}$ \\
\hline
\end{tabular}




\begin{tabular}{|c|c|c|c|}
\hline $\begin{array}{l}\text { Kazda et } \\
\text { al., } 2009\end{array}$ & EUA & $\begin{array}{l}\text { Questionário com } 81 \text { questões e } \\
\text { utilização de sistemas de informação } \\
\text { geográfica } \\
\text { Instrumento quantitativo }\end{array}$ & $\begin{array}{l}\text { Idade, raça, gênero, educação, língua nativa, crise financeira, problemas para comprar } \\
\text { alimentos, cobertura de seguro de saúde (incluindo Medicare e Medicaid), percepção } \\
\text { sobre a saúde, acesso aos serviços de saúde, problemas com os filhos, como } \\
\text { imunização, e se conseguiu resolvê-los, doenças relatadas, uso de álcool e tabaco, uso } \\
\text { de cinto de segurança nos automóveis, criminalidade, comportamentos agressivos do } \\
\text { parceiro. }\end{array}$ \\
\hline $\begin{array}{l}\text { Negri Filho, } \\
\text { Achury, } \\
2008\end{array}$ & Colômbia & $\begin{array}{l}\text { Dados secundários, identificação de } \\
\text { atores institucionais e sociais, e } \\
\text { discussões em grupo ou plenárias. A } \\
\text { estrutura do instrumento tem cinco } \\
\text { categorias. } \\
\text { Instrumento quanti-qualitativo }\end{array}$ & $\begin{array}{l}\text { 1. Caracterização do território: limites, perfil da população, etnia, gênero, condições } \\
\text { socioeconômicas, meio ambiente, . 2. Distribuição da população por ciclo no território, } \\
\text { pela posição ocupacional, patrimônio material representado pela posse do domicílio. } 3 \text {. } \\
\text { Dados gerais da população no território pela posição ocupacional. } 4 \text {. Dados coletivos da } \\
\text { população no território representado na garantia de direitos: emprego - renda, segurança } \\
\text { social, assistência social, educação, habitação, nutrição e segurança alimentar, } \\
\text { ambientes seguros, deficiência, cultura, lazer e desporto, serviços de saúde, sexualidade } \\
\text { e reprodução; participação e organização, o grau de defesa e representação nas áreas } \\
\text { de definição e desenho de políticas públicas. } 5 \text {. Caracterização das possibilidades de } \\
\text { desenvolvimento da autonomia das populações no território, considerando os impactos } \\
\text { físicos, psicológicos e sociais das restriççes avaliadas anteriormente. }\end{array}$ \\
\hline $\begin{array}{l}\text { Granados, } \\
\text { Aguilera, } \\
\text { Martín, } \\
2007\end{array}$ & Espanha & $\begin{array}{l}\text { Composição de um índice de } \\
\text { necessidades de saúde regionais, } \\
\text { utilizando modelos de regressão } \\
\text { Instrumento quantitativo }\end{array}$ & $\begin{array}{l}\text { Fatores objetivos condicionantes da saúde: dias por ano de ausência no trabalho, } \\
\text { doenças diagnosticadas. Fatores subjetivos condicionantes da saúde: estado subjetivo } \\
\text { da saúde, limitação pessoal. Outros fatores condicionantes da saúde: idade dos } \\
\text { respondentes menos a média da amostra, gênero, presença de incapacidade, estado } \\
\text { civil, número de pessoas que vivem juntas, tamanho da residência, uso de tabaco, } \\
\text { número de cigarros/dia, uso de álcool, exercício físico, principal fonte de recursos } \\
\text { econômicos, escolaridade, seguro médico. Local de residência. Cinco variáveis sobre } \\
\text { utilização de serviços: consumo de medicamentos, utilização de serviços médicos e de } \\
\text { enfermagem, utilização de análises diagnósticas, internações hospitalares e intervenções } \\
\text { cirúrgicas. }\end{array}$ \\
\hline
\end{tabular}




\begin{tabular}{|c|c|c|c|}
\hline $\begin{array}{l}\text { Novins et } \\
\text { al., } 2004\end{array}$ & EUA & $\begin{array}{l}\text { Grupo focal para identificar percepções } \\
\text { da comunidade sobre as dificuldades } \\
\text { das famílias e sobre a disponibilidade, } \\
\text { acessibilidade e aceitabilidade de } \\
\text { serviços existentes. Dados secundários } \\
\text { e de pesquisas científicas } \\
\text { Instrumento quanti-qualitativo }\end{array}$ & $\begin{array}{l}\text { Características da comunidade (contexto histórico e cultural, sociodemográfico - trabalho, } \\
\text { renda e pobreza - e de saúde), números de utilização de serviços de programas } \\
\text { estaduais, como Medicaid, e informações de organizações de serviços, tais como } \\
\text { programas de comportamento de saúde, escolas, agências de serviços sociais, e do } \\
\text { direito }\end{array}$ \\
\hline WHO, 2001 & Dinamarca & $\begin{array}{l}\text { Dados quantitativos apresentados em } \\
\text { mapas. Entrevistas } \\
\text { Instrumento quanti-qualitativo }\end{array}$ & $\begin{array}{l}\text { 1. Área geográfica, número de pessoas, idade, gênero, raça, religião, tendências da } \\
\text { população, 2. Mortalidade por idade, gênero e causa da morte, morbidade, qualidade de } \\
\text { vida, uso de serviço, desigualdades de saúde, fatores locais que afetam a saúde, } \\
\text { trabalho e emprego, doenças ocupacionais, satisfação com o trabalho, pobreza e renda, } \\
\text { meio ambiente, poluição, esgotamento sanitário, domicílio, transporte, suporte social, } \\
\text { migração, lazer. 1. Quais são as principais características da população? } \\
\text { 2. Qual é o estado de saúde das pessoas? } \\
\text { 3. Fatores Que locais estão a afetar a sua saúde e qual o impacto que eles têm (bom } \\
\text { e ruim)? } \\
\text { 4. Que serviços estão atualmente a ser fornecido? } \\
\text { 5. O que as pessoas locais veem como suas necessidades de saúde } \\
\text { 6. Quais são as prioridades nacionais e locais para a saúde? }\end{array}$ \\
\hline
\end{tabular}




\begin{tabular}{|c|c|c|c|}
\hline $\begin{array}{c}\text { Murray, } \\
\text { Graham, } \\
1995\end{array}$ & Escócia & $\begin{array}{l}\text { Avaliação participativa rápida } \\
\text { (documentos existentes sobre o bairro, } \\
\text { entrevistas com uma série de } \\
\text { informantes e observações diretas } \\
\text { sobre o bairro), pesquisa postal, análise } \\
\text { de estatísticas rotineiramente } \\
\text { disponíveis, e compilação informações } \\
\text { locais (registros médicos, relatórios } \\
\text { anuais) } \\
\text { Instrumento quanti-qualitativo }\end{array}$ & $\begin{array}{l}\text { Avaliação participativa: Base da pirâmide - Composição da comunidade: Organização e } \\
\text { estrutura, perfil e capacidade para agir. 10 andar: Fatores socioeconômicos: dados } \\
\text { socioeconômicos, de doenças e deficiências. } 2^{\circ} \text { andar: serviços: educação, saúde e } \\
\text { social - existência, cobertura, acessibilidade, aceitação e identificação de áreas com } \\
\text { necessidade de mudanças. Topo: políticas nacionais, regionais e locais de saúde. } \\
\text { Pesquisa postal: doenças crônicas e agudas, percepção sobre a saúde e necessidade } \\
\text { de serviços, uso de serviços nos últimos seis meses. Análise de estatísticas: idade, } \\
\text { causas de mortes, atendimentos ambulatoriais e hospitalares, diagnóstico na alta } \\
\text { hospitalar, procedimentos hospitalares, readmissões hospitalares em um ano, dados } \\
\text { obstétricos. Dados locais: doenças crônicas, prescrições medicamentosas, uso de } \\
\text { recursos, como laboratório e pronto-socorro, doença agudas no último ano, contato com } \\
\text { profissional de saúde, dados de promoção da saúde, como tabaco, álcool e vacinação. }\end{array}$ \\
\hline
\end{tabular}




\section{APÊNDICE 7 - Comentários dos especialistas nos campos de inclusão, modificação ou exclusão do instrumento de validação}

\begin{tabular}{|c|c|c|c|}
\hline \multicolumn{2}{|c|}{ Módulo/Etapa } & Comentário & Alteração \\
\hline \multirow{4}{*}{\multicolumn{2}{|c|}{ Introdução }} & $\begin{array}{l}\text { Na página } 07 \text {, o penúltimo parágrafo não está } \\
\text { claro para a ideia proposta. }\end{array}$ & Modificaria \\
\hline & & Deixaria a parte introdutória mais sintética & Modificaria \\
\hline & & Equidade no SUS & Incluiria \\
\hline & & Contextualizar melhor necessidades radicais & Modificaria \\
\hline \multirow[t]{11}{*}{ Módulo A } & Etapa 1 & MT ,MAPA E INSS & Incluiria \\
\hline & Etapa 2 & População ativa e não ativa outras & Incluiria \\
\hline & Etapa 2 & Tive dúvida sobre a questão da aposentada & Modificaria \\
\hline & Etapa 2 & $\begin{array}{l}\text { Abrir campo para "outros", de modo a admitir } \\
\text { categorias sócio-ocupacionais emergentes, a } \\
\text { exemplo de assistentes religiosos, } \\
\text { "cuidadores", "facilitadores" na escolarização, } \\
\text { etc. }\end{array}$ & Incluiria \\
\hline & Etapa 3 & $\begin{array}{l}\text { Incluiria uma discussão para municípios que } \\
\text { não possuem estatístico. A variância e um } \\
\text { julgamento estatístico de difícil entendimento. } \\
\text { Como trabalhar divisão do trabalho, ou } \\
\text { categorias de trabalhadores com \% se } \\
\text { categorias?? }\end{array}$ & Incluiria \\
\hline & Etapa 3 & $\begin{array}{l}\text { Inseriria possíveis fontes de dados para coletar } \\
\text { essas informações. }\end{array}$ & Incluiria \\
\hline & Etapa 3 & $\begin{array}{l}\text { Explicação mais clara sobre análise de } \\
\text { correspondência e de cluster }\end{array}$ & Modificaria \\
\hline & Etapa 3 & $\begin{array}{l}\text { Incluir definição/especificação do que seria } \\
\text { popular }\end{array}$ & Incluiria \\
\hline & Etapa 4 & $\begin{array}{l}\text { Incluiria o mapeamento sem programa } \\
\text { computacional. Não é uma realidade dos } \\
\text { municípios brasileiros, a utilização de } \\
\text { georreferenciamento. }\end{array}$ & Incluiria \\
\hline & Etapa 4 & $\begin{array}{l}\text { Essa etapa não necessita de apoio de } \\
\text { profissional que possua manejo nesses } \\
\text { programas? Se sim, apontar }\end{array}$ & Incluiria \\
\hline & Etapa 4 & $\begin{array}{l}\text { Incluir algumas sugestões de programas de } \\
\text { processamento de dados espaciais }\end{array}$ & Incluiria \\
\hline \multirow[t]{2}{*}{ Módulo B } & Etapa 1 & $\begin{array}{l}\text { Incluiria as metodologias participativas como } \\
\text { possibilidade de referências legítimas da } \\
\text { historicidade dos município. }\end{array}$ & Incluiria \\
\hline & Etapa 1 & Informar a evolução dos dados & Incluiria \\
\hline
\end{tabular}




\begin{tabular}{|c|c|c|c|}
\hline & Etapa 1 & EPI & Incluiria \\
\hline & Etapa 1 & $\begin{array}{l}\text { Colocaria referências bibliográficas por } \\
\text { metodologia }\end{array}$ & Modificaria \\
\hline & Etapa 1 & $\begin{array}{l}\text { Nos materiais necessários, entrevistas com } \\
\text { moradores mais antigos }\end{array}$ & Incluiria \\
\hline & Etapa 2 & $\begin{array}{l}\text { É necessário explicitar o que é o setor } \\
\text { secundário e quais as atividades estão } \\
\text { incluídas nesta denominação. }\end{array}$ & Incluiria \\
\hline & Etapa 2 & Possíveis fontes de dados & Incluiria \\
\hline & Etapa 2 & Definir Urbano e rural & Incluiria \\
\hline & Etapa 2 & Só IBGE? & Modificaria \\
\hline & Etapa 2 & $\begin{array}{l}\text { Além da presença de indústrias, dos serviços, } \\
\text { formal e informal. }\end{array}$ & Incluiria \\
\hline & Etapa 3 & $\begin{array}{l}\text { Explicitar melhor o que quer dizer com } \\
\text { "geograficamente", entendi que era para } \\
\text { apontar as informações em um mapa, mas } \\
\text { fiquei com duvida. }\end{array}$ & Modificaria \\
\hline & Etapa 3 & $\begin{array}{l}\text { Área degradada, retirada de areia, } \\
\text { saneamento básico }\end{array}$ & Incluiria \\
\hline & Etapa 3 & Migração rural e os de Veranista & Incluiria \\
\hline & Etapa 3 & Como vai fazer isso & Modificaria \\
\hline & Etapa 3 & Incluir coleta seletiva (recicláveis, orgânicos) & Incluiria \\
\hline & Etapa 4 & Condomínios fechados, minha casa minha vida & Incluiria \\
\hline & Etapa 4 & Acampamentos Nômades, Ciganos e outros & Incluiria \\
\hline & Etapa 4 & $\begin{array}{l}\text { Detalhar aspectos que definem os } \\
\text { assentamentos como precários em novo } \\
\text { Quadro ou no Apêndice. }\end{array}$ & Incluiria \\
\hline Módulo C & Etapa 1 & $\begin{array}{l}\text { Uma melhor explicação sobre as fontes de } \\
\text { dados a serem pesquisadas para obtenção } \\
\text { destes dados }\end{array}$ & Modificaria \\
\hline & Etapa 1 & $\begin{array}{l}\text { As informações acerca dos benefícios advindos } \\
\text { do trabalho seriam coletadas onde? }\end{array}$ & Modificaria \\
\hline & Etapa 1 & $\begin{array}{l}\text { Quais os tipos de atividades e operações } \\
\text { insalubres. }\end{array}$ & Incluiria \\
\hline & Etapa 1 & Descrever significados das siglas & Incluiria \\
\hline & Etapa 1 & $\begin{array}{l}\text { Incluir o BPC (benefício de prestação } \\
\text { continuada). Muitos idosos que não são } \\
\text { aposentados recebem esse benefício. Critérios } \\
\text { para obtenção do benefício: } 65 \text { anos ou mais e } \\
\text { deficientes que tenham renda menor que } 1 / 4 \\
\text { do SM por pessoa do grupo familiar }\end{array}$ & Incluiria \\
\hline & Etapa 2 & $\begin{array}{l}\text { Forma de armazenamento dos alimentos. E } \\
\text { eletrodomésticos presente no domicilio. }\end{array}$ & Incluiria \\
\hline & Etapa 2 & $\begin{array}{l}\text { O IBGE não apresenta uma categorização } \\
\text { desses dados? }\end{array}$ & Modificaria \\
\hline
\end{tabular}




\begin{tabular}{|c|c|c|c|}
\hline & Etapa 2 & $\begin{array}{l}\text { A explicação - acesso a microcomputador com } \\
\text { acesso a internet está igual ao item acesso a } \\
\text { internet }\end{array}$ & Modificaria \\
\hline & Etapa 2 & $\begin{array}{l}\text { a) Forma de transporte coletivo (ônibus, trem, } \\
\text { vans, motos, etc.), com acessibilidade. } \\
\text { b) Violência (agressões, roubos, etc.) }\end{array}$ & Incluiria \\
\hline & Etapa 3 & $\begin{array}{l}\text { O tipo de provedor da família, o tempo de } \\
\text { lazer de cada membro da família, presença de } \\
\text { presidiários na família. }\end{array}$ & Incluiria \\
\hline & Etapa 3 & Essa informação consta nos dados do IBGE? & Modificaria \\
\hline & Etapa 3 & Incluir faixa etária & Incluiria \\
\hline & Etapa 3 & $\begin{array}{l}\text { Modificar tempo de moradia no município } \\
\text { para tempo médio de moradia no município }\end{array}$ & Modificaria \\
\hline & Etapa 3 & Gênero e sexo. & Modificaria \\
\hline & Etapa 4 & $\begin{array}{l}\text { O índice caracterizando os tipos de violência, } \\
\text { como doméstica, criança, violência sexual e } \\
\text { em todo ciclo vital. }\end{array}$ & Incluiria \\
\hline & Etapa 4 & $\begin{array}{l}\text { Violência contra a mulher, Acidentes por } \\
\text { causas externas, Ocorrências por drogas. }\end{array}$ & Incluiria \\
\hline & Etapa 4 & $\begin{array}{l}\text { Trocaria perfil de saúde por perfil de } \\
\text { adoecimento }\end{array}$ & Modificaria \\
\hline & Etapa 4 & $\begin{array}{l}\text { Idosos com idade igual ou superior a } 80 \text { anos } \\
\text { (número de idosos muito idosos está } \\
\text { aumentando - demandam cuidado em saúde e } \\
\text { social, são mais frágeis, etc.). }\end{array}$ & Incluiria \\
\hline & Etapa 4 & $\begin{array}{l}\text { Ao invés de taxas, substituir pelo método da } \\
\text { auto-referência dos problemas de saúde, cf } \\
\text { Pesquisa Nacional de Saúde } 2013 .\end{array}$ & Modificaria \\
\hline Módulo D & Assistência social & Área de abrangência territorial & Incluiria \\
\hline & Assistência social & População sob cobertura do serviço & Excluiria \\
\hline & Assistência social & $\begin{array}{l}\text { Incluiria a especificação de alguns serviços } \\
\text { sociais (centro dia, república para idosos, } \\
\text { centros de convivência, ILPI) }\end{array}$ & Incluiria \\
\hline & Assistência social & Administração regional ou distrital & Incluiria \\
\hline & Educação & $\begin{array}{l}\text { Escola profissionalizante pública e privada e } \\
\text { Educação para Adultos, Tipo de acesso } \\
\text { disponível. }\end{array}$ & Incluiria \\
\hline & Educação & $\begin{array}{l}\text { Seria importante verificar os serviços de } \\
\text { "creches" particulares? }\end{array}$ & Incluiria \\
\hline & Segurança pública & $\begin{array}{l}\text { Fundação casa masculino e Fundação casa } \\
\text { feminino. }\end{array}$ & Incluiria \\
\hline & Segurança pública & IML & Incluiria \\
\hline & Lazer e cultura & Clubes Sociais & Incluiria \\
\hline & Lazer e cultura & Parques públicos & Incluiria \\
\hline
\end{tabular}




\begin{tabular}{|c|c|c|c|}
\hline & Lazer e cultura & Centro de convivência para idosos & Incluiria \\
\hline & Saúde & Incluiria a vulnerabilidade programática & Incluiria \\
\hline & Saúde & $\begin{array}{l}\text { Ambulância - } 3 \text { tipos, públicas e privadas, } \\
\text { Farmácia Popular, Consultórios de Rua }\end{array}$ & Incluiria \\
\hline & Saúde & $\begin{array}{l}\text { Centro de convivência para idosos se } \\
\text { enquadra nos serviços sociais. Incluir sigla de } \\
\text { NASF }\end{array}$ & Modificaria \\
\hline & Transporte & As condições dos transportes e das rodovias. & Incluiria \\
\hline & Transporte & $\begin{array}{l}\text { Transporte público urbano (ônibus, metrô, } \\
\text { transporte para deficientes, ciclovias) }\end{array}$ & Incluiria \\
\hline & Transporte & $\begin{array}{l}\text { Não percebi a relevância no contexto do } \\
\text { território. Ver observação sobre condições de } \\
\text { vida. Se for o caso de manter, definir como } \\
\text { sistema de transporte público municipal em } \\
\text { termos de acessibilidade. }\end{array}$ & Excluiria \\
\hline \multirow[t]{9}{*}{ Módulo E } & Etapa 1 & Conselhos municipais? & Modificaria \\
\hline & Etapa 1 & Direitos civis & Modificaria \\
\hline & Etapa 3 & Redação (reivindicados) & Modificaria \\
\hline & Etapa 3 & $\begin{array}{l}\text { Identificar os problemas para os quais os } \\
\text { grupos organizados reivindicam soluções }\end{array}$ & Modificaria \\
\hline & Etapa 4 & Coluna para as ações & Incluiria \\
\hline & Etapa 4 & $\begin{array}{l}\text { No quadro de fontes de dados eu colocaria } \\
\text { quais itens do instrumento estão relacionados } \\
\text { a eles. }\end{array}$ & Modificaria \\
\hline & Etapa 4 & Direitos civis, GLBT & Incluiria \\
\hline & Etapa 4 & $\begin{array}{l}\text { O Quadro deve estar abaixo e cada item a } \\
\text { medida que se identifica o objetivo }\end{array}$ & Modificaria \\
\hline & Etapa 4 & $\begin{array}{l}\text { Identificar as propostas de superação, } \\
\text { relacionadas aos problemas para os quais se } \\
\text { reivindicam soluções, assim como as ações } \\
\text { realizadas }\end{array}$ & Incluiria \\
\hline
\end{tabular}




\begin{tabular}{|c|c|c|}
\hline Gerais & $\begin{array}{l}\text { O instrumento está bem elaborado e de fácil } \\
\text { preenchimento, adequado aos objetivos a que } \\
\text { se propõe. Contudo o instrumento não está } \\
\text { aberto à escuta da população e ao } \\
\text { encaminhamento conjunto de ações. Fiz } \\
\text { sugestões neste sentido, ainda que limitadas } \\
\text { pelo caráter do instrumento. Por outro lado, o } \\
\text { informal está ausente, desde as } \\
\text { autoconstruções até formas de lazer próprias. } \\
\text { Também não estão incluídas as atividades } \\
\text { "comunitárias" que funcionam para suprir } \\
\text { carências sociais no âmbito do direito e, } \\
\text { portanto, das responsabilidades do Estado, ou } \\
\text { complementarmente, dada a insuficiência da } \\
\text { atenção pública, ou ainda as mediações } \\
\text { políticas clientelísticas. O argumento de que a } \\
\text { ausência do Estado indica o informal tem } \\
\text { sentido, mas não permite identificar quais as } \\
\text { alternativas que a preenchem. É importante } \\
\text { dispor de um tópico para "Observações gerais" } \\
\text { anotadas à mão que não possam estar } \\
\text { referidas no instrumento, a exemplo da } \\
\text { segurança pública "informal". }\end{array}$ & Modificaria \\
\hline
\end{tabular}


Apêndice 8 - Versão final do instrumento 


\section{INSTRUMENTO DE \\ LEVANTAMENTO DE \\ NECESSIDADES DE SAÚDE PARA \\ SUBSIDIAR O PLANEJAMENTO \\ REGIONAL EM SAÚDE}
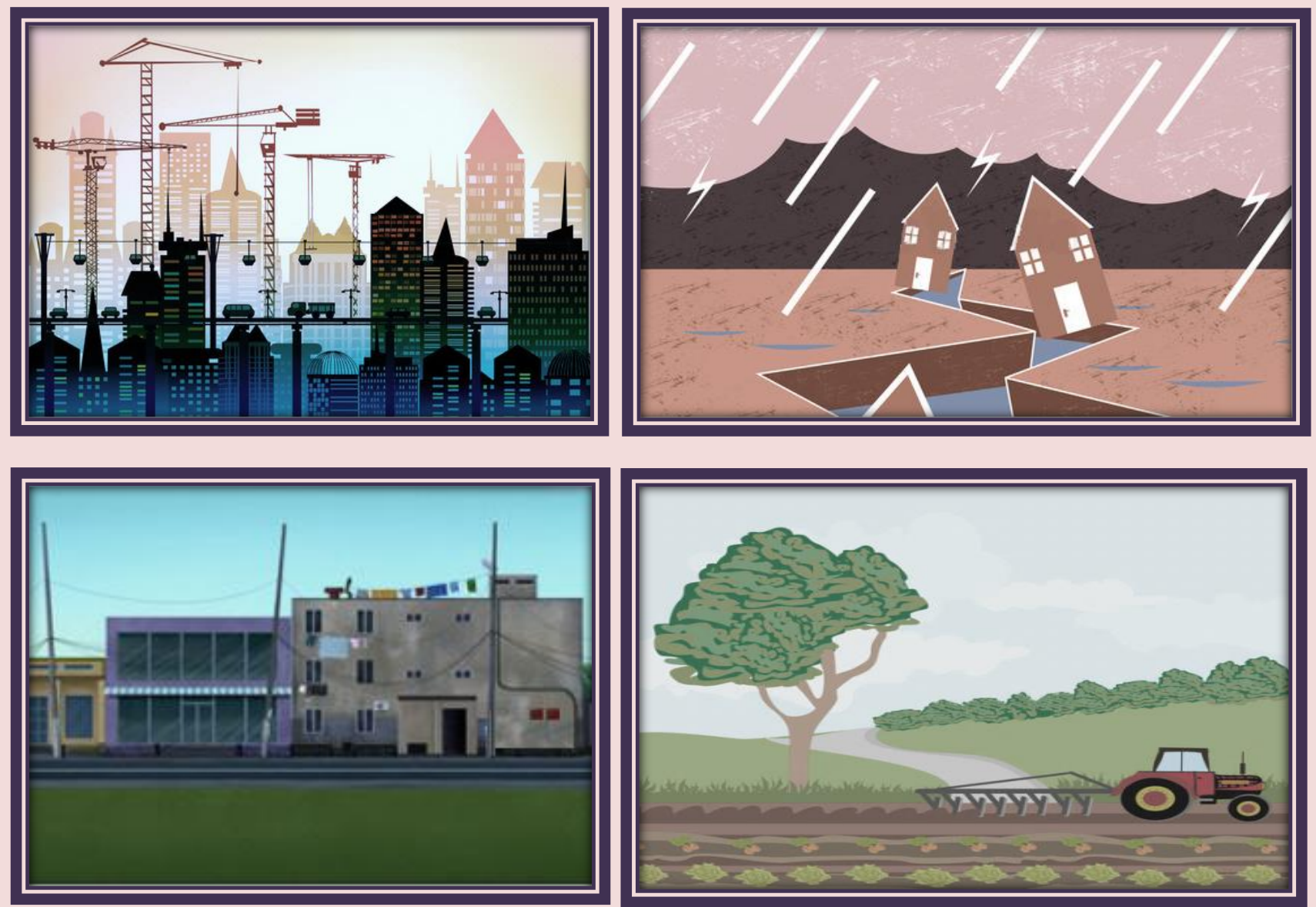


\section{Sumário}

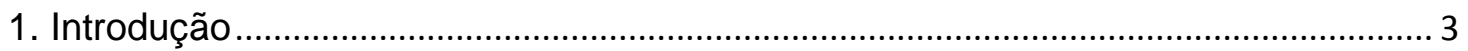

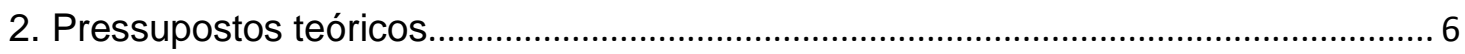

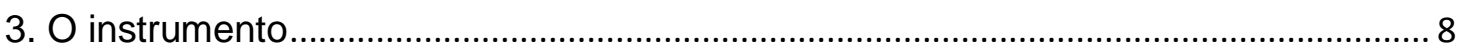

Módulo A - Identificação das classes sociais e distribuição espacial no território.... 9

Módulo B - Caracterização do território ...................................................................... 13

Módulo C - Necessidades de reprodução social......................................................... 16

Módulo D - Necessidades de presença do Estado...................................................... 21

Módulo E - Necessidade de participação política .......................................................... 27

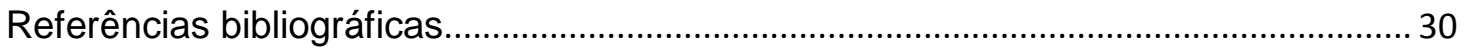




\section{Introdução}

O planejamento regional em saúde toma como ponto de partida 0 reconhecimento de necessidades de saúde de grupos sociais que vivem em territórios onde se produz a vida social. Dessa forma, identificar necessidades, reconhecendo as características sociais do território e as desigualdades que alberga, constitui etapa fundamental para o planejamento em saúde.

O governo federal orienta que o planejamento e a execução de ações e serviços de saúde sejam realizados regionalizadamente, a partir das necessidades dos municípios (Brasil, 2011). Nessa perspectiva, a federação define a região de saúde como a base territorial do planejamento, composta por municípios vizinhos, em espaço geográfico delimitado, a partir das características econômicas, sociais culturais, e de redes de comunicação e infraestrutura de transportes compartilhados (Brasil, 2011).

A tarefa de propor um instrumento para o planejamento em saúde, baseado em necessidades de saúde, demandou buscar em autores da geografia social e da epidemiologia crítica alguns conceitos-chave. Dessa forma, a partir de Milton Santos (2007) se capturou o conceito de território como espaço particular, dinâmico, histórico, social e desigual, ocupado diferentemente em função das distintas classes sociais em que se divide a sociedade; e, a partir de Lombardi et al. (1988) e Santos (2013), considerou-se a abordagem de classe social, proposta no âmbito da epidemiologia, coerente à explicação teórica que coloca o processo saúde-doença na condição de processo socialmente determinado (Laurel, 1989), no contexto internacional e principalmente no Brasil, que apresenta históricas desigualdades sociais regionais e intra-regionais. Breilh e Granda (1989) também apoiam essa construção, mostrando que as desigualdades sociais em saúde são produzidas pela inserção social desigual dos indivíduos nas classes sociais, o que determina as diferentes possibilidades de acesso à riqueza social, à propriedade e ao poder.

Nesse sentido, ignorar que a sociedade é dividida em classes constitui um dos maiores problemas para entender o território e a pobreza urbana (Santos, 2009). Explicações falsas, parciais e/ou simplistas, como a de que "o pobre pode melhorar

\footnotetext{
"Esse instrumento é produto da Tese de Doutorado de Tatiana Yonekura, Pós-Graduanda do Programa de Pós-Graduação em Enfermagem (PPGE) da Escola de Enfermagem da Universidade de São Paulo (EEUSP) e pesquisadora do Laboratório de Inovação em Planejamento, Gestão, Avaliação e Regulação de Políticas, Sistemas, Redes e Serviços de Saúde do Hospital do Coração (LIGRESS/HCor).
} 
sua situação, através do esforço individual, da iniciativa pessoal ou da educação" e a de que a pobreza constitui questão isolada ou situação transitória são também encontradas na literatura e se multiplicam pelos meios de comunicação de massa. Tais ideologias dificultam explicações coerentes e críticas sobre a pobreza urbana (Santos, 2009, p.20) e direcionam o planejamento em saúde para caminhos distorcidos.

O planejamento em saúde é desvirtuado principalmente pela explicação dominante sobre saúde-doença, que coloca a atenção às doenças já instaladas em lugar central. Os problemas de saúde não são discutidos pelas suas raízes, mas pelas suas consequências, evidenciadas a partir de indicadores de morbidade e mortalidade.

De acordo com Nakano e Koga (2013), é preciso aprofundar a análise dos problemas de saúde, já que é insuficiente relatar o número e a porcentagem de indivíduos com uma determinada doença. Dadas as diferenças de classe, é necessário reconhecer em que território esses indivíduos trabalham e vivem, suas condições socioeconômicas e acessibilidade aos serviços.

A repercussão das desigualdades sociais sobre o processo saúde-doença é claramente evidenciável pela distribuição epidemiológica das doenças. Conjunto expressivo da literatura epidemiológica, ainda que partindo de explicações distintas quanto ao processo saúde-doença, mostra resultados semelhantes quanto à distribuição social das doenças.

Muitas causas de doenças se relacionam com a insalubridade, precariedade e exclusão, em relação aos acessos a políticas públicas existentes nos locais de moradia e nos espaços geossociais (Nakano, Koga, 2013, p.163).

Assim, o planejamento em saúde, que se propõe a ter como eixo as necessidades de saúde, não pode desconhecer as relações de determinação entre trabalho, vida e saúde, que conformam os perfis epidemiológicos das classes sociais (Breilh, 1991). Em função da divisão social em classes, há diferentes perfis de reprodução social (condições de trabalho e vida) que determinam os perfis de saúde e doença (Viana, Soares, Campos, 2013). Nessa perspectiva, o referencial da Determinação Social discute o caráter histórico-social do processo saúde-doença, visando a superação da limitação da análise de causas e relação entre variáveis epidemiológicas (Rocha, David, 2015). 
Nos estudos epidemiológicos, o arcabouço teórico-metodológico da epidemiologia crítica oferece os fundamentos para investigar o caráter social do processo saúde-doença, tendo a desigualdade social como um dos seus principais objetos de intervenção (Breilh, 2006).

Planejamento baseado nas necessidades envolve ainda a definição do que (serviços ou ações) e para quem (toda população ou população vulnerável). São duas indagações importantes que, a depender das respostas, propõem ações totalmente diferentes, já que há diversos interesses e sujeitos envolvidos (Rivera, Artmann, 2012).

A universalidade, um dos princípios fundamentais do SUS, determina que todos têm direito de acesso ao sistema de saúde, às ações e serviços de saúde. Dessa forma, o princípio da universalidade impõe a inclusão das necessidades sociais de todos, como direito (Negri Filho, 2013).

Segundo Rivera e Artmann (2012, p.12) o planejamento deve ser entendido como "um processo vinculado fortemente ao contexto histórico-social no qual se inserem os problemas e os atores que interagem no enfrentamento desses problemas". A utilização de ferramentas operacionais é útil para incidir nas causas dos problemas em uma realidade complexa, com um olhar estratégico e situacional (Brasil, 2015).

Em entrevista para Huertas (1996, p.12), Carlos Matus ressalta o potencial da visão de futuro do planejamento estratégico situacional:

Planejar significa pensar antes de agir, pensar sistematicamente, com método; explicar cada uma das possibilidades e analisar suas respectivas vantagens e desvantagens; propor-se objetivos. É projetar-se para o futuro, porque as ações de hoje terão sido eficazes, ou ineficazes, dependendo do que pode acontecer amanhã e do que pode não acontecer. O planejamento é a ferramenta para pensar e criar o futuro (Huertas, 1996, p.12).

Assim, de acordo com o Ministério da Saúde, os desafios atuais do SUS para uma resposta oportuna e efetiva às necessidades de saúde exigem aprimorar estruturas instrumentais e construir novos processos e novas ferramentas de apoio ao planejamento (Brasil, 2015).

O instrumento aqui apresentado teve sua construção fundamentada, em geral, nos pressupostos teóricos da Saúde Coletiva e, particularmente, nos fundamentos da Epidemiologia Crítica. Reconhece-se que a satisfação das necessidades de saúde é um dos direitos fundamentais dos brasileiros e dever do 
Estado, expressas na Constituição Federal de 1988 e pelo movimento da Reforma Sanitária Brasileira. Reconhece-se também que necessidades de saúde são necessidades sociais visto que estão na rede de determinação social.

\section{Pressupostos teóricos}

A Figura 1 sintetiza os pressupostos teóricos desta construção.

Figura 1 - Pressupostos teóricos do instrumento de levantamento de necessidades de saúde para o planejamento em saúde.
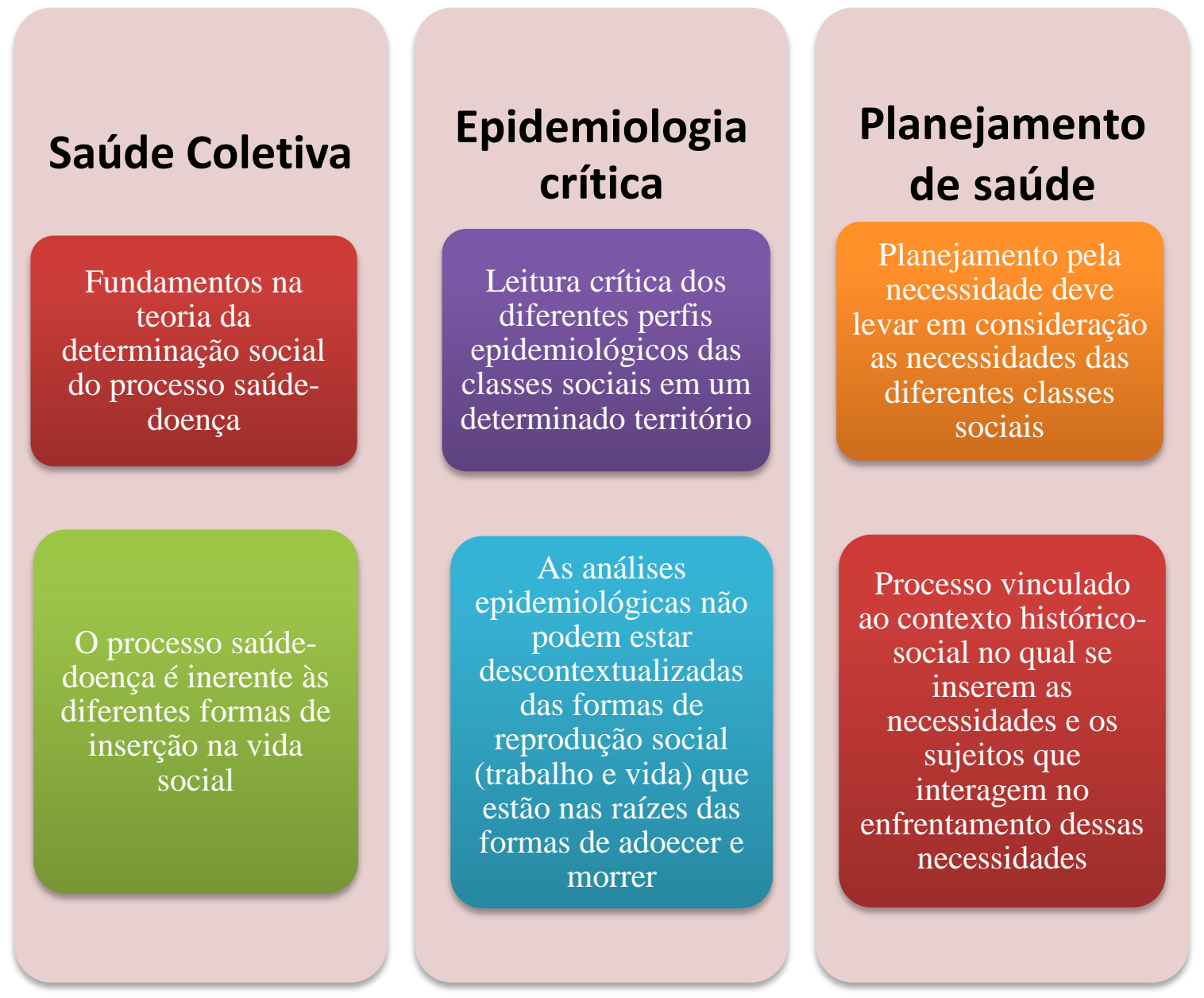

Fontes: Laurell (1989); Castiel, Rivera (1985); Paim, Almeida Filho (1998); Breilh e Granda (1989); Rivera e Artmann (2012); Negri Filho (2013); Nakano, Koga (2013). 
O conceito de necessidades para o planejamento regional em saúde foi sintetizado abaixo:

Figura 2 - Conceito de necessidades de saúde.

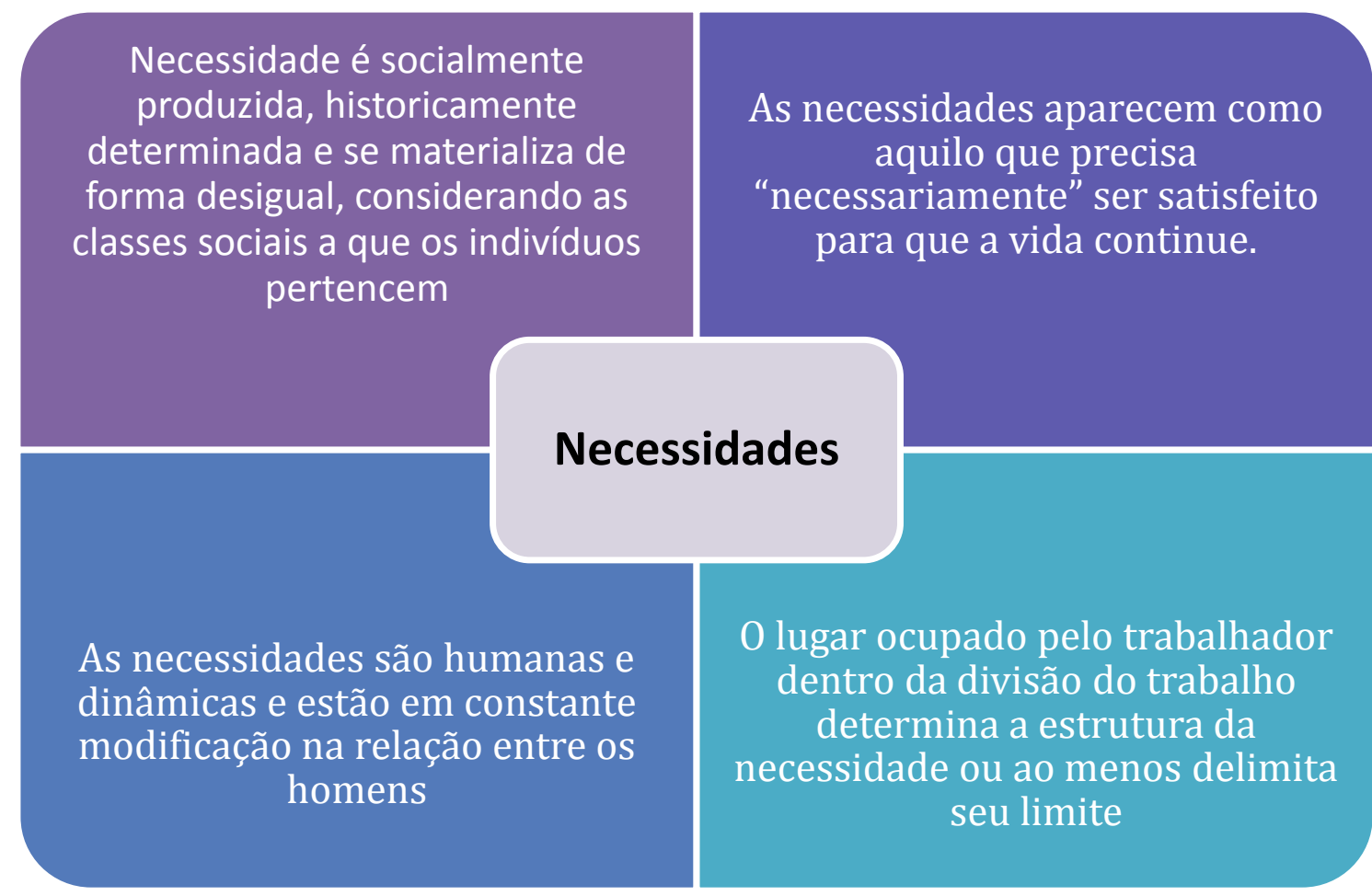

Fonte: Marx, Engels (1977); Heller (1978); Stotz (1991); Mendes-Gonçalves (1992), Campos, Mishima (2005); Silva, Batistella, Gomes (2007).

Campos e Mishima (2005) propuseram três categorias para a análise das necessidades de saúde, que basearam a estrutura deste instrumento:

- Necessidades de reprodução social (sobrevivência dos indivíduos e famílias que compõem as classes sociais), condições de trabalho e vida, que constituem o âmbito da determinação do processo saúde-doença);

- Presença do Estado (responsabilidade dos governos pela garantia de acesso dos indivíduos e famílias das diferentes classes sociais a serviços públicos e a direitos universais);

- Necessidade de participação política (grupos organizados da sociedade civil que lutam pela garantia dos direitos dos interessados). 


\section{3. $O$ instrumento}

Objetivo: subsidiar o levantamento de necessidades de saúde de um território para o planejamento regional em saúde.

Público-alvo: gestores, planejadores e técnicos estaduais e municipais, pesquisadores e demais interessados na temática.

Processo de construção deste instrumento: (1) Análise da literatura nacional e internacional sobre identificação de necessidades; (2) Entrevistas com gestores estaduais e municipais para compreender as dificuldades atuais do planejamento baseado nas necessidades de saúde para ser incorporado no material; (3) Categorização do conteúdo; e (4) Validação de conteúdo por especialistas da área.

O instrumento foi dividido em cinco módulos:

* Módulo A - Identificação das classes sociais: utilização de metodologia para identificação das classes sociais e de sua distribuição no território, mensurando as concentrações e dispersões no território entre os grupos sociais ${ }^{\S}$;

* Módulo B - Reconhecimento do território: descrição de características do território;

* Módulo C - Necessidades de reprodução social: descrição das condições de trabalho e vida e dos perfis epidemiológicos das classes sociais;

- Módulo D - Necessidades de presença do Estado: descrição da presença do estado, por meio da oferta de serviços;

* Módulo E - Necessidade de participação política: descrição dos grupos organizados da sociedade civil que lutam pela garantia dos direitos dos interessados.

\footnotetext{
${ }^{\S}$ Há um conjunto grande de propostas que de operacionalização do conceito de classes no referencial marxista, relacionada à divisão social do trabalho. A metodologia do Observatório das Metrópoles (Ribeiro, Ribeiro, 2011) foi descrita, já que tem potencialidade de identificar as diferentes classes sociais distribuídas no território, por meio de dados secundários, considerando os seguintes critérios: (1) Capital X trabalho; (2) Trabalho manual X trabalho não-manual; (3) Trabalho de comando X trabalho subordinado; e (4) Trabalho público X trabalho privado.
} 


\section{Módulo A - Identificação das classes sociais e distribuição espacial no território}

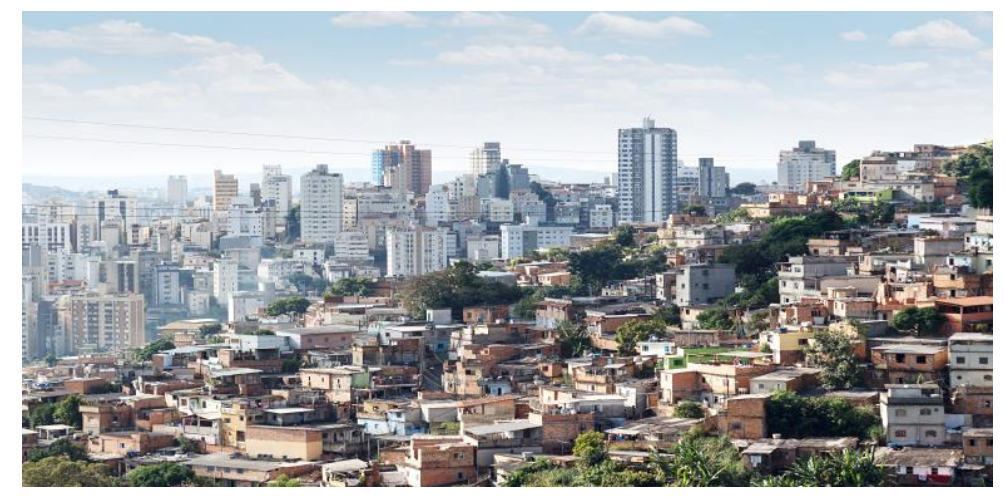

Objetivo do módulo: identificar as classes sociais e sua distribuição no território.

\section{Etapas:}

\begin{tabular}{|l|l|}
\hline 1 & $\begin{array}{l}\text { - Identificação das ocupações, por meio de banco de dados } \\
\text { secundários }\end{array}$ \\
\hline 1 & $\begin{array}{l}\text { - Agrupamento das ocupações em categorias sócio-ocupacionais e em } \\
\text { agregados sócio-ocupacionais }\end{array}$ \\
\hline 3 & $\begin{array}{l}\text { Análises estatísticas para identificação das classes sociais, por meio } \\
\text { de um programa estatístico }\end{array}$ \\
\hline 4 & $\begin{array}{l}\text { Geoprocessamento para identificar a distribuição das classes no } \\
\text { território }\end{array}$ \\
\hline
\end{tabular}

\section{Materiais necessários:}

- Base de dados do censo demográfico do Instituto Brasileiro de Geografia e Estatística (IBGE) e do Instituto Nacional de Pesquisas Espaciais (INPE);

- Suporte de estatístico (ou outro trabalhador capacitado para análises estatísticas) e de Programa estatístico ${ }^{* *}$;

- Programa computacional de processamento de dados espaciais (há vários softwares gratuitos para Geoprocessamento e programas para realizar mapas, como Excel, TerraView, Spring do INPE). Imagens de satélites também podem ser utilizadas.

\footnotetext{
** Nos casos de indisponibilidade de estatístico, buscar os dados sobre ocupações no IBGE e realizar a distribuição das diferentes ocupações pelo território, de forma a caracterizá-lo pela dispersão ou concentração geográfica de ocupações, ou utilizar um proxy de classe social, como .
} 
Etapa 1. Identificação das ocupações, por meio de banco de dados secundários $^{\dagger \dagger}$

- Determinar a área geográfica a ser analisada - setor (es) censitário(s), município(s), região (ões) de saúde, estado(s) ou país (es);

- Identificar o quantitativo de trabalhadores e as diferentes ocupações presentes do território, com auxílio de um estatístico;

Observação: O Instituto Brasileiro de Geografia e Estatística (IBGE) disponibiliza dados sobre as ocupações, a partir de censos demográficos nacionais.

Etapa 2. Agrupamento das ocupações em categorias sócio-ocupacionais e em agregados sócio-ocupacionais

- Agrupar as ocupações em 24 categorias, de acordo com os códigos ocupacionais, conforme Quadro 1, com o auxílio de um estatístico;

- Agrupar as 24 categorias em oito agregados, conforme Quadro abaixo, descrevendo o quantitativo de cada agregado, com auxílio de um estatístico;

\footnotetext{
"Etapas extraídas na metodologia do Observatório das Metrópoles (Ribeiro, Ribeiro, 2011).
} 
Quadro 1 - Distribuição das categorias sócio-ocupacionais e códigos ocupacionais por agregados sócio-ocupacionais.

\begin{tabular}{|c|c|c|}
\hline Códigos & Categorias sócio-ocupacionais & $\begin{array}{l}\text { Agregados sócio- } \\
\text { ocupacionais }\end{array}$ \\
\hline CAT 11 & Grandes Empregadores & \multirow[t]{3}{*}{ Dirigentes (DIR) } \\
\hline CAT 12 & Dirigentes do Setor Público & \\
\hline CAT 13 & Dirigentes do Setor Privado & \\
\hline CAT 21 & $\begin{array}{l}\text { Profissionais Autônomos de Nível } \\
\text { Superior }\end{array}$ & \multirow[t]{4}{*}{$\begin{array}{l}\text { Profissionais de nível } \\
\text { superior (PNS) }\end{array}$} \\
\hline CAT 22 & $\begin{array}{l}\text { Profissionais Estatutários de Nível } \\
\text { Superior }\end{array}$ & \\
\hline CAT 23 & $\begin{array}{l}\text { Profissionais Empregados de Nível } \\
\text { Superior }\end{array}$ & \\
\hline CAT 24 & Professores de Nível Superior & \\
\hline CAT 31 & Pequenos Empregadores & $\begin{array}{l}\text { Pequenos empregadores } \\
\text { (PE) }\end{array}$ \\
\hline CAT 41 & Artistas e similares & \multirow[t]{6}{*}{ Ocupações médias (OM) } \\
\hline CAT 42 & Ocupações de Supervisão & \\
\hline CAT 43 & Ocupações de Escritório & \\
\hline CAT 44 & Ocupações Técnicas & \\
\hline CAT 45 & Ocupações da Saúde e Educação & \\
\hline CAT 46 & $\begin{array}{l}\text { Ocupações da Justiça, Segurança } \\
\text { Pública e Correios }\end{array}$ & \\
\hline CAT 51 & Trabalhadores da Indústria Moderna & \multirow{4}{*}{$\begin{array}{l}\text { Trabalhadores do } \\
\text { secundário (TS) }\end{array}$} \\
\hline CAT 52 & $\begin{array}{l}\text { Trabalhadores da Indústria } \\
\text { Tradicional }\end{array}$ & \\
\hline CAT 53 & $\begin{array}{l}\text { Trabalhadores dos Serviços } \\
\text { Auxiliares }\end{array}$ & \\
\hline CAT 54 & Operários da Construção Civil & \\
\hline CAT 61 & Trabalhadores do Comércio & \multirow{2}{*}{$\begin{array}{l}\text { Trabalhadores do } \\
\text { terciário especializado } \\
\text { (TTE) }\end{array}$} \\
\hline CAT 62 & $\begin{array}{l}\text { Prestadores de Serviços } \\
\text { Especializados }\end{array}$ & \\
\hline CAT 71 & $\begin{array}{l}\text { Prestadores de Serviços Não } \\
\text { Especializados }\end{array}$ & \multirow[t]{3}{*}{$\begin{array}{l}\text { Trabalho do terciário não } \\
\text { especializado (TTNE) }\end{array}$} \\
\hline CAT 72 & Ambulantes e Biscateiros & \\
\hline CAT 73 & Trabalhadores Domésticos & \\
\hline CAT 81 & Agricultores & $\begin{array}{l}\text { Trabalhadores agrícolas } \\
\text { (AGR) }\end{array}$ \\
\hline
\end{tabular}

Fonte: Elaborado pelo Observatório das Metrópoles (Ribeiro, Ribeiro, 2011, p.30) 
Etapa 3. Análises estatísticas para identificação das classes sociais no território, por meio de um programa estatístico

- Realizar análise de correspondência ${ }^{\ddagger \ddagger}$, com o auxílio de um estatístico e um programa estatístico, para identificar as categorias sócio-ocupacionais em cada território (geração de uma matriz, na qual na linha aparecem as áreas territoriais e nas colunas as categorias sócio-ocupacionais);

- Realizar análise de cluster (ou de agrupamentos) ( $^{\S \S}$ para identificar as classes sociais no território (a definição da quantidade de classes sociais no território variará de acordo com a variância intra-classe e da variância inter-classe).

Um exemplo de quatro agrupamentos no território está abaixo descrito:

- Superior (maior proporção de pessoas nas categorias de dirigentes, profissionais de nível superior e pequenos empregadores, que são as categorias mais elevadas da hierarquia social);

- Médio (maior proporção de pessoas na categoria ocupações médias);

- Popular-operário (maior proporção na categoria dos trabalhadores do terciário especializado);

- Popular (maior proporção na categoria dos trabalhadores do secundário).

\section{Etapa 4. Geoprocessamento}

- Utilizar um programa computacional de geoprocessamento para visualizar a distribuição das classes sociais no território, de acordo com a dispersão e concentração das mesmas.

Observação: Atualmente há diversos programas computacionais de processamento de dados espaciais (georreferenciados) gratuitos que geram mapas, possibilitando a visualização da distribuição das classes no território.

\section{Observações gerais}

\footnotetext{
\# Análise de correspondência: irá mostrar o número de pessoas ocupadas de cada área territorial correspondente a cada categoria sócio-ocupacional.

\$§ O número de agrupamentos depende da variância intra-classe e inter-classe (quanto menor a variância, mais homogêneo o agrupamento formado). Um critério para a definição das classes sociais é a variância intra-classe em torno de $25 \%$ e variância inter-classe em torno de $75 \%$.
} 


\section{Módulo B - Caracterização do território}

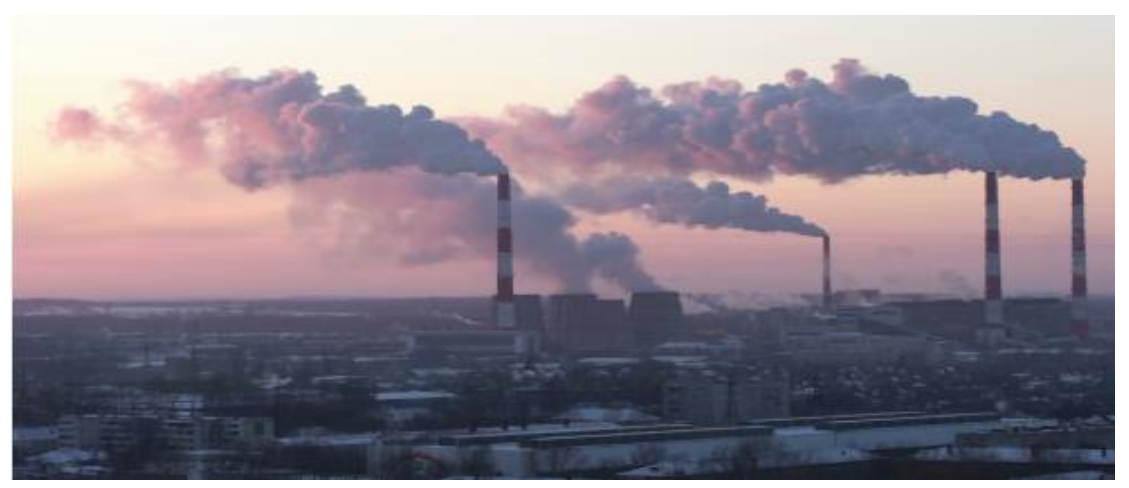

Objetivo do módulo: Descrever as características do território e localizá-las geograficamente.

Etapas:

\begin{tabular}{|l|l|l|}
\hline & - Caracterização histórica do território \\
\hline 3 & Caracterização da atividade econômica \\
\hline & - Caracterização ambiental \\
\hline & & \\
\hline
\end{tabular}

Materiais necessários:

- Referências acessíveis para a descrição da historicidade do território;

- Metodologias qualitativas ou ativas, como busca de informantes-chave, entrevistas com moradores, lideranças comunitárias e representantes institucionais, observações participantes, visitas aos territórios, entre outros.

- Programas computacionais de processamento de dados espaciais (há vários softwares livres para Geoprocessamento e programas para realizar mapas, como Excel, TerraView, Spring do INPE). Imagens de satélites também permitem identificar espacialmente diversas características do território. 


\section{Etapa 1. Caracterização histórica do território}

- Identificar como o território foi constituído e ocupado até a configuração atual.

\section{Etapa 2. Caracterização da atividade econômica}

- Caracterizar as atividades econômicas do setor primário (atividades de extração): agricultura e pecuária, extração de minério e de recursos de plantas e árvores. Diferenciar trabalho cooperativado, familiar e fazendas sem produção;

- Caracterizar as atividades econômicas do setor secundário (atividades de manufatura): presença de Indústrias e descrição dos produtos;

- Caracterizar as atividades econômicas do setor terciário (atividades de comércio): caracterizar as atividades que ocupam os trabalhadores;

- Caracterizar atividades de economia informal e ilícita (atividades de venda de produtos sem taxação de impostos, narcotráfico, prostituição);

- Caracterizar áreas públicas de consumo de drogas;

- Diferenciar área urbana e rural;

- Outras características relevantes.

\section{Etapa 3. Caracterização ambiental}

- Identificar e localizar geograficamente, no território, as áreas de preservação ambiental, áreas de desmatamento e áreas com risco de desmoronamento;

- Identificar o impacto das atividades econômicas no ambiente, como poluição do ar, utilização de agrotóxicos e contaminação do solo e da água;

- Diferenciar área urbana e rural;

- Identificar e localizar geograficamente áreas de extração de plantas nativas;

- Identificar e localizar geograficamente terrenos baldios urbanos;

- Identificar os rios e lagoas e suas possíveis utilizações: irrigação, transporte, pesca, entre outras;

- Identificar e localizar geograficamente esgotos a céu aberto, córregos canalizados, destino do esgoto e tratamento de esgoto;

- Identificar depósitos regulares e irregulares de lixo e usina de reciclagem;

- Outras características relevantes. 


\section{Etapa 4. Caracterização de assentamentos precários ${ }^{\star \star *}$}

- Identificar e localizar geograficamente os assentamentos precários, como favelas, áreas de moradores de rua e condomínios/conjuntos habitacionais precários. Acampamentos nômades, como de ciganos, também podem ser identificados nessa etapa.

\section{Observações gerais}

\footnotetext{
*** O Guia para o mapeamento e caracterização de assentamentos precários do Ministério das Cidades (Brasil, 2010) define que assentamento precário, como cortiços, loteamentos irregulares de periferia, favelas e conjuntos habitacionais que se acham degradados, é ocupado por moradores de baixa renda.
} 


\section{Módulo C - Necessidades de reprodução social}

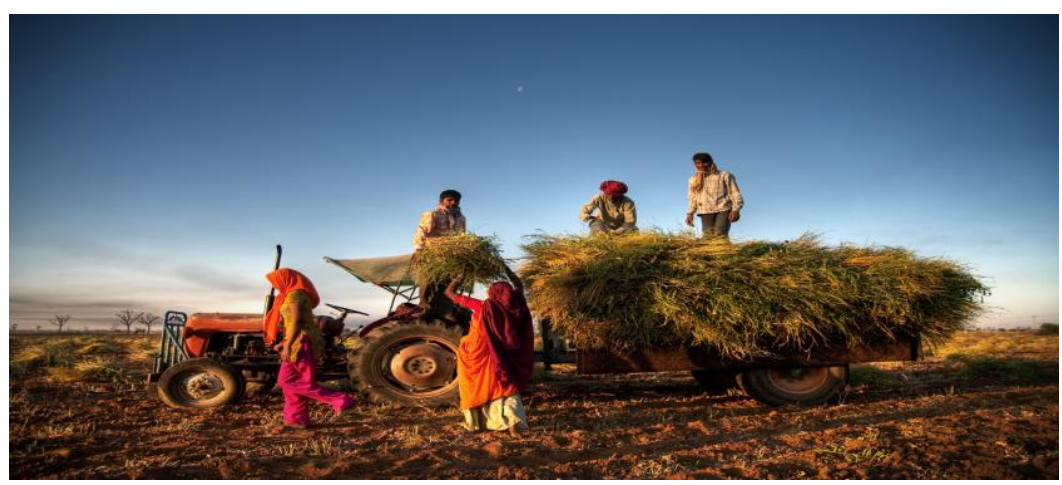

Objetivo do módulo: Identificar os perfis de reprodução social (condições de trabalho e vida) das diferentes classes sociais do território.

\section{Etapas:}

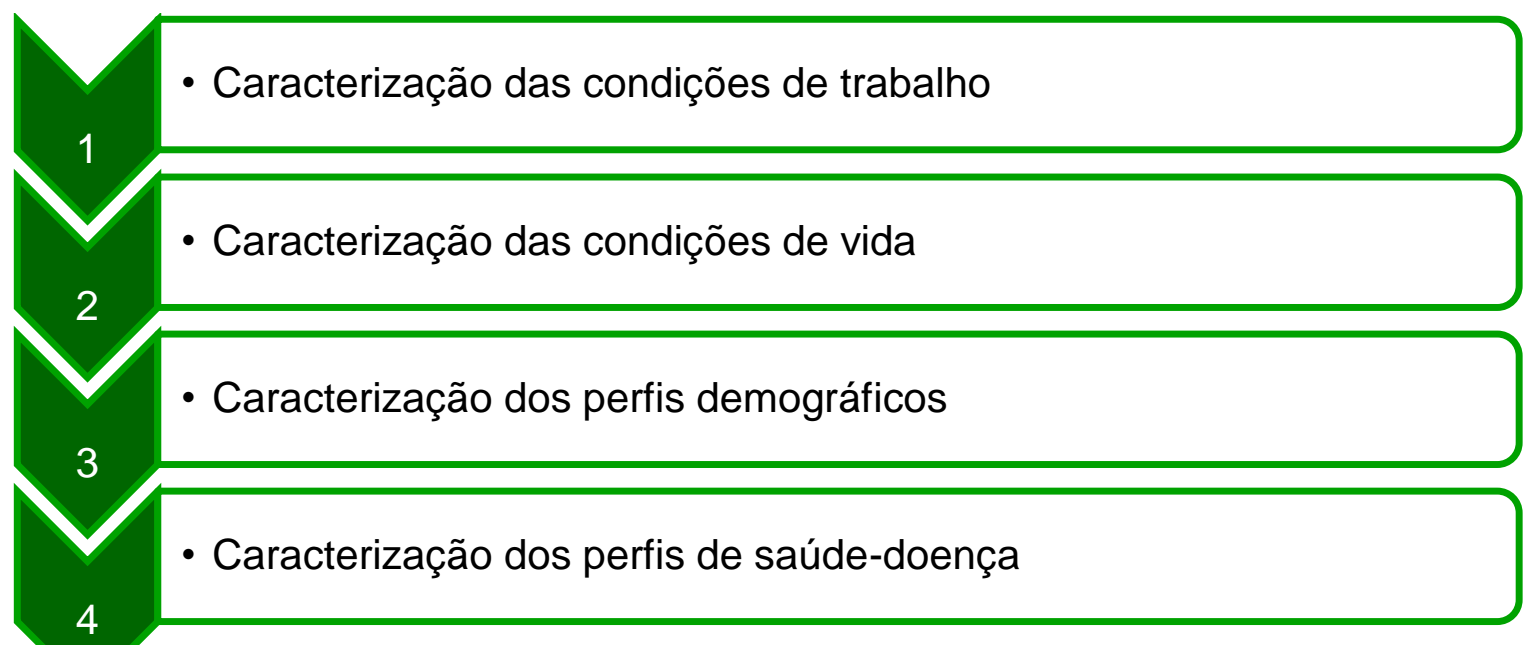

\section{Materiais necessários:}

- $\quad$ Sistemas de informação - Pesquisa Nacional de Saúde, censo demográfico do IBGE, Sistema de Informação sobre Mortalidade (SIM), Sistema de Informações Sobre Nascidos Vivos (SINASC), Sistema de Informação de Agravos de Notificação (SINAN), Pesquisa de Amostra de domicílios (PNAD), entre outros, conforme Apêndice 1; 
- $\quad$ Suporte de um estatístico ${ }^{\dagger t+}$

- Aplicativo computacional estatístico.

Etapa 1. Caracterização das condições de trabalho:

- Identificar como as seguintes variáveis se distribuem nas diferentes classes sociais e por ciclo vital social (infância, adolescência/juventude, vida adulta e envelhecimento):

\section{sukㅅㅅㅅ}

- Número de trabalhadores: número e porcentagem de trabalhadores;

- Formalidade: número e porcentagem dos trabalhadores com registro em carteira;

- Benefícios específicos nacionais, estaduais ou municipais para determinadas populações como Bolsa Família, Benefício de Prestação Continuada: número e porcentagem dos beneficiários;

- Jornada semanal de trabalho: média de horas por semana;

- Seguro desemprego: quantidade de beneficiários;

- Outras características relevantes

\section{Etapa 2. Caracterização das condições de vida}

- Identificar como as seguintes variáveis se distribuem nas diferentes classes sociais:

- Propriedade do domicílio: número e porcentagem de domicílios próprios, alugados, cedidos, entre outras;

- Tipo de domicílio: número e porcentagem de casas, cortiços, asilos, orfanatos, entre outros;

- Material predominante do domicílio: número e porcentagem de domicílios de alvenaria, madeira, taipa, entre outros;

\footnotetext{
\#† Nos casos de indisponibilidade de auxilio de estatístico, buscar os dados sobre ocupações no IBGE e realizar a distribuição das diferentes ocupações pelo território, de forma a caracterizá-lo pela dispersão ou concentração geográfica de ocupações.
} 
- Cômodos como dormitório: número e porcentagem de domicílios com cômodos como dormitório ( 0 cômodo, 1 cômodo, 2 cômodos, entre outros;

- Número de automóveis: número e porcentagem de domicílios com automóveis;

- Número de motocicletas: número e porcentagem de domicílios com motocicletas;

- Forma do abastecimento de água: número e porcentagem de domicílios com as diferentes formas de abastecimento de água: rede geral de distribuição, poço ou nascente localizada, rio, entre outras;

- Forma de abastecimento de iluminação elétrica: número e porcentagem de domicílios com energia elétrica de companhia distribuidora;

- Esgotamento sanitário: número e porcentagem de domicílios com as diferentes formas de esgotamento sanitário: rede geral de esgoto, fossa séptica, sem banheiro, entre outros;

- Destino do lixo: número e porcentagem de domicílios com as diferentes coletas e destinos do lixo: coletado por serviço de limpeza, caçamba, coleta seletiva (recicláveis e orgânicos), entre outros;

- Acesso à internet: número e porcentagem de domicílios com acesso à internet;

- Densidade morador/dormitório: porcentagens das diferentes densidades de moradores por dormitório: 0 a 1, 1 a 2, 2 a 3, entre outros;

- Atividades culturais: organizadas pela sociedade civil como bailes, encontros musicais, e outras atividades recreativas.

- Outras características relevantes

Etapa 3. Caracterização do perfil sociodemográficos:

- Identificar como as seguintes variáveis se distribuem nas diferentes classes sociais por ciclo vital:

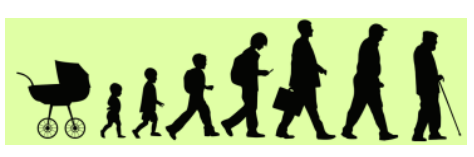


- População: Número e proporção por ciclo vital social, inclusive idosos com idade igual ou superior a 80 anos;

- Gênero: número e porcentagem de homens e mulheres;

- Estado civil: número e porcentagem do estado civil das pessoas: solteiros, casados, divorciados, viúvos, entre outros;

- Cor ou raça: número e porcentagem da população por cor: branca, negra, amarela, indígena, entre outras;

- Religião: número e porcentagem de acordo com as religiões: católica, evangélica, espírita, entre outros;

- Nacionalidade: número e porcentagem de população estrangeira;

- Tempo médio de moradia no município: número de pessoas por tempo médio de moradia no município;

- Escolaridade: número e porcentagem de pessoas, de acordo com a escolaridade: sem escolaridade, ensino fundamental incompleto, ensino fundamental completo, ensino médio incompleto, ensino médico completo, ensino superior incompleto, ensino superior completo, entre outras;

- Taxa de fecundidade: número médio de filhos que uma mulher tem ao longo da vida;

- Movimentos migratórios: número e porcentagem da população que não residia no município onde nasceu, deslocamento do município de moradia para trabalhar, aumento da população em épocas de turismo ou colheitas, entre outros.

- Outras características relevantes

Etapa 4. Caracterização do perfil de saúde-doença:

- Identificar como as seguintes variáveis se distribuem nas diferentes classes sociais por ciclo vital social e se relacionam com as condições de vida e trabalho: 
- Percepção do estado de saúde: auto referência dos problemas de saúde;

- Doenças prevalentes/incidentes: taxa das doenças prevalentes e incidentes presentes no território (do que adoecem a população);

- Doenças relacionadas ao trabalho: taxa das doenças relacionadas ao trabalho;

- Acidentes de trânsito: taxa dos acidentes de trânsito;

- Acidentes por causas externas: taxa dos acidentes por causas externas;

- Mortalidade infantil: taxa de mortalidade infantil;

- Mortalidade/Causas de morte: taxa de mortalidade por causa de morte;

- Violência: número e porcentagem de pessoas que sofreram violência (contra criança, mulher, assaltos, entre outros)

- Taxa de natalidade: número de nascidos-vivos por cada mil habitantes;

- Pessoas com deficiência: número e porcentagem de pessoas com deficiência e tipo de deficiência.

- Outras características relevantes

Observações gerais 


\section{Módulo D - Necessidades de presença do Estado}

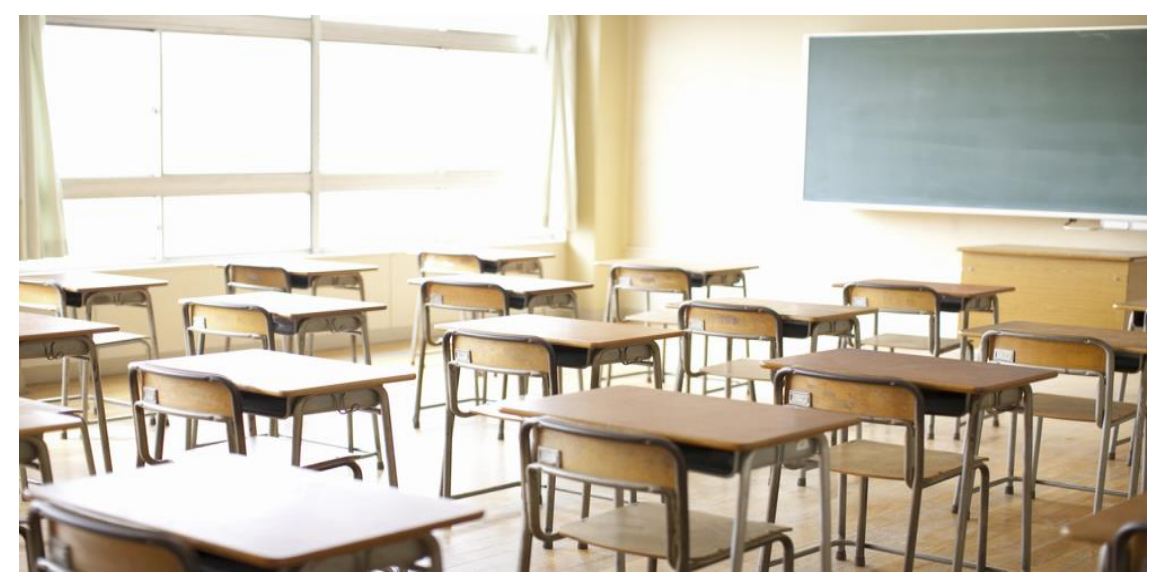

Objetivo do módulo: identificar a presença do Estado no território, em relação a serviços, população coberta, quantidade de atendimentos e cobertura territorial.

\section{Etapas:}

\begin{tabular}{|l|l|}
\hline 1 & - Identificação de serviços de responsabilidade do Estado \\
\hline & - Identificação da população sob cobertura do serviço \\
\hline 4 & - Identificação da quantidade de atendimentos \\
\hline
\end{tabular}

\section{Materiais necessários:}

- Fonte interna de dados das secretarias municipais e estaduais de saúde e de outros setores;

- Base de dados do Cadastro Nacional de Estabelecimentos de Saúde (CNES), Sistema de Informação Ambulatorial (SAI), Sistema de Informação Hospitalar (SIH), Instituto Nacional de Estudos e Pesquisas Educacionais (Inep), Sistema de Assistência Social (SUASnet) ;

- Suporte de um estatístico;

- Aplicativo computacional estatístico. 
Etapas 1 a 4. Identificação de serviços de responsabilidade do Estado, população sob cobertura do serviço, quantidade de atendimentos e bairros, municípios ou regiões atendidas:

- Identificar os serviços de acordo com os setores: assistência social, educação, transporte, segurança pública, lazer e cultura e saúde.

\section{Assistência social}

\begin{tabular}{|c|c|c|c|}
\hline \multirow[b]{2}{*}{ Serviço } & \multirow[b]{2}{*}{$\begin{array}{l}\text { Quantidade } \\
\text { de serviços }\end{array}$} & \multicolumn{2}{|c|}{ Área de abrangência territorial } \\
\hline & & $\begin{array}{l}\text { Quantidade de } \\
\text { pessoas atendidas }\end{array}$ & $\begin{array}{l}\text { Municípios, bairros } \\
\text { ou regióes atendidas }\end{array}$ \\
\hline $\begin{array}{l}\text { Centro de Referência da } \\
\text { Assistência Social (CRAS) }\end{array}$ & & & \\
\hline $\begin{array}{l}\text { Centro de Referência } \\
\text { Especializado de Assistência } \\
\text { Social (CREAS) }\end{array}$ & & & \\
\hline Centro Dia para idosos & & & \\
\hline $\begin{array}{l}\text { Centro de Vivência do Idoso } \\
\text { Centro de Referência do Idoso }\end{array}$ & & & \\
\hline $\begin{array}{l}\text { Instituição de longa } \\
\text { permanência para idosos (ILPI) }\end{array}$ & & & \\
\hline Outros & & & \\
\hline
\end{tabular}

\section{Educação}

\begin{tabular}{|c|c|c|c|}
\hline \multirow{2}{*}{ Serviço } & \multirow{2}{*}{$\begin{array}{l}\text { Quantidade } \\
\text { de serviços }\end{array}$} & \multicolumn{2}{|c|}{ Área de abrangência territorial } \\
\hline & & $\begin{array}{c}\text { Quantidade de } \\
\text { estudantes }\end{array}$ & $\begin{array}{l}\text { Municípios, bairros } \\
\text { ou regióes atendidas }\end{array}$ \\
\hline Creches públicas & & & \\
\hline Creches privadas & & & \\
\hline Escolas públicas de ensino infantil & & & \\
\hline Escolas privadas de ensino infantil & & & \\
\hline
\end{tabular}




\begin{tabular}{|l|l|l|l|}
\hline $\begin{array}{l}\text { Escolas públicas de ensino } \\
\text { fundamental }\end{array}$ & & & \\
\hline $\begin{array}{l}\text { Escolas privadas de ensino } \\
\text { fundamental }\end{array}$ & & & \\
\hline Escolas públicas de ensino médio & & & \\
\hline Escolas privadas de ensino médio & & & \\
\hline $\begin{array}{l}\text { Escolas públicas de ensino } \\
\text { profissionalizante }\end{array}$ & & & \\
\hline $\begin{array}{l}\text { Escolas privadas de ensino } \\
\text { profissionalizante }\end{array}$ & & & \\
\hline $\begin{array}{l}\text { Escolas públicas de educação para } \\
\text { adultos }\end{array}$ & & & \\
\hline $\begin{array}{l}\text { Escolas privadas de educação para } \\
\text { adultos }\end{array}$ & & & \\
\hline $\begin{array}{l}\text { Faculdades, universidades e centros } \\
\text { universitários públicos }\end{array}$ & & & \\
\hline $\begin{array}{l}\text { Faculdades, universidades e centros } \\
\text { universitários privados }\end{array}$ & & \\
\hline \begin{tabular}{l} 
Outros \\
\hline
\end{tabular} & & & \\
\hline
\end{tabular}

\section{Infraestrutura - Transporte}

\begin{tabular}{|l|l|l|l|}
\multicolumn{1}{|c|}{ Infraestrutura } & $\begin{array}{c}\text { Caracterizar e } \\
\text { descrever } \\
\text { atuais } \\
\text { condições }\end{array}$ & Municípios, bairros ou regiões acessados \\
\hline Aeroportos & & & \multicolumn{1}{|c|}{ Área de abrangência territorial } \\
\hline $\begin{array}{l}\text { Ciclovias, metrô, trem e/ou } \\
\text { embarcações fluviais }\end{array}$ & & & \\
\hline Estações ferroviárias & & & \\
\hline Linhas de ônibus & & & \\
\hline Portos & & & \\
\hline $\begin{array}{l}\text { Postos rodoviários } \\
\text { fronteiriços }\end{array}$ & & & \\
\hline $\begin{array}{l}\text { Rodovias federais, estaduais } \\
\text { e municipais }\end{array}$ & & & \\
\hline Ruas sem asfalto & & & \\
\hline $\begin{array}{l}\text { Transporte para pessoas com } \\
\text { deficiência }\end{array}$ & & & \\
\hline Outros & & & \\
\hline
\end{tabular}




\section{Segurança pública}

\begin{tabular}{|c|c|c|c|}
\hline \multirow[b]{2}{*}{ Serviço } & \multirow[b]{2}{*}{$\begin{array}{l}\text { Quantidade } \\
\text { de serviços }\end{array}$} & \multicolumn{2}{|c|}{ Área de abrangência territorial } \\
\hline & & $\begin{array}{l}\text { Quantidade de } \\
\text { pessoas }\end{array}$ & $\begin{array}{c}\text { Municípios, bairros } \\
\text { ou regiões de origem } \\
\text { das pessoas }\end{array}$ \\
\hline \multicolumn{4}{|l|}{ Delegacias } \\
\hline \multicolumn{4}{|l|}{ Fundações Casa femininas } \\
\hline \multicolumn{4}{|l|}{ Fundações Casa masculinas } \\
\hline \multicolumn{4}{|l|}{ Institutos Médicos Legais } \\
\hline \multicolumn{4}{|l|}{ Postos policiais } \\
\hline \multicolumn{4}{|l|}{ Presídios femininos } \\
\hline \multicolumn{4}{|l|}{ Presídios masculinos } \\
\hline $\begin{array}{l}\text { Outras formas de segurança } \\
\text { pública }\end{array}$ & & & \\
\hline
\end{tabular}

\section{Lazer e Cultura}

\begin{tabular}{|c|c|c|}
\hline \multirow[b]{2}{*}{ Serviço } & \multirow{2}{*}{$\begin{array}{l}\text { Quantidade } \\
\text { de } \\
\text { instituições }\end{array}$} & \multirow{2}{*}{$\begin{array}{c}\text { Área de abrangência territorial } \\
\text { Municípios, bairros ou regiões de origem } \\
\text { das pessoas }\end{array}$} \\
\hline & & \\
\hline $\begin{array}{l}\text { Bibliotecas privadas com } \\
\text { domínio público }\end{array}$ & & \\
\hline Bibliotecas Públicas & & \\
\hline $\begin{array}{l}\text { Centros poliesportivos } \\
\text { públicos }\end{array}$ & & \\
\hline $\begin{array}{l}\text { Centros poliesportivos } \\
\text { privados }\end{array}$ & & \\
\hline $\begin{array}{l}\text { Estádios ou ginásios } \\
\text { poliesportivos }\end{array}$ & & \\
\hline Instituições religiosas & & \\
\hline Museus ou centros cultura & & \\
\hline Parques públicos & & \\
\hline Praças & & \\
\hline $\begin{array}{l}\text { Teatros, salas de } \\
\text { espetáculos ou Cineclubes }\end{array}$ & & \\
\hline $\begin{array}{l}\text { Outras formas de lazer e } \\
\text { cultura }\end{array}$ & & \\
\hline
\end{tabular}




\section{Saúde}

\begin{tabular}{|c|c|c|c|}
\hline \multirow{2}{*}{ Serviços/Equipamentos } & \multirow{2}{*}{$\begin{array}{l}\text { Quantidade } \\
\text { de serviços }\end{array}$} & \multicolumn{2}{|c|}{ Área de abrangência territorial } \\
\hline & & $\begin{array}{l}\text { Quantidade de } \\
\text { atendimentos }\end{array}$ & $\begin{array}{l}\text { Municípios, bairros } \\
\text { ou regiōes atendidas }\end{array}$ \\
\hline \multicolumn{4}{|l|}{ Academia da Saúde } \\
\hline \multicolumn{4}{|l|}{ Academia do Idoso } \\
\hline \multicolumn{4}{|l|}{ Academia Popular } \\
\hline \multicolumn{4}{|l|}{$\begin{array}{l}\text { Ambulância municipal - suporte } \\
\text { básico }\end{array}$} \\
\hline \multicolumn{4}{|l|}{$\begin{array}{l}\text { Ambulância municipal - suporte } \\
\text { avançado }\end{array}$} \\
\hline \multicolumn{4}{|l|}{ Ambulância privada } \\
\hline \multicolumn{4}{|l|}{$\begin{array}{l}\text { Ambulatórios/ Centro de } \\
\text { especialidades/Clínica } \\
\text { Especializada públicos }\end{array}$} \\
\hline \multicolumn{4}{|l|}{$\begin{array}{l}\text { Ambulatórios/Centro de } \\
\text { especialidades/Clínica } \\
\text { Especializada privados }\end{array}$} \\
\hline \multicolumn{4}{|l|}{$\begin{array}{l}\text { Centro de Atenção Psicossocial } \\
\text { CAPS/CAPS Ad/CAPSi }\end{array}$} \\
\hline \multicolumn{4}{|l|}{$\begin{array}{l}\text { Centro de Atenção à Pessoa Vítima } \\
\text { de Violência }\end{array}$} \\
\hline \multicolumn{4}{|l|}{$\begin{array}{l}\text { Centro de Atenção à Saúde da } \\
\text { Criança e do Adolescente }\end{array}$} \\
\hline \multicolumn{4}{|l|}{$\begin{array}{l}\text { Centro de Atenção à Saúde da } \\
\text { Mulher }\end{array}$} \\
\hline \multicolumn{4}{|l|}{$\begin{array}{l}\text { Centros de Convivência em Saúde } \\
\text { Mental }\end{array}$} \\
\hline \multicolumn{4}{|l|}{$\begin{array}{l}\text { Centro de Especialidades } \\
\text { Odontológicas }\end{array}$} \\
\hline \multicolumn{4}{|l|}{$\begin{array}{l}\text { Centro de Testagem e } \\
\text { Aconselhamento }\end{array}$} \\
\hline \multicolumn{4}{|l|}{ Clínica de Reabilitação } \\
\hline \multicolumn{4}{|l|}{ Consultório de rua } \\
\hline \multicolumn{4}{|l|}{ Farmácia Básica } \\
\hline \multicolumn{4}{|l|}{ Farmácia Cidadã } \\
\hline \multicolumn{4}{|l|}{ Farmácia popular } \\
\hline \multicolumn{4}{|l|}{ Hospital filantrópico } \\
\hline \multicolumn{4}{|l|}{ Hospital privado } \\
\hline \multicolumn{4}{|l|}{ Hospital público } \\
\hline $\begin{array}{l}\text { Laboratório de Análises Clínicas e } \\
\text { de imagem/ Unidade de Apoio }\end{array}$ & & & \\
\hline
\end{tabular}




\begin{tabular}{|l|l|l|}
\hline Diagnose e Terapia & & \\
\hline $\begin{array}{l}\text { Núcleo de Apoio à Saúde da Família } \\
\text { (NASF) }\end{array}$ & & \\
\hline Policlínicas & & \\
\hline $\begin{array}{l}\text { Pronto atendimento geral e } \\
\text { especializado }\end{array}$ & & \\
\hline $\begin{array}{l}\text { Pronto socorro geral e } \\
\text { especializado }\end{array}$ & & \\
\hline $\begin{array}{l}\text { Serviço de Atendimento Móvel de } \\
\text { Urgência (SAMU) }\end{array}$ & & \\
\hline Unidades Básicas de Saúde (UBS) & & \\
\hline $\begin{array}{l}\text { UBS com Estratégias Saúde da } \\
\text { Família }\end{array}$ & & \\
\hline Outros & & \\
\hline
\end{tabular}

Observações gerais 


\section{Módulo E - Necessidade de participação política}

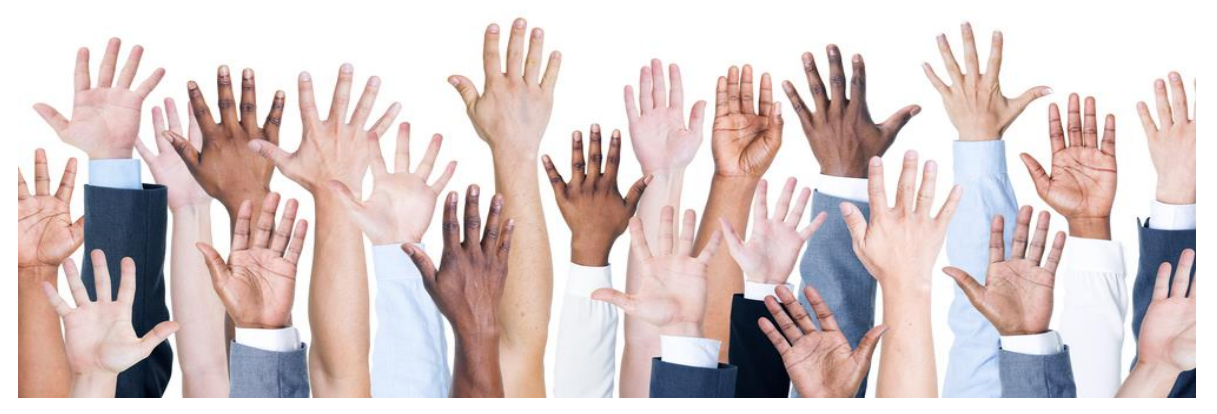

Objetivo do módulo: identificar os grupos organizados da sociedade civil que lutam pela garantia dos direitos dos interessados e os temas reinvidicados pelos grupos organizados.

\section{Etapas:}

- Identificação de grupos organizados da sociedade civil que lutam pela garantia dos direitos dos interessados.

1

- Identificação da área central da reivindicação (saúde, saneamento, entre outros)

2

- Identificação dos problemas reivindicados

3

- Identificação das propostas de superação e ações já realizadas

4

\section{Materiais necessários:}

- Fonte interna de dados das secretarias municipais e estaduais de saúde, conselhos municipais e de outros setores;

- Metodologias qualitativas ou ativas, como busca de informantes-chave, entrevistas com moradores, lideranças comunitárias e representantes institucionais, observações participantes, visitas aos territórios, entre outros. 
Etapa 1. Identificação de grupos organizados da sociedade civil que lutam pela garantia dos direitos civis.

- Identificar os grupos organizados da sociedade civil atuantes no território, conforme Quadro 2.

Observação: Busca-se a participação de grupos organizados historicamente não incluídos nos processos decisórios do país para a influência na definição e a execução da política de saúde.

Etapa 2. Identificação da área central da reivindicação (saúde, saneamento, entre outros)

- Identificar a área central da reivindicação: assistência social, educação, infraestrutura relacionada ao transporte, segurança pública, lazer e cultura, saúde e outros, conforme Quadro 2.

\section{Etapa 3. Identificação dos problemas reivindicados}

- Identificar os problemas para os quais os grupos organizados reivindicam soluções, conforme Quadro 2 abaixo.

Etapa 4. Identificação das propostas de superação e ações já realizadas

- Identificar as propostas de superação, relacionadas aos problemas para os quais se reivindicam soluções, assim como as ações realizadas, conforme Quadro 2. 
Quadro 2 - Descrição de grupos organizados da sociedade civil, da área central dos problemas reivindicados e das propostas de superação e ações já realizadas.

\begin{tabular}{|c|c|c|c|c|}
\hline Áreas & Grupos organizados & $\begin{array}{l}\text { Problemas } \\
\text { reivindicados }\end{array}$ & $\begin{array}{l}\text { Propostas de } \\
\text { superação }\end{array}$ & $\begin{array}{c}\text { Ações } \\
\text { realizadas }\end{array}$ \\
\hline \multicolumn{5}{|l|}{ Assistência } \\
\hline \multicolumn{5}{|l|}{ Social } \\
\hline \multicolumn{5}{|l|}{ Educação } \\
\hline \multirow{2}{*}{\multicolumn{5}{|c|}{$\begin{array}{l}\text { Infraestrutura - } \\
\text { Transporte }\end{array}$}} \\
\hline & \multicolumn{4}{|c|}{ Transporte } \\
\hline \multicolumn{5}{|l|}{ Segurança } \\
\hline \\
\hline \multicolumn{5}{|l|}{ Lazer e Cultura } \\
\hline & & & & \\
\hline \multicolumn{5}{|l|}{ Saúde } \\
\hline & & & & \\
\hline \multicolumn{5}{|l|}{ Outros } \\
\hline & & & & \\
\hline
\end{tabular}

\section{Observações gerais}




\section{Referências bibliográficas}

Brasil. Decreto no 7.509, de 29 de junho de 2011. Regulamenta a Lei no 8.080, de 19 de setembro de 1990, para dispor sobre a organização do Sistema Único de Saúde SUS, o planejamento da saúde, a assistência à saúde e a articulação interfederativa, e dá outras providências.

Brasil. Ministério da Saúde. Manual de planejamento no SUS / Ministério da Saúde, Fundação Oswaldo Cruz. Brasília: Ministério da Saúde, 2015a.

Brasil. Ministério das Cidades. Guia para mapeamento e caracterização de assentamentos precários. Brasília: Ministério das Cidades; 2010.

Breilh J. Epidemiologia: economia, política e saúde. São Paulo: Ed. UNESP; 1991.

Breilh J. Epidemiologia crítica. Rio de Janeiro: Fiocruz; 2006.

Breilh J, Granda E. Investigação da Saúde na Sociedade: guia pedagógico sobre um novo enfoque do método epidemiológico. São Paulo: Cortez; 1989.

Campos CMS, Mishima SM. Necessidades de saúde pela voz da sociedade civil e do Estado. Cad. Saúde Pública. 2005;21(4):1260-1268.

Castiel LD, Rivera FJU. Planejamento em saúde e epidemiologia no Brasil: casamento ou divórcio? Cad. de Saúde Pública. 1985;1(4):447-456.

Huertas F. O método PES: entrevista com Matus. São Paulo: FUNDAP; 1996.

Laurell AC. A saúde-doença como processo social. In: Nunes ED, organizador. Medicina Social: aspectos históricos e teóricos. São Paulo: Global; 1989.

Lombardi C, Bronfman M, Facchini LA, Victora CG, Barros FC, Béria JU. Operacionalização do conceito de classe social em estudos epidemiológicos. Rev Saúde Pública. 1988; 22(4):253-265.

Mendes-Gonçalves RB. Práticas de saúde: processos de trabalho e necessidades. São Paulo: CEFOR, 1992.

Nakano AK, Koga D. Os territórios da urbanidade e a promoção da saúde. in: Soares CB, Campos CMS (organizadoras). Fundamentos de Saúde Coletiva e o cuidado de enfermagem. Barueri: Manole; 2013.

Negri Filho A. Esquema de classe para abordar a desigualdade de saúde no Brasil. In: Rosenberg FJ (organizador). Classes sociais, território e saúde: questões metodológicas e políticas. Rio de Janeiro: FIOCRUZ; 2013.

Paim JS, Almeida Filho N. Saúde Coletiva: uma "nova saúde pública" ou campo aberto a novos paradigmas? Rev. Saúde Pública. 1998;32(4):299-316.

Ribeiro LCQ, Ribeiro MG. Análise social do espaço urbano-metropolitano: Fundamentos teórico-metodológicos e descrição dos procedimentos técnicos. Rio de 
Janeiro: Institutos Nacionais de Ciência e Tecnologia, Observatório das Metrópoles; 2011

Rivera FJU, Artmann E. Planejamento e gestão em saúde: conceitos, historia e propostas. Rio de Janeiro: FIOCRUZ; 2012.

Rocha PR, David HMSL. Determinação ou determinantes? Uma discussão com base na Teoria da Produção Social da Saúde. Rev. Esc. Enferm. USP. 2015;49(1):129-135.

Santos M. Pobreza urbana. São Paulo: Hucitec; 2009.

Santos M. O espaço do cidadão. São Paulo: Editora da Universidade de São Paulo; 2007.

Santos JAF. Esquema de classe para abordar a desigualdade de saúde no Brasil. In: Rosenberg FJ (organizador) Classes sociais, território e saúde: questões metodológicas e políticas. Rio de Janeiro: FIOCRUZ; 2013.

Silva JPV, Batistella C, Gomes ML. Problemas, Necessidades e Situação de Saúde: uma revisão de abordagens para a reflexão e ação da equipe de saúde da família In: Fonseca AF, Corbo AMD (organizadores). Problemas, território e o processo saúdedoença. Rio de Janeiro: EPSJV/Fiocruz, 2007. p.159-176.

Stotz EM. Necessidades de saúde: mediações de um conceito (contribuições das Ciências Sociais para a fundamentação teórico-metodológica de conceitos operacionais da área de planejamento em saúde) [tese]. Rio de Janeiro: Escola Nacional de Saúde Pública; 1991.

Viana N, Soares CB, Campos CMS. Reprodução social e o processo saúde-doença. In: Soares CB, Campos CMS. Fundamentos de saúde coletiva e o cuidado de enfermagem. Barueri: Manole; 2013. p.107-142. 


\section{Apêndice 1 - Sistemas de informação para busca dos dados solicitados}

\begin{tabular}{|c|c|c|c|}
\hline Fonte & Amostra & Dados/ Indicadores & $\begin{array}{c}\text { Módulo/ } \\
\text { Periodicidade }\end{array}$ \\
\hline $\begin{array}{l}\text { Censo } \\
\text { demográfico }\end{array}$ & $\begin{array}{l}\text { População } \\
\text { total }\end{array}$ & $\begin{array}{l}\text { Situação do domicílio, tipo de domicílio, condição de ocupação, valor do } \\
\text { aluguel, aluguel em número de salários mínimos, material predominante } \\
\text { do domicílio, número de cômodos, número de cômodos como dormitório, } \\
\text { número de banheiros, esgotamento sanitário, abastecimento de água, } \\
\text { destino do lixo, energia elétrica, existência de medidor ou relógio, } \\
\text { companhia distribuidora, existência de rádio, televisão, máquina de lavar } \\
\text { roupa, geladeira, telefone celular, telefone fixo, microcomputador, acesso } \\
\text { à internet, motocicleta, automóvel, número de moradores, densidade } \\
\text { morador/cômodo, densidade morador/dormitório, emigração internacional, } \\
\text { responsabilidade pelo domicílio, rendimento mensal, ocupação, atividade, } \\
\text { horas trabalhadas, migração, rendimento domiciliar, rendimento domiciliar } \\
\text { per capita, rendimento mensal habitual de aposentadoria ou pensão de } \\
\text { instituto de previdência oficial, sexo, cor ou raça, indígena, nacionalidade, } \\
\text { ano e local de nascimento, tempo de moradia no município, educação, } \\
\text { estado civil, registro de nascimento, dados de falecimento, deficiências, }\end{array}$ & $\begin{array}{l}\text { Módulo } \mathbf{A} \\
\text { Módulo } \mathbf{C} \\
\text { A cada } 10 \text { anos }\end{array}$ \\
\hline
\end{tabular}




\begin{tabular}{|c|c|c|c|}
\hline & & $\begin{array}{l}\text { deslocamento para estudo, nupcialidade, fecundidade } \\
\underline{\text { http://censo2010.ibge.gov.br }}\end{array}$ & \\
\hline $\begin{array}{l}\text { Pesquisa } \\
\text { nacional por } \\
\text { amostra de } \\
\text { domicílios } \\
\text { (PNAD) }\end{array}$ & $\begin{array}{l}\text { Domiciliar } \\
\text { por } \\
\text { amostragem }\end{array}$ & $\begin{array}{l}\text { Número de moradores, nome, sexo, data de nascimento, condição na } \\
\text { unidade domiciliar, condição na família, cor ou raça, mãe viva, mãe mora } \\
\text { no domicílio, sabe ler e escrever, frequência da escola ou creche, tipo de } \\
\text { escola, curso que frequenta, duração do curso, concluiu com aprovação } \\
\text { pelo menos a primeira série do curso que frequentou, última série que } \\
\text { concluiu, motivo de morar no domicílio, intenção de se mudar e constituir } \\
\text { outro domicílio, vive em companhia de cônjuge ou companheiro, natureza } \\
\text { da união, estado civil, registro de nascimento, local de nascimento, } \\
\text { moradia em outro Estado, tempo de moradia, tipo do domicílio, material } \\
\text { predominante na construção das paredes externas do domicílio, material } \\
\text { predominante na cobertura (telhado), número de cômodos, número de } \\
\text { cômodos como dormitório, propriedade do domicílio, valor mensal do } \\
\text { aluguel, valor mensal da prestação, propriedade do terreno, abastecimento } \\
\text { de água, existência e quantidade de banheiro, escoadouro do banheiro, } \\
\text { coleta de lixo, iluminação, bens de consumo, telefone celular móvel, } \\
\text { telefone fixo convencional, fogão de duas ou mais bocas, fogão de uma } \\
\text { boca, combustível do fogão, filtro d'água, rádio, televisão em cores, } \\
\text { televisão em preto e branco, aparelho de DVD, geladeira, freezer, máquina }\end{array}$ & $\begin{array}{l}\text { Módulo C } \\
\text { Anual } \\
\text { Temas } \\
\text { específicos: } \\
\text { eventual }\end{array}$ \\
\hline
\end{tabular}




\begin{tabular}{|c|c|c|}
\hline & & $\begin{array}{l}\text { de lavar roupa, microcomputador, acesso à Internet, carro ou motocicleta } \\
\text { de uso pessoal, utilização de internet, trabalho remunerado, tarefas em } \\
\text { cultivo, pesca ou criação de animais destinados à própria alimentação das } \\
\text { pessoas moradoras no domicílio, tarefas em construção de prédio, } \\
\text { cômodo, poço ou outras obras de construção destinadas ao próprio uso } \\
\text { das pessoas moradoras no domicílio, número de trabalhos, trabalho } \\
\text { principal, atividade principal do empreendimento, atividade agrícola, } \\
\text { características de trabalho e rendimento, formas de pagamento, venda de } \\
\text { alguma parte da produção do trabalho, parcela da alimentação consumida } \\
\text { pelas pessoas moradoras no domicílio foi retirada dessa produção, jornada } \\
\text { de trabalho, jornada noturna, vínculo trabalhista, setor e área do emprego, } \\
\text { serviços domésticos, auxílio moradia, auxílio alimentação, auxílio } \\
\text { transporte, auxílio para educação ou creche, carteira de trabalho } \\
\text { assinada, auxílio para saúde ou reabilitação, rendimento mensal, tipo de } \\
\text { rendimento, empreendimento registrado no CNPJ, empreendimento com } \\
\text { fatura ou nota fiscal para emitir aos clientes, deslocamento, horas } \\
\text { semanais, tempo de permanência no trabalho principal, trabalho, } \\
\text { contribuinte de instituto de previdência, saída de algum trabalho, seguro- } \\
\text { desemprego, trabalho secundário, outros trabalhos, afazeres domésticos, } \\
\text { trabalho infantil, fecundidade, filho nascido vivo, quantos filhos moravam }\end{array}$ \\
\hline
\end{tabular}




\begin{tabular}{|c|c|c|c|}
\hline & & $\begin{array}{l}\text { no domicílio, quantos filhos moravam em outro local, morte de filhos, } \\
\text { características dos filhos, gestação. } \\
\text { http://www.ibge.gov.br/home/estatistica/pesquisas/pesquisa resultados. } \\
\text { php?id pesquisa=149 }\end{array}$ & \\
\hline $\begin{array}{l}\text { Região } \\
\text { Redes }\end{array}$ & Variado & $\begin{array}{l}\text { População e NNo de municípios: Municípios das Regiões Ampliadas de } \\
\text { Articulação Urbana, Municípios das Regiões Ampliadas de Articulação } \\
\text { Urbana, municípios das Regiões Imediatas de Articulação Urbana, } \\
\text { Municípios das Regiões Intermediárias de Articulação Urbana, Municípios } \\
\text { do Projeto QualiSUS-Rede (quantidade), Número de municípios que fazem } \\
\text { parte da faixa de fronteira (conforme IBGE), Pessoas de } 10 \text { anos e mais } \\
\text { de idade - total - 2010, População - Censo } 2000 \text { e 2010, Projeção de } \\
\text { População } 2011 \text { - 2030. Características Socioeconômicas e Físicas: PIB } \\
\text { do Brasil, rendimento mensal domiciliar per capita nominal, escolaridade, } \\
\text { valor adicionado bruto de diversos setores. Condições de saúde da } \\
\text { população: AIDS, dengue, hepatites virais, malária, tuberculose (numero } \\
\text { de casos identificados, notificados, confirmados no Sinan 2010-2012). } \\
\text { Capacidade instalada: dados sobre estabelecimentos de saúde, dados } \\
\text { sobre leito. Recursos humanos: dados sobre a força de trabalho de } \\
\text { médicos e outros profissionais. Produção ambulatorial: por prestador e } \\
\text { nível de complexidade. Produção hospitalar: número de internações por }\end{array}$ & $\begin{array}{l}\text { Módulo B } \\
\text { Módulo C } \\
\text { Módulo D } \\
\text { Variado }\end{array}$ \\
\hline
\end{tabular}




\begin{tabular}{|c|c|c|c|}
\hline & & $\begin{array}{l}\text { prestador, por doença e ciclo gravídico-puerperal, taxa de morbidade (de } \\
\text { doenças do aparelho circulatório, doenças infecciosas e parasitárias, } \\
\text { neoplasia, causas externas). Financiamento: despesas em serviços } \\
\text { terceirizados, transferências, despesa por pessoal, despesa total por } \\
\text { habitante, impostos e transferências. Cobertura: número de beneficiários } \\
\text { de planos de saúde. } \\
\text { http://www.resbr.net.br/indicadores/view/ }\end{array}$ & \\
\hline $\begin{array}{l}\text { Infraestrutura } \\
\text { Nacional de } \\
\text { Dados } \\
\text { Espaciais } \\
\text { (INDE) }\end{array}$ & Brasil & $\begin{array}{l}\text { Características, possibilidades e limitações dos dados geoespaciais, } \\
\text { produtos cartográficos, bases cartográficas em diversas escalas, dados } \\
\text { geodésicos e metadados, atlas e mapas temáticos relativos às áreas de } \\
\text { geografia e meio ambiente, obtidos de uma variedade de fontes. } \\
\text { http://www.metadados.inde.gov.br/geonetwork/srv/por/main.home }\end{array}$ & $\begin{array}{l}\text { Módulo B } \\
\text { Variado }\end{array}$ \\
\hline
\end{tabular}




\begin{tabular}{|c|c|c|}
\hline $\begin{array}{l}\text { Observatório } \\
\text { de equidade }\end{array}$ & $\begin{array}{l}\text { Desigualdades na Educação: média de anos de estudo da população de } \\
15 \text { anos ou mais de idade, taxa/proporção de analfabetos, proporção de } \\
\text { adultos analfabetos que frequentam cursos de alfabetização, taxa de } \\
\text { evasão dos cursos do programa Brasil Alfabetizado, proporção de recém } \\
\text { alfabetizados que ingressaram em EJA, percentual de escolas públicas } \\
\text { que oferecem EJA, proporção de analfabetos que anteriormente } \\
\text { frequentaram escola, taxa de frequência à creche: crianças de } 0 \text { a } 3 \text { anos, } \\
\text { taxa de frequência à pré-escola: criança de } 4 \text { a } 5 \text { anos, taxa de aprovação, } \\
\text { repetência, evasão, índice de desenvolvimento da educação básica - } \\
\text { IDEB, proporção de escolas de ensino regular com inclusão de alunos com } \\
\text { deficiência, percentual de escolas que possuem dependências e vias } \\
\text { adequadas a alunos com deficiências, escolas sem biblioteca, escolas } \\
\text { sem quadra de esporte, rendimento médio de professor, professores sem } \\
\text { licenciatura, investimento por aluno/ano, percentual de pessoas de } 6 \text { a } 14 \\
\text { anos que frequentam escolar pública de famílias com renda per capita } \\
\text { inferior a 1/2 salário mínimo, média de horas/aula diárias, percentual de } \\
\text { recursos federais aplicados na educação infantil, percentual de municípios } \\
\text { que não têm oferta de creches públicas, percentual de crianças que } \\
\text { frequentam educacão infantil pública sem parque infantil, proporção de }\end{array}$ & $\begin{array}{l}\text { Módulo C } \\
\text { Módulo D }\end{array}$ \\
\hline
\end{tabular}




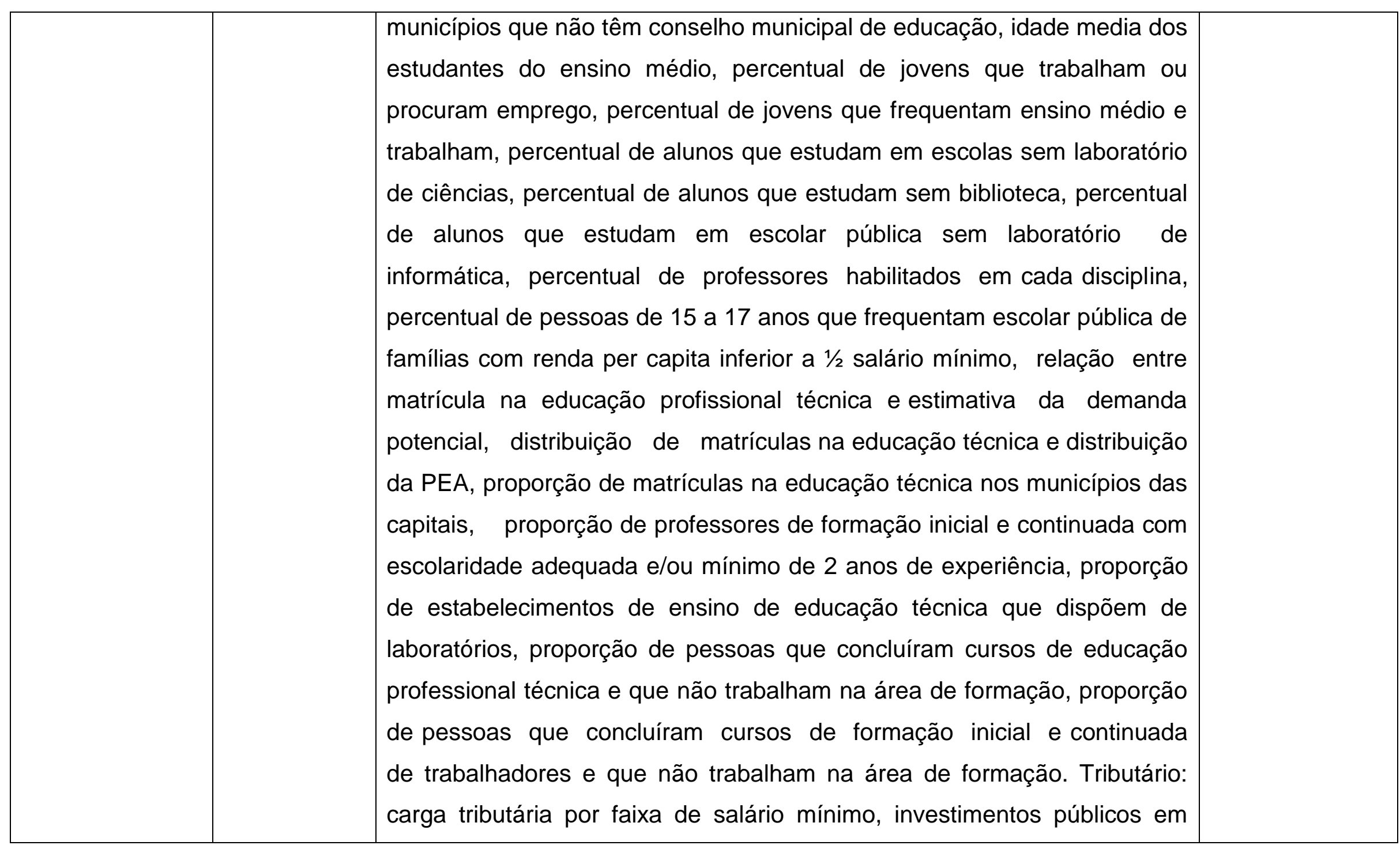




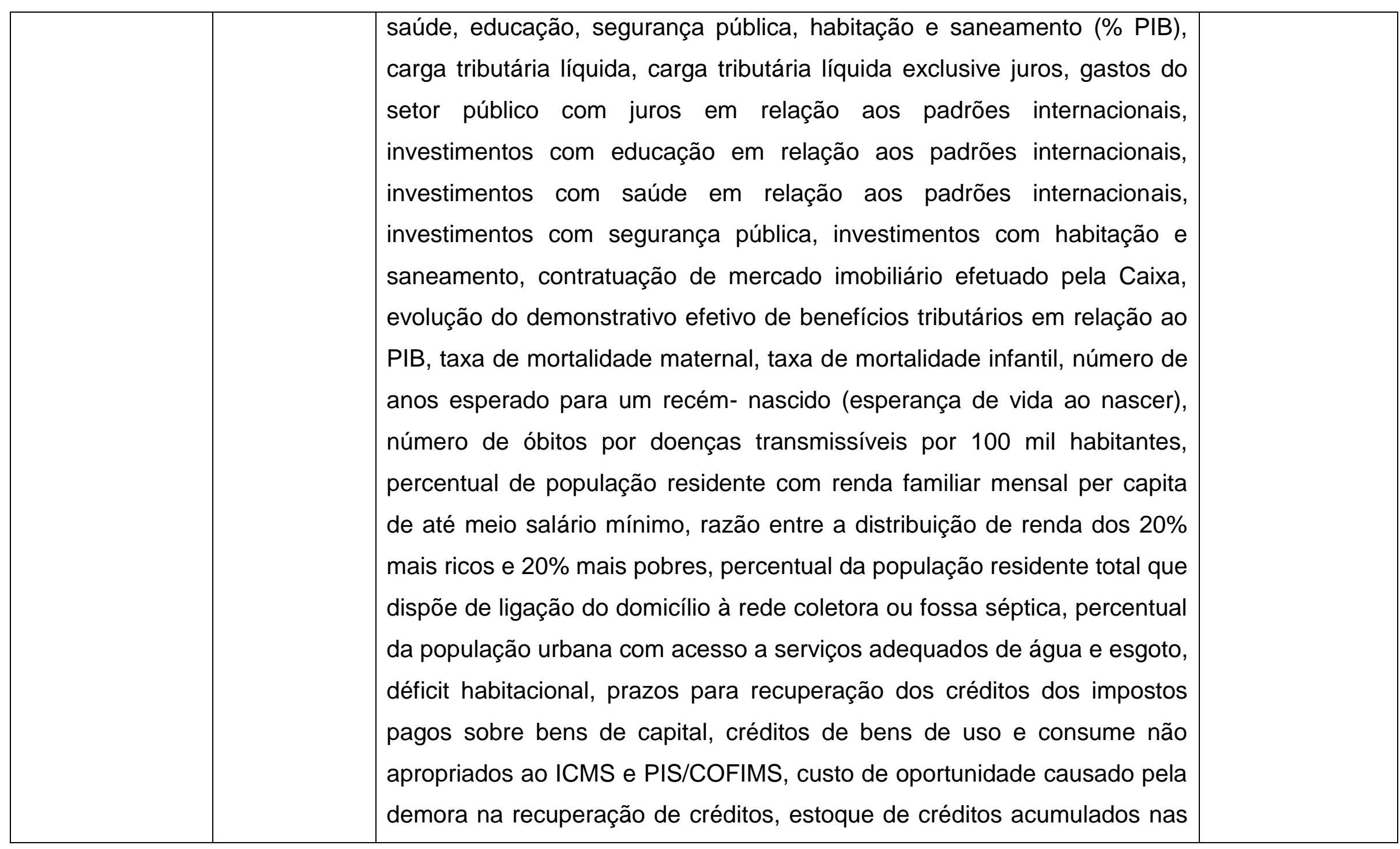




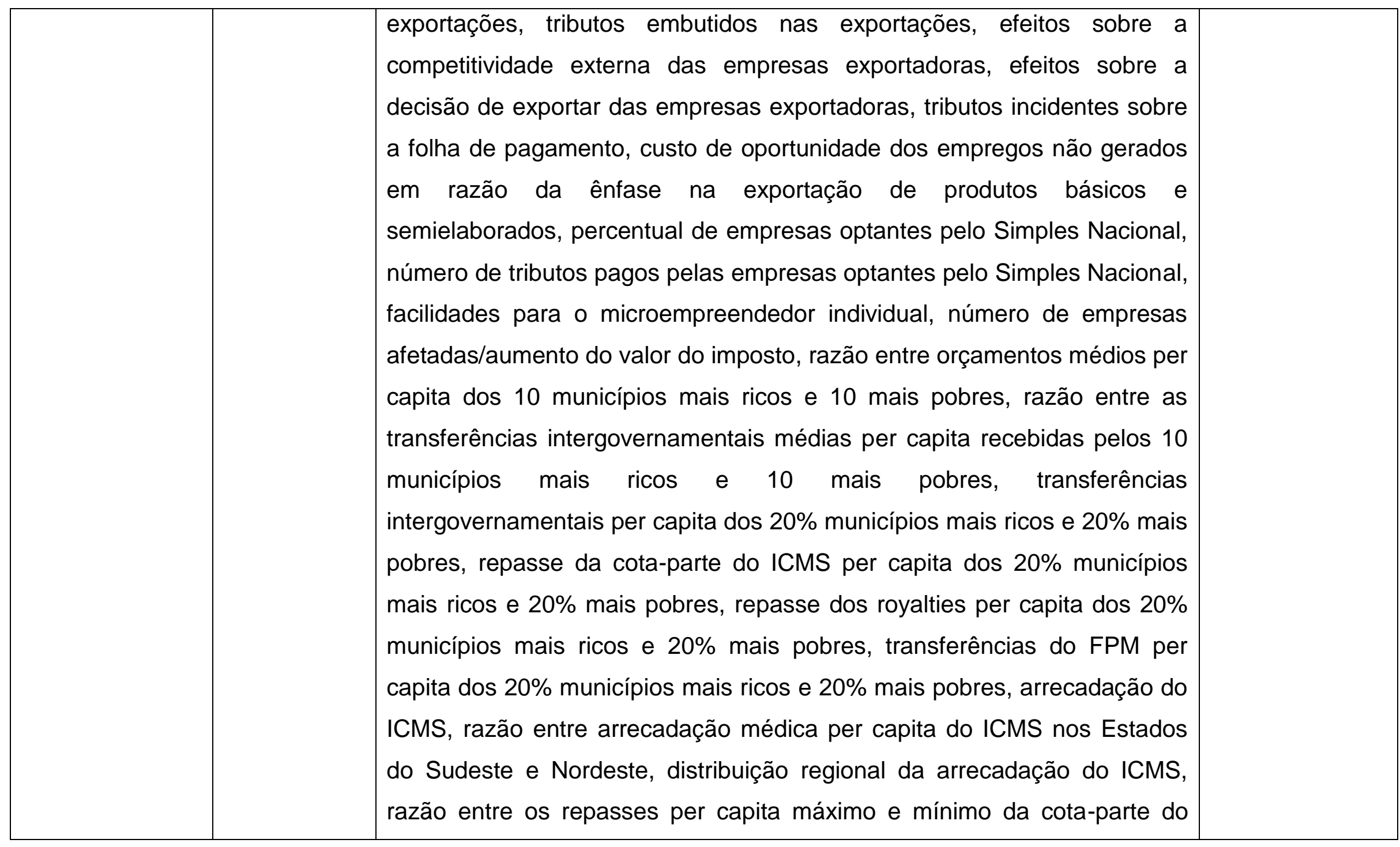




\begin{tabular}{|c|c|c|c|}
\hline & & $\begin{array}{l}\text { ICMS municipal em estados selecionados, importância dos royalties } \\
\text { minerais e das rendas do petróleo no valor da produção, distribuição das } \\
\text { rendas do petróleo entre os Estados, renda do petróleo per capita, } \\
\text { distribuição das rendas de petróleo entre os municípios, distribuição dos } \\
\text { royalties minerais entre os municípios, razão entre o repasse médio da } \\
\text { FPM per capita recebido pelos } 10 \text { mil municípios mais ricos e } 10 \text { mais } \\
\text { pobres, investimentos per capita com a função saúde e educação dos } 20 \% \\
\text { municípios mais pobres e } 20 \% \text { mais ricos, razão entre os investimentos } \\
\text { médios per capita com função saúde nos Estados do Sudeste e Nordeste, } \\
\text { razão entre os investimentos médios per capita com a função educação } \\
\text { nos Estados do Sudeste e Nordeste, grande número de impostos } \\
\text { incidentes sobre os produtos finais regidos por distintas regras, número de } \\
\text { municípios que implantaram o PNEF, número de dias sem regulamentação } \\
\text { da lei (medidas para que os consumidores sejam esclarecidos a cerca dos } \\
\text { impostos que incidam sobre mercadorias e serviços). } \\
\text { http://www.cdes.gov.br/observatoriodaequidade/default.php }\end{array}$ & \\
\hline $\begin{array}{l}\text { Pesquisa de } \\
\text { orçamentos } \\
\text { familiares }\end{array}$ & $\begin{array}{l}\text { Domiciliar } \\
\text { por } \\
\text { amostragem }\end{array}$ & $\begin{array}{l}\text { Estrutura de gastos (despesas), rendimento total, variação patrimonial, } \\
\text { poupanças, características domiciliares, da família e moradores, descrição } \\
\text { do alimento consumido. }\end{array}$ & $\begin{array}{l}\text { Módulo C } \\
\text { Completa }\end{array}$ \\
\hline
\end{tabular}




\begin{tabular}{|c|c|c|c|}
\hline (POF) & Brasil & $\begin{array}{l}\text { http://www.ibge.gov.br/home/estatistica/pesquisas/pesquisa resultados. } \\
\text { php?id pesquisa=25 }\end{array}$ & $\begin{array}{l}\text { cada } 5 \text { anos } \\
\text { Simplificada: } \\
\text { anual }\end{array}$ \\
\hline $\begin{array}{l}\text { Pesquisa } \\
\text { nacional sobre } \\
\text { demografia e } \\
\text { saúde (PNDS) }\end{array}$ & $\begin{array}{l}\text { Domiciliar } \\
\text { probabilística } \\
\text { Sub-amostra } \\
\text { da PNAD }\end{array}$ & $\begin{array}{l}\text { Níveis de fecundidade, mortalidade infantil e materna, anticoncepção, } \\
\text { saúde da mulher e da criança, conhecimentos e atitudes relacionadas com } \\
\text { doenças sexualmente transmissíveis e aids. } \\
\text { http://bvsms.saude.gov.br/bvs/pnds/index.php }\end{array}$ & $\begin{array}{l}\text { Módulo C } \\
\text { Eventual }\end{array}$ \\
\hline $\begin{array}{l}\text { Estimativas e } \\
\text { projeções }\end{array}$ & & $\begin{array}{l}\text { Projeção da população do Brasil: por sexo, grupos especiais de idade, } \\
\text { Taxa de fecundidade total, Taxas Brutas de Natalidade, Taxas Brutas } \\
\text { de Mortalidade, Taxa de mortalidade infantil, Taxa de mortalidade infantil } \\
\text { por sexo, Nascimentos, Óbitos, Esperança de Vida, Esperança } \\
\text { de Vida - Homens e mulheres. } \\
\text { http://www.ibge.gov.br/home/estatistica/populacao/default sistemasproj } \\
\text { ecao.shtm }\end{array}$ & $\begin{array}{l}\text { Módulo C } \\
\text { Anual }\end{array}$ \\
\hline
\end{tabular}




\begin{tabular}{|l|l|l|l|}
\hline Pesquisa & Todos os & Estabelecimentos de saúde: caracterização, serviços disponíveis, & Módulo D \\
sobre & estabelecime & produção de serviços, recursos humanos e equipamentos & \\
assistência & ntos de & http://www.ibge.gov.br/home/estatistica/populacao/condicaodevida/ams/ & Eventual \\
médico- & saúde & $\underline{\text { 2009/ }}$ & \\
sanitária (AMS) & existentes & & \\
\hline
\end{tabular}

